SERVIÇO DE PÓS-GRADUAÇÃO DO ICMC-USP Data de Depósito: 11/03/2005

Data de Deposito: $11 / 03 / 2005$

Assinatura: LAna Paulo ampaio trelora

\title{
CITRUSVIS - Um sistema de visão computacional para a identificação do fungo Guignardia citricarpa, causador da mancha preta em citros ${ }^{1}$
}

Mário Augusto Pazoti

Orientador: Prof. Dr. Odemir Martinez Bruno

Dissertação apresentada ao Instituto de Ciências Matemáticas e de Computação - ICMC/USP - como parte dos requisitos para obtenção do título de Mestre em Ciência da Computação e Matemática Computacional.

\section{USP - São Carlos}

Março/2005

${ }^{1}$ Trabalho realizado com auxílio financeiro da FAPESP. 
Aluno: Mário Augusto Pazoti

A Comissão Julgadora:

Prof. Dr. Odemir Martinez Bruno

Prof. Dr. João do Espírito Santo Batista Neto

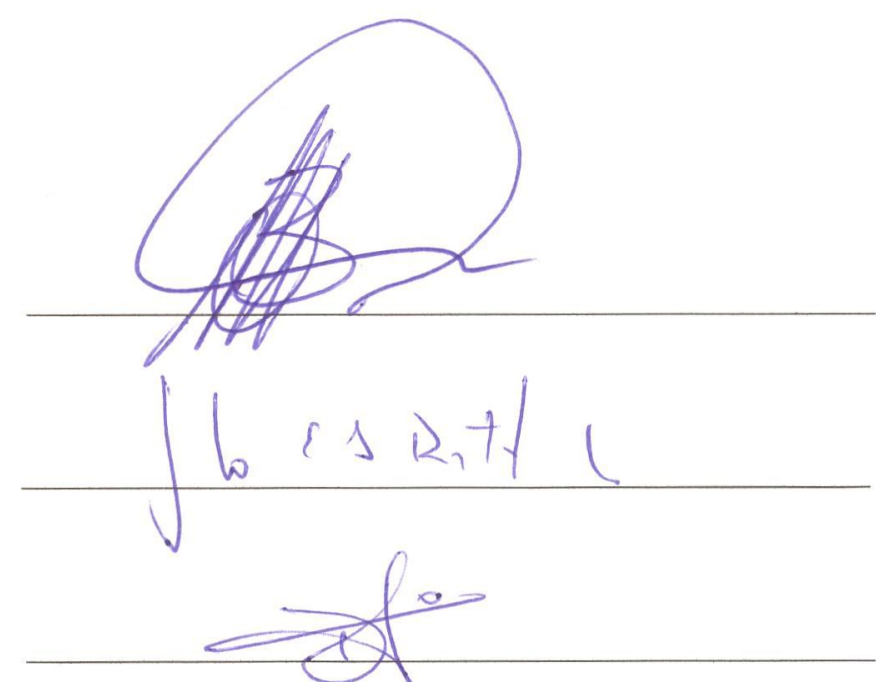

Prof. Dr. José Dalton Cruz Pessoa 


\section{Aos meus pais e irmãos.}




\section{Agradecimentos}

A Deus, pois foi Nele que encontrei forças nos momentos difíceis.

Aos meus pais e irmãos, que mesmo d̀ distância, me apoiaram e me encorajaram em todos os momentos. Eles são o meu porto seguro.

A meus familiares, pela motivação que sempre recebi deles.

Ao Prof. Dr. Odemir Martinez Bruno pela orientação, amizade e paciência.

Aos meus amigos Rogério, Menotti, Luiz Henrique e Kémelli, os quais considero co-responsáveis por eu ter dado esse importante passo em minha vida e que sempre me incentivaram e me deram apoio, incondicionalmente. Destaco ainda, Rogério e Menotti pelo companheirismo, pelas histórias e pelas "lições de vida".

Aos demais amigos, que também são muito importantes para mim: Érika, Otávio, Sandra, Eduardo, Cris, Reginaldo, Chico, Leandro, Letícia, Mão, Maurício, Vanderlei, Daniel, Ronaldo, Sílvio, Tati, Juliana, Andrea, Luciana, Richard, Bira, André, André Rocha, Adenilson, Rodrigo, Júlio, Christian, Cássio, Caio, Cláudia, Danilo, Marcelo, Fabiano, Marco, Ana Paula, Camila, Cláudio, o pessoal do LCAD e do LABES e a galera do vôlei.

Ao Dr. José Dalton Cruz Pessoa (CNPDIA/Embrapa) pela colaboração.

Ao Fundecitrus e à UNESP de Jaboticabal (Dr. Marcel B. Spósito, MSc. Ricardo B. Baldassari, José Antonio Bellote e Davi Rinaldo) pelo fornecimento das imagens e pelo auxílio quanto às questões biológicas envolvidas no projeto.

Aos professores e funcionários do ICMC - USP.

A todos que, direta ou indiretamente, colaboraram comigo.

À FAPESP pelo apoio financeiro. 
"É melhor tentar e falhar, que preocupar-se e ver a vida passar; é melhor tentar, ainda que em vão, que sentar-se fazendo nada até o final.

Eu prefiro na chuva caminhar, que em dias tristes em casa me esconder. Prefiro ser feliz, embora louco, que em conformidade viver ..." (Martin Luther King) 


\section{Resumo}

As pragas e doenças apresentam-se como um desafio para a citricultura brasileira em razão do impacto econômico que elas causam à produção. Neste trabalho é dado destaque à doença da mancha preta (MPC), causada pelo fungo Guignardia citricarpa. Essa doença provoca lesões no fruto, depreciando-o no mercado de frutas in natura, além de causar amadurecimento $\mathrm{e}$ queda precoce. Um dos principais agravantes da doença é a demora no aparecimento dos sintomas, sendo muito importante detectar a presença dos esporos do fungo no pomar, antes que os sintomas apareçam. Dessa maneira, há a possibilidade de se controlar a doença de forma eficaz, aplicando-se quantidades menores de fungicidas e, conseqüentemente, reduzindo os custos da produção e os efeitos deletérios ao meio-ambiente. Atualmente, a deteç̧ão desses esporos é realizada por meio da análise de amostras coletadas nos pomares. Essa análise é efetuada por especialistas que realizam a identificação e a contagem dos ascósporos manualmente. Com o objetivo de automatizar esse processo, um conjunto de técnicas para a análise das imagens e a caracterização dos ascósporos do fungo a partir da forma foi estudado e comparado. Dentre as técnicas, a curvatura e os descritores de Fourier apresentaram resultados bastante satisfatórios e foram utilizados na implementação do protótipo de um sistema de visão computacional - o CitrusVis, que analisa e identifica os ascósporos existentes nas imagens dos discos de coleta.

Palavras chaves: Visão computacional, análise de formas, reconhecimento de padrões, Guignardia citricarpa e fitossanidade 


\section{Abstract}

The pest and disease management is one of the significant factors in the citrus culture. This work focuses on the black spot disease (CBS), a fungal disease caused by Guignardia citricarpa that occasions sunken lesions in the rind of fruits causing precocious maturation, accented fall, depreciation for in natura fruit market and increase of the production costs for disease controlling. One of the main problems to control the CBS disease is the delay to appearance of symptom (when the orchard is already infected), and the fungal presence identification is necessary as soon as possible, allowing the appliance of procedures to control it. Nowadays, spores identification, particularly the ascospores (sexual spores), is made by collecting suspended particles in orchards blown on discs, which are analyzed by specialists using the microscope. The use of a computer aided vision system to assist the spores identification is one of the strategies to speed up this process. In this work, methods to analyze and characterize the spores, based on its shape, were studied and compared. Among them, the shape curvature method and the Fourier descriptors, chosen for presenting the best result, were implemented in a system - the CITRUSVIS - to analyze the images and identify the ascospores.

Keywords: Computer vision, shape analysis, pattern recognition, Guignardia citricarpa and phytosanity. 


\section{Lista de Figuras}

2.1 Lesões causadas pelo fungo Guignardia citricarpa em frutos . . . . . . . . . 18

2.2 Ciclo da Mancha Preta . . . . . . . . . . . . . . . . . . . . . . . 19

2.3 Sintomas da folha infectada pelo fungo Guignardia citricarpa . . . . . . . . . 19

2.4 Tipos de lesões causadas pelo fungo Guignardia citricarpa . . . . . . . . . . 20

2.5 Ascósporo da Guignardia citricarpa . . . . . . . . . . . . . . . . . . . . . 20

2.6 Coletor de partículas. . . . . . . . . . . . . . . . . . . . 21

2.7 Sistema de aquisição de partículas suspensas. . . . . . . . . . . . 21

2.8 Esboço do disco de coleta. . . . . . . . . . . . . . . 21

3.1 Cubo de cores RGB. . . . . . . . . . . . . . . . . 23

3.2 Representações do modelo HSI . . . . . . . . . . . . . . . . . . 24

3.3 Conversão de RGB para HSI . . . . . . . . . . . . . . . . . . . . . . . 25

3.4 Limiarização de uma imagem em tons de cinza . . . . . . . . . . . . . . 27

3.5 Comparação entre a aplicação de filtros lineares e não-lineares . . . . . . . . . 29

3.6 Estrutura representando a discretização usada na implementação numérica do modelo de Perona-Malik . . . . . . . . . . . . . . . . . 30

3.7 Filtragem morfológica . . . . . . . . . . . . . . . . . . . 33

3.8 Representação dos termos usados na Transformada watershed . . . . . . . . . 34

3.9 Representação do processo de imersão . . . . . . . . . . . . . . . . . . 34

3.10 Exemplo de supersegmentação e do uso de marcadores para contornar o problema 36

3.11 Processo de Segmentação a partir de uma imagem binária . . . . . . . . . . . 36

3.12 Exemplo da extração do contorno de uma forma, no sentido horário. . . . . . . . 38

3.13 Sinais de $x$ e $y$ obtidos do contorno paramétrico . . . . . . . . . 38

3.14 Formas com o respectivo centróide marcado por um ponto. . . . . . . . . . . . 40

3.15 Formas com o diâmetro indicado pela linha tracejada. . . . . . . . . . . . . . 40

3.16 Excentricidade da forma. . . . . . . . . . . . . . . . . . . 41

3.17 Assinatura de uma forma . . . . . . . . . . . . . . . . . . . 41

3.18 Assinatura de uma forma amostrada pelo ângulo . . . . . . . . . . . . 42

3.19 Assinaturas por projeção . . . . . . . . . . . . . . . . 42

3.20 Exemplos dos experimentos de Attneave . . . . . . . . . . . . . . . . . 43

3.21 Critério de concavidade adotado de acordo com o sentido da curva . . . . . . . . 44

3.22 Exemplo da curvatura multi-escala e representação por meio do curvograma . . 49

3.23 Reconstrução do contorno por meio de Descritores de Fourier . . . . . . . . 51

3.24 Decomposição pela transformada de Fourier . . . . . . . . . . . . . . . 55

3.25 Decomposição pela transformada Wavelet . . . . . . . . . . . . . . 56

3.26 Decomposição do sinal em aproximação e detalhe pela transformada Wavelet . 56

3.27 Famílias de wavelets . . . . . . . . . . . . . . . . . . 57

3.28 Transformada Wavelet $2 \mathrm{D} \ldots \ldots \ldots \ldots \ldots$ 
3.29 Exemplos do classificador de distância mínima . . . . . . . . . . . . . . 60

3.30 Etapas do agrupamento realizado com o método $k$-means . . . . . . . . . . 62

3.31 Um simples neurônio de McCulloch-Pitts . . . . . . . . . . . . . . . 63

3.32 Representações de algumas funções de ativação . . . . . . . . . . . . . . . . . 64

3.33 Representações de uma camada da rede neural. . . . . . . . . . . . . . . . . . . . 65

3.34 Representação abreviada da rede com 3 camadas . . . . . . . . . . . 65

4.1 Esquema usado na normalização das amostras quanto aos efeitos da rotação. . . 68

4.2 Perímetros referentes às amostras de ascósporos, com o respectivo limiar inferior e superior definido. . . . . . . . . . . . . . . . . . . . 69

4.3 Sinais paramétricos de $x(n)$ e $y(n)$ obtidos a partir da forma de um ascósporo. $\quad 70$

4.4 Sinal paramétrico de $x(n)$ extraído de amostras de ascósporos. . . . . . . . 71

4.5 Sinal paramétrico de $x(n)$ extraído de amostras de outras partículas também encontradas nos discos de coletas. . . . . . . . . . . . . 71

4.6 Comparação entre os sinais paramétricos de $x(n)$ extraídos das amostras apresentadas nas Figuras $4.4 \mathrm{e}$ 4.5. Em destaque apenas os sinais referentes às amostras de ascósporos. . . . . . . . . . . . . . . 71

4.7 Sinal paramétrico de $y(n)$ extraído de amostras de ascósporos. . . . . . . . 72

4.8 Sinal paramétrico de $y(n)$ extraído de amostras de outras partículas também encontradas nos discos de coletas. . . . . . . . . . . . . . . 72

4.9 Comparação entre os sinais paramétricos de $y(n)$ extraídos das amostras apresentadas nas Figuras 4.7 e 4.8. Em destaque os sinais referentes às amostras de ascósporos.

4.10 Assinatura da forma de um ascósporo com base na distância entre o centróide e os pontos do contorno. . . . . . . . . . . . . . . . . . 73

4.11 Assinaturas distância do centróide extraídas de amostras de ascósporos. . . . . 74

4.12 Assinaturas distância do centróide extraídas de amostras de outras partículas também encontradas nos discos de coletas. . . . . . . . . . . . . . . .

4.13 Comparação entre as assinaturas distância do centróide extraídas das amostras apresentadas nas Figuras 4.11 e 4.12 . Em destaque as assinaturas referentes às amostras de ascósporos. . . . . . . . . . . . . . . . 74

4.14 Projeção horizontal da forma de um ascósporo. . . . . . . . . . . . . . . 75

4.15 Projeções horizontais extraídas de amostras de ascósporos. . . . . . . . . . . 76

4.16 Projeções horizontais extraídas de amostras de outras partículas também encontradas nos discos de coletas. . . . . . . . . . . . . . . 76

4.17 Comparação entre as projeções horizontais extraídas das amostras apresentadas nas Figuras 4.15 e 4.16. Em destaque os sinais referentes às amostras de

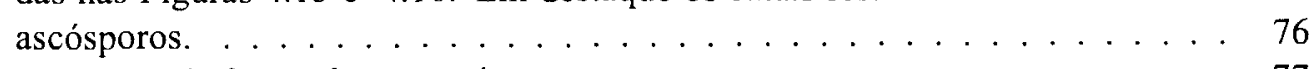

4.18 Curvatura da forma de um ascósporo. . . . . . . . . . . . . . 77

4.19 Curvaturas extraídas de amostras de ascósporos. . . . . . . . . . . . 78

4.20 Curvaturas extraídas de amostras de outras partículas também encontradas nos discos de coletas. . . . . . . . . . . . . . . . . . . . 78

4.21 Comparação entre as curvaturas extraídas das amostras apresentadas nas Figuras 4.19 e 4.20. Em destaque os sinais referentes às amostras de ascósporos. . . 78

4.22 Descritores obtidos a partir dos momentos do contorno. . . . . . . . . . 79

4.23 Distância calculada entre os vetores de características baseados nos momentos do contorno e o vetor médio referente à classe de ascósporos. . . . . . . . . . 79

4.24 Descritores obtidos a partir dos momentos do contorno aplicado sobre a curvatura. 80

4.25 Distância calculada entre os vetores de características baseados nos momentos do contorno usando a curvatura e o vetor médio referente à classe de ascósporos. 80 
4.26 Descritores de Fourier obtidos a partir do contorno da forma das amostras apresentadas à direita. . . . . . . . . . . . . . . . .

4.27 Distância calculada entre os vetores de características baseados no contorno da forma e o vetor médio referente à classe Ascósporos. . . . . . . . . . . . .

4.28 Descritores de Fourier obtidos a partir da assinatura distância do centróide de cada uma das amostras apresentadas à direita. . . . . . . . . . . . . . . . 84

4.29 Distância calculada entre os vetores de características baseados na assinatura da forma e o vetor médio referente à classe Ascósporos. . . . . . . . . . . . . . 85

4.30 Descritores de Fourier obtidos a partir da projeção horizontal de cada uma das amostras apresentadas à direita. . . . . . . . . . . . . . . . 86

4.31 Distância calculada entre os vetores de características baseados na projeção horizontal da forma e o vetor médio referente à classe Ascósporos. . . . . . . . . 86

4.32 Descritores de Fourier obtidos a partir da curvatura extraída de cada uma das amostras apresentadas à direita. . . . . . . . . . . . . . . . 87

4.33 Distância calculada entre os vetores de características baseados na curvatura da forma e o vetor médio referente à classe Ascósporos. . . . . . . . . . . . . . . . . . 88

4.34 Funções da wavelet Daubechies db4 . . . . . . . . . . . . . . . . . . 88

4.35 Árvore de decomposição aplicando a wavelet Daubechies db4 sobre a curvatura de um ascósporo . . . . . . . . . . . . . . . . . . . . . 89

4.36 Sinal resultante da decomposição da curvatura de um ascósporo em 5 níveis. . . 90

4.37 Descritores selecionados a partir da decomposição da curvatura das amostras por wavelets. . . . . . . . . . . . . . . . . . . 90

4.38 Distância calculada entre os vetores de características baseados nos descritores de wavelets e o vetor médio referente à classe dos ascósporos. . . . . . . . . 91

5.1 Etapas do Sistema de Visão Computacional Cirrus Vis. . . . . . . . . . . . . . 94

5.2 Imagem digital adquirida do disco de coleta ampliado por um microscópio . . . 94

5.3 Limiarização por meio do matiz usando o modelo HSI . . . . . . . . . . . . 96

5.4 Problema encontrado com a limiarização por meio do matiz . . . . . . . . . . . . 96

5.5 Comparação entre a aplicação dos filtros linear e não-linear e o respectivo resultado após a limiarização da imagem . . . . . . . . . . . . . . . . . 98

5.6 Aplicação do filtro morfológico para eliminação de ruídos, lacunas e pequenas

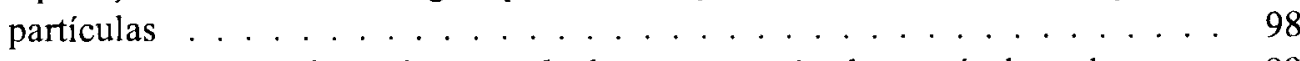

5.7 Aplicação da Transformada watershed para separação das partículas sobrepostas 99

5.8 Problemas encontrados com a aplicação da Transformada watershed para separação de partículas aglomeradas . . . . . . . . . . . . . . . . . . . 100

5.9 Contornos extraídos da imagem do disco de coleta obedecendo o critério de pré-seleção. . . . . . . . . . . . . . . . . . . . 101

5.10 Topologia da rede utilizada no CITRUSVIS. . . . . . . . . . 102

5.11 Interface do protótipo do CitrusVis. . . . . . . . . . . . 103

5.12 Imagens obtidas após o processo de análise . . . . . . . . . . . 107

5.13 Imagens obtidas após o processo de análise que apresentaram erro na identificação 108 


\section{Lista de Tabelas}

3.1 Aspectos geométricos caracterizados por meio da curvatura . . . . . . . . . . . 44

4.1 Resumo dos resultados obtidos em cada um dos experimentos. . . . . . . . . 92

5.1 Resultados obtidos com as imagens do Disco 1. 105

5.2 Resultados obtidos com as imagens do Disco 2. . . . . . . . . . . . . . . . . . . . . . . . . . . . . . .

5.3 Resultados obtidos com as imagens do Disco 3. . . . . . . . . . . . . . . . . 106

5.4 Resultado geral considerando todas as imagens . . . . . . . . . . . . . . 106

5.5 Resultados obtido considerando todas as partículas segmentadas. . . . . . . . . 109 


\section{Sumário}

Lista de Figuras . . . . . . . . . . . . . . . . . . . 7

Lista de Tabelas . . . . . . . . . . . . . . . . . . . . . 10

1 Introdução 13

1.1 Objetivos . . . . . . . . . . . . . . . . . . . . . . . . . . . . . 14

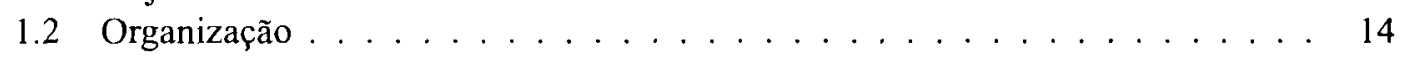

2 Caracterização do Problema 16

2.1 A Patologia da Mancha Preta na Citricultura . . . . . . . . . . . . . . . . 17

2.2 Técnica de Detecção do Esporo no Pomar . . . . . . . . . . . . . . . . . 20

2.3 Considerações Finais . . . . . . . . . . . . . . . . . . 21

3 Métodos de Visão Artificial 22

31 Cores $\ldots \ldots \ldots 22$

3.1 .1 Modelo RGB . . . . . . . . . . . . . . . . . . . 23

3.12 Modelo HSI ....... 23

3.2 Segmentação de Imagens . . . . . . . . . . . . . . . . . . . 26

3.2 .1 Limiarização . . . . . . . . . . . . . . . . . . . . . . . . 26

3.2 .2 Filtros de Difusão Não-Linear . . . . . . . . . . . . . . . . . . . . 28

3.2 .3 Operações Morfológicas . . . . . . . . . . . . . . . . 31

3.2 .4 Transformada Watershed . . . . . . . . . . . . . . . . 33

3.3 Descrição e Caracterização de Formas . . . . . . . . . . . . . . . . . 37

3.3 .1 Contorno Paramétrico . . . . . . . . . . . . . . . . . . 37

3.3 .2 Descritores Gerais . . . . . . . . . . . . . . . . . . 38

3.3 .3 Curvatura ......................... 43

3.3 .4 Descritores de Fourier . . . . . . . . . . . . . . . 50

3.3 .5 Momentos . . . . . . . . . . . . . . . . . . . . 52

3.3 .6 Transformada Wavelet . . . . . . . . . . . . . . . . . . . . 55

3.4 Reconhecimento de Padrões . . . . . . . . . . . . . . . . . . . 58

3.4.1 Reconhecimento Estatístico de Padrões . . . . . . . . . . . . . . . 59

3.4 .2 Redes Neurais . . . . . . . . . . . . . . . . . . . 62

3.5 Considerações Finais . . . . . . . . . . . . . . . . 66

4 Estudo Comparativo entre Métodos de Análise de Formas 67

4.1 Seleção e Pré-processamento das Amostras . . . . . . . . . . . . . . . . . 67

4.2 Descritores Gerais . . . . . . . . . . . . . . . . . . . 68

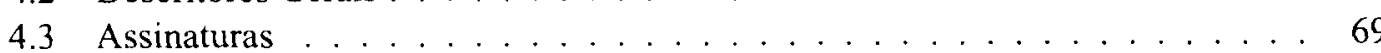

4.3.1 Sinais Paramétricos de $x(n)$ e $y(n) \ldots \ldots \ldots 69 . \ldots \ldots$

4.3.2 Assinatura com base no centróide . . . . . . . . . . . . 70 
4.3.3 Assinatura por Projeção $\ldots . .73$

4.3 .4 Curvatura . . . . . . . . . . . . . . . . . 75

4.4 Momentos do Contorno . . . . . . . . . . . . . . . . . . . . . . . 77

4.5 Análise do Espectro de Fourier . . . . . . . . . . . . . . . . . . . . 81

4.5.1 Experimentos aplicando a Análise do Espectro da Potência . . . . . . . 81

4.6 Descritores de Wavelets . . . . . . . . . . . . . . . . . . . . . . 87

4.7 Considerações Finais . . . . . . . . . . . . . . . . . . . . 91

5 Sistema de Visão Computacional e Resultados Experimentais 93

5.1 Sistema Citrus Vis . . . . . . . . . . . . . . . . . . . 93

5.1 .1 Aquisição das Imagens . . . . . . . . . . . . . . . . . . . . . 93

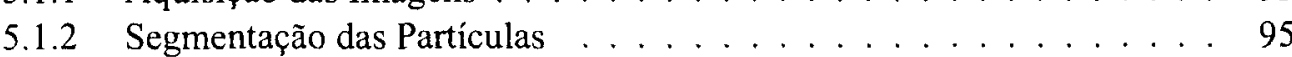

5.1.3 Análise e Extração de Características . . . . . . . . . . . . . . . 100

5.1 .4 Identificação dos Ascósporos . . . . . . . . . . . . . . . . . . 101

5.2 Protótipo do Sistema de Visão Computacional - CiTRUS VIS . . . . . . . . . . 102

5.3 Resultados Experimentais . . . . . . . . . . . . . . . . . . . . . 104

5.4 Considerações Finais . . . . . . . . . . . . . . . . . . 106

6 Conclusão 110

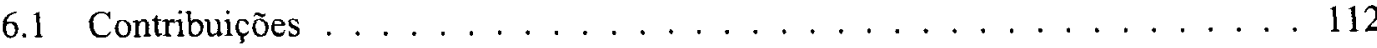

6.2 Trabalhos Futuros . . . . . . . . . . . . . . . . . 112 


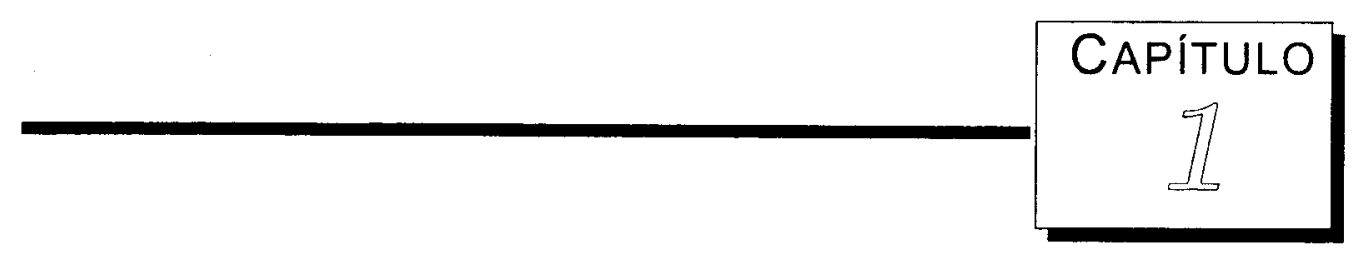

Introdução

sentido da visão pode ser considerado o meio mais eficiente de que o ser humano dispõe para captar as informações presentes no ambiente que o cerca. A capacidade humana para processar e interpretar imensas quantidades de dados de natureza visual motiva o desenvolvimento de técnicas e dispositivos, de modo a permitir que sistemas de computador também sejam dotados de tal capacidade e sensibilidade. Conhecer o comportamento do sistema visual humano e algumas técnicas disponíveis para melhor adequar a imagem à aplicação é importante para poder explorar, de forma mais eficiente, os recursos dos sistemas destinados a esse fim. Embora ainda se esteja longe de se desenvolver sistemas de visão que se igualem ao sistema de visão biológico, existem, atualmente, mecanismos que realizam certas atividades de maneira mais eficiente que o sistema de visão humano, por exemplo. É o caso de sistemas para a extração de medidas, biometria, instrumentação, entre outros.

Os sistemas de visão artificial visam a obter um conjunto de técnicas que possam apoiar o desenvolvimento de produtos suficientemente eficientes e confiáveis para aplicações práticas em diversas áreas. Eles vêm sendo usados na indústria para uma variedade de tarefas e, atualmente, estão também sendo aplicados na agricultura. Esses sistemas com funções de análise de imagens e tomada de decisão estão assumindo um lugar relevante no controle e garantia de qualidade de produtos, realizando tarefas usualmente designadas a inspetores humanos. No caso da agricultura, a inserção de tecnologias de visão artificial objetiva auxiliar no processo produtivo, por exemplo, no manejo de pragas e doenças.

Dado o destaque internacional da citricultura brasileira, em razão da quantidade de plantas e de sua importância para a economia mundial, esforços para melhorar a produtividade estão sendo empregados. Doenças, como a mancha preta (MPC), são um dos principais fatores que afetam a produção de citros. No caso da MPC, especificamente, um grande impacto é ocasionado pela redução da produtividade, devido à queda precoce do fruto, depreciação do fruto para a comercialização in natura, além da elevação do custo da produção por causa dos gastos com fungicidas para o controle da doença. No estado de São Paulo está sendo utilizado um 
mecanismo que coleta os esporos do fungo, juntamente com outras partículas sólidas suspensas nos pomares, a fim de detectar o quanto antes a presença da doença no pomar, pois os sintomas demoram a aparecer. Uma vez detectada uma proporção significativa de esporos presentes no pomar, aplicações de fungicidas para combater a doença são realizadas. No entanto, como a doença pôde ser identificada no início, a doença pode ser controlada com a aplicação de uma quantidade menor de fungicida. Com isso, tanto o custo com a produção quanto os efeitos nocivos causados ao meio-ambiente são reduzidos.

A detecção dos esporos, atualmente, é realizada por especialistas, que analisam visualmente os discos de coleta com o auxílio de um microscópio. Esse processo é demorado e cansativo e no sentido de auxiliar esse processo é que foi proposto neste trabalho o estudo de um sistema de visão artificial para a identificação e a contagem dos esporos do fungo Guignardia citricarpa, causador da mancha preta em citros. O desenvolvimento desta pesquisa contou com a parceria da Embrapa - Instrumentação Agrícola de São Carlos, da UNESP de Jaboticabal e do Fundecitrus $^{1}$, que forneceram as imagens dos discos de coleta e auxiliaram quanto às questões biológicas envolvidas. O projeto recebeu auxílio financeiro da FAPESP - Fundação de Amparo à Pesquisa do Estado de São Paulo (Processo No: 03/04826-9).

\subsection{Objetivos}

O objetivo deste projeto foi estudar técnicas de visão computacional capazes de caracterizar os ascósporos do fungo Guignardia citricarpa, a partir de imagens microscópicas obtidas dos discos de coleta. Além disso, desenvolver uma ferramenta de análise de imagens para identificar eventuais esporos capturados no disco, realizando a identificação e a contagem dos ascósporos do fungo, a partir do conjunto de técnicas selecionado.

\subsection{Organização}

A presente dissertação é composta por seis capítulos e os principais assuntos abordados em cada um deles são apresentados a seguir:

Capítulo 2 Nesse capítulo é apresentada a caracterização do problema, a importância da citricultura para o pais, a patologia da mancha preta em citros e o mecanismo utilizado atualmente para deteç̧ão dos esporos no pomar. É justificada, também, a importância de um sistema de visão artificial para a identificação e contagem dos esporos do fungo;

Capítulo 3 Nesse capítulo é realizada uma revisão bibliográfica do conjunto de técnicas de visão computacional estudadas durante o desenvolvimento do trabalho. Foram abordadas técnicas relacionadas às etapas necessárias a um sistema de visão artificial;

Capítulo 4 Nesse capítulo é apresentado um estudo comparativo entre as técnicas para caracterização dos ascósporos por meio da análise da forma. A partir desse estudo é que foram selecionadas as técnicas empregadas para a análise e a identificação dos ascósporos;

'Fundo de Defesa da Citricultura, Araraquara - SP 
Capítulo 5 As etapas para o desenvolvimento do sistema de análise e identificação dos ascósporo, bem como as técnicas empregadas em cada uma delas são apresentadas nesse capítulo. Também são apresentados os experimentos realizados e os resultados alcançados;

Capítulo 6 Nesse capitulo são apresentadas a conclusão e as contribuições deste trabalho. As propostas para trabalhos futuros também são apresentadas. 


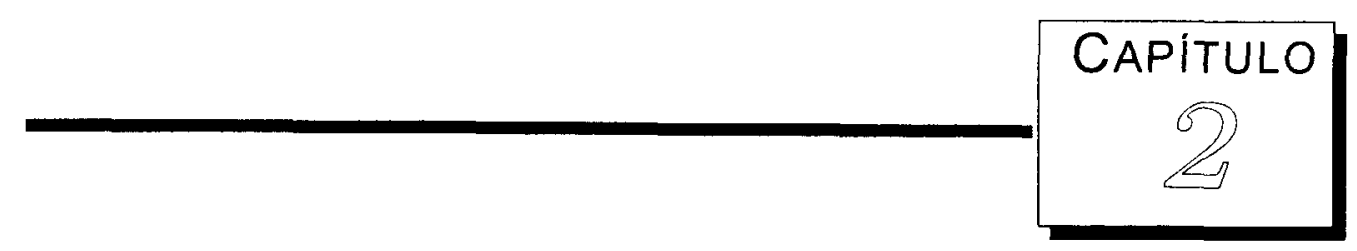

\section{Caracterização do Problema}

citricultura brasileira se destaca como a maior do mundo em número de plantas aproximadamente 650 mil hectares de pomares que reúnem mais de 200 milhões de árvores - e em importância econômica. Com base na análise dos dados de 2003, a cadeia agroindustrial citrícola movimenta 3,23 bilhões de dólares, dos quais 1,33 bilhão de dólares são com exportações, sendo $72 \%$ provenientes das remessas de suco (Toledo, 2005). A participação do Brasil no comércio mundial de suco de laranja é significativa ( $80 \%$ do comércio mundial), enquanto que a da fruta in natura é marginal $(0,7 \%)$, porém significativa quando se fala na exportação nacional de frutas, perdendo apenas para a maçã e o melão em volume de exportação (SECEX, 2003). Os produtos que a citricultura brasileira oferece para o mercado nacional e internacional são diversos, desde a fruta in natura, passando pelos sucos cítricos, até diversos subprodutos como óleos essenciais, d'limonene e o farelo de polpa cítrica. Eles são destinados a diferentes fins no mercado interno e externo, os quais incluem fabricação de produtos químicos e solventes, aromas e fragrâncias, tintas, cosméticos, complemento para ração animal, entre outros.

O Estado de São Paulo é o principal responsável pela pujança dessa "commodity" internacional. O Estado produziu 360 milhões de caixas $(40,8 \mathrm{~kg})$, sendo $71 \%$ destinado à indústria de suco concentrado, $28 \%$ ao mercado interno e $1 \%$ à exportação de fruta fresca. Essa agroindústria gera cerca de 400 mil empregos diretos, envolvendo vários municípios (322 municípios paulistas e 11 de Minas Gerais), numa faixa que vai do sul ao noroeste paulista e ainda avança sobre o Triângulo Mineiro, envolvendo 15 mil produtores rurais. A produção anual de suco concentrado é da ordem de 1,3 milhão de toneladas (Toledo, 2005). A produtividade média é de 22 ton/ha e pode ser considerada muito baixa quando comparada à da Flórida (EUA), que é de 45 ton/ha - aproximadamente 4,5 caixas por árvore contra 2,5 no Brasil.

A grande expansão da citricultura brasileira nos anos 60 e 70 deveu-se muito mais à expansão da área de plantio do que ao aumento de produtividade, a qual é considerada baixa quando comparada à Flórida (EUA), por exemplo. A baixa produtividade brasileira está associada a vá- 
rios fatores: 1) à expansão simultânea de pragas e doenças, com significativo reflexo nos custos de produção, 2) ao fato de grande parte dessa produção ser conduzida em áreas não irrigadas, 3) à estreita base genética utilizada, e 4) à falta de suporte tecnológico, como a agricultura de precisão, aplicado a essa cadeia produtiva, buscando racionalizar a utilização de insumos. A importância do aumento na competitividade do produto, além do fator econômico, também é social. Os preços devem estar nas faixas internacionais de mercado para se manterem competitivos; entretanto, no período entre janeiro de 1994 a janeiro de 1996 os insumos aumentaram, bem como a mão-de-obra. Caso a cultura chegue ao estágio de inviabilidade econômica, uma crise social gerada pelo desemprego é esperada, agravando os problemas de êxodo rural. Não há possibilidade de viabilizar a cultura pelo repasse dos custos nos preços do produto. Não há outra possibilidade de se manter no mercado a não ser pela melhoria do processo de produção. Há premência, portanto, na melhoria e otimização do processo produtivo.

O manejo de praga e doenças é um fator importante que afeta a produção de citros. A grande maioria dos problemas fitossanitários que atualmente desafiam a citricultura reflete uma estratégia de expansão acelerada, muitas vezes sem a devida atenção quanto a fatores de ordem biótica (pragas e doenças) e abiótica (solo, água, clima, etc). Devido ao longo ciclo de vida de uma planta de citros, não é possível realizar trocas rápidas de variedades ou de condições ambientais, como usualmente se faz em culturas anuais. O caráter sistêmico de muitas doenças, sua etiologia e as facilidades de dispersão tornam o controle químico praticamente impossível. No entanto, existe uma suficiente variabilidade genética dentro do grupo que permite antever a solução de quase todos os desafios apenas aproveitando-se desse conjunto de genes. Os principais fatores bióticos limitantes aos citros incluem doenças como a clorose variegada dos citros (CVC), o cancro cítrico, a leprose, a citrus tristeza virus (CTV), a mancha preta (MPC), a morte súbita dos citros (MSC) e pragas, como o ácaro da leprose. Desses fatores, vale a pena ressaltar a mancha preta e o ácaro da leprose. A MPC causa um grande impacto econômico pela redução da produtividade em pomares, pela depreciação dos frutos para o mercado in natura e por seu controle aumentar os custos da produção. Ela foi constatada em plantios comerciais somente em 1980, e tem se disseminado rapidamente pelo Brasil nas duas últimas décadas. Ela é considerada uma doença quarentenária Al pela união Européia, o que vem causando restrições nas exportações de frutos cítricos brasileiros para seus países membros (barreiras não-tarifárias) pois os frutos podem expressar os sintomas apenas no país destino (Neves et. al., 2004; Spósito, 2003). As estimativas dos gastos anuais com acaricidas na citricultura nacional são da ordem de 90 milhões de dólares, dos quais, no ano de 1999, aproximadamente 70 milhões de dólares foram destinados ao controle do ácaro vetor da leprose (Neves e Marino, 2002; Poletti, 2002), representando um gasto significativo adicionado ao custo total da produção.

\subsection{A Patologia da Mancha Preta na Citricultura}

A doença da mancha preta (MPC) ou pinta preta, cujo agente causal é o fungo Guignardia citricarpa, afeta folhas e frutos de laranjas, pomelos, limões, algumas variedades de tangerina e híbridos. Uma das principais características da doença é a demora na manifestação dos sinto- 
mas, que podem levar até 12 meses para surgir. Isso depende das condições ambientais como a incidência direta da radiação, que combinada com altas temperaturas favorecem a manifestação dos sintomas e aumentam as lesões nos frutos expostos. Os frutos infectados tornam-se impróprios para o mercado de fruta in natura (Figura 2.1) (Baldassari, 2001; Baldassari et. al., 2001).

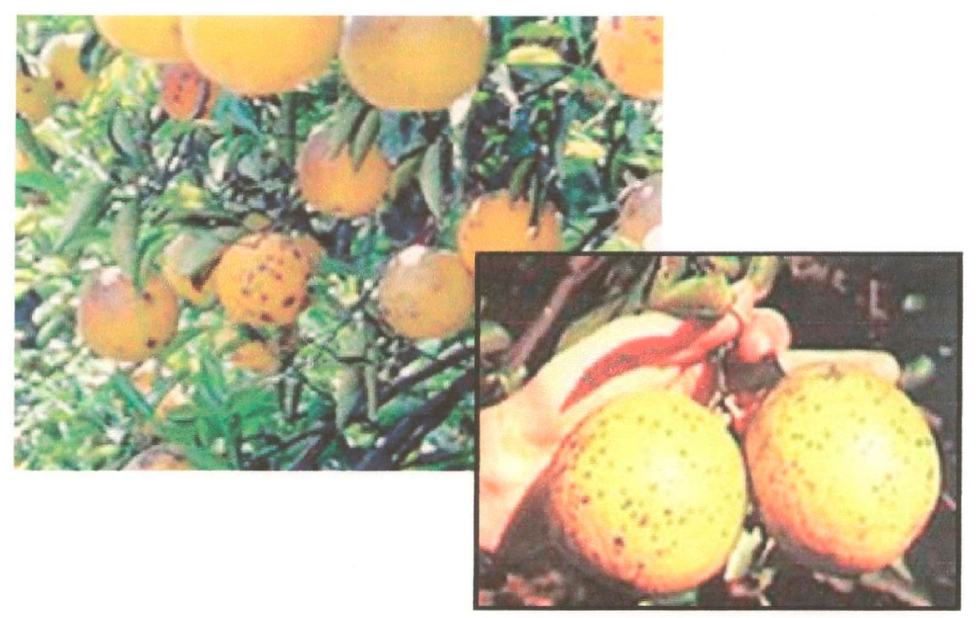

Figura 2.1: Lesões causadas pelo fungo Guignardia citricarpa em frutos (Fundecitrus, 2004).

Nos frutos, a suscetibilidade ao fungo ocorre até cerca de cinco meses após a queda das pétalas das flores, já nas folhas esse período é de até cerca de quatro semanas. O fungo se desenvolve com maior facilidade nas folhas em decomposição no solo e, portanto, fatores que provoquem a queda de folhas ou debilitem a planta favorecem o desenvolvimento da doença. Na Figura 2.2 é mostrado o ciclo da doença.

A Guignardia citricarpa pode infectar folhas e frutos por meio de seus dois tipos de esporos: os assexuais (picnidiósporos), que se desenvolvem em frutos e folhas fixadas à planta; e os sexuais (ascósporos), que se desenvolvem nas folhas em decomposição no solo. Os pcnidiósporos se desenvolvem, principalmente, em frutos e são disseminados a curtas distâncias, normalmente pela água da chuva, irrigação e orvalho, infectando frutos da mesma planta ou de plantas vizinhas. Os ascósporos, que se desenvolvem em folhas em decomposição no solo, são disseminados tanto a curta quanto a longa distância. Além da água da chuva, irrigação e orvalho, os ascósporos também podem ser transmitidos pelo vento e, desse modo, infectar pomares a quilômetros de distância. A Figura 2.3 ilustra os sintomas da doença em folhas, caracterizados por lesões com coloração cinza-escura e depressão na área central. Quando ocorrem, são evidentes nas duas faces da folha e as lesões são semelhantes às da mancha dura que ocorre nos frutos. No centro das lesões podem aparecer pontuações escuras, características dos picnídios do fungo, onde os esporos assexuais são produzidos (Baldassari, 2001; Noronha, 2002).

Nos frutos os sintomas da mancha preta são caracterizados pelas lesões, que podem ser classificadas em seis diferentes tipos (Spósito, 2003), que são mostradas na Figura 2.4: mancha sardenta, mancha marrom ou mancha dura, mancha virulenta, falsa melanose, mancha rendilhada e mancha trincada. Além dessas lesões, há também variações e combinações desses sintomas. A caracterização das lesões está associada as condições climáticas e a suscetibilidade 


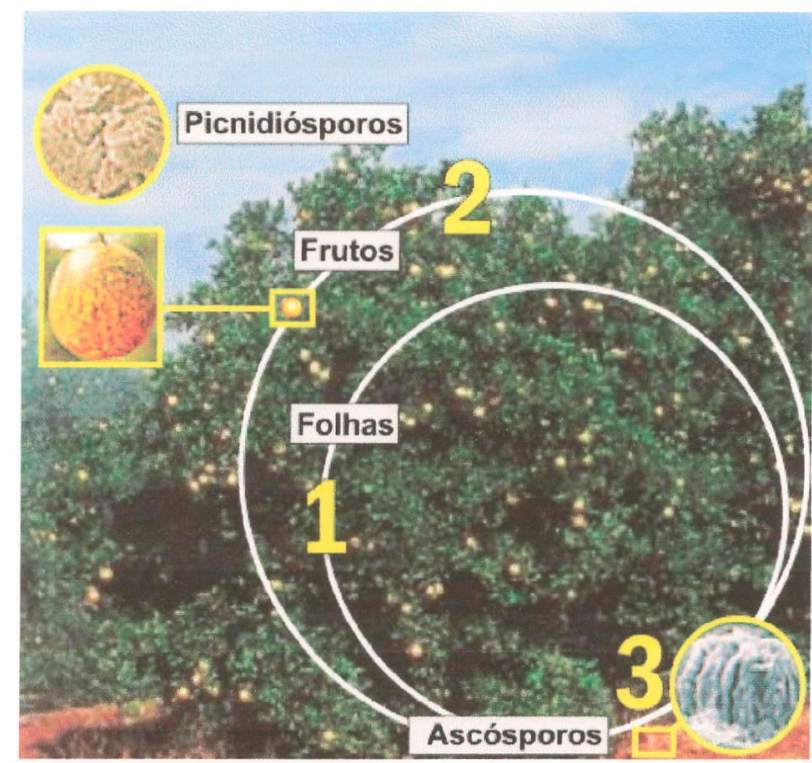

Figura 2.2: Ciclo da Mancha Preta: 1) Infecção de folhas e frutos pelos ascósporos, que são produzidos pelas folhas em decomposição no solo; 2) Surgimento das lesões nos frutos, onde são produzidos os picnidiósporos e 3) Queda das folhas contaminadas, que produzem os ascósporos quando entram em decomposição (Fundecitrus, 2004).

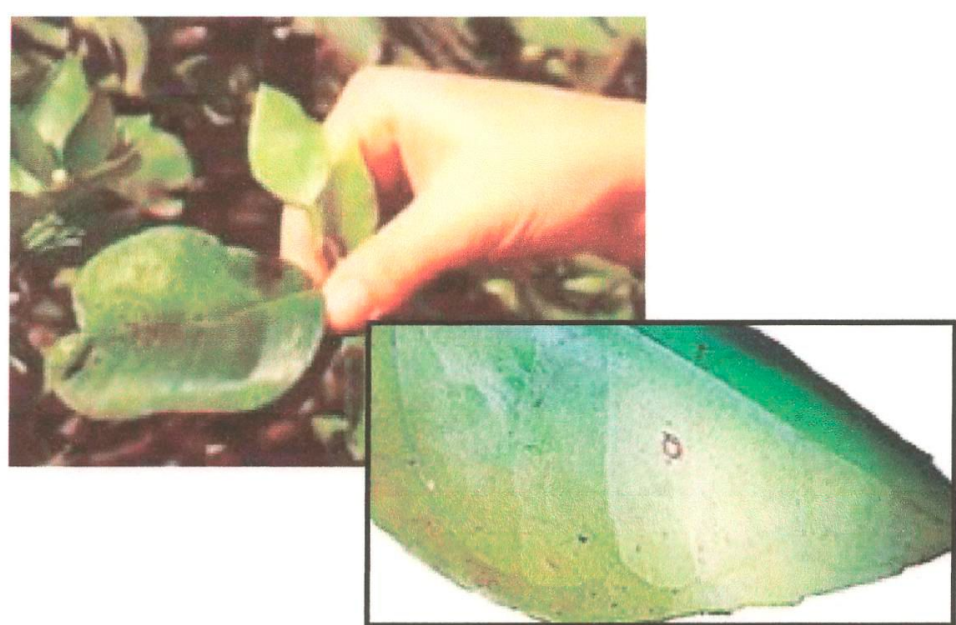

Figura 2.3: Sintomas da folha infectada pelo fungo Guignardia citricarpa (Fundecitrus, 2004).

dos frutos ao fungo.

Embora os picnidiósporos também possam causar a doença, a atenção é voltada para a presença dos ascósporos nos pomares, por serem eles os responsáveis pela introdução do patógeno na área e pelo início das epidemias a cada ciclo da cultura (Noronha, 2002). Os ascósporos são unicelulares, ligeiramente curvos com extremidades arredondadas e com o centro dilatado, medindo por volta de 10,5 por $3,5 \mu$ (Baldassari et. al., 2001). Na Figura 2.5 é mostrada a imagem de um ascósporo, ampliada por um microscópio.

\subsection{Técnica de Deteç̧ão do Esporo no Pomar}

O longo período de incubação da doença, do momento em que os esporos atingem concentrações perigosas no pomar até sua manifestação como praga, torna indispensável sua detecção 


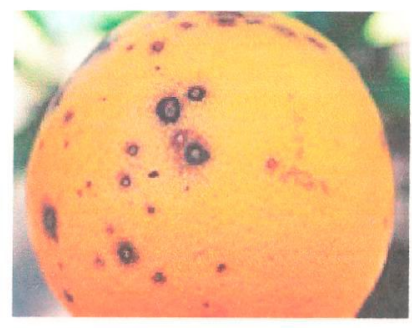

(a)

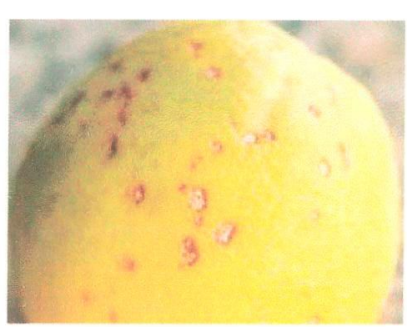

(d)

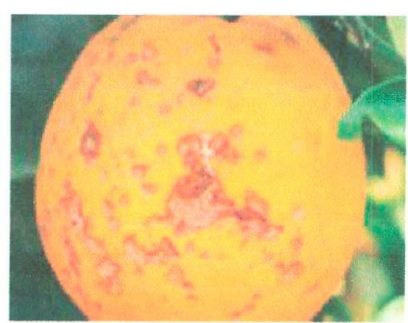

(b)

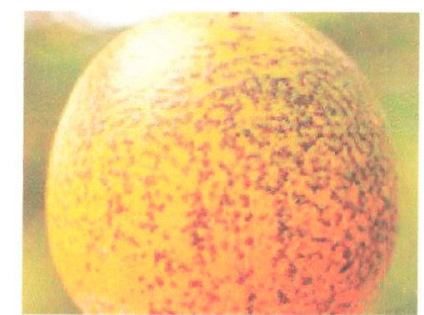

(e)

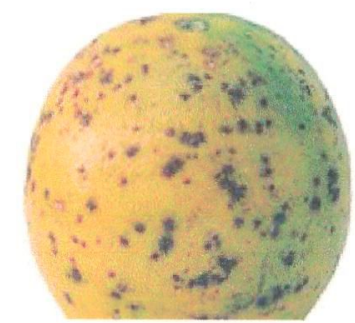

(c)

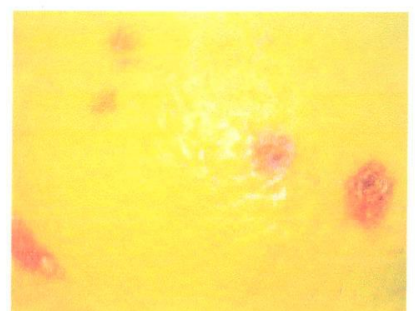

Figura 2.4: Tipos de lesões causadas pelo fungo Guignardia citricarpa: mancha dura (a), mancha virulenta (b), falsa melanose (c), mancha sardenta (d), mancha rendilhada (e) e mancha trincada (f) (Fundecitrus, 2004).

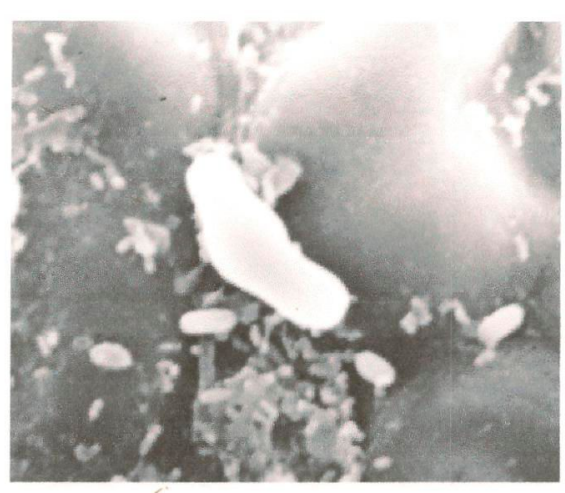

Figura 2.5: Ascósporo da Guignardia citricarpa (Baldassari et. al., 2001).

tão logo quanto possível, o que permite ao produtor aplicar quantidades menores de fungicidas, evitando aumentar o custo de produção e os efeitos deletérios ao meio-ambiente.

O mecanismo utilizado em fazendas paulistas para deteç̧ão do esporo causador da Mancha Preta (Figura 2.6) sopra amostras do ar ambiente do pomar em um disco de acrílico que gira em uma seqüência de passos pré-definidos. A superfície do disco contém uma camada de material aderente transparente ${ }^{1}$ que retém apenas as partículas sólidas microscópicas em suspensão, entre elas os esporos. Esse sistema é instalado em pontos estratégicos nas ruas do pomar, permanecendo alguns dias coletando as partículas (Figura 2.7). Periodicamente, um operador vai ao campo coletar os discos para serem analisados visualmente, com o auxílio de um microscópio, por especialistas que necessitam em torno de duas horas para completar a busca de esporos em cada disco (Figura 2.8), lembrando que apenas uma região amostral do disco é analisada.

\footnotetext{
O material aderente é vaselina líquida, que é pulverizada sobre a superfície dos discos. Além de aderente, ela é uma substância capaz de matar os esporos fixados, não permitindo, dessa maneira, que eles germinem e atrapalhem o processo de leitura. Essa vaselina é recomendada pela empresa fabricante do equipamento.
} 
Com o auxílio de técnicas computacionais apresentadas neste trabalho, as imagens obtidas a partir desses discos de coleta são analisadas e as partículas existentes nessas imagens são submetidas a um processo de identificação automática. Com isso, o presente trabalho apresenta uma alternativa a fim de automatizar tal etapa, procurando auxiliar, dessa maneira, o trabalho desenvolvido pelo especialista.

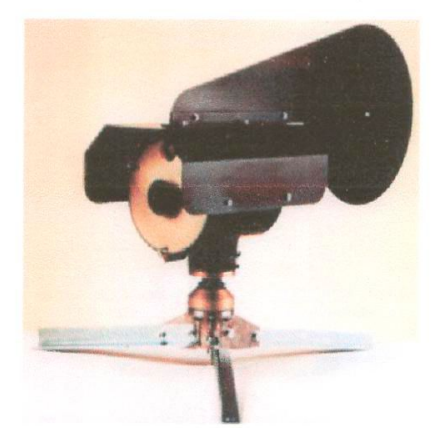

Figura 2.6: Coletor de partículas.

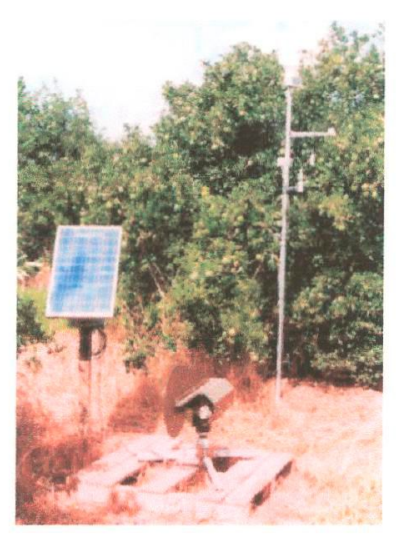

Figura 2.7: Sistema de aquisição de partículas suspensas.

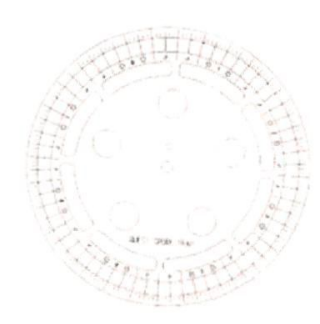

Figura 2.8: Esboço do disco de coleta.

\subsection{Considerações Finais}

Neste capítulo foi apresentada uma visão geral do problema, bem como a colaboração que um sistema de visão artificial pode proporcionar para o aperfeiçoamento no controle de doenças na produção de citros. Destacou-se também a importância da produção cítrica para o país e o interesse no desenvolvimento de recursos tecnológicos para o melhoramento da mesma. Além disso, uma introdução sobre a patologia da mancha preta e o mecanismo utilizado atualmente para coleta dos ascósporos foram apresentados.

No próximo capítulo são apresentados alguns métodos de visão computacional estudados neste trabalho. A partir desse estudo, algumas técnicas foram selecionadas mediante a alguns testes para posterior aplicação das mesmas na identificação dos ascósporos coletados nos pomares. 


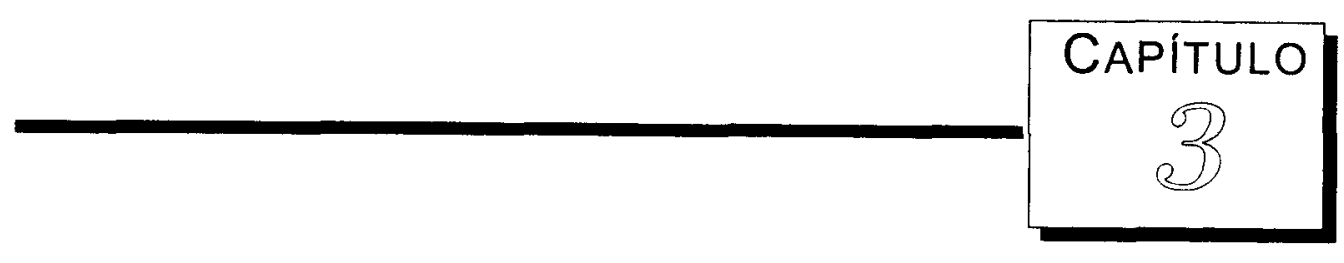

Métodos de Visão Artificial

$\mathcal{U}$

m sistema de visão tradicional é composto pelas etapas de aquisição, segmentação, extração de características e classificação (Gonzalez e Woods, 2002). Dentre os passos fundamentais no processamento de imagens, a etapa de segmentação apresenta-se como uma das mais importantes, e também como uma das mais difíceis. Isso deve-se ao fato de que o sucesso das etapas seguintes depende do bom êxito dela. Neste capítulo são abordadas técnicas para segmentação e análise de imagens e classificação. A discussão inicial é realizada em modelos de cores e técnicas para filtragem das imagens a fim de amenizar os problemas quanto a ruídos são apresentados. Em seguida, é apresentado um conjunto de técnicas para análise e descrição de objetos, dentre as principais técnicas abordadas têm-se assinaturas, curvatura, momentos, descritores de Fourier, descritores de wavelets, entre outros. Por fim, são consideradas as técnicas para classificação e identificação de objetos, dentre as quais têm-se a classificação por distância mínima e redes neurais artificiais. De um modo geral, neste capítulo são abordadas as técnicas relacionadas às três últimas etapas de um sistema de visão, a partir das quais um estudo comparativo foi realizado a fim de selecionar o conjunto de técnicas, que combinadas, seja capaz de proporcionar uma solução possibilitando o desenvolvimento do sistema para identificação dos ascósporos do fungo Guignardia citricarpa.

\subsection{Cores}

Existem dois fatores que motivam o uso de cores no processamento de imagens. O primeiro está relacionado ao fato da cor ser um descritor poderoso que simplifica a identificação do objeto e a extração de uma cena. O segundo motivo baseia-se na análise de imagens desempenhada pelos seres humanos, que são capazes de distinguir milhares de cores, enquanto estão limitados a cerca de duas dúzias de tons de cinza (Gonzalez e Woods, 1993).

A fim de facilitar a especificação das propriedades ou o comportamento das cores num contexto particular, foram criados os modelos de cores. No entanto, não existe um modelo que explique todos os aspectos relacionados à cor. Por isso, diferentes modelos são utilizados 
para ajudar a descrever as diferentes características da cor que são percebidas pelo ser humano (Hearn e Baker, 1994). De forma geral, um modelo de cor é especificado por um sistema de coordenadas tridimensionais que contém um subespaço dentro do qual cada cor é representada por um único ponto (Gonzalez e Woods, 1993).

Os modelos de cores mais usados em processamento de imagens são o RGB (vermelho, verde e azul) e o HSI (matiz, saturação e intensidade).

\subsubsection{Modelo RGB}

No modelo RGB de cores, uma imagem consiste de três planos independentes, sendo cada um referente a um dos componentes espectrais primários: vermelho, verde e azul. A partir de diferentes quantidades atribuídas a cada um desses componentes primários é possível se formar as diferentes cores. O modelo RGB baseia-se em um sistema de coordenadas cartesianas, cujo subespaço de cores pode ser representado por um cubo unitário, como é mostrado na Figura 3.1 (Gonzalez e Woods, 1993; Weeks, 1996).

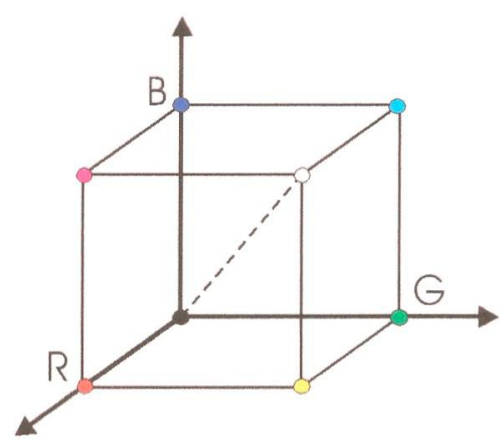

Figura 3.1: Cubo de cores RGB.

A cor preta é representada pela origem, enquanto que a cor branca é representada pelo vértice de coordenadas $(1,1,1)$. Os vértices que estão sobre os eixos representam as cores primárias e os demais vértices representam o complemento de cada cor primária (ciano, magenta e amarelo). Os tons de cinza são representados ao longo da diagonal principal do cubo, onde um tom específico de cinza é formado por quantidades iguais de cada componente. As demais cores são representadas por qualquer outro ponto interno ao cubo, obtido por meio das coordenadas $(R, G, B)$ (Hearn e Baker, 1994).

\subsubsection{Modelo HSI}

O modelo HSI é formado pelos componentes: matiz, saturação e intensidade. Esse modelo representa melhor o entendimento quanto à cor, por ser mais intuitivo do que as combinações do conjunto de cores primárias. Desses três componentes, o matiz é considerado componente chave no processo de reconhecimento humano, pois é a partir dele que se representa a cor dominante, ou seja, quando se diz que um objeto é vermelho, azul ou laranja, na verdade está sendo especificado o seu matiz.

O modelo HSI é baseado no triângulo de Maxwell que é derivado do cubo de cor RGB, onde o componente de intensidade é separado do componente cromático, como mostrado na 
Figura 3.2(a). Os vértices do triângulo representam as cores primárias e no centro há uma linha tracejada que conecta a cor branca à preta, que representa os níveis de cinza. É através dessa linha que se define a intensidade no modelo HSI. A saturação é obtida por meio da distância do vetor que parte do centro do triângulo até o ponto $p$ (Figura 3.2(b)), sendo que os pontos sobre as bordas do triângulo equivalem a $100 \%$ de saturação. O matiz, por sua vez, é definido pelo ângulo que varia de 0 a $360^{\circ}$, sendo que o vértice que representa a cor vermelha está no ângulo 0 . No caso da cor amarela, por exemplo, o ângulo é de $60^{\circ}$. A combinação dos três componentes (matiz, saturação e intensidade) resulta em uma estrutura piramidal quando representada em um espaço tridimensional (Figura 3.2(c)).

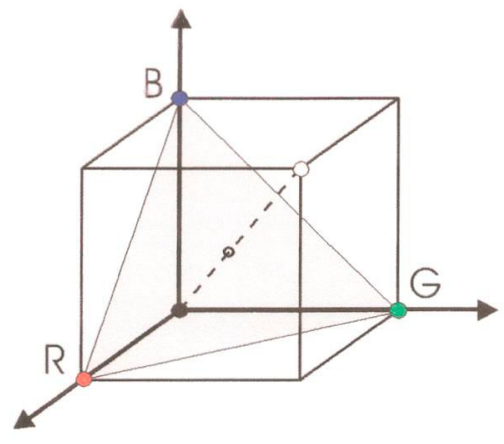

(a)

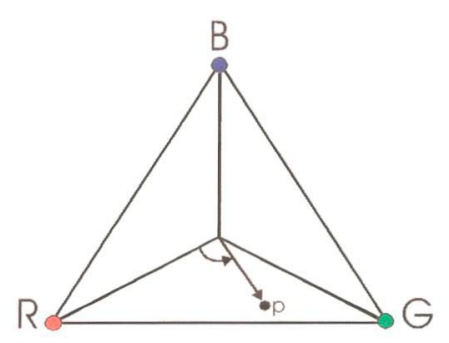

(b)

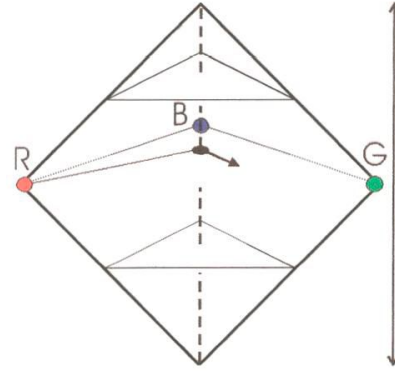

(c)

Figura 3.2: Triângulo obtido a partir do cubo RGB (a), triângulo de cores HSI (b) e sólido de cores HSI (c)

\subsubsection{Conversão de RGB para HSI}

Para derivar as equações que realizam a transformação de RGB para HSI e a inversa, é necessário que o componente $H$ (matiz) seja dividido em três regiões que estão ao longo dos três vértices, como é mostrado na Figura 3.2(b) (Weeks, 1996). Quando o componente azul $B$ é o menor dos três, a cor está localizada na parte de baixo do triângulo, e o matiz está entre 0 e $120^{\circ}$. Da mesma maneira, quando o componente vermelho $R$ é o menor, a cor está localizada no lado direito do triângulo e o matiz está entre $120^{\circ}$ e $240^{\circ}$. Por fim, quando o componente verde $G$ é o menor, a cor está localizada no lado esquerdo do triângulo e o matiz está entre $240^{\circ}$ e $360^{\circ}$.

Os componentes de intensidade, saturação e matiz, em termos de RGB, podem ser definidos a partir das seguintes equações:

$$
\begin{gathered}
I=\frac{(R+G+B)}{3} \\
S=1-\frac{3 \cdot \min [R, G, B]}{(R+G+B)}
\end{gathered}
$$




$$
H= \begin{cases}\cos ^{-1}\left(\frac{\frac{1}{2}((R-G)+(R-B))}{\sqrt{(R-G)^{2}+(R-B)(G-B)}}\right) & \text { se } G \geq B \\ 2 \pi-\cos ^{-1}\left(\frac{\frac{1}{2}((R-G)+(R-B))}{\sqrt{(R-G)^{2}+(R-B)(G-B)}}\right) & \text { se } G<B\end{cases}
$$

Nota-se que a equação 3.3 envolve exponenciação, raiz quadrada e a inversa de funções trigonométricas, cálculos esses custosos computacionalmente. Para contornar esse problema, uma outra maneira para se obter o valor do matiz foi proposta por Bajon (1986) apud Rick (2000) sem o uso de funções trigonométricas, conforme é apresentado na equação 3.4.

$$
H=\left\{\begin{array}{lc}
\frac{(G-B)}{3(R+G-2 B)} & \operatorname{semin}(R, G, B)=B \\
\frac{(B-R)}{3(G+B-2 R)}+\frac{1}{3} & \operatorname{semin}(R, G, B)=R \\
\frac{(R-G)}{3(R+B-2 G)}+\frac{2}{3} & \operatorname{semin}(R, G, B)=G \\
\text { indefinido } & \text { se } R=B=G
\end{array}\right.
$$

O menor valor entre os pontos $R, G$ e $B$ indicam onde o $H$ (matiz) está posicionado e, a partir disso, três resultados são possíveis. Se o componente de menor valor for:

- $B \rightarrow$ a cor está entre $300^{\circ}$ e $60^{\circ}$ (magenta e amarelo);

- $R \rightarrow$ a cor está entre $60^{\circ}$ e $180^{\circ}$ (amarelo e ciano);

- $G \rightarrow$ a cor está entre $180^{\circ}$ e $300^{\circ}$ (ciano e magenta).

O matiz é válido quando os valores de $R, G$ e $B$ são diferentes, caso contrário é considerado acromático. Os resultados obtidos após a conversão de RGB para HSI são mostrados na Figura 3.3.

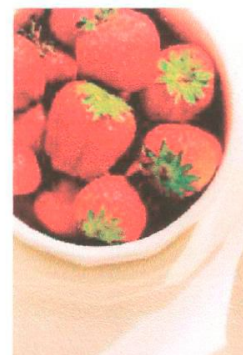

(a)

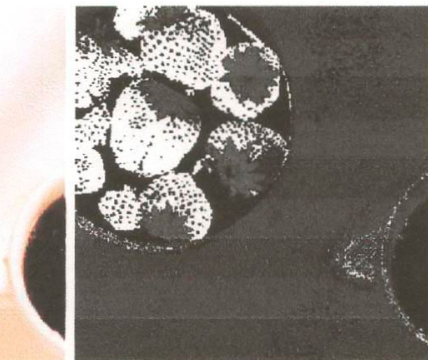

(b)

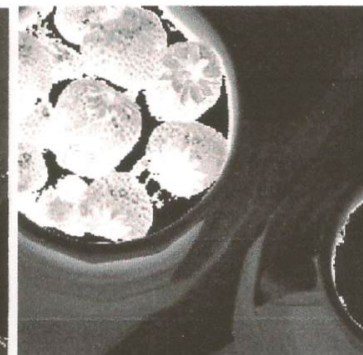

(c)

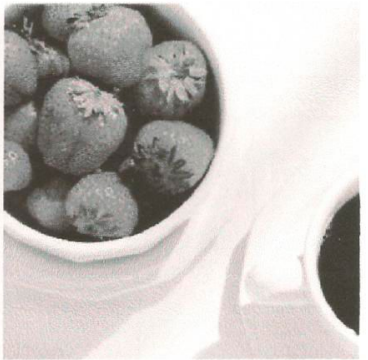

(d)

Figura 3.3: Conversão de RGB para HSI: Imagem em RGB (a), Matiz (b), Saturação (c) e Intensidade (d). 


\subsection{Segmentação de Imagens}

No processo de análise de imagens, uma das etapas aplicada é a segmentação, na qual é realizada a separação da imagem em regiões, isolando os componentes de interesse para a análise (Russ, 2002). Essa etapa pode determinar o sucesso ou, então, o fracasso na análise se não for bem definida. Realizar uma segmentação autônoma que obtenha resultados satisfatórios é uma tarefa uma tanto quanto dificil (Gonzalez e Woods, 1993).

$\mathrm{Na}$ literatura existem diferentes classificações para os métodos de segmentação de imagens. Dentre elas, há a adotada por Gonzalez e Wintz (1987), que classifica os métodos em três grupos: limiarização, segmentação baseada em bordas e segmentação baseada em regiões. A limiarização baseia-se na divisão da imagem em duas ou mais regiões por meio da seleção de limiares, na maioria das vezes definidos com base na análise do histograma da imagem. A segmentação baseada em bordas explora a descontinuidade dos níveis de cinza. Após a detecção dessas descontinuidades, aplica-se algum método capaz de extrair os contornos que estejam associados com os contornos reais dos objetos. A segmentação baseada em regiões consiste na separação de uma imagem em diferentes regiões, que são agrupadas de acordo com um critério de similaridade.

Outras categorias também começaram a ser consideradas, dentre elas a dos métodos baseados em cores (Gonzalez-Rodriguez et. al., 1990; Lim e Lee, 1990), a dos métodos que aplicam redes neurais e lógica fuzzy (Bezdek e Pal, 1992) e a dos métodos baseados em algoritmos genéticos (Ankenbrandt et. al., 1990). No entanto, é importante ressaltar que não há uma técnica de segmentação universal, aplicável a todo o tipo de imagem.

\subsubsection{Limiarização}

O processo de limiarização consiste na separação de uma imagem em diferentes regiões de acordo com a distribuição de níveis de cinza. Nesse método, o valor de cada ponto é comparado a um limiar definido por meio da análise do histograma de niveis de cinza da imagem (Weeks, 1996). Uma vez definido o limiar, é possível determinar dois grupos: o fundo da imagem e os objetos contidos nela, onde os pontos com intensidade menor que o limiar definido são considerados partes do fundo da imagem, e os demais são considerados partes dos objetos. Uma imagem limiarizada $g(x, y)$ é definida como:

$$
g(x, y)= \begin{cases}1 & \text { sef }(x, y)>T \\ 0 & \operatorname{sef}(x, y) \leq T\end{cases}
$$

sendo $T$ o limiar selecionado. Os pontos rotulados com o valor 1 correspondem ao objeto, enquanto os rotulados com 0 correspondem ao fundo da imagem. Na Figura 3.4 é mostrado o histograma com o limiar $T$ definido e a imagem limiarizada.

A limiarização é um método simples e bastante intuitivo de segmentação. Esse método se torna fácil se os niveis de cinza que definem o objeto forem distintos dos níveis que compõem o fundo da imagem. Em uma imagem complexa, os niveis de cinza nem sempre estão bem definidos para ambas as partes, dificultando a seleção de um limiar ideal. Realizar uma análise 


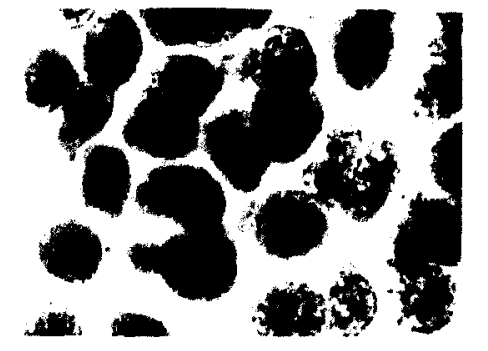

(a)

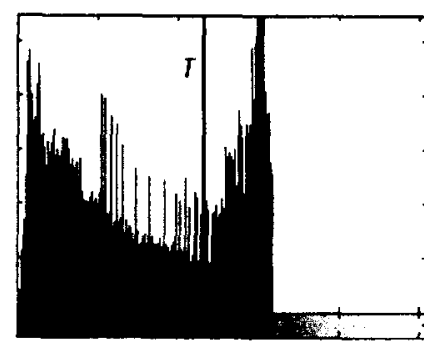

(b)

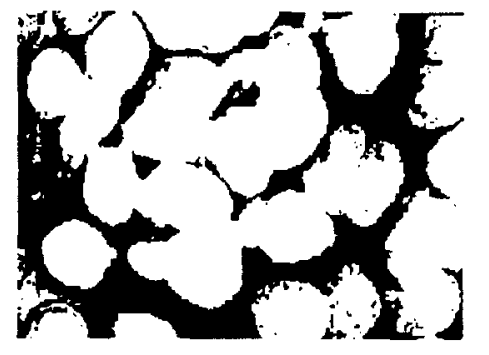

(c)

Figura 3.4: Limiarização: imagem original em tons de cinza (a), histograma com $T$ definido (b) e imagem limiarizada (c).

automática do histograma para definir esse limiar não é uma tarefa simples (Pavlidis, 1982; Weeks, 1996)

Existem várias técnicas de limiarização, por exemplo, a seleção manual obtida após vários testes efetuados pelo próprio usuário, ou então, detectar o mínimo local mais próximo ao centro do histograma, que é uma das técnicas mais tradicionais e intuitivas (Método do Vale) (Sahoo et. al., 1988). No entanto, alguns histogramas podem apresentar vales longos e planos tornando a busca do limiar arbitrária. Outros podem apresentar valores muito baixos tornando-se bastante sensíveis a ruídos. Em geral, a determinação do limiar baseia-se em certos critérios. Com base nisso, os métodos podem ser classificados em duas categorias (Sahoo et. al., 1988): dependente do ponto, na qual o limiar é determinado somente a partir do nível de cinza de cada ponto, e dependente da região, na qual o limiar é determinado a partir da propriedade local da vizinhança de cada ponto, por exemplo a distribuição local dos níveis de cinza. Além disso, uma técnica de limiarização é dita global quando se define apenas um único limiar para toda a imagem, enquanto que em uma técnica de limiarização local, particiona-se uma imagem determinando para cada uma dessas partes um limiar.

Um método bastante utilizado é o proposto por Otsu (Gonzalez e Wintz, 1987; Sahoo et. al., 1988; Weeks, 1996), que baseia-se na análise discriminante. A imagem em niveis de cinza é tratada como uma classificação de problemas em que duas classes são geradas a partir de um conjunto de pontos contidos nela. A primeira classe define o conjunto de pontos com nível de cinza igual ou abaixo de um limiar determinado, e a segunda classe define o conjunto cujos pontos possuem nível de cinza acima do limiar. O objetivo desse método é selecionar um limiar que minimize a área das duas classes, enquanto maximiza a distância (variância) entre elas. Para todos os valores de $t$ possíveis, considera-se como limiar ótimo o que resultar no menor valor de $\eta$, critério determinado pela função (Parker, 1997; Sahoo et. al., 1988):

$$
\eta=\frac{\sigma_{B}^{2}}{\sigma_{T}^{2}}
$$


sendo

$$
\begin{array}{ll}
\sigma_{T}^{2}=\sum_{i=0}^{N-1}\left(i-\mu_{T}\right)^{2} p_{i}, \quad \mu_{T}=\sum_{i=0}^{N-1} i p_{i}, & \\
\sigma_{B}^{2}=\omega_{0} \omega_{1}\left(\mu_{1} \mu_{0}\right)^{2}, & \omega_{0}=\sum_{i=0}^{N-1} p_{i}, \quad \omega_{1}=1-\omega_{0}, \\
\mu_{1}=\frac{\mu_{T}-\mu_{t}}{1-\omega_{0}}, & \mu_{0}=\frac{\mu_{t}}{\omega_{0}}, \quad \mu_{t}=\sum_{i=0}^{t} i p_{i},
\end{array}
$$

onde $N$ é a quantidade de níveis de cinza e $p_{i}$ é a quantidade de pontos de intensidade $i$.

Outro método de limiarização é o de Seleção Iterativa, o qual baseia-se na suposição de um limiar inicial que será refinado por passagens consecutivas pela imagem. Esse limiar inicial pode ser simplesmente a média dos níveis de cinza, o qual é usado para coletar estatísticas das regiões pretas e brancas da imagem. Primeiramente, encontra-se o nível de cinza médio de todos os pontos da imagem inferiores ao limiar, que é chamado de $T_{\text {fundo }}$. O mesmo é feito para se obter o nivel de cinza médio de todos os pontos com intensidade maior ou igual ao limiar, que é chamado de $T_{\text {objeto. }}$ Em seguida, realiza-se uma nova estimativa por meio da média dos níveis médios para cada classe de pontos, ou seja, $\left(T_{\text {fundo }}+T_{o b j e t o}\right) / 2$. O processo é repetido usando o novo limiar. Esses passos continuam sendo executados até que não ocorra mais mudanças no limiar em dois passos consecutivos, encerrando-se o processo.

$\mathrm{Na}$ implementação desse método, o histograma é utilizado para estimar o limiar. O limiar $T_{k}$ é obtido por meio da equação 3.8 , na qual $p$ é a quantidade de pontos de uma determinada intensidade, e $k$ representa a $k$-ésima estimativa do limiar, que pode variar de $0 \ldots N$ sendo $N$ a quantidade de níveis de cinza. Por fim, quando $T_{k}=T_{k+1}$ então $T_{k}$ é considerado o limiar ideal e o processo para determinar o limiar é encerrado (Parker, 1997).

$$
T_{k}=\frac{\sum_{i=0}^{T_{k}-1} i p_{i}}{2 \sum_{i=0}^{T_{k}-1} p_{i}}+\frac{\sum_{j=T_{k}}^{N} j p_{j}}{2 \sum_{j=T_{k}}^{N} p_{j}}
$$

É importante ressaltar que na literatura há vários métodos para limiarização de imagens (Parker, 1997; Sahoo et. al., 1988; Sonka et. al., 1999), e a seleção do método mais adequado depende da aplicação em desenvolvimento.

\subsubsection{Filtros de Difusão Não-Linear}

Uma questão central em visão computacional é a simplificação de uma dada imagem para particioná-la em regiões, ou seja, segmentá-la. Para isso, as informações contidas na imagem original são filtradas, eliminando-se os detalhes desnecessários e os ruídos. Existem vários métodos que são usualmente utilizados para esse fim, tais como limiarização, eliminação de pequenas regiões, algoritmos de expansão e compressão e filtros de freqüência. Para contornar esse tipo de problema, técnicas que enfatizam regiões foram propostas com base em equações diferenciais. Equações diferenciais parciais (EDP) têm recentemente sido adotadas em visão computacional, processamento e análise de imagens (Suri et. al., 2002). Com técnicas de segmentação baseadas em equações diferenciais, tornou-se possível desenvolver técnicas de visão computacional de baixo nível para implementar sistemas de segmentação mais robustos, con- 
fiáveis, precisos e que mantenham proximidade à forma original.

A presença de ruídos em imagens é inevitável e para amenizar esse problema, geralmente, são aplicados filtros passa-baixa, como o filtro Gaussiano. Entretanto, alguns problemas ocorrem com a aplicação desses filtros, como o deslocamento das regiões de fronteiras decorrente do processo de suavização (borramento) efetuado em toda a imagem, dificultando, dessa maneira, a deteç̧ão e localização das mesmas. No entanto, outras técnicas baseadas em EDP também foram propostas, dentre elas, as técnicas de Perona e Malik (1990), Alvarez et. al. (1992), Catté et. al. (1992), Weickert (1997), Black et. al. (1998) e Bajla e Holländer (1998). O trabalho de Perona e Malik foi o pioneiro e fez com que os filtros de difusão não-linear se tornassem uma ferramenta popular em processamento de imagens e visão computacional. O trabalho consistia em um modelo para realizar uma suavização seletiva na imagem. Com o objetivo de eliminar os problemas de suavização apresentados pelos filtros de difusão linear, foi proposto um método de difusão não uniforme que reduz a difusão nos locais com probabilidade de serem bordas locais com gradientes maiores - preservando-as (Morel e Solimini, 1995). A comparação entre os resultados obtidos com filtros de difusão linear e não-linear é mostrada na Figura 3.5.

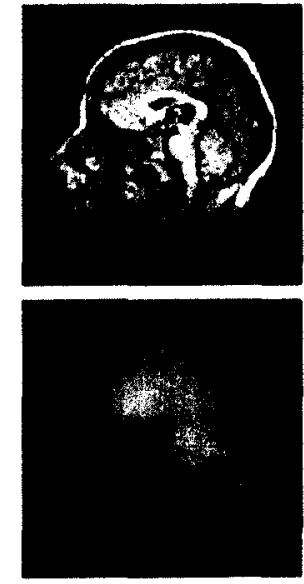

(a)
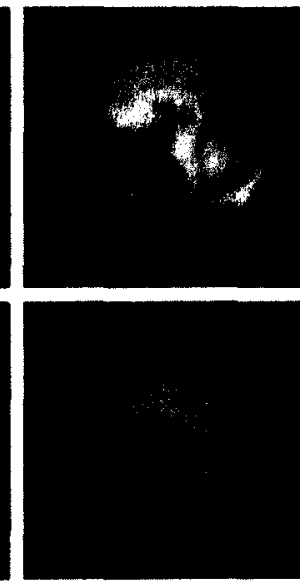

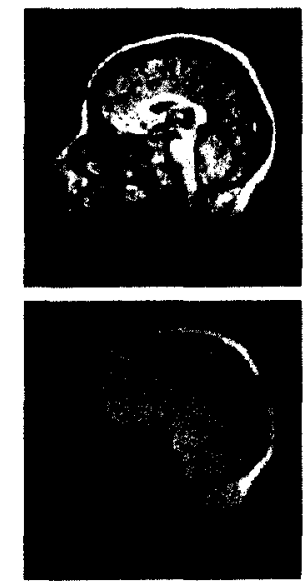

(b)

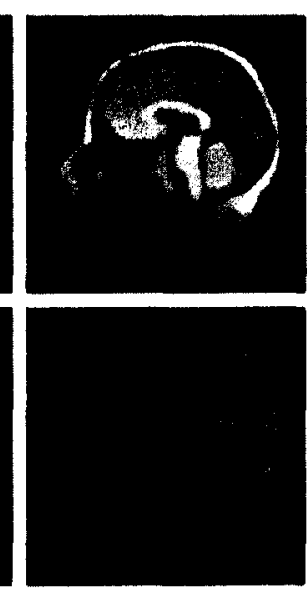

Figura 3.5: Comparação entre a aplicação de filtros lineares (a) e não-lineares (b) sobre uma imagem. Cada um dos quadrantes refere-se a um diferente número de iteração. b) (Fonte: http://www.s2.chalmers.se/undergraduate/courses/ess060)

A idéia é apoiada na introdução de coeficiente de difusão dependente do espaço-escala, isto é, $g(x, y, t)$. Dessa maneira, a equação de difusão aplicada sobre a imagem $I$, baseada na equação de calor, assume a seguinte forma (Voci et. al., 2004):

$$
\frac{\delta I(x, y, t)}{\delta t}=\operatorname{div}(g(x, y, t) \nabla I(x, y, t))
$$

Se o coeficiente de difusão é uma constante, então se têm a equação linear de difusão de calor. Entretanto, se ao invés da constante for usada uma função $g(\cdot)$, dois efeitos básicos são obtidos: incentivo à suavização dentro das regiões e redução da suavização na fronteira dessas regiões. Isso pode ser alcançado atribuindo ao coeficiente de difusão $g(\cdot)=1$ para o interior 
das regiões e $g(\cdot)=0$ para as regiões de fronteira. A suavização ocorre separadamente em cada região, não havendo interação entre elas. A definição dos coeficientes de difusão pode ser realizada por meio da identificação das bordas da imagem em cada uma das iterações e o uso do gradiente da imagem, $\nabla I(x, y, t)$, tem apresentado um bom resultado (Perona e Malik, 1990). Dessa maneira, o coeficiente de difusão é selecionado localmente por meio da magnitude do gradiente da imagem (considerando-se as intensidades dos pontos), isto é,

$$
g(x, y, t)=g(\|\nabla I(x, y, t)\|)
$$

Em razão do valor de difusão $g(\cdot)$ não ser mais uma constante, mas uma função de gradiente, Perona e Malik chamaram esse modelo de anisotrópico. A Equação 3.9 pode ser discretizada sobre uma grade, com a intensidade dos pontos da imagem associado aos vértices, e os coeficientes de difusão aos arcos (Figura 3.6). Com isso, pode ser usada a discretização por vizinhança de 4 do operador Laplaciano (Perona e Malik, 1990):

$$
I_{x, y}^{t+1}=I_{x, y}^{t}+\lambda\left[c_{N} \cdot \nabla_{N} I+c_{S} \cdot \nabla_{S} I+c_{L} \cdot \nabla_{L} I+c_{O} \cdot \nabla_{O} I\right]_{x, y}^{t}
$$

sendo $0 \leq \lambda \leq 1 / 4$ o incremento do tempo, que deve ser pequeno o bastante para garantir a convergência para um estado estável. Com a implementação numérica do modelo de Perona-Malik, é necessária a discretização do tempo e a introdução desse tempo está ligada à estabilidade da evolução do modelo, a qual pode ser comprometida se esse parâmetro entre as iterações aumen$\operatorname{tar}$ (Voci et. al., 2004)

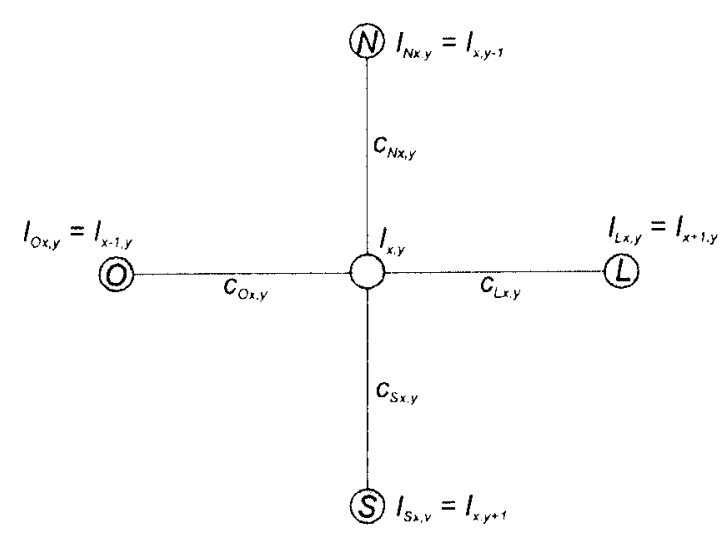

Figura 3.6: Estrutura representando a discretização usada na implementação numérica (Adaptado de Perona e Malik (1990)).

Os gradientes em todas as direções (diferença entre as vizinhanças) são determinados por

$$
\begin{aligned}
& \nabla_{N} I_{x, y} \equiv I_{x, y-1}-I_{x, y} \\
& \nabla_{S} I_{x, y} \equiv I_{x, y+1}-I_{x, y} \\
& \nabla_{L} I_{x, y} \equiv I_{x+1, y}-I_{x, y} \\
& \nabla_{O} I_{x, y} \equiv I_{x-1, y}-I_{x, y}
\end{aligned}
$$


sendo $N, S, L$ e $O$, as direções Norte, Sul, Leste e Oeste, respectivamente. E a cada iteração, cada um dos coeficientes de difusão são atualizados por

$$
\begin{aligned}
& c_{N x, y}^{t}=g\left(\left\|\nabla_{N} I_{x, y}\right\|\right) \\
& c_{S x, y}^{t}=g\left(\left\|\nabla_{S} I_{x, y}\right\|\right) \\
& c_{L x, y}^{t}=g\left(\left\|\nabla_{L} I_{x, y}\right\|\right) \\
& c_{O x, y}^{t}=g\left(\left\|\nabla_{O} I_{x, y}\right\|\right)
\end{aligned}
$$

sendo

$$
g(\|\nabla I\|)=\frac{1}{1+\left(\frac{\|\nabla I\|}{K}\right)^{2}}
$$

A constante $K$ é considerada um parâmetro de contraste, isso porque as regiões onde $\|\nabla I\|>$ $K$ são consideradas como fronteiras e o processo de difusão tem pouco efeito. Com isso, a equação passou a ser considerada um modelo de difusão não-linear, fornecendo um algoritmo potencial para segmentação de imagens, remoção de ruídos, deteç̧ão de bordas e realce de imagem, tornando-se indispensável também para outras linhas de pesquisa.

\subsubsection{Operações Morfológicas}

O termo morfologia vem originalmente do estudo de formas de plantas e animais. A mesma palavra é usada no contexto de morfologia matemática para o estudo da topologia ou estrutura de objetos a partir de suas imagens (Jain, 1989). As operações morfológicas podem ser aplicadas tanto na extração de fronteiras, esqueletos e fecho convexo, quanto no pré e pós-processamento de imagens como: afinamento, filtragem morfológica e poda (Gonzalez e Woods, 1993).

A morfologia matemática baseia-se na teoria dos conjuntos. São por meio de conjuntos que a forma dos objetos contidos em uma imagem é representada. No caso de imagens binárias, os conjuntos são membros de um espaço bidimensional $\mathbb{Z}^{2}$, onde cada elemento é um vetor que corresponde às coordenadas $(x, y)$ dos pontos que compõem o objeto. Também foram definidas operações para se trabalhar com as imagens, as quais podem ser descritas simplesmente em termos de adição e remoção de pontos de uma imagem binária (Russ, 2002).

\subsubsection{Dilatação e Erosão}

A maioria das operações morfológicas podem ser definidas por meio de dois operadores básicos: dilatação e erosão. A dilatação de um conjunto $A$ por um conjunto $B$, denotada por $A \oplus B$, é definida por:

$$
A \oplus B=\left\{x \mid(\hat{B})_{x} \cap A \neq \varnothing\right\}
$$

sendo a dilatação de $A$ por $B$ o conjunto de todos os deslocamentos $x$ tais que a reflexão do conjunto $B$ em torno de sua origem $(\hat{B})$ e $A$ se sobreponham em pelo menos um elemento não nulo. Mediante a essa interpretação, a equação 3.15 pode ser reescrita da seguinte maneira:

$$
A \oplus B=\left\{x \mid\left([\hat{B})_{x} \cap A\right] \subseteq A\right\}
$$


De modo similar, a erosão de um conjunto $A$ por um conjunto $B$, denotada por $A \ominus B$, é definida por:

$$
A \ominus B=\left\{x \mid(B)_{x} \subseteq A\right\}
$$

sendo a erosão de $A$ por $B$ o conjunto de todos os pontos $x$ tais que $B$, quando transladado em $x$, esteja contido em $A$.

O conjunto $B$, que aparece nas definições, é também conhecido como elemento estruturante nas operações morfológicas. As operações de dilatação e erosão aumentam e reduzem o tamanho da forma do objeto, respectivamente, e permitem variações nas regras que decidem qual ponto da forma será adicionado ou removido.

\subsubsection{Abertura e Fechamento}

Erosão e dilatação não são transformações inversas, entretanto a combinação dessas operações pode gerar uma versão simplificada e menos detalhada da imagem original (Sonka et. al., 1999). As operações de abertura e fechamento nada mais são do que a combinação das operações de dilatação e erosão, como citado anteriormente. A operação de abertura geralmente é aplicada para suavização do contorno de um objeto, assim como para romper pequenas ligações e eliminar protusões finas. A operação de fechamento também é aplicada para a suavização de contornos, mas diferentemente da operação de abertura, ela serve para fundir partes, eliminar pequenos buracos e preencher fendas presentes na forma de um objeto (Gonzalez e Woods, 1993).

A abertura de um conjunto $A$ por um conjunto $B$ (elemento estruturante), denotada por $A \circ B$, é definida como:

$$
A \circ B=(A \ominus B) \oplus B
$$

na qual realiza-se a erosão do conjunto $A$ pelo elemento estruturante $B$, seguida da dilatação do conjunto resultante pelo mesmo elemento estruturante.

$\mathrm{O}$ fechamento é similar à abertura, invertendo apenas a ordem das operações básicas. $\mathrm{O}$ fechamento é denotado por $A \bullet B$ e definido como:

$$
A \bullet B=(A \oplus B) \ominus B
$$

na qual efetua-se a dilatação do conjunto $A$ pelo elemento estruturante $B$, seguida da erosão do conjunto resultante também pelo elemento estruturante $B$.

Uma das aplicações para as operações de abertura e fechamento está na construção do filtro morfológico $(A \circ B) \bullet B$. Esse filtro tem como objetivo eliminar os ruidos presentes em uma imagem binária, procurando distorcer o mínimo possível a forma original do objeto. Para exemplificar a utilização desse filtro, considere como imagem de entrada a Figura 3.7(a), que consiste de um objeto corrompido com ruídos (pontos escuros no fundo e lacunas internas ao objeto). Aplicando a abertura com um elemento estruturante maior do que os componentes ruidosos, efetua-se a remoção dos ruídos externos ao objeto, resultado do estágio de erosão, como mostrado na Figura 3.7(c). Por fim, o fechamento é aplicado para remover as lacunas internas (Figura 3.7(c)), as quais são eliminadas no estágio de dilatação, tendo o resultado final mostrado 
na Figura 3.7(e)

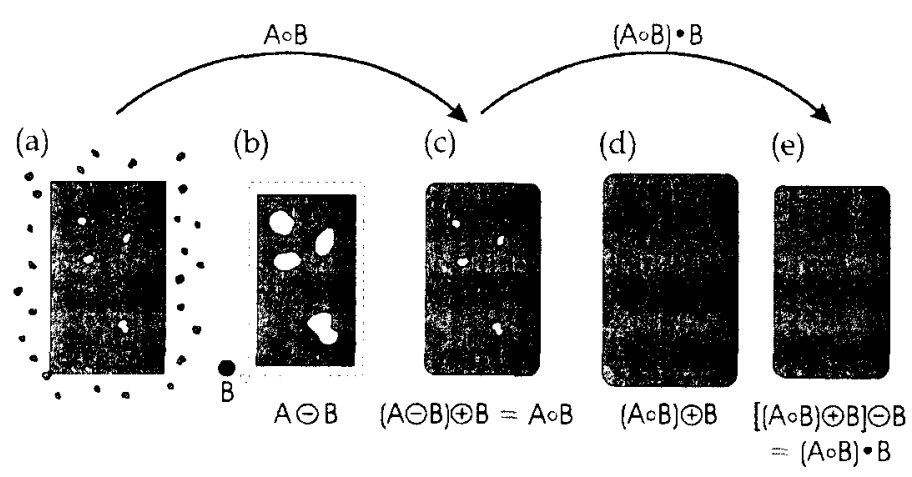

Figura 3.7: Filtragem morfológica: imagem de entrada (a), resultado da erosão (b), abertura de A (c), resultado da dilatação do resultado da abertura (d), resultado final com o fechamento (e) (Gonzalez e Woods, 1993).

\subsubsection{Transformada Watershed}

Uma das dificuldades encontradas na segmentação de imagens refere-se à sobreposição e conexão entre os objetos presentes na imagem, que ocorre com maior freqüência em imagens com grande quantidade de objetos, por exemplo, imagens biológicas.

$\mathrm{Na}$ área de processamento de imagens, particularmente em morfologia matemática, uma das alternativas empregadas para a segregação das partículas sobrepostas é a transformada $w a-$ tershed, que faz analogia à inundação de regiões. Nessa técnica, as imagens em escala de cinza são consideradas como relevos topográficos, em que a intensidade de cada ponto da imagem representa a elevação da superfície (Roerdink e Meijster, 2000). Dessa maneira, em uma imagem podem ser encontradas regiões que se assemelham a vales e outras a montanhas. A partir dessa analogia alguns termos, ilustrados na Figura 3.8, são definidos:

- Bacia de captação: nome dado aos vales, nos quais será iniciado o processo de inundação para separação das regiões;

- Linha divisória (dique): divisória formada por pontos onde ocorre a junção de duas regiões durante a inundação;

- Mínimos locais: ponto ou conjunto de pontos com a menor altitude de cada vale.

Vincent e Soille (1991) apresentaram uma abordagem que pode ser considerada uma definição algorítmica, por ser aplicável na implementação prática. A idéia, representada na Figura 3.9, é simples: considere que em cada região de mínimo local exista uma perfuração. Em seguida, considere que a superfície esteja sendo imersa em um lago. Iniciando-se pelas regiões com menor altitude, as bacias de captação, formadas pelos vales, vão enchendo-se de água e nos pontos em que ocorre o encontro de águas pertencentes a diferentes bacias de captação, são construídos diques que dividem essas regiões. Ao final da imersão da superfície, cada um dos mínimos locais estará cercado por esses diques, delimitando as diferentes regiões. 


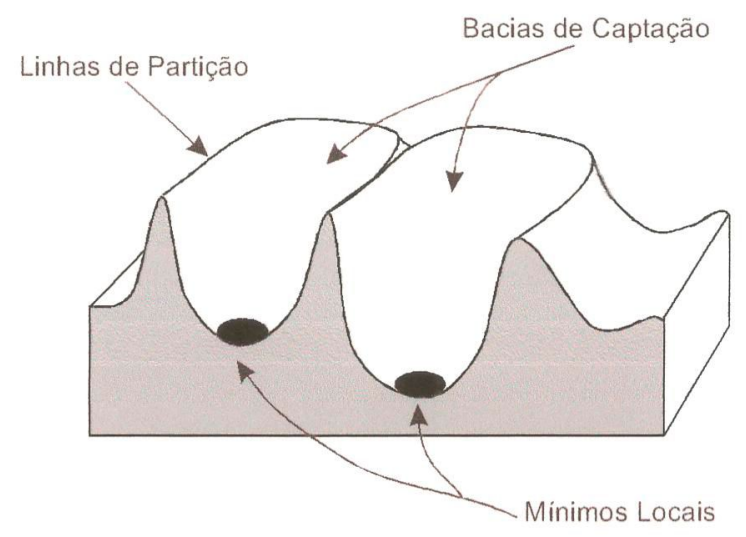

Figura 3.8: Representação dos termos usados na Transformada watershed. (Adaptado de Vincent e Soille (1991)).

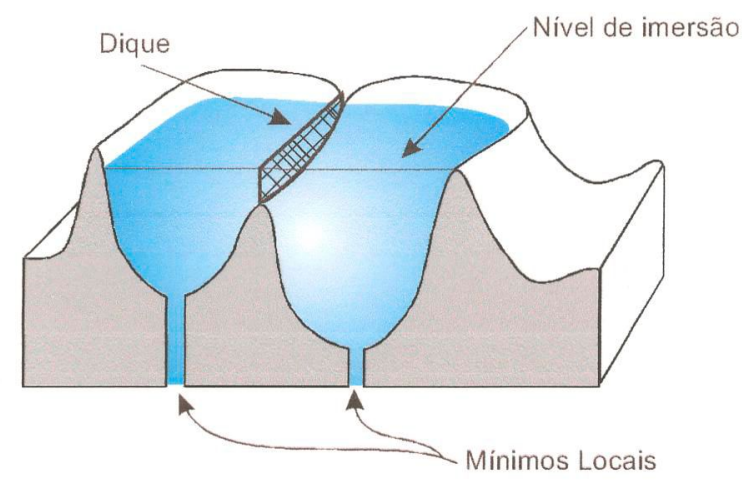

Figura 3.9: Representação do processo de imersão. (Adaptado de Vincent e Soille (1991)).

\subsubsection{Algoritmo}

Considere $M_{1}, M_{2}, \ldots, M_{R}$ os conjuntos denotando as coordenadas de pontos das regiões mínimas de uma imagem $g(x, y)$ e $C\left(M_{i}\right)$ denotando o conjunto das coordenadas dos pontos pertencentes à bacia de captação associada à região mínima $M_{i}$. A notação $\min$ e $\max$ são usadas para denotar os valores mínimos e máximos de $g(x, y)$, respectivamente. $T[n]$ representa o conjunto de coordenadas $(s, t)$ em que $g(s, t)<n$, sendo $n$ o nível. Geometricamente, $T[n]$ é o conjunto de coordenadas de pontos em $g(x, y)$ abaixo do plano $g(x, y)=n$ (Gonzalez e Woods, 2002).

A topografia é preenchida em incrementos inteiros, de $n=\min +1$ até $n=\max +1$. Em qualquer estágio $n$ do preenchimento, o algoritmo precisa saber quais os pontos já foram preenchidos. Para facilitar o entendimento, considere como a região já preenchida os pontos em preto de uma imagem binária, os quais correspondem aos pontos abaixo do plano $g(x, y)=n$. Considere também que $C_{n}\left(M_{i}\right)$ denota o conjunto dos pontos associados à bacia de captação $M_{i}$ preenchida até o estágio $n . C_{n}\left(M_{i}\right)$ também pode ser visto como a imagem binária dada por $C_{n}\left(M_{i}\right)=C\left(M_{i}\right) \cap T[n]$. Em outras palavras, $C_{n}\left(M_{i}\right)=1$ na coordenada $(x, y)$ se 
$(x, y) \in C\left(M_{i}\right) A N D(x, y) \in T[n]$; caso contrário, $C_{n}\left(M_{i}\right)=0$. O operador $A N D$ está sendo usado para isolar, no estágio $n$ de preenchimento, a porção da imagem binária em $T[n]$ associada à região mínima $M_{i}$. Em seguida, $C[n]$ denota a união das porções preenchidas das bacias de captação no estágio $n$, isto é,

$$
C[n]=\bigcup_{i=1}^{R} C_{n}\left(M_{i}\right) .
$$

Então, $C[\max +1]$ é a união de todas as bacias de captação, ou seja,

$$
C[\max +1]=\bigcup_{i=1}^{R} C\left(M_{i}\right) .
$$

Isso mostra que os elementos em $C_{n}\left(M_{i}\right)$ e $T[n]$ não se sobrepõem durante a execução do algoritmo e que o número de elementos nesses dois conjuntos ou aumentam ou permanecem o mesmo quando o $n$ é incrementado. Assim, $C[n-1]$ é um subconjunto de $C[n]$, que é um importante resultado, visto que cada componente conexa de $C[n-1]$ está contida em exatamente uma componente conexa de $T[n]$.

O algoritmo para encontrar as linhas divisórias é inicializado com $C[\min +1]=T[\min +1]$. O mesmo procede recursivamente assumindo no estágio $n$ que $C[n-1]$ foi construído. Dado que $Q$ denota o conjunto de componentes conexas em $T[n]$, então, para cada componente conexa $q \in Q[n]$ há três possibilidades:

a) $q \cap C[n-1]$ é vazio.

b) $q \cap C[n-1]$ contém uma componente conexa de $C[n-1]$.

c) $q \cap C[n-1]$ contém mais do que uma componente conexa de $C[n-1]$.

A construção de $C[n]$ a partir de $C[n-1]$ depende de que uma dessas três condições seja válida. A condição (a) ocorre quando um novo mínimo é encontrado e, nesse caso, a componente conexa $q$ é incorporado a $C[n-1]$ para formar $C[n]$. A condição (b) ocorre quando $q$ fica dentro da bacia de captação de alguma região mínima, e que nesse caso $q$ é incorporado a $C[n-1]$ para formar $C[n]$. A condição (c) ocorre quando é encontrado um topo, ou parte dele, separando duas ou mais bacias de captação. O próximo estágio do preenchimento causaria a mistura das águas e, por isso, um dique deve ser construído nesse estágio (Gonzalez e Woods, 2002).

A eficiência do algoritmo é melhorada usando apenas valores de $n$ que correspondem aos niveis de cinza existentes em $g(x, y)$. Esses valores, bem como os valores de min e max podem ser obtidos a partir do histograma de $g(x, y)$. Um algoritmo eficiente é apresentado por Vincent e Soille (1991), que se baseia na ordenação crescente das intensidades dos pontos da imagem seguida dos estágios de preenchimento, os quais consistem em uma rápida varredura de todos os pontos na ordem dada pela escala de cinza. Durante a etapa de ordenação, um histograma é construído. Simultaneamente, uma lista de ponteiros para os pontos de nível de cinza $n$ é criada 
e associada a cada intensidade no histograma, permitindo um acesso direto a todos os pontos de qualquer nível de cinza. Suponha que o preenchimento tenha sido efetuado até um nível $n$. Dessa maneira, todos os pontos com intensidade menor ou igual a $n$ terão sido associados a uma bacia de captação (rótulo de uma região mínima). Em seguida, os pontos de intensidade $n+1$ deverão ser processados (Sonka et. al., 1999).

A aplicação direta do algoritmo de segmentação, no entanto, leva geralmente a supersegmentação por causa de ruídos e outras irregularidades locais. Uma abordagem para contornar esse problema se baseia no uso de marcadores. Um marcador é uma componente conexa pertencente à imagem. Existem marcadores internos, associados aos objetos de interesse, e externos, associados ao fundo da imagem. A definição dos mesmos envolve dois passos: (1) pré-processamento e (2) a definição de um conjunto de critérios que os marcadores devam satisfazer (Gonzalez e Woods, 2002). Na Figura 3.10 são mostrados dois exemplos, um de supersegmentação (b) e outro usando marcadores (c e d).

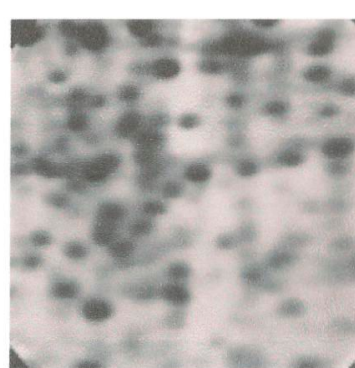

(a)

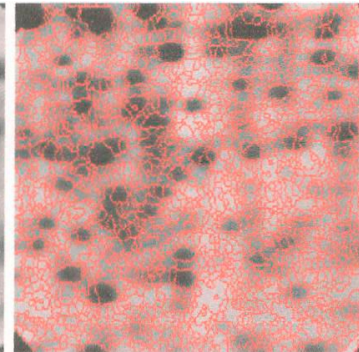

(b)

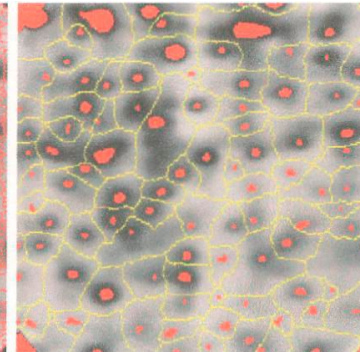

(c)

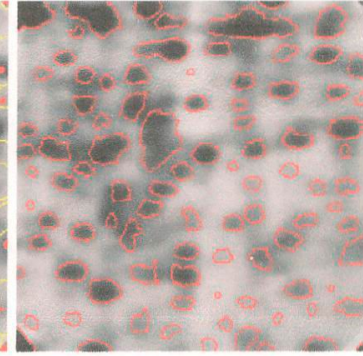

(d)

Figura 3.10: Exemplo de supersegmentação e do uso de marcadores para contornar o problema: Imagem original (a), supersegmentação (b), definição de marcadores (c) e resultado obtido como uso de marcadores (d) (Fonte: http://cmm.ensmp.fr/ beucher/wtshed.html).

As etapas do processo de segmentação efetuado a partir de uma imagem binária são mostradas na Figura 3.11. Calcula-se o mapa de distâncias, aplicando a Transformada da Distância Euclidiana (Saito e Toriwaki, 1994) sobre a imagem binária (b). Considerando a imagem como um relevo, define-se os mínimos locais (c) e após o processo de imersão obtém-se as linhas divisórias, as quais permitem a segregação dos objetos de interesse contidos na imagem (d).

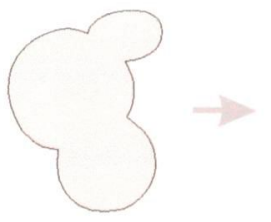

(a)

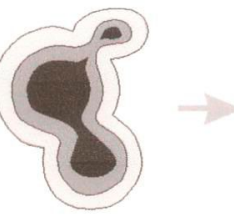

(b)

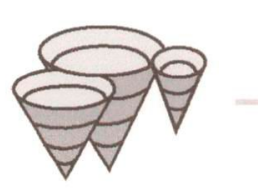

(c)

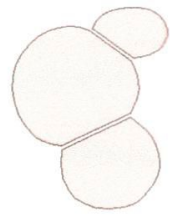

(d)

Figura 3.11: Processo de Segmentação a partir de uma imagem binária: Imagem original (a), mapa de distância (b), definição dos mínimos locais e aplicação do processo de imersão (c) e o resultado com as regiões separadas (d). (Adaptado de Vincent e Soille (1991)). 


\subsection{Descrição e Caracterização de Formas}

A aquisição de informação sobre os objetos do mundo real é um dos principais problemas relacionados à análise de formas. Conseqüentemente, várias técnicas para descrição e caracterização de formas foram desenvolvidas, cuja seleção e aplicação dependem do tipo de característica que se deseja detectar. Essas características, no entanto, são selecionadas de acordo com a natureza do objeto em estudo e do problema a ser solucionado. Segundo Loncaric (1998), o objetivo de se descrever uma forma é caracterizá-la por meio de um vetor descritor cuja propriedade requerida é a invariância quanto à translação, escala e rotação, que por definição não modificam a forma do objeto. Costa e Cesar (2000) classificam diferentes abordagens para extração de informações de formas, dentre elas:

- dimensões da forma;

- transformações da forma, baseado em processamento de sinais;

- decomposição da forma;

- descrição da forma por meio de estrutura de dados;

- visualização da forma;

- compressão da forma.

Dentre as diferentes abordagens, uma das mais comuns é a extração de dimensões da forma, que define e mensura características específicas como área, perímetro, curvatura, diâmetro, entre outras. A aplicação de técnicas de transformações é outra importante abordagem, a qual permite que características possam ser obtidas a partir da forma transformada. São exemplos dessa abordagem os descritores obtidos por meio das transformadas de Fourier, wavelet, Gabor e Karhunen-Loève. É importante notar que as técnicas de transformação são freqüentemente usadas para representação e descrição da forma, e nesse caso os coeficientes obtidos são usados como características no processo de classificação.

Segundo Marr (1996), os seres humanos são bem adaptados quanto ao reconhecimento de formas por meio de silhuetas, mesmo não tendo informações visuais quanto à cor, textura e estruturas tridimensionais. Com base nisso, uma vez obtida a imagem binária e o contorno da forma, é possível extrair uma série de características, tanto com base na extração de medidas quanto na aplicação de transformadas, para obtenção de descritores.

\subsubsection{Contorno Paramétrico}

O contorno de uma forma pode ser representado em termos de uma lista de pontos, que é obtida a partir de uma imagem binária, processo esse adotado em várias literaturas (Costa e Cesar, 2000; Jain, 1989; Pavlidis, 1982; Sonka et. al., 1999). Como exemplificada na Figura 3.12, a extração do contorno paramétrico pode ser realizada com a definição de um ponto inicial a partir do qual percorre-se pela borda do objeto para obter a curva que o represente, seja no sentido 
horário ou anti-horário. Se for uma curva aberta, o contorno é atravessado de uma extremidade à outra, caso contrário, percorre-se pela borda até retornar novamente ao ponto inicial.

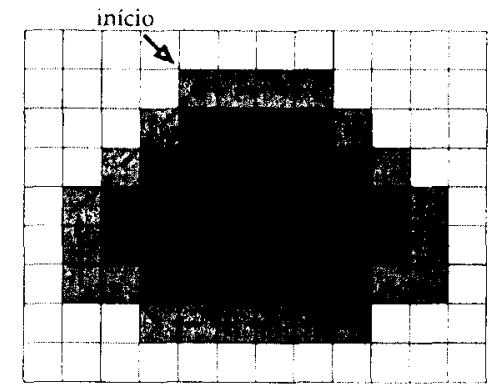

Figura 3.12: Exemplo da extração do contorno de uma forma, no sentido horário.

O contorno obtido pode ser parametrizado em termos de duas listas de pontos inteiros $(x \mathrm{e}$ $y$ ). Na Figura 3.13 são mostrados os sinais $x$ e $y$ no eixo horizontal.

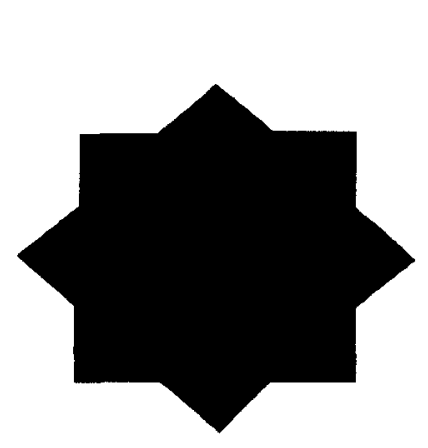

(a)

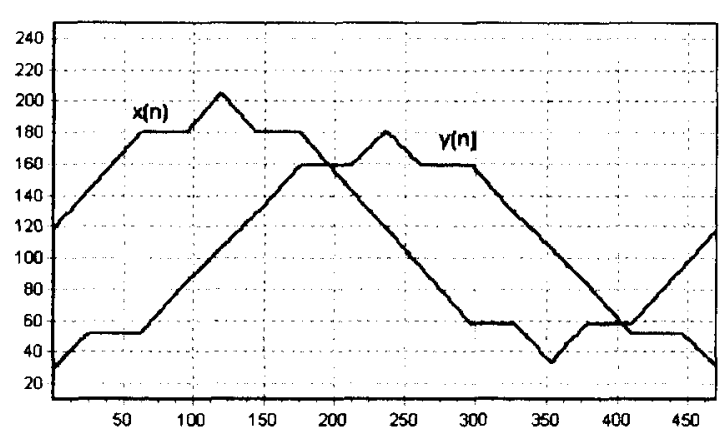

(b)

Figura 3.13: Sinais de $x$ e $y$ obtidos do contorno paramétrico: forma do objeto (a), sinais de $x(n)$ e $y(n)(b)$.

Há vários algoritmos para extração do contorno a partir de uma imagem binária, dentre eles o algoritmo seguidor de contorno cujos detalhes de implementação são encontrados em Costa e Cesar (2000); Jain (1989); Pavlidis (1982); Sonka et. al. (1999)

\subsubsection{Descritores Gerais}

Existe um conjunto considerável de descritores que se baseiam em medidas simples. Eles são úteis quando o tamanho da forma é um fator importante, entretanto, a maioria das técnicas apresenta um bom desempenho apenas em situações específicas (Costa e Cesar, 2000). Um dos problemas enfrentados por essas técnicas é que formas diferentes podem apresentar valores característicos iguais, como é o caso da área que pode ser a mesma para objetos com formas totalmente diferentes. Por esse motivo, essa classe de características tem sido criticada na literatura. No entanto, algumas métricas podem ser usadas com sucesso em casos particulares, tornando o uso dessa categoria de descritores uma abordagem possível. Vale destacar também que não é uma tarefa fácil realizar a seleção das métricas, uma vez que procura-se encontrar o conjunto mais adequado de características para uma determinada aplicação. 


\subsubsection{Perímetro}

$\mathrm{O}$ perímetro de uma forma pode ser estimado usando diferentes abordagens, dentre as quais a mais simples é a que define o perímetro pela quantidade de pontos que compõe o contorno, se for 4-conectado. Caso o contorno seja 8-conectado, o resultado final terá problemas uma vez que as distâncias entre os pontos não são mais constantes, isto é, os pontos conectados pela diagonal apresentam distância $\sqrt{2}$ e os demais, distância 1 . Pode-se utilizar a solução apresentada por Castleman (1996), que com base no Código da Cadeia de Freeman, obtém o perímetro a partir da equação 3.22 , sendo $N p$ a quantidade de códigos pares e $N i$ de códigos ímpares.

$$
P=N p+N i \cdot \sqrt{2}
$$

Uma outra maneira de se calcular o perímetro é a partir da distância Euclidiana entre os pontos do contorno, como apresenta a equação 3.23 (Weeks, 1996).

$$
P=\sum_{i=0}^{M-2} \sqrt{(x(i+1)-x(i))^{2}+(y(i+1)-y(i))^{2}}
$$

Caso o contorno seja representado pelo sinal complexo $u(n)=x(n)+j \cdot y(n)$, com $j=$ $\sqrt{-1}$, o perímetro pode ser estimado por meio da equação 3.24 (Costa e Cesar, 2000).

$$
P=\sum_{i=0}^{N-1}|u(n)-u(n-1)|
$$

\subsubsection{2 Área}

Um método bastante simples para se calcular a área de uma forma é a soma dos pontos conectados que a representam. No caso de uma imagem binária, a quantidade de pontos que compõe o objeto é que representa a sua área. Uma outra abordagem leva em conta que metade dos pontos da borda pertence ao fundo da imagem e metade pertence ao objeto, e com base nisso a área pode ser obtida por meio da equação 3.25, na qual $N i$ corresponde ao número de pontos internos à forma e $N b$ corresponde ao número de pontos pertencentes à borda (Castleman, 1996).

$$
A=N i-\left[\frac{N b}{2}+1\right]
$$

\subsubsection{Centróide}

As coordenadas de centro de massa de uma forma podem ser obtidas a partir da média dos valores das coordenadas dos pontos que a definem, conforme as equações 3.26 e 3.27 (Weeks, 1996).

$$
x_{\text {centroide }}=\frac{1}{N} \sum_{i=0}^{N-1} x(i)
$$




$$
y_{\text {centroide }}=\frac{1}{N} \sum_{i=0}^{N-1} y(i)
$$

O centróide também pode ser obtido a partir do contorno da forma. Se o contorno for representado pelo sinal complexo $u(n)$, uma maneira é calcular a média dos pontos que o compõe, como apresentado na equação 3.28. Isso resulta no número complexo $C=c_{1}+j \cdot c_{2}$, sendo $c_{1} \mathrm{e}$ $c_{2}$ as coordenadas do centro de massa (Costa e Cesar, 2000). Os contornos de duas folhas, com o respectivo centro de massa indicado, são mostrados na Figura 3.14.

$$
C=\frac{\sum_{i=0}^{N-1} u(i)}{N}
$$

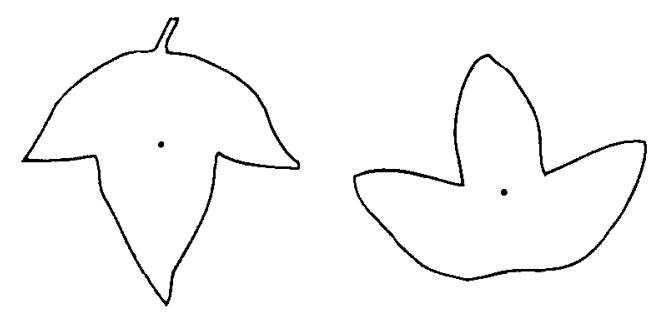

Figura 3.14: Formas com o respectivo centróide marcado por um ponto.

\subsubsection{Diâmetro}

O diâmetro é definido pela maior distância entre dois pontos extremos da forma. Uma maneira de obter essa medida é realizar a comparação entre todos os pontos do contorno aos pares, verificando a distância entre eles. Na Figura 3.15 é mostrado o contorno de duas folhas e os pontos de maior distância em cada uma delas.

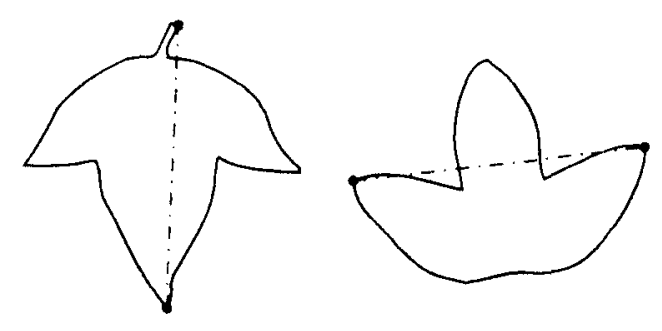

Figura 3.15: Formas com o diâmetro indicado pela linha tracejada.

\subsubsection{Excentricidade}

A característica de excentricidade é a razão entre o maior eixo $A$ e o maior eixo $B$ perpendicular ao eixo $A$. Na Figura 3.16 são mostrados os eixos $A$ e $B$ identificados na forma. A excentricidade é também conhecida por medida de circularidade da forma. 


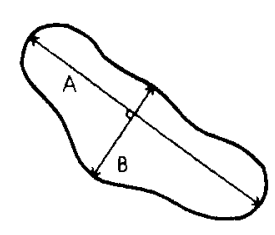

Figura 3.16: Excentricidade da forma.

\subsubsection{Assinatura}

Gonzalez e Wintz (1987) definem a assinatura como uma representação capaz de descrever uma forma bidimensional por meio de sinais gerados por um ou mais sinais unidimensionais. Uma importante vantagem é que tendo a forma descrita por um sinal unidimensional, técnicas de processamento de sinal podem ser aplicadas a fim de se extrair características dela. A assinatura é gerada com base na distância Euclidiana entre o centróide e os pontos do contorno e pode ser representada por um gráfico, como mostrado na Figura 3.17(b).

A assinatura de uma forma é invariante à translação, entretanto, o mesmo não ocorre em relação à escala e à rotação. Alguns critérios podem ser estabelecidos com o intuito de garantir que a assinatura sempre inicie no mesmo ponto. Gonzalez e Woods (1993) descrevem duas alternativas. A primeira delas consiste na escolha do ponto mais distante do centróide e, para isso, deve-se ter a garantia de que o mesmo é único e independente de rotação. A segunda alternativa consiste na escolha do ponto mais distante do centro de massa sobre o auto-eixo principal, mas isso requer cálculos mais complexos.

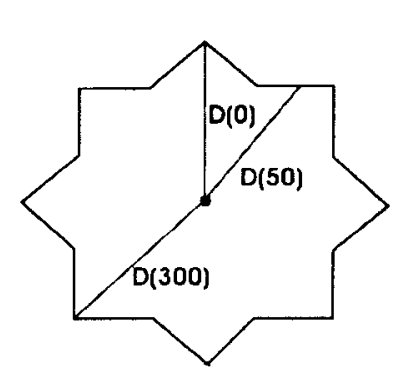

(a)

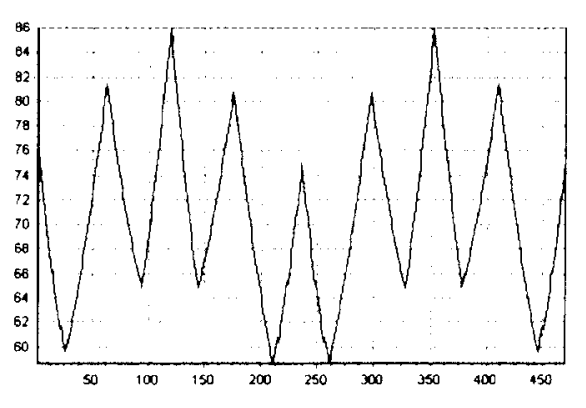

(b)

Figura 3.17: Contorno da forma (a) e assinatura a partir da distância entre o centróide e os pontos do contorno (b).

Uma outra maneira de se obter a assinatura é calcular a distância entre o centróide e todos os pontos do contorno por meio de uma amostragem realizada em função do ângulo. Nesse caso, os valores são amostrados em intervalos iguais, calculando-se a distância em relação aos pontos do contorno sob um respectivo ângulo. Alguns critérios devem ser definidos caso mais de um ponto do contorno esteja sob um determinado ângulo. Na Figura 3.18 é apresentada a assinatura amostrada pelo ângulo $\alpha$ e a ccorrência de mais de um ponto do contorno sob o mesmo ângulo. Considerar a menor ou a maior distância, ou calcular a média das distâncias dos pontos encontrados nessa situação são algumas alternativas (Costa e Cesar, 2000). 


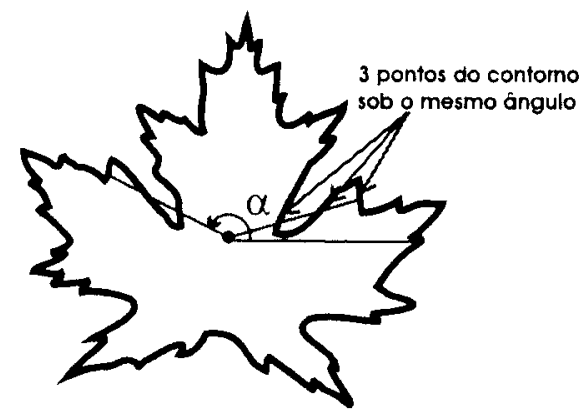

Figura 3.18: Assinatura a partir da distância entre o centróide e os pontos do contorno amostrado pelo ângulo $\alpha$.

\subsubsection{Projeções}

Além da representação da região por meio do contorno, é possível também representá-la com projeções, também conhecida como assinatura por projeção. Esse método se resume à soma dos pontos de uma imagem binária, contidos em um segmento de reta orientado por um ângulo. Gera-se, então, um histograma formado pela soma dos pontos, deslocando esse segmento de reta sobre toda a imagem, sem alterar o ângulo (Jain, 1989; Tao et. al., 2001). Na Figura 3.19 são mostradas diferentes assinaturas obtidas por projeção: horizontal, vertical e diagonal $\left(\theta=45^{\circ}\right)$. Note que $A, B$ e $C$ representam os pontos somados para a distância $k$, sob um ângulo de $135^{\circ}$.

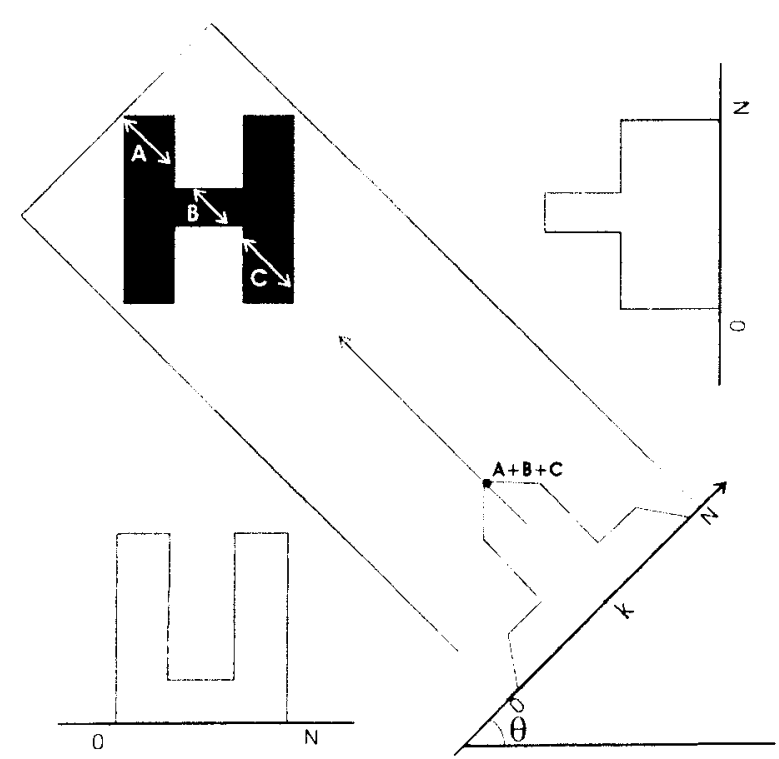

Figura 3.19: Assinaturas por projeção: horizontal, vertical e diagonal $\left(\theta=45^{\circ}\right)$.

Algumas características desse histograma são úteis no processo de análise. A partir das projeções é possivel obter os locais de máximo e mínimo, que podem ser usados para determinar a casca convexa e o retângulo básico, aplicados em alguns problemas de segmentação. Além 
disso, a projeção pode ser usada como característica regenerativa de um objeto (Jain, 1989). Uma outra abordagem é a técnica de projeção central (CPT) proposta por Tao et. al. (2001) aplicada a formas que apresentem mais de um contorno, como por exemplo letras do alfabeto chinês.

\subsubsection{Curvatura}

A curvatura é uma importante característica que pode ser extraída do contorno de uma forma Costa e Cesar (2000), com base na pesquisa efetuada por Fred Attneave em 1954, estabeleceram algumas relações contrapondo as características que apresentam muita e pouca informação na percepção das formas. Dentre as características que apresentam muita informação, vale destacar os vértices e pontos de alta curvatura e as bordas. Na pesquisa realizada por Attneave destacam-se dois experimentos. O primeiro experimento foi obtido a partir de um conjunto de formas apresentado a diferentes pessoas, as quais escolheram dez pontos aleatórios que para elas permitiria representar a respectiva forma. A partir dos votos obtidos gerou-se um histograma representado pelos segmentos de reta na Figura 3.20(a), no qual destacaram-se os pontos de alta curvatura. O segundo experimento foi obtido através da identificação dos pontos de alta curvatura da foto de um gato dormindo. A ligação desses pontos por meio de retas formou a imagem apresentada na Figura 3.20(b).

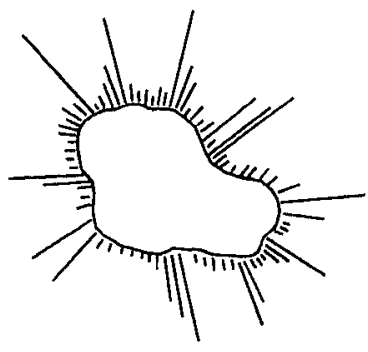

(a)

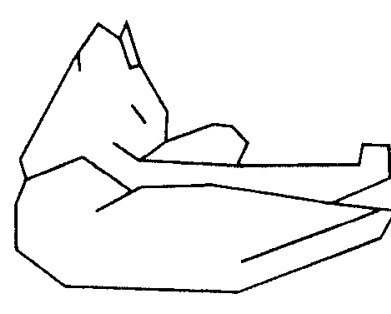

(b)

Figura 3.20: Exemplos dos experimentos de Attneave (Cesar, 1997).

Com base nesses experimentos, nota-se a importância das curvas no processo de análise do próprio sistema de visão humana, o que fez com que pesquisas baseadas na análise da curvatura começassem a ser desenvolvidas em Visão Computacional, em busca de métodos de representação de formas que explorassem tal característica. Algumas funções, com base na curvatura, foram extraídas com o intuito de possibilitar a identificação de formas primitivas. Com isso, Levine (1985) apresentou alguns aspectos geométricos que podem ser caracterizados por meio da curvatura. Esses aspectos são apresentados na tabela 3.1 .

\subsubsection{Extração da Curvatura}

Uma curva planar é um conjunto de pontos que pode ser representada pela equação $u(t)=$ $(x(l), y(t))$, sendo $u(t)$ a função paramétrica da curva. A primeira derivada da função, $\dot{u}(t)=$ $(\dot{x}(t), \dot{y}(t))$, define o campo tangencial unitário e a segunda derivada, $\ddot{u}(t)=(\ddot{x}(t), \ddot{y}(t))$, expressa as mudanças de orientação no campo tangencial. Conseqüentemente, para uma curva 
Tabela 3.1: Aspectos geométricos caracterizados por meio da curvatura (Adaptado de Costa e Cesar (2000))

\begin{tabular}{|l|l|}
\hline Curvatura & $\begin{array}{l}\text { Aspectos Geométricos (parametrização } \\
\text { anti-horária) }\end{array}$ \\
\hline \hline Máximo valor absoluto da curvatura local & Vértice genérico \\
\hline Máxima curvatura local positiva & Vértice convexo \\
\hline Máxima curvatura local negativa & Vértice côncavo \\
\hline Curvatura constante em zero & Segmento de reta \\
\hline Curvatura constante diferente de zero & Circunferência (Segmento circular) \\
\hline Cruzamento em zero & Ponto de inflexão \\
\hline $\begin{array}{l}\text { Média da alta curvatura em valores absolutos ou } \\
\text { quadrados }\end{array}$ & $\begin{array}{l}\text { Complexidade da forma (relacionado à energia de } \\
\text { dobramento) }\end{array}$ \\
\hline
\end{tabular}

parametrizada pelo tamanho do $\operatorname{arco}^{1}$ a segunda derivada da curva é sempre o vetor normal em relação à tangente da curva. Para uma curva parametrizada $\vec{p}(t)$, a magnitude da segunda derivada, $k(t)=\|\ddot{\vec{p}}(t)\|$, é a curvatura da curva $t$. Contudo, essa expressão não produz valores negativos (Costa e Cesar, 2000; Mokhtarian e Mackworth, 1992).

No caso geral, a curvatura pode ser definida pela equação 3.29 , que envolve a primeira e segunda derivada dos sinais $x(t)$ e $y(t)$ (Mokhtarian e Mackworth, 1992). Esses sinais, por sua vez, compõem a curva planar, que não é necessariamente parametrizada pelo tamanho do arco. Os valores produzidos por essa equação podem ser positivos e negativos e é por meio do sinal desses valores que se identifica a concavidade local da curva. No entanto, a determinação da concavidade por meio do sinal é dependente do sentido no qual o contorno foi extraído ( $\mathrm{Ce}$ sar, 1997). Para contornos extraídos no sentido horário, sinais positivos na curvatura indicam regiões côncavas e sinais negativos regiões convexas. Caso contrário, essa relação se inverte como mostrado na Figura 3.21).

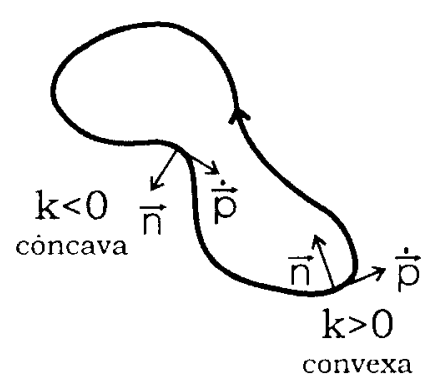

(a)

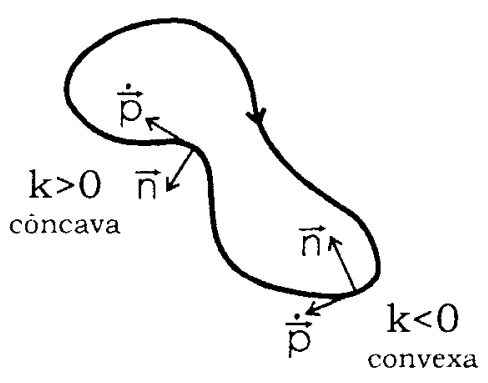

(b)

Figura 3.21: Critério de concavidade adotado de acordo com o sentido da curva: sentido anti-horário (a) e sentido horário (b) (Adaptado de Costa e Cesar (2000)).

$$
k(t)=\frac{\dot{x}(t) \ddot{y}(t)-\dot{y}(t) \ddot{x}(t)}{\left(\dot{x}(t)^{2}+\dot{y}(t)^{2}\right)^{\frac{3}{2}}}
$$

\footnotetext{
'Um vetor é dito parametrizado pelo tamanho do arco, se e somente se, o campo tangencial tem magnitude unitária (Costa e Cesar, 2000).
} 
Devido ao cálculo da primeira e da segunda derivada na análise computacional ser aplicado sobre um contorno na forma digital (espaço amostrado), algumas alternativas foram propostas com o intuito de contornar os problemas que ocorrem em vista desse fato:

a) Curvatura de uma curva discreta, baseada no ângulo entre dois vetores: a partir de um ponto do contorno obtêm-se dois vetores em relação ao $i$-ésimo vizinho, um da esquerda e outro da direita, como definido na equação 3.30. Uma vez obtidos os vetores $v 1_{i}$ e $v 2_{i}$, estima-se o ângulo entre eles a partir da equação 3.31 (Rosenfeld e Johnston, 1973), sendo $r_{i}(n)$ o co-seno do ângulo entre os dois vetores. Para $r_{i}=1$ o ângulo é 0 , enquanto para $r_{i}=-1$, tem-se um segmento de reta.

$$
\begin{gathered}
v 1_{i}(n)=(x(n)-x(n-i), y(n)-y(n-i)) \\
v 2_{i}(n)=(x(n)-x(n+i), y(n)-y(n+i)) \\
r_{i}=\frac{v 1_{i}(n) v 2_{i}(n)}{\left\|v 1_{i}(n)\right\|\left\|v 2_{i}(n)\right\|}
\end{gathered}
$$

b) Interpolação de $\boldsymbol{x}(\boldsymbol{n})$ e $\boldsymbol{y}(\boldsymbol{n})$ seguido por diferenciações: a partir da derivada de $x(n)$ e $y(n)$ em termos de diferença finita, como definida na equação 3.32 , estima-se a curvatura substituindo os valores calculados na equação 3.29, que embora seja uma abordagem simples, é bastante sensível a ruídos. Existem técnicas mais elaboradas, como as baseadas na aproximação do contorno em termos da $B$-spline cúbica (Medioni e Yasumoto, 1987).

$$
\begin{aligned}
& \dot{x}(n)=x(n)-x(n-1) \\
& \dot{y}(n)=y(n)-y(n-1) \\
& \ddot{x}(n)=\dot{x}(n)-\dot{x}(n-1) \\
& \ddot{y}(n)=\dot{y}(n)-\dot{y}(n-1)
\end{aligned}
$$

c) Curvatura através da Transformada de Fourier: aplicando a propriedade de derivação da transformada de Fourier, é possível estimar a $i$-ésima derivada de um dado sinal $u(n)$. Com base nisso, a partir dos sinais $x(n)$ e $y(n)$ calcula-se a primeira e a segunda derivada, como definido a seguir:

$$
\begin{aligned}
& \dot{X}(f)=j 2 \pi f X(f) \\
& \dot{Y}(f)=j 2 \pi f Y(f) \\
& \ddot{X}(f)=-(2 \pi f)^{2} X(f) \\
& \ddot{Y}(f)=-(2 \pi f)^{2} Y(f)
\end{aligned}
$$

sendo $j$ o número complexo $(\sqrt{-1})$ e $\dot{X}(f), \dot{Y}(f), \ddot{X}(f)$ e $\ddot{Y}(f)$ a transformada de Fourier de $\dot{x}(t), \dot{y}(t), \ddot{x}(t)$ e $\ddot{y}(t)$, respectivamente. Para obter os valores a serem substituídos na 
equação 3.29, aplica-se a transformada inversa de Fourier, como mostrado a seguir

$$
\begin{aligned}
& \dot{x}(t)=F^{-1}\{\dot{X}(f)\} \\
& \dot{y}(t)=F^{-1}\{\dot{Y}(f)\} \\
& \ddot{x}(t)=F^{-1}\{\ddot{X}(f)\} \\
& \ddot{y}(t)=F^{-1}\{\ddot{Y}(f)\}
\end{aligned}
$$

Por fim, a curvatura pode ser obtida de maneira direta, realizando as substituições e simplificações adequadas. Dessa maneira, obtém-se a equação 3.35 aplicando-se diretamente a transformada de Fourier e sua inversa (Cesar, 1997).

$$
k(t)=\frac{F^{-1}\{f X(f)\}(t) F^{-1}\left\{f^{2} Y(f)\right\}(t)-F^{-1}\left\{f^{2} X(f)\right\}(t) F^{-1}\{f Y(f)\}(t)}{\left[\left(F^{-1}\{f X(f)\}(t)\right)^{2}+\left(F^{-1}\{f Y(f)\}(t)\right)^{2}\right]^{1.5}}
$$

d) Curvatura por meio de $\boldsymbol{u}(\boldsymbol{t})$ : o cálculo da derivada a partir da formulação básica pode ser obtido com as derivadas do sinal complexo $u(t)$, isto é,

$$
\begin{aligned}
& \dot{u}(t)=\dot{x}(t)+j \dot{y}(t) \\
& \ddot{u}(t)=\ddot{x}(t)+j \ddot{y}(t)
\end{aligned}
$$

Aplicando a propriedade de derivada da transformada de Fourier, também obtém-se $\dot{u}(t)$ e $\ddot{u}(t)$ da seguinte forma:

$$
\begin{aligned}
& \dot{u}(t)=F^{-1}\{\dot{U}(f)\} \\
& \ddot{u}(t)=F^{-1}\{\dot{U}(f)\}
\end{aligned}
$$

sendo

$$
\begin{aligned}
& \dot{U}(f)=j 2 \pi f U(f) \\
& \ddot{U}(f)=-(2 \pi f)^{2} U(f)
\end{aligned}
$$

Observe que a parte imaginária da equação 3.39, multiplicada por -1 , é equivalente ao numerador da equação da curvatura (Equação 3.29). A mesma similaridade é observada quanto ao denominador da equação de curvatura, quando comparada à relação 3.40 .

$$
\begin{gathered}
\dot{u}(t) \ddot{u}^{*}(t)=\dot{x}(t) \ddot{x}(t)+\dot{y}(t) \ddot{y}(t)-j(\dot{x}(t) \ddot{y}(t)-\ddot{x}(t) \dot{y}(t)) \\
|\dot{u}(t)|^{3}=\left(\sqrt{\dot{x}(l)^{2}+\dot{y}(t)^{2}}\right)^{3}=\left(\dot{x}(l)^{2}+\dot{y}(t)^{2}\right)^{\frac{3}{2}}
\end{gathered}
$$

Dessa maneira, substituindo as equações 3.39 e 3.40 na equação de curvatura (3.29), tem-se:

$$
k(l)=\frac{-\operatorname{Im}\left\{\dot{u}(t) \ddot{u}^{*}(t)\right\}}{|\dot{u}(t)|^{3}}
$$

permitindo, dessa maneira, o cálculo da curvatura a partir dos sinais complexos $\dot{u}(t)$ e $\ddot{u}(t)$ (Cesar, 1997). 


\subsubsection{Descritores de Forma baseados em Curvatura}

Embora a curvatura por si só possa ser usada como um vetor de características, alguns problemas são apontados. Um deles é quanto à quantidade de pontos que compõem o sinal, que pode alcançar os milhares. Outro problema está relacionado ao fato do sinal poder apresentar alta redundância. Mediante a isso, algumas medidas podem ser extraídas a partir da curvatura estimada a fim de contornar esses problemas, tais como (Costa e Cesar, 2000):

- Amostragem da Curvatura: obter a partir do sinal da curvatura um conjunto menor de características. Por exemplo, realizar uma amostragem do sinal em um intervalo de pontos definido de acordo com o problema.

- Estatísticas com base na Curvatura: extrair a partir da curvatura medidas estatísticas globais, tais como: mediana, média, variância, desvio padrão, momentos, entre outras.

- Pontos Máximo, Mínimo e de Inflexão: analisar os pontos de maior influência (pontos dominantes), onde suas posições ao longo do contorno e o respectivo valor da curvatura podem ser usados como medidas de forma, no caso de pontos de curvatura máxima e mínima.

- Energia de Dobramento (Energia de Fronteira): calcular a energia de dobramento média, que é definida no caso contínuo pela equação 3.42 , sendo $P$ o perímetro do contorno, e $k(t)$ é a função de curvatura em um ponto $t$ do contorno. Essa é uma das mais importantes medidas globais relacionadas à complexidade da forma, a qual será dada maior ênfase na abordagem multi-escala.

$$
B=\frac{1}{P} \int k(t)^{2} d t
$$

\subsubsection{Curvatura Multi-Escala}

Como visto anteriormente, os cálculos realizados para se chegar à curvatura são baseados em diferenciação numérica. Esse processo aumenta a influência dos ruídos contidos no sinal original, nesse caso, o contorno da forma. Para amenizar esse problema, um mecanismo multi-escala é utilizado no processo de obtenção da curvatura.

Os mecanismos multi-escala permitem a análise de um sinal $u(t)$ por uma transformada $U(b, a)$, na qual a variável $b$ está associada à informação de tempo (parâmetro $t$ do sinal $u(t)$ ) e a variável $a$ está associada à informação de escala. Isso porque o sinal pode apresentar um conjunto de informações, mesmo que em diferentes escalas. O sinal unidimensional $u(t)$ é, então, desdobrado em um sinal bidimensional $U(b, a)$, com intuito de tornar explícitas as informações sobre as estruturas que se mantiveram presentes nas diferentes escalas. Em contrapartida, há um aumento substancial de redundância, o que pode complicar a análise. No entanto, com uma aplicação adequada da transformada multi-escala e o uso de algoritmos extratores para um sinal $U(b, a)$ pode se alcançar resultados satisfatórios (Cesar, 1997). 


\section{Filtro Gaussiano e a Abordagem Multi-Escala}

Com o intuito de controlar a influência exercida pelas altas freqüências contidas no sinal, o processo de derivação, baseado na propriedade da transformada de Fourier, é seguido de um filtro gaussiano (passa-baixa). O filtro gaussiano no domínio da freqüência $G(f)$ é definido pela equação 3.43 , sendo a largura de banda controlada pelo parâmetro $\tau$. É a partir da variação do parâmetro $\tau$, dentro de um intervalo determinado, que o mecanismo multi-escala é incorporado, ou seja, pode-se entender o mecanismo multi-escala como a aplicação de um banco de filtros gaussianos ordenados pelo parâmetro $\tau$. Esse processo é equivalente no domínio tempo, pois a transformada de Fourier de uma gaussiana $g(t)$ é outra gaussiana $G(f)$, como apresentado na equação 3.43 .

$$
g(t)=\frac{1}{a \sqrt{2 \pi}} \exp \left(\frac{-t^{2}}{2 a^{2}}\right) \Leftrightarrow G(f)=\exp \left(\frac{-(2 \pi)^{2} f^{2}}{2 \tau^{2}}\right), \tau=1 / a
$$

A função gaussiana pode ser formulada de diferentes maneiras, até mesmo com o uso de diferentes normalizações. Por estar trabalhando com um conjunto de filtros gaussianos, Cesar (1997) adotou em seu trabalho filtros que mantivessem a área constante, os quais são definidos pela equação 3.44. Sendo a variável $a$ relacionada à escala e a variável $\tau=1 / a$ relacionada à largura de banda do filtro, tem-se que as duas variáveis estão inversamente relacionadas. Conseqüentemente, pode-se obter uma família de curvas suavizadas variando o parâmetro $a$, e com isso definir uma família de filtros $G_{1 / a}(f)$, isto é, $G(f)=G_{1 / a}(f)$.

$$
G(f)=\frac{1}{\tau \sqrt{2 \pi}} \exp \left(\frac{-f^{2}}{2 \tau^{2}}\right)
$$

Dessa maneira, a definição de uma família de curvas suavizadas $\hat{u}(t, a)$ é dada pela filtragem de $U(f)$ pelo banco de filtros $G_{1 / a}$, seguida da transformada inversa de Fourier, como é mostrado na equação 3.45 (Cesar, 1997; Costa e Cesar, 2000). As derivadas são obtidas analogamente, aplicando-se o banco de filtros $G_{1 / a}(f)$ sobre $\dot{U}(f)$ e $\ddot{U}(f)$, que são definidos a partir do sinal complexo $u(t)$, de acordo com a equação 3.38 .

$$
\hat{u}(t, a)=u * g_{a}(t)=F^{-1}\left\{U_{1 / a}(f)\right\}=F^{-1}\left\{U(f) G_{1 / a}(f)\right\}
$$

Após a obtenção das curvaturas nas diferentes escalas, as mesmas podem ser representadas por um gráfico tridimensional, conhecido por curvograma. Ele expressa a curvatura multi-escala estimada em cada uma das posições do contorno em termos de um conjunto de escalas. O curvograma pode ser considerado como o diagrama multi-escala da curvatura (Cesar e Costa, 1996a). Segundo Cesar (1997), a principal vantagem do curvograma está no fato dele ser uma representação baseada na curvatura, que é uma das características mais importantes no que diz respeito às curvas bidimensionais. No entanto, essa abordagem é cara computacionalmente por envolver cálculos para a primeira e segunda derivada do sinal $u(t)$.

Na Figura 3.22 é apresentado um exemplo utilizando o contorno da letra "H" (Figura 3.22(a)) A partir dos sinais $x(n)$ e $y(n)$ (Figura 3.22(b)), obteve-se a curvatura da forma (Figura 3.22(c)), 
na qual é possível identificar as regiões de maior curvatura e discriminar quais são as regiões côncavas e convexas de acordo com o sinal da curvatura. Além disso, calculou-se a curvatura multi-escala com base nos mesmos sinais, da qual obteve-se a representação por meio do curvograma, como é mostrado na Figura 3.22(d). A seqüência dos filtros aplicados pode ser visualizada ao longo do eixo $z$, onde há a variação da escala $(\tau)$.

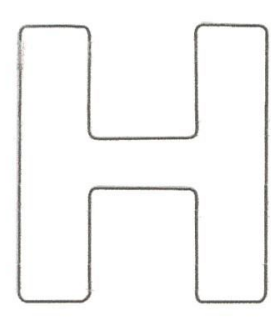

(a)

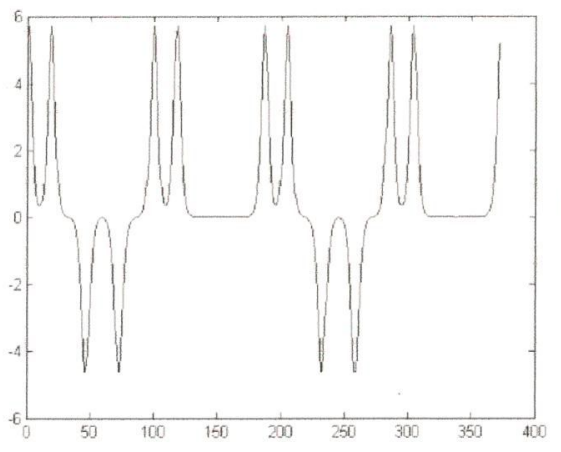

(c)

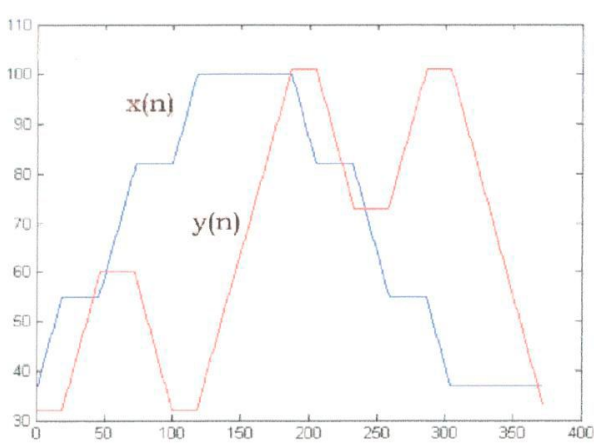

(b)

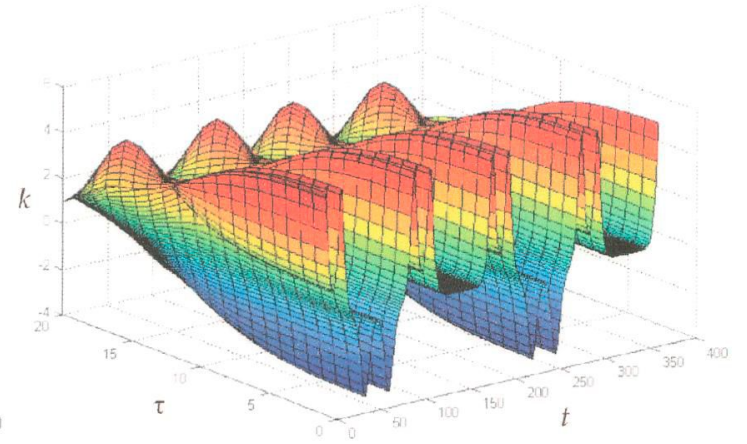

(d)

Figura 3.22: Exemplo da curvatura multi-escala: contorno da forma (a), sinais $x(n)$ e $y(n)$, curvatura (c) e representação multi-escala por meio do curvograma (d).

Além do curvograma, existem outras formas de representação para os mecanismos multi-escala. Uma comparação entre o curvograma e outras três representações foi realizada por Cesar (1997), sendo elas: a Representação- $W$ com a wavelet de Marr e de Morlet e a Transformada de Gabor do contorno.

\section{Energia de Dobramento Multi-Escala}

As representações multi-escala são apenas o primeiro passo em muitos problemas de aplicação prática. A partir delas podem ser extraídas medidas que caracterizam a forma e que podem ser usadas em classificadores estatísticos. Pode-se obter do curvograma a energia de dobramento com base no conceito de energia multi-escala. Outras energias multi-escala também podem ser obtidas de outras representações, como é o caso da energia multi-escala wavelet, extraída da representação- $W$ (Costa e Cesar, 2000).

A energia de dobramento, também conhecida por energia de fronteira, foi inspirada na teoria da elasticidade. Ela expressa o quanto de energia é necessária para transformar um dado contorno em um círculo de mesmo perímetro. A energia de dobramento é usada como uma medida 
global da forma para análise e classificação em aplicações com imagens. Ela tem sido bastante aplicada em problemas de reconhecimento de objetos e aplicações biomédicas (Duncan et. al., 1991, 1988). Esse descritor do contorno é invariante à translação, rotação, escala e reflexão, além de poder ser usado como uma medida de complexidade.

A versão discreta da média da energia de dobramento apresentada na equação 3.42 é definida como:

$$
B=\frac{1}{N} \sum_{n=0}^{N-1} k(n)^{2}
$$

sendo $N$ o número de pontos do contorno. Já a versão multi-escala aplica a equação de energia sobre cada linha do curvograma indexada pela escala, como é apresentado na equação 3.47 .

A energia de dobramento multi-escala é dependente da escala e para que a mesma seja invariante é preciso normalizá-la. Para isso, incorpora-se ao cálculo o fator $L$, que é o perímetro do contorno, conforme é mostrado na equação 3.48 (Cesar, 1997; Cesar e Costa, 1996b; Costa e Cesar, 2000)

$$
\begin{aligned}
& B(a)=\frac{1}{N} \sum_{n=0}^{N-1} k(a, n)^{2} \\
& B(a)=\frac{L^{2}}{N} \sum_{n=0}^{N-1} k(a, n)^{2}
\end{aligned}
$$

Dependendo da aplicação, pode-se usar a energia de dobramento sem precisar normalizá-la. Isso ocorre nos casos em que a dimensão do objeto é uma característica discriminante, o que faz com que a dependência à escala seja preferível. À medida que se aumenta a escala, as informações referentes aos detalhes do contorno vão desaparecendo, preservando, conseqüentemente, os detalhes originais. Dessa maneira, a energia de dobramento tende a refletir a estrutura global do contorno.

\subsubsection{Descritores de Fourier}

Tratando-se de representações de formas para aplicações de reconhecimento de padrões, não se pode deixar de mencionar sobre a classe dos descritores de Fourier. Existem várias maneiras de se definir um conjunto de descritores de Fourier, por esse motivo, alguns autores os consideram como uma classe ao invés de método. A idéia básica dos descritores de Fourier é obter um sub-conjunto de coeficientes aplicando a transformada de Fourier sobre um sinal unidimensional ou bidimensional, por exemplo, o contorno do objeto. A partir do sinal no domínio da freqüência, seleciona-se como descritores os $i$ coeficientes que sejam capazes de representar a forma, desconsiderando os demais. Vale destacar que os descritores de baixa freqüência, localizados nas extremidades dos coeficientes devido à natureza da transformada discreta de Fourier, contêm as informações gerais da forma. Já os descritores de alta freqüência, localizados nos coeficientes intermediários, são responsáveis pelas informações de detalhe da forma (Cesar, 1997; Kauppinen et. al., 1995).

O contorno da forma pode ser definido pelo sinal complexo $u(n)=x(n)+j \cdot y(n)$, para $j=$ 
$\sqrt{-1}$ e $n=0 . . N-1$, sendo $N$ a quantidade de pontos que formam o contorno. Essa abordagem tem a vantagem de reduzir o problema de duas dimensões para apenas uma dimensão. Os coeficientes complexos $U(s)$, chamados de descritores de Fourier, são obtidos aplicando-se a transformada discreta de Fourier (Equação 3.49) sobre o sinal $u(n)$ (Jain, 1989).

$$
\begin{gathered}
U(s)=\frac{1}{N} \sum_{n=0}^{N-1} u(n) e^{-j 2 \pi s n / N}, s=0, \ldots, N-1 \\
u(n)=\sum_{n=0}^{N-1} U(s) e^{j 2 \pi s n / N}, s=0, \ldots, N-1
\end{gathered}
$$

Os descritores de Fourier também são considerados características regenerativas da forma, isso porque a partir dos mesmos é possível reconstruir o contorno da forma. Para se obter novamente o contorno a partir dos descritores, aplica-se sobre os mesmos a transformada inversa de Fourier (Equação 3.50). O número de descritores a serem selecionados depende da precisão desejada, podendo em alguns casos ser necessário todos os coeficientes para se reconstruir a forma. Na Figura 3.23 são mostrados os contornos reconstruídos a partir de três diferentes conjuntos de descritores, obtidos a partir dos $i$ primeiros e dos $i$ últimos coeficientes de Fourier. Observa-se que a Figura 3.23(b), contendo 20 coeficientes $(i=10)$, apresenta um contorno mais grosseiro, enquanto a Figura 3.23(c), contendo 60 coeficientes, já apresenta as principais características da forma. Quanto maior o conjunto de descritores, mais detalhes podem ser recuperados em relação ao contorno original (Figura 3.23(a)). Isso é mostrado na Figura 3.23(d), que é formada a partir de 140 descritores de um total de 372 coeficientes que compõem o contorno original.

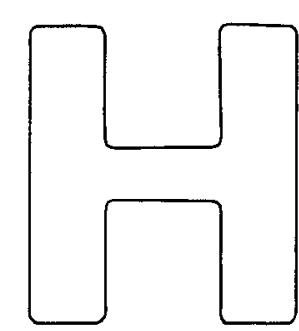

(a) original

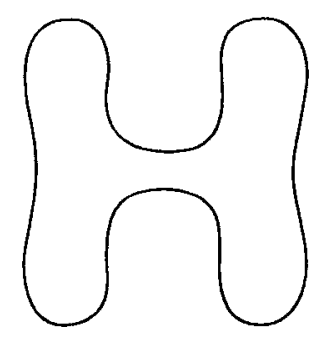

(b) $i=10$

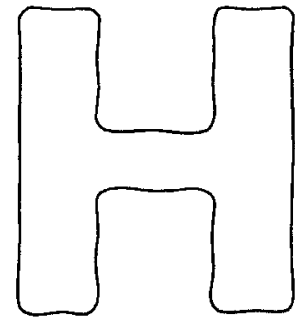

(c) $\mathrm{i}=\mathbf{3 0}$

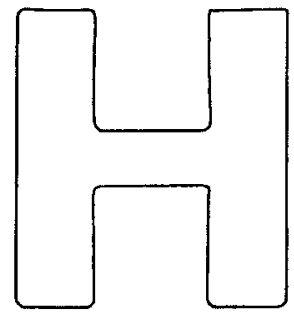

(d) $\mathrm{i}=70$

Figura 3.23: Reconstrução do contorno por meio de diferentes conjuntos de Descritores de Fourier.

O fato de alguns poucos coeficientes poderem concentrar bastante informação de uma forma, 
permite que os descritores de Fourier sejam utilizados como vetores de características aplicados em reconhecimento de padrões. Um modo alternativo de descritores de Fourier pode ser obtido por meio da transformada discreta definida pela equação 3.49 , no entanto, para $f=-N / 2+1, \ldots, N / 2$. Esta série pode ser usada para representar um conjunto de descritores invariantes à escala, rotação, translação e deslocamento. Para isso, os descritores são normalizados da seguinte maneira (Costa e Cesar, 2000):

$$
F D(f)=\|N F D(f)\|
$$

para

$$
N F D(f)= \begin{cases}0 & s=0 \\ U(f) / U(1) & s \neq 0\end{cases}
$$

Somente a magnitude dos coeficientes de Fourier, $\|U(f)\|=\sqrt{\operatorname{Re}(U(f))+\operatorname{Im}(U(f))}$, conhecida como espectro da freqüência, é usada como descritor (Costa e Cesar, 2000). Também se pode considerar como descritor o espectro da potência, conhecido também como densidade espectral. O espectro da potência consiste basicamente no quadrado da magnitude do espectro, ou seja, $\|U(f)\|^{2}$. Uma característica importante do espectro de potência é que nele não há variação quando a função original é transladada no domínio do espaço, característica muito explorada pelos descritores de Fourier, uma vez que não se considerada a fase do sinal. Além disso, o espectro da freqüência permite evidenciar características existentes no domínio da freqüência, podendo serem melhor exploradas as pequenas diferenças existentes entre dois sinais diferentes. Dentre as principais vantagens obtidas com os descritores de Fourier, quando aplicados em reconhecimento de padrões, têm-se a robustez quanto à presença de ruídos e também a possibilidade de redução do número de características, podendo uma forma ser representada por uma quantidade menor de coeficientes.

Kauppinen et. al. (1995) descrevem em seu trabalho que os descritores de Fourier, especialmente os métodos baseados em contorno, apresentam bons resultados mesmo quando a forma apresenta distorções perspectivas ou ruídos. Essa conclusão foi obtida por meio de comparações realizadas entre os descritores auto-regressivos e de Fourier. Em geral, as representações baseadas em contorno vêm sendo consideradas boas maneiras de se descrever a forma de um objeto. Loncaric (1998) aponta como maior vantagem dos descritores de Fourier, a facilidade de implementação, a qual baseia-se em uma teoria de análise por Fourier bem desenvolvida. No entanto, apresenta desvantagens quanto ao não fornecimento de informações locais da forma. Isso porque depois que se é aplicada a transformada de Fourier, as informações locais são distribuídas para todos os coeficientes, não sendo possível sua localização no domínio da freqüência.

\subsubsection{Momentos}

A teoria dos momentos fornece uma alternativa interessante e algumas vezes útil para representar a forma de um objeto (Jain, 1989). Momentos estão dentro dos mais comuns meios de derivação invariante e tem sido considerado uma ferramenta clássica para reconhecimento de objetos (Flusser, 2000; Salama e Abbott, 1998). Momentos podem ser usados para imagens bi- 
nárias e em niveis de cinza, assumindo-se que as mesmas possuem regiões formadas por pontos com intensidade diferente de zero. Entretanto, um momento de ordem $(p+q)$ é dependente de escala, rotação, translação e, até mesmo, das transformações de níveis de cinza (Sonka et. al., 1999).

Para uma função de distribuição de densidade bidimensional $f(x, y)$ os momentos de ordem $(p+q)$ podem ser definidos como:

$$
m_{p q}=\int_{-\infty}^{\infty} \int_{-\infty}^{\infty} x^{p} y^{q} f(x, y) d x d y
$$

sendo $x$ e $y$ as coordenadas dos pontos que formam a região. Para uma imagem digitalizada, os momentos podem ser obtidos por meio de somatórios, conforme apresentado na equação 3.54 , sendo $i$ e $j$ as coordenadas dos pontos da imagem digitalizada.

$$
m_{p q}=\sum_{i=-\infty}^{\infty} \sum_{j=-\infty}^{\infty} i^{p} j^{q} f(i, j)
$$

A invariância quanto à translação é alcançada por meio dos momentos centrais apresentados na equação 3.55 , sendo $x_{c}$ e $y_{c}$ as coordenadas do centro de massa da região, obtidas pela equação 3.56. O momento de ordem $0\left(m_{00}\right)$ representa a área do objeto.

$$
\begin{gathered}
\mu_{p q}=\sum_{i=-\infty}^{\infty} \sum_{j=-\infty}^{\infty}\left(i-x_{c}\right)^{p}\left(j-y_{c}\right)^{q} f(i, j) \\
x_{c}=\frac{m_{10}}{m_{00}} \\
y_{c}=\frac{m_{01}}{m_{00}}
\end{gathered}
$$

A invariância quanto à escala é obtida por meio dos momentos centrais normalizados, os quais são definidos pela equação 3.57 .

$$
\begin{aligned}
\eta_{p q} & =\frac{\mu_{p q}}{\left(\mu_{00}\right)^{\gamma}} \\
\text { sendo } \gamma & =\frac{p+q}{2}+1, p+q=2,3, \ldots
\end{aligned}
$$

$\mathrm{Hu}$ (1962) introduziu sete momentos característicos invariantes à escala, translação e rotação. Entretanto, essa abordagem não produz momentos invariantes às transformações afins. Um conjunto completo de quatro momentos invariantes afins, derivados dos momentos de segunda e terceira ordem, foram propostos por Flusser e Suk (1993) e são apresentados nas equações 3.58-3.61.

$$
I_{1}=\frac{1}{\mu_{00}^{4}}\left(\mu_{20} \mu_{02}-\mu_{11}^{2}\right)
$$




$$
\begin{gathered}
I_{2}=\frac{1}{\mu_{00}^{10}}\left(\mu_{30}^{2} \mu_{03}^{2}-6 \mu_{30} \mu_{21} \mu_{12} \mu_{03}+4 \mu_{30} \mu_{12}^{3}+4 \mu_{03} \mu_{21}^{3}-3 \mu_{21}^{2} \mu_{12}^{2}\right) \\
I_{3}=\frac{1}{\mu_{00}^{7}}\left(\mu_{20}\left(\mu_{21} \mu_{03}-\mu_{12}^{2}\right)-\mu_{11}\left(\mu_{30} \mu_{03}-\mu_{21} \mu_{12}\right)+\mu_{02}\left(\mu_{30} \mu_{12}-\mu_{21}^{2}\right)\right) \\
I_{4}=\left(\mu_{20}^{3} \mu_{03}^{2}-6 \mu_{20}^{2} \mu_{11} \mu_{12} \mu_{03}-6 \mu_{20}^{2} \mu_{02} \mu_{21} \mu_{03}+9 \mu_{20}^{2} \mu_{02} \mu_{12}^{2}\right. \\
+12 \mu_{20} \mu_{11}^{2} \mu_{21} \mu_{03}+6 \mu_{20} \mu_{11} \mu_{02} \mu_{30} \mu_{03}-18 \mu_{20} \mu_{11} \mu_{02} \mu_{21} \mu_{12} \\
-8 \mu_{11}^{3} \mu_{30} \mu_{03}-6 \mu_{20} \mu_{02}^{2} \mu_{30} \mu_{12}+9 \mu_{20} \mu_{02}^{2} \mu_{21}^{2} \\
\left.+12 \mu_{11}^{2} \mu_{02} \mu_{30} \mu_{12}-6 \mu_{11} \mu_{02}^{2} \mu_{30} \mu_{21}+\mu_{02}^{3} \mu_{30}^{2}\right) / \mu_{00}^{11}
\end{gathered}
$$

Por apresentar invariância quanto às transformações lineares, os momentos invariantes tornaram-se características consideráveis aos problemas de reconhecimento de padrões. Na literatura encontra-se uma série de técnicas que aplicam momentos, ou variações das mesmas. Os momentos são úteis para análise de formas e têm sido usados na diferenciação entre formas de aeronaves (Dudani et. al., 1977), reconhecimento de caracteres (Chong et. al., 2004; Flusser e Suk, 1994), sistemas de visão em automação e robótica (Tahri e Chaumette, 2003) e aplicações de reconhecimento de objetos em cenas reais (Lowe, 1999).

Outra abordagem aplicada a momentos pode ser usada na descrição de formas, considerando a representação da região por meio de sua fronteira. O contorno fechado é caracterizado por uma seqüência ordenada $z(i)$ que representa a distância Euclidiana entre o centróide e os pontos da fronteira (assinatura da forma)(Sonka et. al., 1999). A partir disso, Gupta e Srinath (1987) definiram momentos invariantes a escala, translação e rotação. $\mathrm{O} r$-ésimo momento do contorno $m_{r}$ e momento central do contorno $\mu_{r}$ podem ser estimados por meio das equações 3.62 e 3.63.

$$
\begin{gathered}
m_{r}=\frac{1}{N} \sum_{i=1}^{N}[z(i)]^{r} \\
\mu_{r}=\frac{1}{N} \sum_{i=1}^{N}\left[z(i)-m_{1}\right]^{r}
\end{gathered}
$$

A normalização do momento e momento central do contorno é definida pelas equações 3.64 e 3.65 .

$$
\begin{aligned}
& \overline{m_{r}}=\frac{m_{r}}{\left(\mu_{2}\right)^{r / 2}} \\
& \overline{\mu_{r}}=\frac{\mu_{r}}{\left(\mu_{2}\right)^{r / 2}}
\end{aligned}
$$

Enquanto o conjunto de momentos invariantes pode ser usado diretamente para representação da forma, resultados menos sensíveis a ruídos podem ser obtidos por meio dos seguintes descritores (Gupta e Srinath, 1987): 


$$
\begin{aligned}
& F_{1}=\frac{\left(\mu_{2}\right)^{1 / 2}}{m_{1}} \\
& F_{2}=\frac{\mu_{3}}{\left.\mu_{2}\right)^{3 / 2}} \\
& F_{3}=\frac{\mu_{4}}{\left.\mu_{2}\right)^{2}} \\
& F_{4}=\overline{\mu_{5}}
\end{aligned}
$$

Em reconhecimento de formas, o uso dos descritores obtidos pelos momentos do contorno possibilita uma menor probabilidade de erro na classificação, quando comparado ao uso dos descritores obtidos pelos momentos baseados na área. Além disso, eles são menos custosos computacionalmente (Gupta e Srinath, 1987; Sonka et. al., 1999).

\subsubsection{Transformada Wavelet}

A partir dos anos 90, surgiu um enorme interesse pela aplicação de wavelets, as quais tiveram implementações bem sucedidas em várias áreas do conhecimento. Em visão computacional, a técnica se destaca na compressão de dados, processamento de sinais e reconhecimento de padrões. As wavelets fornecem uma abordagem alternativa às técnicas de processamento de sinal tradicionais, como a análise de Fourier. O incentivo por trás da análise de wavelet é a sua propriedade de localizar características tanto no tempo (espaço) como na freqüência (escala). Isso fornece um mapa espaço-escala do sinal, permitindo a extração de características, o que torna as wavelets uma ferramenta ideal para analisar sinais de natureza transiente ou não-estacionária.

Enquanto a transformada de Fourier decompõe o sinal em uma série de senóides de freqüências diferentes (Figura 3.24), a transformada wavelet decompõe o sinal em wavelets, que são versões escaladas e transladadas da wavelet original, também chamadas de wavelet mãe (Figura 3.25). Há, entretanto, algumas diferenças muito distintas. Os senóides são suaves e contínuos, já as wavelets são irregulares na forma e compactas (com duração limitada). Sua forma irregular possibilita a análise de sinais com descontinuidade ou com mudanças bruscas, enquanto sua natureza compacta permite a localização temporal das características dos sinais.

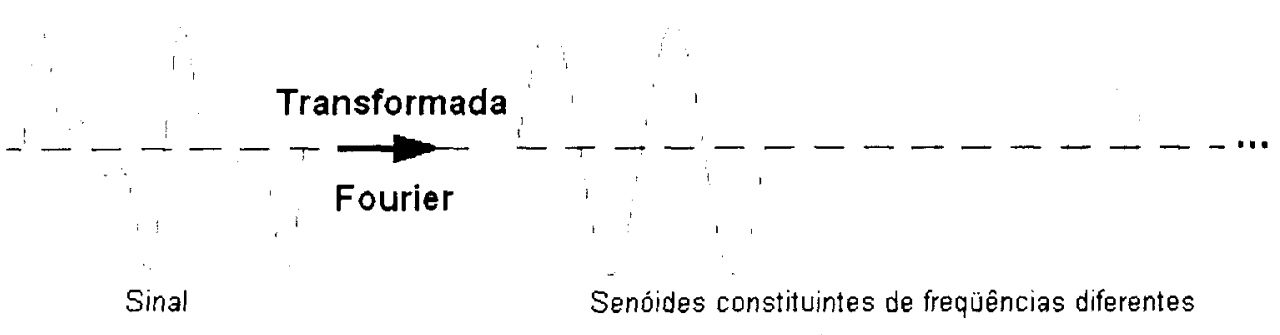

Figura 3.24: Decomposição pela transformada de Fourier (Adaptado de Misiti et. al. (2004)).

Uma implementação eficiente da transformada wavelet foi desenvolvida por Mallat (1999) usando um esquema de filtros. Para muitos sinais, as baixas frequiências contêm as informações mais importantes, ou seja, são elas que dão ao sinal sua identidade. Em contrapartida, 


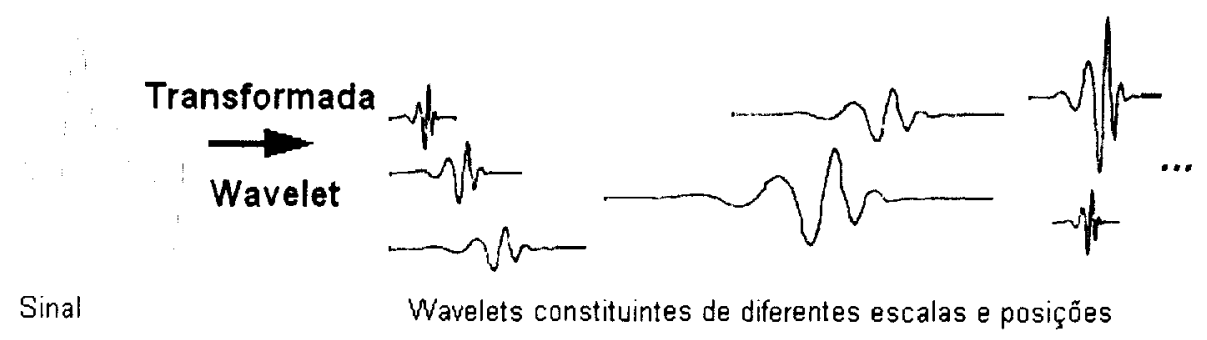

Figura 3.25: Decomposição pela transformada Wavelet (Adaptado de Misiti et. al. (2004))

as altas freqüências são responsáveis pelos detalhes. $\mathrm{Na}$ análise de wavelets, as baixas e altas freqüências são chamadas de aproximação e detalhe, respectivamente.

A base ortonormal das wavelets é formada pela dilatação e translação da função $\psi(x)$.

$$
\psi_{j, k}(x)=2^{-j / 2} \psi\left(2^{-j} x-k\right)
$$

sendo $j, k \in \mathbb{Z}$. Em conjunto com a função $\psi(x)$, há também uma função de escala $\phi(x)$, as quais satisfazem a seguinte relação:

$$
\begin{aligned}
& \phi(x)=\sqrt{2} \sum_{k=0}^{L-1} h_{k} \phi(2 x-k) \\
& \psi(x)=\sqrt{2} \sum_{k=0}^{L-1} g_{k} \phi(2 x-k)
\end{aligned}
$$

sendo $h_{k}$ e $g_{k}$ coeficientes de filtros de passa-baixa e passa-alta, respectivamente. Na Figura 3.26 é mostrado o esquema de decomposição por filtros, onde se tem como resultado a aproximação (tendência) e o detalhe do sinal original.

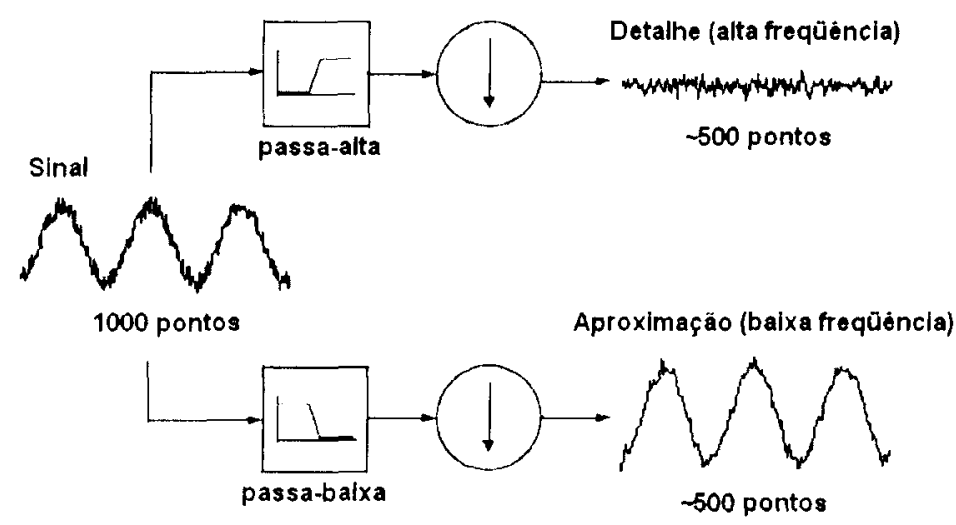

Figura 3.26: Decomposição do sinal em aproximação e detalhe pela transformada Wavelet (Misiti et. al., 2004).

Várias famílias de wavelets têm comprovado serem muito úteis. Dentre elas, a primeira e a mais simples é a wavelet de Haar (Figura 3.27(a)). Ela é descontínua e lembra a função escada. Outra família bastante popular são as wavelets de Daubechies, as quais tornaram viável a análise 
discreta. Essa família é composta por 10 membros, sendo a Daubechies 1 igual à wavelet de Haar (Misiti et. al., 2004). Na Figura 3.27(b) são mostradas apenas as wavelets de Daubechies 2, 3 e 4. Além dessas duas famílias, há também as wavelets biortogonais, Coiflets, Symlets, Morlet, entre outras.

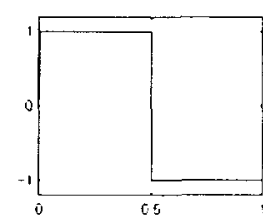

(a) Haar

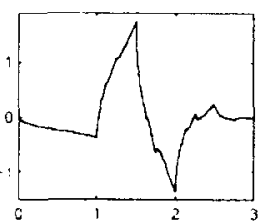

(b) Daubechies 2, 3 e 4

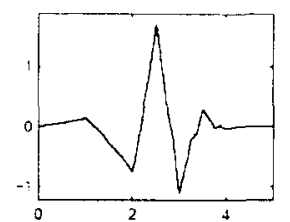

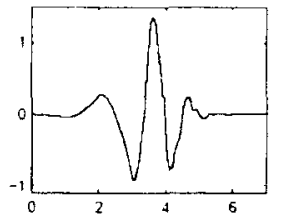

004).

Seguindo essa abordagem, a transformada wavelet também pode ser facilmente estendida para funções 2D, como imagens. Nesse caso, são necessárias uma função de escala bidimensional $\phi(x, y)$ e três wavelets bidimensionais sensíveis à direção, $\psi^{V}(x, y), \psi^{D}(x, y)$ e $\psi^{H}(x, y)$. Cada uma delas é o produto da função escala $\phi$ unidimensional com a wavelet $\psi$ correspondente (Gonzalez e Woods, 2002).

Na Figura 3.28 é mostrado o resultado obtido com a decomposição da imagem pela transformada wavelet 2D em três níveis. Também na Figura 3.28(e), é mostrado o diagrama referente a decomposição de uma imagem no terceiro nível. No diagrama, a aproximação obtida no terceiro nível é representada por $\mathbf{a}_{3}$ e os detalhes são representados em cada nível $n$ por $\mathbf{d}_{n}^{m}$, sendo $m$ as direções horizontal $(\mathrm{H})$, vertical $(\mathrm{V})$ e diagonal $(\mathrm{D})$ referentes às wavelets.

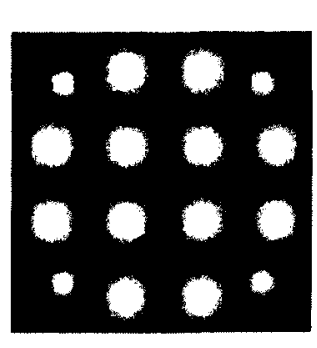

(a)

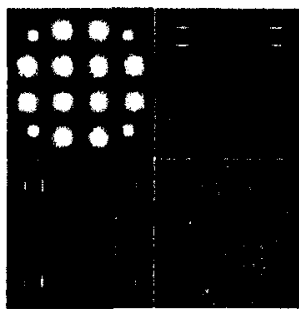

(b) nível 1

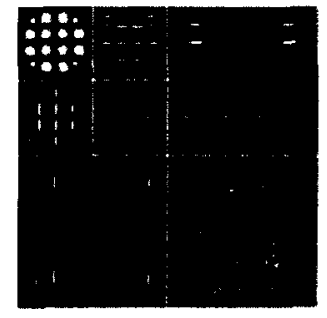

(c) nível 2

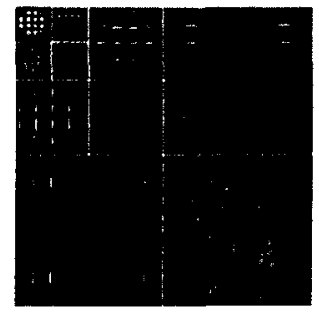

(d) nível 3

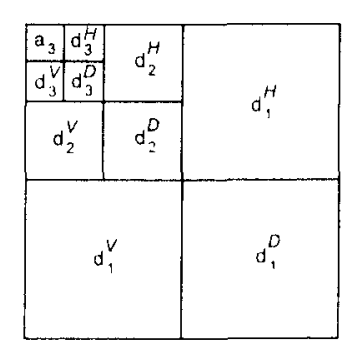

(e)

Figura 3.28: Transformada Wavelet 2D: imagem original (a), a decomposição da imagem por wavelets em três níveis (b-d) e o diagrama referente a decomposição $2 \mathrm{D}$ para três níveis (e) (Gonzalez e Woods, 2002). 
A aplicação mais popular para wavelet é a compressão de imagens (Mallat, 1999; Parker, 1997), entretanto essa transformada tem sido aplicada em visão computacional para extração de características de sinais de contorno (Tao et. al., 2001), reconhecimento de padrões através de descritores de wavelet (Osowski e Nghia, 2002), entre outras.

\subsection{Reconhecimento de Padrões}

A habilidade do ser humano em reconhecer e classificar objetos é algo impressionante. Desde o início da computação, a implementação de algoritmos para emular essa capacidade humana tem se apresentado como uma tarefa intrigante e desafiadora. O reconhecimento de padrões estuda uma maneira de as máquinas também poderem observar o ambiente, aprender a distinguir padrões de interesse e tomar decisões sobre as categorias de padrões (Jain et. al., 2000). Para isso, técnicas e abordagens foram criadas e são usadas de maneira integrada para a solução de diversos problemas práticos.

Para serem reconhecidos e classificados por um sistema automático, os padrões devem ser compostos por um conjunto de características mensuráveis, as quais são extraídas de um objeto ou entidade de interesse em uma imagem, por exemplo. Quando essas características são similares dentro de um grupo de padrões, diz-se que esses padrões pertencem a uma mesma classe. $\mathrm{O}$ objetivo dos sistemas de reconhecimento é determinar, com base nas informações disponiveis, a classe de padrões responsável pela produção de um conjunto de medidas similar ao do padrão sob análise. No entanto, o reconhecimento correto depende da quantidade de informação discriminante contida nas características extraídas e da utilização efetiva dessas informações (Tou e Gonzalez, 1974).

O reconhecimento/classificação de padrões pode consistir de uma das duas tarefas (Costa e Cesar, 2000; Jain et. al., 2000)

- classificação supervisionada (análise discriminante): o padrão de entrada é identificado como um membro de uma classe pré-definida. Um ou mais exemplos de cada classe previamente conhecida são utilizados como modelo (protótipos) para a classificação de novos objetos. Esse tipo de classificação freqüentemente envolve dois estágios: aprendizado, quando os critérios e métodos são testados nos modelos, e reconhecimento, quando o sistema treinado é usado para classificar novos objetos;

- classificação não-supervisionada (clustering ou agrupamento): o padrão é associado a uma classe até então desconhecida. Esse é o caso em que se tem um conjunto de objetos e tenta-se encontrar a classe mais adequada, sem modelo específico ou características e critérios disponíveis. Nesse caso, a busca por um critério de classificação e características apropriadas caracteriza-se como um processo de descoberta, através do qual são criados novos conceitos e identificados relacionamentos entre os objetos.

Existem várias abordagens que podem ser empregadas na solução de problemas, dentre elas (Duda et. al., 2001): Reconhecimento Estatístico de Padrões, Reconhecimento Sintático de Padrões, Redes Neurais Artificiais e Sistemas Fuzzy. Apenas duas abordagens são tratadas 
aqui: reconhecimento estatístico de padrões e redes neurais. A abordagem estatística, também denominada de Teoria da Decisão, assume que as características das classes são regidas por determinados modelos probabilísticos. As redes neurais, no entanto, procuram determinar um mapeamento ótimo entre entradas e saídas inspirando-se em modelos de neurônios do cérebro. Esse mapeamento consiste em uma rede de grafos direcionados sendo os nós os neurônios artificiais e os arcos as conexões entre as saídas e as entradas dos neurônios.

É importante ressaltar que o reconhecimento de padrões é uma área geral, ampla e não desenvolvida completamente. Muitas contribuições estão sendo obtidas em diversas áreas e uma vantagem quanto a isso é que muitos conceitos e resultados alcançados em uma área específica podem ser usados em outras áreas, o que permite considerar uma grande variedade de perspectivas.

\subsubsection{Reconhecimento Estatístico de Padrões}

Nessa abordagem, um objeto é caracterizado por meio de uma descrição quantitativa, e conseqüentemente, um padrão é formado por um conjunto dessas características. Da mesma forma, uma classe de padrões pode ser vista como uma família de padrões que compartilham características em comum (Gonzalez e Woods, 1993). O principal arranjo de padrões usado na prática para descrições quantitativas são os vetores de características (3.73), também conhecidos como vetores de padrões, sendo $\mathbf{x}$ o padrão e $x_{i}$ as características que o compõem.

$$
\mathbf{x}=\left[\begin{array}{c}
x_{1} \\
x_{2} \\
\vdots \\
x_{n}
\end{array}\right]
$$

Como já mencionado, o reconhecimento de padrões consiste na associação de classes aos objetos e o responsável por realizar essa tarefa é chamado de classificador. O classificador estatístico é um dispositivo com $n$ entradas e apenas uma saída. Cada entrada é usada para informar uma das $n$ características que são extraídas do objeto a ser classificado e a saída corresponde ao identificador da classe, que é interpretada pelo usuário como a decisão sobre a classe a que pertence o objeto processado. Dessa maneira, um classificador para $M$ classes $\omega_{1}, \omega_{2}, \ldots, \omega_{M}$ gera como saída o identificador de apenas umas dessas classes, ou seja, da classe do novo objeto (Sonka et. al., 1999). Conceitos da teoria de decisão são utilizados para estabelecer a fronteira de decisão entre as classes de padrões e, para isso, faz-se necessário encontrar $M$ funções de decisão, $d_{1}(\mathbf{x}), d_{2}(\mathbf{x}), \ldots, d_{M}(\mathbf{x})$, cuja propriedade é a de que se um padrão desconhecido $\mathbf{x}$ pertence à classe $\omega_{i}$, então a função de decisão $d_{i}(\mathbf{x})$ deve apresentar o maior valor numérico, ou seja,

$$
d_{i}(\mathbf{x})>d_{j}(\mathbf{x}) \quad \operatorname{paraj}=1,2, \ldots, M e j \neq i
$$

Em caso de empate, a decisão é tomada de forma arbitrária (Gonzalez e Woods, 1993; Tou e Gonzalez, 1974).

A fronteira de decisão que separa as classes $\omega_{i}$ e $\omega_{j}$ corresponde aos valores de $\mathbf{x}$ em que 
a função de decisão resulte no mesmo valor para as duas classes, ou seja, $d_{i}(\mathbf{x})-d_{j}(\mathbf{x})=0$. Dessa maneira, a fronteira de decisão para apenas duas classes pode ser identificada pela função $d_{i j}=d_{i}(\mathbf{x})-d_{j}(\mathbf{x})=0$, sendo $\mathbf{x}$ pertencente à classe $\omega_{i}$ para $d_{i j}>0$, ou à classe $\omega_{j}$ para $d_{i j}<0$.

\subsubsection{Classificador de Distância Mínima}

Um classificador pode ser obtido com base no princípio da distância mínima, o qual apresenta vantagens por ser de fácil implementação. Considera-se, nesse caso, que cada classe é representada por um vetor médio $\mathbf{m}_{i}$ (amostra do padrão). O classificador de distância mínima classifica um padrão $\mathbf{x}$ na classe mais próxima, ou seja, naquela que apresentar a menor distância entre o vetor médio $\mathbf{m}_{i}$ e o padrão $\mathbf{x}$ (Sonka et. al., 1999).

$$
d(\mathbf{x})=w_{i} \Leftrightarrow\left|\mathbf{m}_{i}-\mathbf{x}\right|=\min _{s=1, \ldots, M}\left|\mathbf{m}_{s}-\mathbf{x}\right|
$$

A distância Euclidiana pode ser usada para determinar a proximidade, reduzindo, assim, o problema ao cálculo das distâncias, sendo $|a|=\left(a^{T} a\right)^{\frac{1}{2}}$ a norma Euclidiana. Em Gonzalez e Woods (1993) é apresentada uma formulação equivalente

$$
d_{i}(\mathbf{x})=\mathbf{x}^{T} \mathbf{m}_{i}-\frac{1}{2} \mathbf{m}_{i}^{T} \mathbf{m}_{i} \quad \text { para } i=1,2, \ldots, M
$$

sendo que, nesse caso, $\mathbf{x}$ é atribuído à classe $\omega_{i}$ se $d_{i}(\mathbf{x})$ for o maior valor, formulação essa de acordo com a função de decisão apresentada na equação 3.74 .

Dessa maneira, a fronteira de decisão entre as classes $\omega_{i}$ e $\omega_{j}$ para o classificador de distância mínima é definida como:

$$
\begin{aligned}
d_{i j}(\mathbf{x}) & =d_{i}(\mathbf{x})-d_{j}(\mathbf{x}) \\
& =\mathbf{x}^{T}\left(\mathbf{m}_{i} \mathbf{m}_{j}\right)-\frac{1}{2}\left(\mathbf{m}_{i} \mathbf{m}_{j}\right)^{T}\left(\mathbf{m}_{i} \mathbf{m}_{j}\right)=0
\end{aligned}
$$

sendo a fronteira obtida a bisseção perpendicular à linha entre $\mathbf{m}_{i}$ e $\mathbf{m}_{j}$, como é mostrado na Figura 3.29(a).

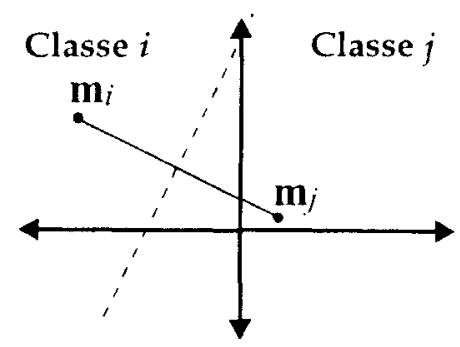

(a)

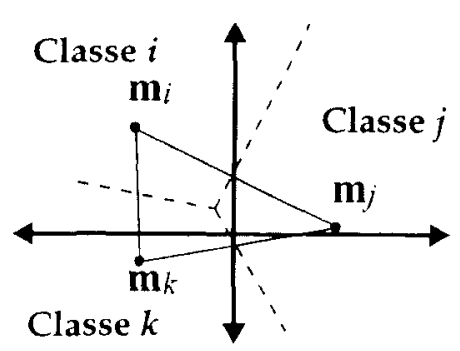

(b)

Figura 3.29: Exemplos do classificador de distância mínima: problema com duas classes (a) e com três classes (b).

Existem outros classificadores estatísticos que são comumente usados, dentre eles (Raudys e Jain, 1991): classificador Bayesiano, função discriminante linear de Fisher, função discriminan- 
te quadrática, janela de Parzen, classificador $K$ vizinhos mais próximos $(K N N)$ e classificador multimodal.

\subsubsection{Análise de Clusters}

Dentre os métodos de classificação há aqueles que não dispõem de um conjunto de treinamento para o estágio de aprendizado. No entanto, pode-se dizer que eles aprendem sozinhos, o que também é conhecido por aprendizado não-supervisionado. Clustering (agrupamento) é o termo geral usado para a classificação não-supervisionada, onde os objetos ou padrões são separados em clusters (grupos) por meio da similaridade existente entre eles (Ma e Chow, 2004). Fukunaga (1990) salienta que o problema de agrupamento não é bem definido a menos que as classes resultantes exibam certas características. Além disso, a escolha das características ou, equivalentemente, a definição de um cluster, é o aspecto fundamental em um problema de agrupamento.

Segundo Jain et. al. (2000), a análise de clusters é uma técnica muito importante e útil. A velocidade, confiabilidade e a consistência com que os algoritmos de agrupamento podem organizar grandes quantidades de dados dão uma razão decisiva para o seu uso em aplicações como mineração de dados, recuperação de informações, segmentação de imagens e aprendizado de máquinas. Na maioria dos problemas, pouca informação é previamente disponibilizada sobre os dados e, por esse motivo, o classificador necessita fazer algumas suposições sobre esses dados (Tou e Gonzalez, 1974). É sob essas limitações que a metodologia de clustering melhor se aplica, explorando os inter-relacionamentos entre os dados de interesse. Com isso, busca-se realizar uma avaliação (possivelmente preliminar) de suas estruturas a fim de encontrar as classes existentes dentro do conjunto analisado (Jain et. al., 1999).

Os métodos de análise de clusters dividem-se em hierárquicos e não-hierárquicos. Os métodos hierárquicos trabalham com uma árvore de agrupamentos, enquanto os não-hierárquicos associam seqüencialmente cada padrão ao seu devido cluster. Os métodos não-hierárquicos podem também ser divididos em paramétricos ou não-paramétricos, os quais destacam-se por serem mais populares e na prática simples e úteis (Jain et. al., 1999). O método de análise k-means (Berkhin, 2002; Faber, 1994; MacQueen, 1967) é um dos mais conhecidos dessa abordagem, o qual agrupa classe por classe em um processo iterativo usando a técnica de distância mínima. Nesse método, assume-se que o número de classes é previamente conhecido e, além disso, os $k$ clusters iniciais, a partir dos quais os grupos serão formados, são escolhidos aleatoriamente. Cada um dos $k$ clusters é representado por um ponto médio, também conhecido como centróide ${ }^{2}$. A proximidade pode ser obtida por meio de alguma medida de distância como a Euclidiana ou a Mahalanobis (Jain et. al., 2000).

Na Figura 3.30 são apresentadas as etapas de agrupamento efetuadas pelo método $k$-means para $k=2$. Na etapa a, os dois círculos preenchidos, que representam os centróides de cada cluster, são escolhidos arbitrariamente. Os círculos abertos, que representam os dados, são agrupados de acordo com a proximidade entre os dados e os centróides. Na etapa b, os centrói-

\footnotetext{
${ }^{2}$ Centro de gravidade para todos os padrões pertencentes a um determinado cluster que pode ser obtido por meio de uma média.
} 
des foram recalculados para cada cluster e os dados novamente associados ao centróide mais próximo. A cada troca os centróides são recalculados e isso se repete até que as partições se estabilizem, como apresentado na etapa c.

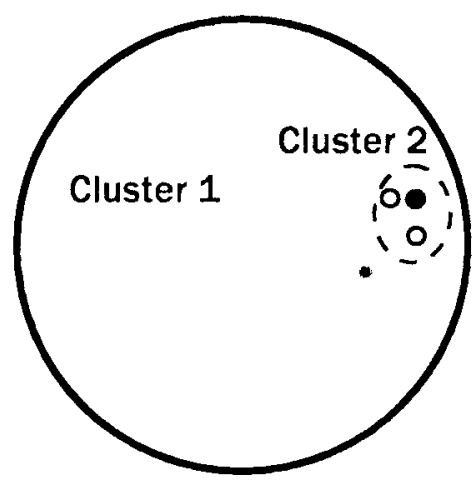

(a)

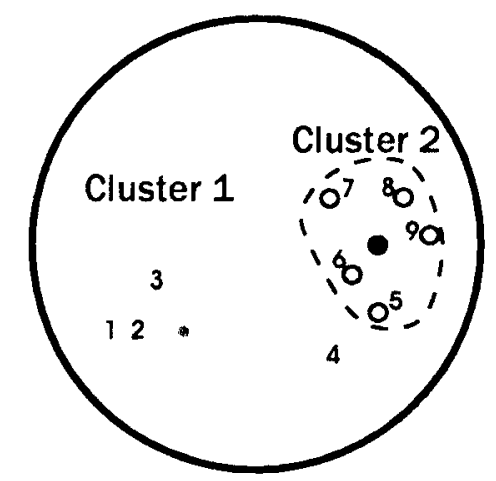

(b)

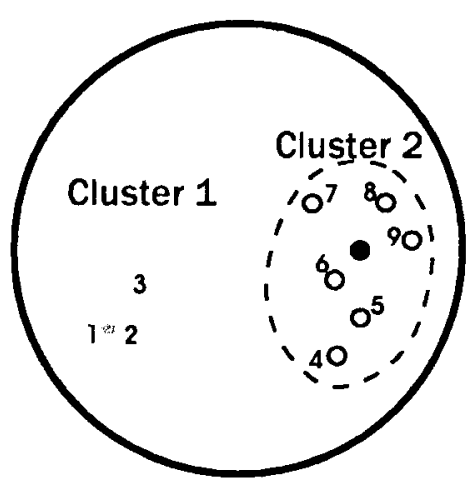

(c)

Figura 3.30: Etapas do agrupamento realizado com o método k-means (Adaptado de Faber (1994)).

O método $k$-means apresenta vantagens quanto à simplicidade. No entanto, a dependência dos clusters iniciais e a escolha arbitrária dos primeiros centróides são algumas das desvantagens do método. Em alguns casos sua utilização requer experimentação com vários valores de $k$ e diferentes escolhas dos parâmetros iniciais (Berkhin, 2002). Variações desse método podem ser encontradas na literatura, como é o caso do Fuzzy C-Means (Barshan e Ayrulu, 2004; Dunn, 1974; Zhang e Chen, 2004), K-modes (Huang, 1997), e K-prototypes (Huang, 1998). Os métodos particionais, comparados aos hierárquicos, são menos custosos em termo de tempo, mas ainda é um processo caro devido ao cálculo repetitivo das distâncias entre os padrões e os respectivos centróides, a fim de encontrar a menor distância (Ma e Chow, 2004). Outros métodos podem ser encontrados em Berkhin (2002) e Jain et. al. (1999).

\subsubsection{Redes Neurais}

As Redes Neurais Artificiais (RNAs) têm sido bastante estudadas desde a sua redescoberta como um paradigma de reconhecimento de padrões no final dos anos 80 . Elas representam uma ferramenta de grande valor em várias aplicações que são vistas como difíceis, particularmente, em reconhecimento de padrões visuais e de fala.

As RNAs baseiam-se na combinação de processadores simples (neurônios), cada qual com um número de entradas e gerando uma única saída. Os neurônios calculam determinadas funções matemáticas, normalmente não-lineares, as quais podem ser discretas ou contínuas dependendo do tipo de rede em uso. Além disso, os neurônios são dispostos em uma ou mais camadas interligados por um grande número de conexões, geralmente unidirecionais (a saída de um neurônio pode conectar-se à entrada de um ou mais neurônios). Na maioria dos modelos essas conexões estão associadas a pesos, os quais armazenam o conhecimento representado no modelo e servem para ponderar a entrada recebida por cada neurônio da rede. O funcionamento 
de toda essa estrutura foi inspirado no cérebro humano com o intuito de imitá-lo (Sonka et. al., 1999).

Inicialmente, as RNAs passam por uma fase de aprendizagem (procedimento usual), na qual um conjunto de exemplos é apresentado para a rede. Nessa etapa são extraídas automaticamente as características necessárias para representar a informação fornecida, as quais serão utilizadas no momento de gerar as respostas a um determinado problema. Um simples neurônio, derivado do trabalho pioneiro em simulação neural conduzido por McCulloch e Pitts (1943), é mostrado na Figura 3.31. O modelo por eles proposto (modelo MCP) é uma simplificação do que se sabia até aquele momento sobre um neurônio biológico. Nesse modelo, as entradas são denotadas por $p_{1}, p_{2}, \ldots, p_{R}$ e os pesos associados à elas por $W_{1}, W_{2}, \ldots, W_{R}$, sendo $R$ o número de entradas. Os neurônios também possuem um escalar bias $b$, que é adicionado ao produto $W . p$. O bias é como um peso, exceto pelo fato de que ele tem uma entrada constante de $b=1$.

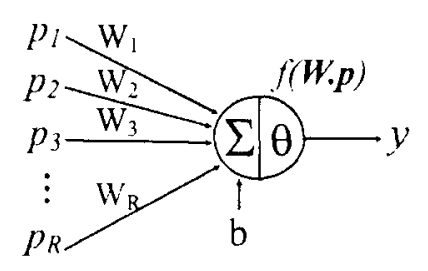

Figura 3.31: Um simples neurônio de McCulloch-Pitts (Adaptado de Sonka et. al. (1999)).

O neurônio biológico dispara uma saída quando a soma dos impulsos que ele recebe excede o seu limiar de excitação. Esse mecanismo é emulado em RNAs de um simples modo: realiza-se a soma dos valores $W_{i} p_{i}$ recebidos (Equação 3.78) e depois compara-se o valor dessa soma a um limiar $\theta$, definido para o neurônio, para saber se ativa ou não a saída.

$$
x=\sum_{i=1}^{R} W_{i} p_{i}+b
$$

No modelo MCP, a ativação do neurônio é obtida por uma função de ativação $f(x)$, que é associada ao neurônio com o objetivo de decidir se ativa ou não a saída com base no resultado da soma ponderada. Os valores produzidos como saída são 0 ou 1, mas podem ser outros valores dependendo da função de ativação selecionada. Diferentes funções de ativação foram derivadas a partir do modelo proposto por McCulloch e Pitts (1943), dentre elas a função passo, a função linear e a função sigmoidal (Braga et. al., 2000; Jain et. al., 1996).

A função passo, ilustrada pela Figura 3.32(a), produz saídas iguais a 0 ou 1 , conforme definido na Equação 3.79 .

$$
f(x)= \begin{cases}0 & \text { se } x \leq 0 \\ 1 & \text { se } x>0\end{cases}
$$

A função linear, é definida pela Equação 3.80, sendo $\alpha$ um número real que define a saída linear $y=f(x)$ para os valores de entrada $x$. Sua representação é mostrada na Figura 3.32(b).

$$
f(x)=\alpha x
$$


A função sigmoidal, mostrada na Figura 3.32(c), é uma função semilinear, limitada e monotônica (Braga et. al., 2000). Uma das funções mais importantes é a função logística definida na Equação 3.81 .

$$
f(x)=\frac{1}{1+e^{-x}}
$$

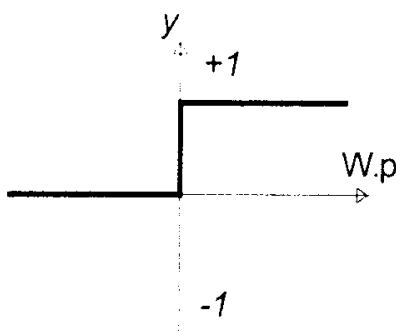

(a)

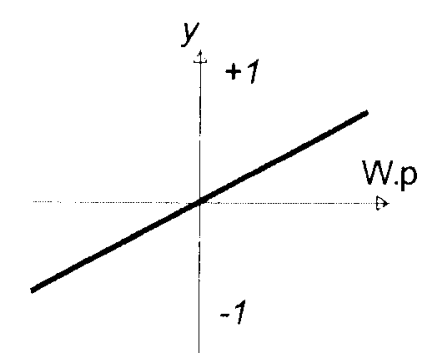

(b)

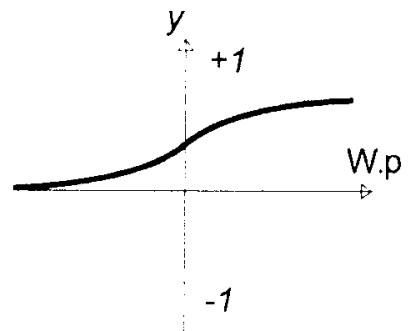

(c)

Figura 3.32: Representações de algumas funções de ativação: Função passo (a), função linear (b) e função sigmoidal (c).

\subsubsection{Redes Multicamadas}

Uma característica importante das redes multicamadas é que elas podem tratar com dados que não são linearmente separáveis. Em uma rede desse tipo, o processamento realizado pelos neurônios é definido pela combinação dos processamentos realizados pelos neurônios da camada anterior. Na Figura 3.33(a) é mostrada uma camada de neurônios da rede. Nessa camada o vetor de entradas, representado por $p$ é conectado a cada um dos neurônios por meio da matriz de pesos $W$, sendo $W_{1,1}$ a conexão entre o primeiro neurônio da camada e a primeira entrada da rede e $W_{S, R}$ a conexão entre o último neurônio e a última entrada. O número de entradas, representado por $R$, não necessita ser igual ao número de neurônios, representado por $S$. O bias é representado por $b$ e a função de ativação por $f$. Uma representação abreviada pode ser usada para ilustrar a camada de uma rede, conforme mostrada na Figura 3.33(b). Nessa figura, as dimensões de cada componente são mostradas abaixo delas, por exemplo a matriz de pesos $W$ que possui dimensão $S \times R$ (Demuth e Beale, 2003).

A representação de uma rede com três camadas é mostrada na Figura 3.34, considerando a representação abreviada. A terceira camada é considerada a camada de saída. Alguns autores referem-se à entrada como uma quarta camada, mas essa designação não será aplicada aqui. Nessa figura, a matriz de pesos da entrada é representada por IW (input weights), enquanto as demais matrizes de pesos são representadas por $L W$ (layer weights). As saídas $y^{n}$ das camadas intermediárias são as entradas para as camadas seguintes.

Para uma rede com pelo menos duas camadas intermediárias, pode-se dizer que o processamento ocorre da seguinte maneira (Braga et. al., 2000): (i) na primeira camada cada neurônio traça retas no espaço de padrões de treinamento, (ii) na segunda camada, cada neurônio combina as retas traçadas pelos neurônios da camada anterior conectados a ele, formando regiões convexas e (iii) na terceira camada (saída), cada neurônio forma regiões que são combinações 


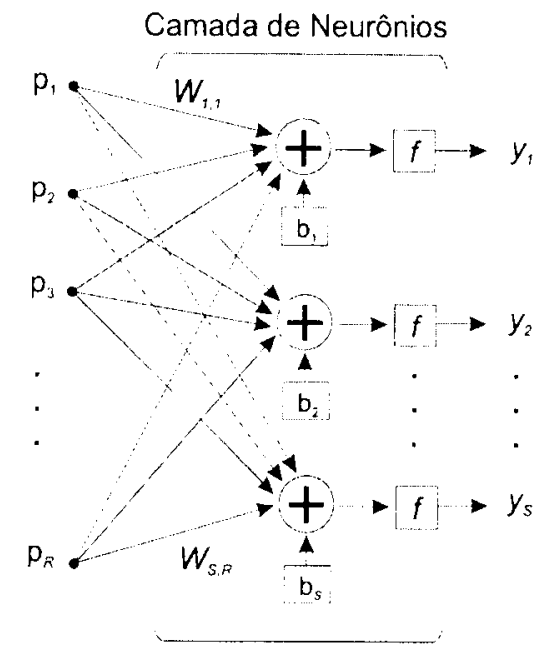

(a)

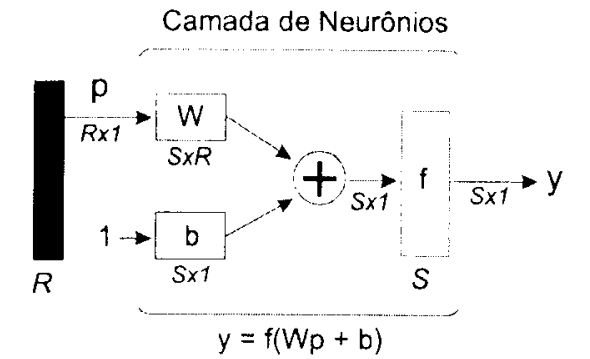

(b)

Figura 3.33: Representações de uma camada da rede neural.

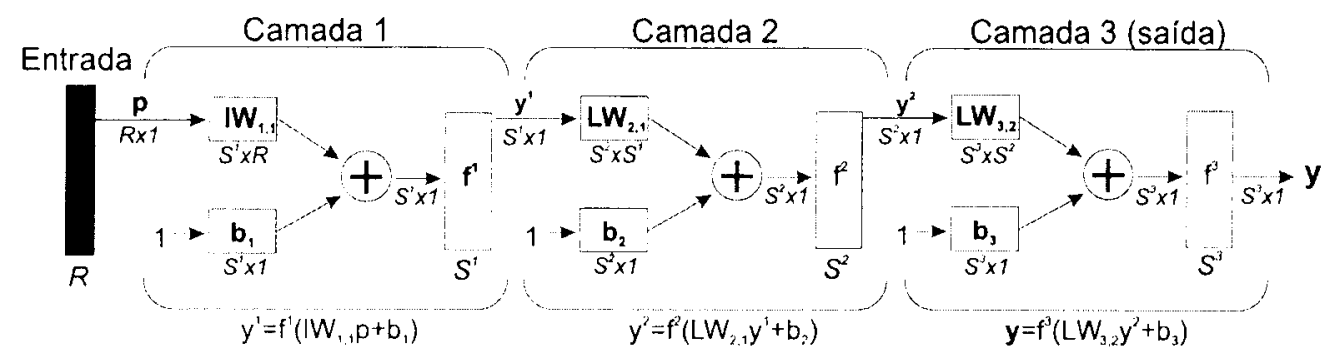

Figura 3.34: Representação abreviada da rede com 3 camadas (Demuth e Beale, 2003).

das regiões convexas definidas pelos neurônios da camada anterior conectados a ele.

A definição do número de neurônios em cada uma das camadas intermediárias é empírica, dependendo fortemente da distribuição dos padrões de treinamento e da validade da rede. As RNAs apresentam soluções bastante atrativas, pois devido à representação interna e ao paralelismo natural inerente à arquitetura é possível alcançar com elas um desempenho superior a alguns modelos convencionais (Braga et. al., 2000). A idéia central das redes neurais é que tais parâmetros possam ser ajustados para que elas possam apresentar o comportamento desejado. Dessa maneira, a rede pode ser treinada para resolver um problema particular ajustando os parâmetros (pesos ou bias)

Dentre os algoritmos de treinamento, o mais popular é o algoritmo backpropagation (Rumelhart e McClelland, 1986), o qual foi um dos principais responsáveis pelo ressurgimento do interesse por redes neurais artificiais. O algoritmo backpropagation é um algoritmo de aprendizado supervisionado, que utiliza um mecanismo de correção de erros para ajustar os pesos considerando os pares (entrada x saída desejada) (Braga et. al., 2000). Esse algoritmo trabalha em duas fases: (i) a fase forward, que define a saída da rede para uma determinada entrada, e (ii) a fase backward, que utiliza a saída obtida pela rede e a saída desejada para ajustar os pesos entre as 
camadas. Algumas variações foram propostas visando a acelerar o tempo de treinamento, como a backpropagation com momentum (Rumelhart e McClelland, 1986), a Levenberg-Marquardt (Hagan e Menhaj, 1994) dentre outras.

A capacidade das RNAs não se resume apenas em mapear as relações de entrada e saída. Sua capacidade de aprender por meio de exemplos e de generalizar a informação aprendida é o principal atrativo para sua aplicação. As famílias de redes neurais comumente usadas em reconhecimento de padrões são as redes feed-forward. Outra família popular de rede é a Self-Organization Map (SOM), ou rede de Kohonen, que é usada principalmente para agrupamento de dados e mapeamento de características (Jain et. al., 2000, 1996). Aplicações de redes neurais em processamento de imagens, especialmente redes feed-forward, Kohonen e Hopfield são discutidas por Egmont-Petersen et. al. (2002).

\subsection{Considerações Finais}

Neste capítulo foram apresentados diferentes métodos/abordagens que podem ser utilizados nas etapas envolvidas em um sistema de visão computacional, apresentando os principais aspectos a serem considerados em cada uma delas. A decisão sobre qual abordagem adotar depende do conjunto de características que será extraído por cada método e do seu comportamento em relação à identificação dos ascósporos do fungo Guignardia citricarpa.

No próximo capítulo é apresentado um estudo comparativo realizado entre as técnicas de análise de formas a fim de identificar quais delas melhor caracteriza as partículas de ascósporos, possibilitando a diferenciação dessas partículas das demais. 


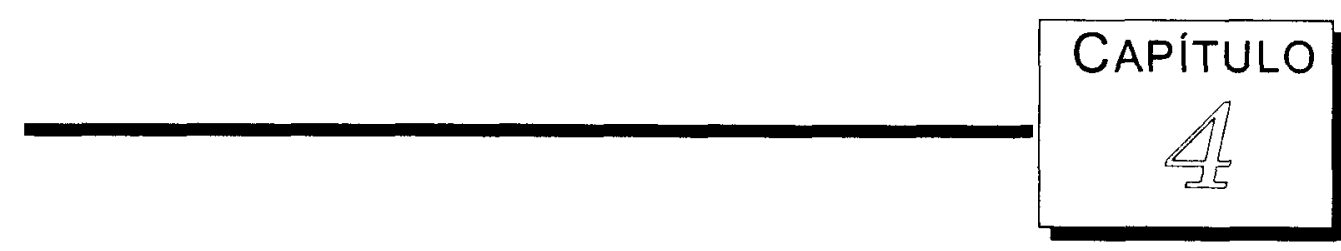

\section{Estudo Comparativo entre Métodos de Análise de Formas}

$\mathcal{D}$ urante o levantamento bibliográfico sobre as técnicas de visão computacional realizado neste projeto, um conjunto de técnicas aplicadas à descrição de objetos com base na forma foi estudado. Com base nele, uma série de testes utilizando as partículas coletadas nos discos foi realizada a fim de selecionar as técnicas capazes de extrair um conjunto de características que melhor distingue os ascósporos das demais partículas coletadas. Para a realização desses testes, amostras de ascósporos e de outras partículas (contra-exemplos) foram selecionadas a partir de algumas imagens digitais capturadas dos discos de coletas.

Neste capítulo são apresentadas as técnicas aplicadas para a descrição das formas. Também são apresentados os resultados prévios alcançados com cada uma delas, assim como, as características que guiaram a seleção de uma dessas técnicas para ser aplicada na identificação dos ascósporos.

\subsection{Seleção e Pré-processamento das Amostras}

Para a realização dos testes com as técnicas abordadas, um conjunto de amostras foi previamente selecionado a partir das imagens digitais dos discos de coleta. A seleção foi realizada manualmente, sendo esse conjunto formado por 60 amostras (20 amostras de ascósporos e 40 amostras de outras partículas). Cada uma dessas amostras foi limiarizada, usando o algoritmo de Otsu (1979), pois as características de interesse estão na forma das partículas. De cada uma dessas amostras foi extraído o contorno, no entanto, existe o problema quanto à variação do ponto inicial do contorno, decorrente da rotação da forma.

Para diminuir os efeitos causados pela variação quanto à rotação, cada umas das amostras foi submetida a um processo de normalização, no qual as formas são rotacionadas para que fiquem na mesma posição - maior eixo na vertical. Para isso, considerou-se como eixo principal o eixo formado pelas duas coordenadas pertencentes à borda mais distantes entre si-coordenadas que 
determinam o diâmetro da forma. Ao invés de usar métodos como a transformada de Hotteling (Gonzalez e Woods, 2002), que se baseia no cálculo de autovetores e autovalores, optou-se por uma abordagem mais simples. A partir das coordenadas que formam o eixo, calcula-se $\Delta x=\left(x_{2}-x_{1}\right)$ e $\Delta y=\left(y_{2}-y_{1}\right)$ e, em seguida, o ângulo $\theta$ necessário para a rotação da forma, para que o eixo formado por essas coordenadas seja posicionado na vertical, ou seja, $\alpha=\arctan (\Delta x / \Delta y)$ e $\theta=\pi / 2-\alpha$. Por fim, aplica-se sobre as coordenadas de interesse a Equação 4.1 para rotacionar a forma com base no ângulo $\theta$.

$$
\begin{gathered}
x^{\prime}=x \cdot \cos \theta+y \cdot \operatorname{sen} \theta \\
y^{\prime}=x \cdot(-\operatorname{sen} \theta)+y \cdot \cos \theta
\end{gathered}
$$

Após a normalização das amostras, o novo ponto inicial para o contorno passa a ser o ponto mais próximo da borda superior da imagem e mais à esquerda, como apresentado na Figura 4.1

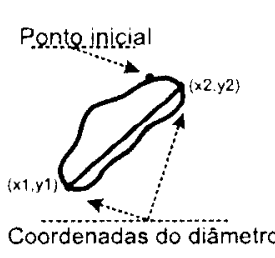

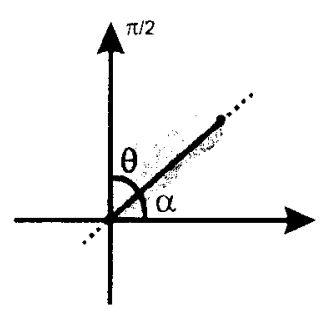

(b)

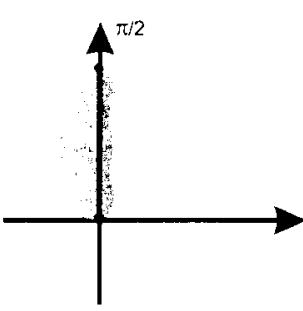

(c)

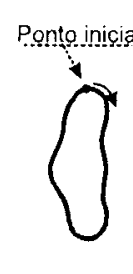

(d)

Figura 4.1: Esquema usado na normalização das amostras quanto aos efeitos da rotação.

\subsection{Descritores Gerais}

Inicialmente os testes foram realizados aplicando-se os descritores gerais da forma, como área, perímetro, excentricidade, dentre outros. De imediato, pôde-se observar que tais descritores não foram capazes de caracterizar as formas das amostras obtidas dos discos. Esse fato já era esperado em razão da simplicidade dos descritores e por haver nas imagens dos discos formas parecidas. Diferentes formas presentes nos discos possuem área ou perímetro bastante próximos, não sendo possível diferenciá-las apenas com o uso desses descritores. No entanto, esses descritores não foram descartados, pois os testes realizados demonstraram que os mesmos poderiam ser aplicados a fim de efetuar uma classificação prévia das partículas a serem submetidas ao processo de identificação. Dentre os descritores, optou-se pelo uso do perímetro por ser um descritor simples e que necessita apenas do contorno da forma para ser calculado, podendo ser obtido logo após o processo de extração do contorno.

Observando o tamanho das partículas encontradas nos discos de coleta, uma pré-seleção das mesmas pôde ser realizada comparando-se o perímetro. Analisando um conjunto de amostras de ascósporos extraído de imagens com o mesmo fator de ampliação, observou-se que essas amostras apresentavam o perímetro entre 120 e 220 pontos, como mostrado no gráfico da Figura 4.2. Nesse gráfico também são mostrados os limiares superior e inferior que foram definidos com base na análise do conjunto de amostras de ascósporos, sendo parte desse conjunto 
mostrado à direita do gráfico (Figura 4.2). Esse intervalo teve que ser considerado em razão das diferentes formas que um ascósporo pode apresentar, tanto pela diferença no tamanho do ascósporo quanto pela variação da forma decorrente da maneira como o ascósporo se adere ao disco, podendo apresentar diferentes perspectivas. Embora seja esta uma abordagem simples, grande parte das partículas que não são de ascósporos é descartada por meio dessa pré-seleção antes mesmo de se extrair o vetor de característica e submetê-lo ao processo de identificação.
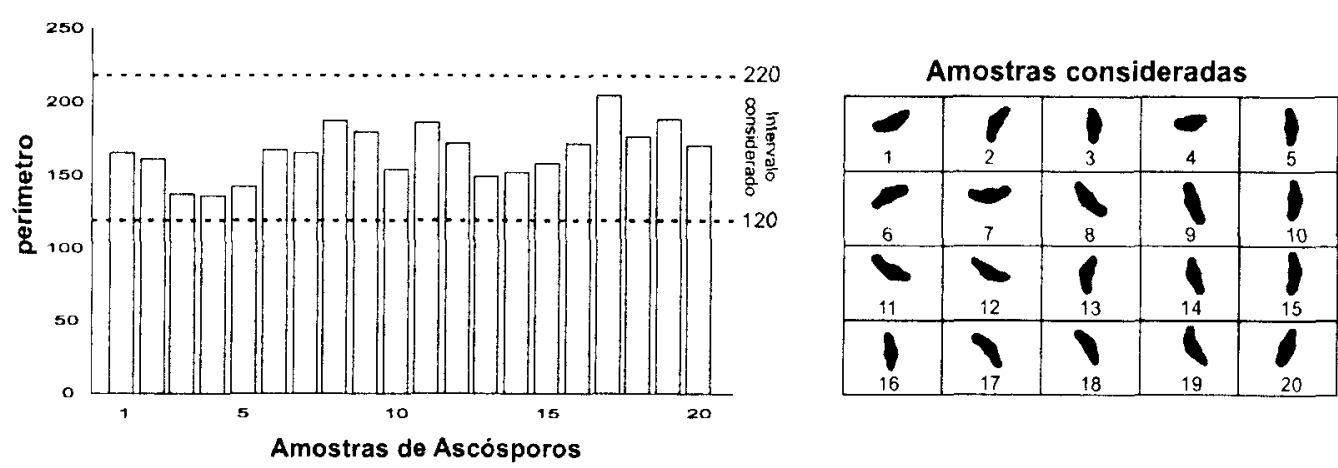

Figura 4.2: Perímetros referentes às amostras de ascósporos, com o respectivo limiar inferior e superior definido.

\subsection{Assinaturas}

Uma das maneiras mais aplicada para se representar uma forma é por meio de assinaturas unidimensionais. Na literatura há diversos métodos que têm por objetivo descrever a forma bidimensional por meio de um ou mais sinais unidimensionais. Uma das maiores vantagens de se trabalhar com sinais unidimensionais consiste em poder aplicar técnicas baseadas em Processamento de Sinais como a Transformada de Fourier e de wavelets às assinaturas. Dentre as técnicas, quatro foram selecionadas para a comparação e avaliação do potencial de aplicação. As quatro técnicas são: contorno paramétrico (sinais paramétricos de $x(n)$ e $y(n)$ ), assinatura da forma (baseada na distância Euclidiana entre as coordenadas do contorno e o centróide), projeção horizontal da forma e curvatura.

A seguir são apresentadas as assinaturas obtidas aplicando-se cada uma dessas técnicas e as principais características extraídas de cada um dos sinais resultantes que possam auxiliar a segregação das partículas.

\subsubsection{Sinais Paramétricos de $x(n)$ e $y(n)$}

Um dos sinais mais simples a ser tratado neste projeto é o próprio contorno da forma, composto por dois sinais unidimensionais - sinal composto pelas coordenadas no eixo $x$ e no eixo $y$. Esses sinais são sensíveis à rotação e, conseqüentemente, ao ponto inicial do contorno. Dependendo do ponto inicial do contorno, o sinal extraído pode ser diferente para uma mesma forma, em razão do deslocamento do sinal. Por esse motivo, as amostras foram submetidas a um pré-processamento, como apresentado anteriormente (Seção 4.1), antes da extração do contorno para minimizar o problema. 
Para a extração do contorno foi aplicado o algoritmo seguidor do contorno (Costa e Cesar, 2000). Na Figura 4.3, são mostrados os sinais de $x(n)$ e $y(n)$, obtidos com a aplicação do algoritmo para a extração do contorno da amostra de um ascósporo.
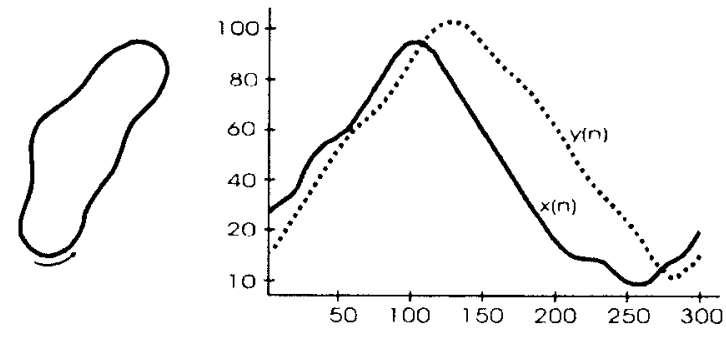

Figura 4.3: Sinais paramétricos de $x(n)$ e $y(n)$ obtidos a partir da forma de um ascósporo.

Nas Figuras 4.4, 4.5, 4.7, 4.8 são mostrados, separadamente, os sinais de $x(n)$ e $y(n)$ extraídos de 3 amostras de ascósporos e de 3 amostras de outras partículas também encontradas nos discos de coletas. As amostras usadas para a extração desses sinais são apresentadas junto ao respectivo gráfico. Nesses gráficos podem ser observados alguns problemas: (i) a diferença existente nos sinais $x(n)$ de algumas amostras de ascósporos (Figuras 4.4(a) e (b)) e (ii) a proximidade entre os sinais de amostras de classes diferentes, apresentada, principalmente, pelos sinais $y(n)$. A diferença existente no sinal de $x(n)$ entre as amostras de ascósporos ocorre por causa do efeito de espelhamento da forma, que também pode ser observado no sinal apresentado nos gráficos. Algumas formas de ascósporos se apresentam levemente curvadas, influenciando no sinal paramétrico extraído. Embora se tenha procurado reduzir os problemas quanto aos efeitos da rotação, problemas como o de espelhamento da forma persistem.

Nas Figuras 4.6 e 4.9 são mostradas as comparações entre os mesmos sinais de $x(n)$ e $y(n)$ permitindo a análise do comportamento dos sinais das diferentes amostras. Os sinais referentes às amostras de ascósporos estão destacados com uma linha mais espessa, para facilitar a identificação. Além de confirmar a proximidade entre os sinais, principalmente em relação ao sinal $y(n)$, pode-se notar que esse tipo de assinatura não permite a segregação eficiente das partículas de ascósporos, especificamente.

\subsubsection{Assinatura com base no centróide}

Essa assinatura é extraída com base na distância Euclidiana entre as coordenadas do contorno da forma e o centro de massa (centróide), de acordo com a abordagem apresentada por Costa e Cesar (2000). Um exemplo da assinatura extraída com a aplicação desse método sobre uma amostra de ascósporo é mostrado na Figura 4.10.

Nas Figuras 4.11 e 4.12 são mostradas as assinaturas baseadas na distância do centróide extraídas de amostras de ascósporos e de outras partículas, respectivamente. É possível notar que não houveram problemas quanto a definição do ponto inicial do contorno para a extração da assinatura, o que demonstra que a solução adotada para minimizar os efeitos da rotação sobre as amostras foi satisfatória, para esse caso. Entretanto, é possível notar a similaridade entre todas as assinaturas. Para confirmar tal similaridade, uma comparação entre as assinaturas das 


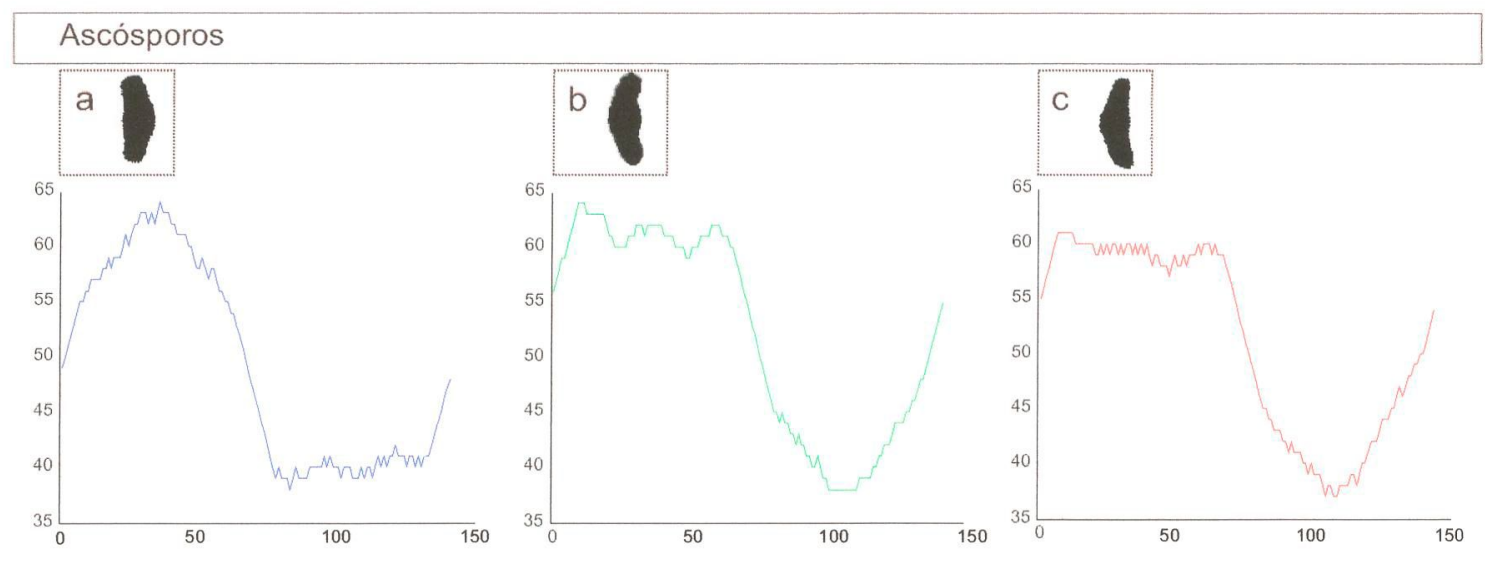

Figura 4.4: Sinal paramétrico de $x(n)$ extraído de amostras de ascósporos.

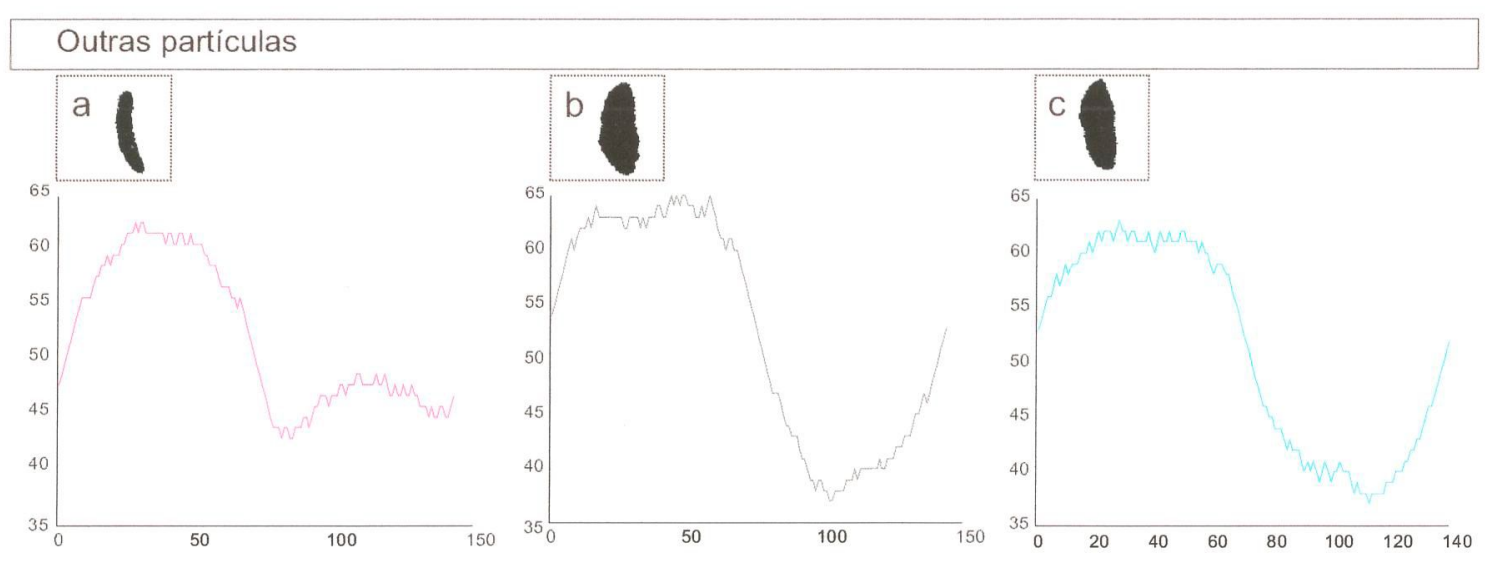

Figura 4.5: Sinal paramétrico de $x(n)$ extraído de amostras de outras partículas também encontradas nos discos de coletas.

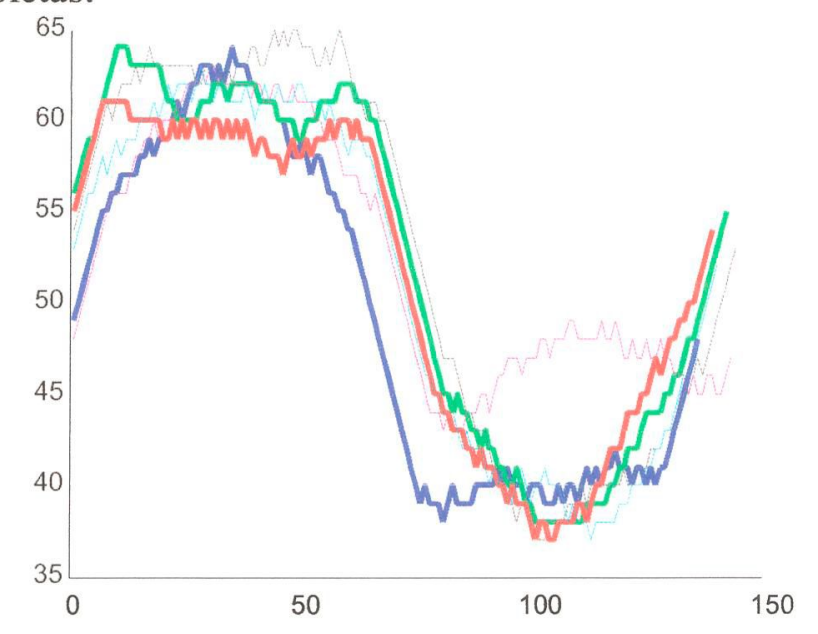

Figura 4.6: Comparação entre os sinais paramétricos de $x(n)$ extraídos das amostras apresentadas nas Figuras 4.4 e 4.5. Em destaque apenas os sinais referentes às amostras de ascósporos. 


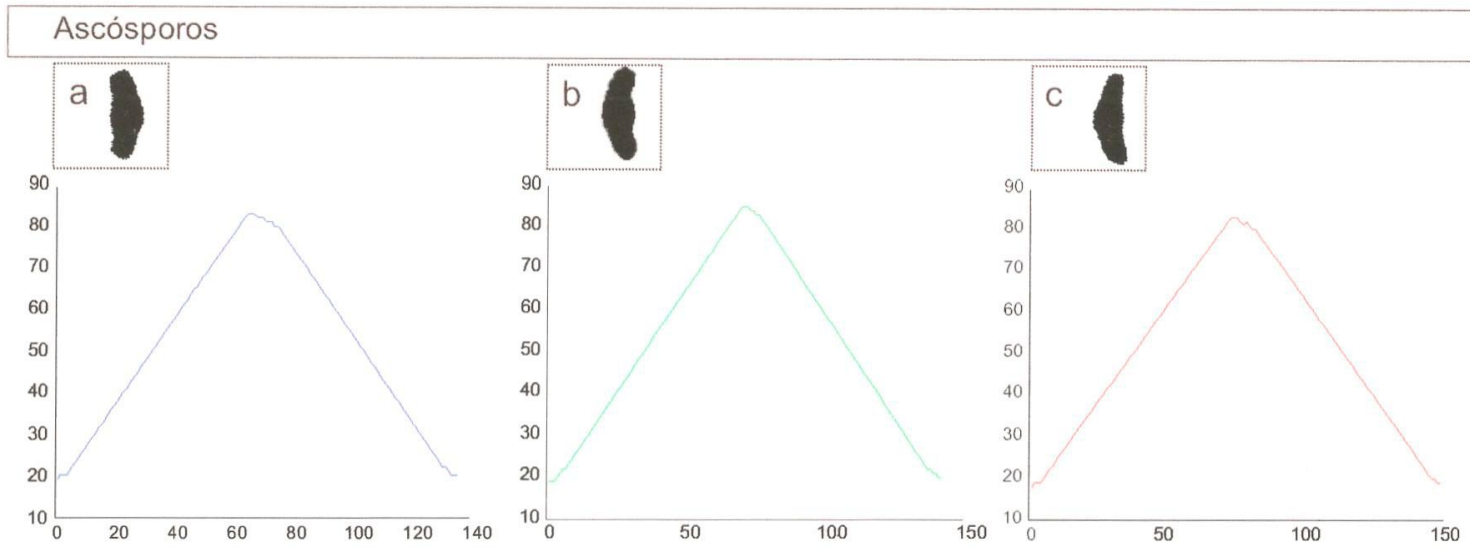

Figura 4.7: Sinal paramétrico de $y(n)$ extraído de amostras de ascósporos.

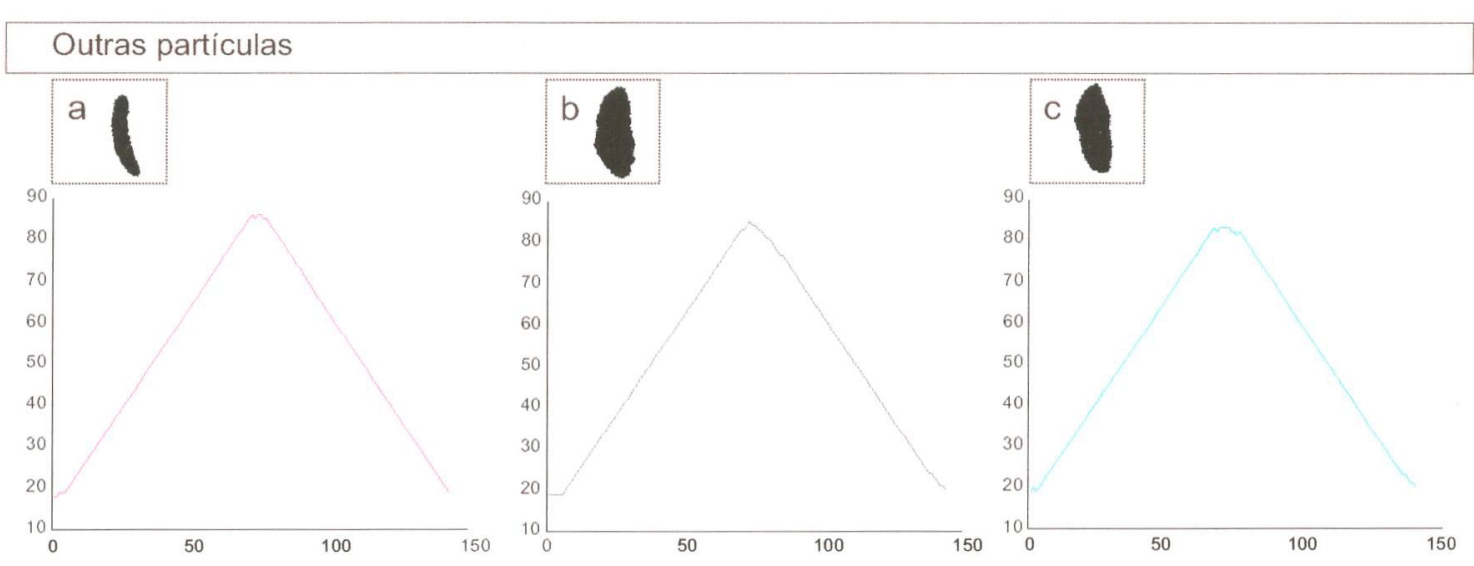

Figura 4.8: Sinal paramétrico de $y(n)$ extraído de amostras de outras partículas também encontradas nos discos de coletas.

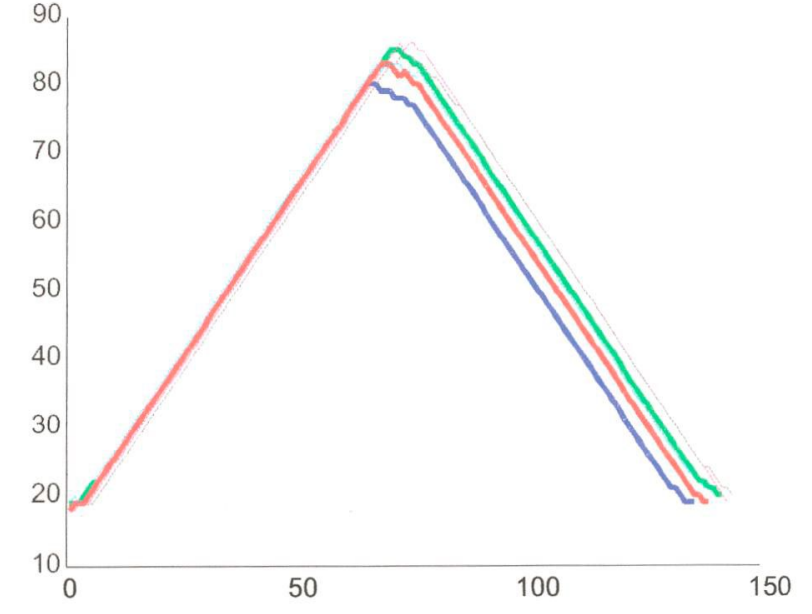

Figura 4.9: Comparação entre os sinais paramétricos de $y(n)$ extraídos das amostras apresentadas nas Figuras 4.7 e 4.8. Em destaque os sinais referentes às amostras de ascósporos. 


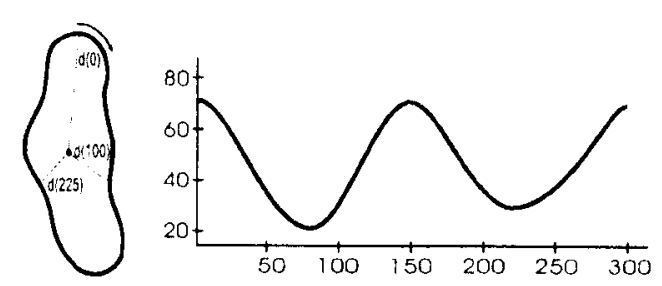

Figura 4.10: Assinatura da forma de um ascósporo com base na distância entre o centróide e os pontos do contorno.

diferentes amostras é apresentada na Figura 4.13, na qual as assinaturas referentes às amostras de ascósporos estão destacadas com uma linha mais espessa para facilitar a identificação. É possível notar que é difícil se obter um resultado satisfatório com esse tipo de assinatura para a identificação dos ascósporos: os detalhes apresentados pela forma são bastante sutis e não foram evidenciados.

\subsubsection{Assinatura por Projeção}

A assinatura por projeção foi extraída das amostras a partir da contagem dos pontos que compõem a forma existentes em cada linha da imagem. Com isso, um sinal unidimensional é gerado, podendo ser usado para a caracterização das amostras. Para a aplicação dessa técnica, ao invés do contorno, utiliza-se a imagem representada pela região. Alternativas para extrair esse sinal a partir do contorno também são possíveis de serem implementadas, porém mais complexas. Na Figura 4.14, um exemplo da obtenção da projeção horizontal da forma de um ascósporo é mostrado. Na maioria das vezes o sinal obtido apresenta ruídos por se tratar da contagem dos pontos que compõe a forma em cada linha da imagem. Entretanto, esse problema é contornado com a aplicação de um filtro Gaussiano. Uma característica interessante observada no sinal obtido com a projeção horizontal foi o destaque dado à dilatação central existente nos ascósporos do fungo Guignardia citricarpa.

Nas Figuras 4.15 e 4.16 são mostradas as projeções obtidas de amostras de ascósporos e de outras partículas. É possível observar que nas projeções extraídas de 3 amostras de ascósporos há um pico central representando a dilatação, o que não aparece na projeção das outras amostras. No entanto, podem ocorrer projeções de outras amostras que não são de ascósporos com sinais parecidos, o que pode atrapalhar o processo de identificação.

Na Figura 4.17, os sinais são mostrados sobrepostos para permitir a comparação das diferentes amostras. Nessa figura é possível observar a diferenciação entre as projeções das amostras de ascósporos e das demais partículas. No entanto, essa diferença não é muito grande, dada a existência de amostras com formato próximo ao de um ascósporo. Problemas também ocorrem em razão de algumas amostras serem curvadas, ocasionando o deslocamento do pico referente à dilatação central para uma das extremidades do sinal, tornando-os similares aos sinais apresentados nas Figuras 4.16(b) e (c). Dessa maneira, dificulta-se a comparação e, conseqüentemente, a classificação correta dos ascósporos. Outras projeções também foram extraídas dessas amos- 


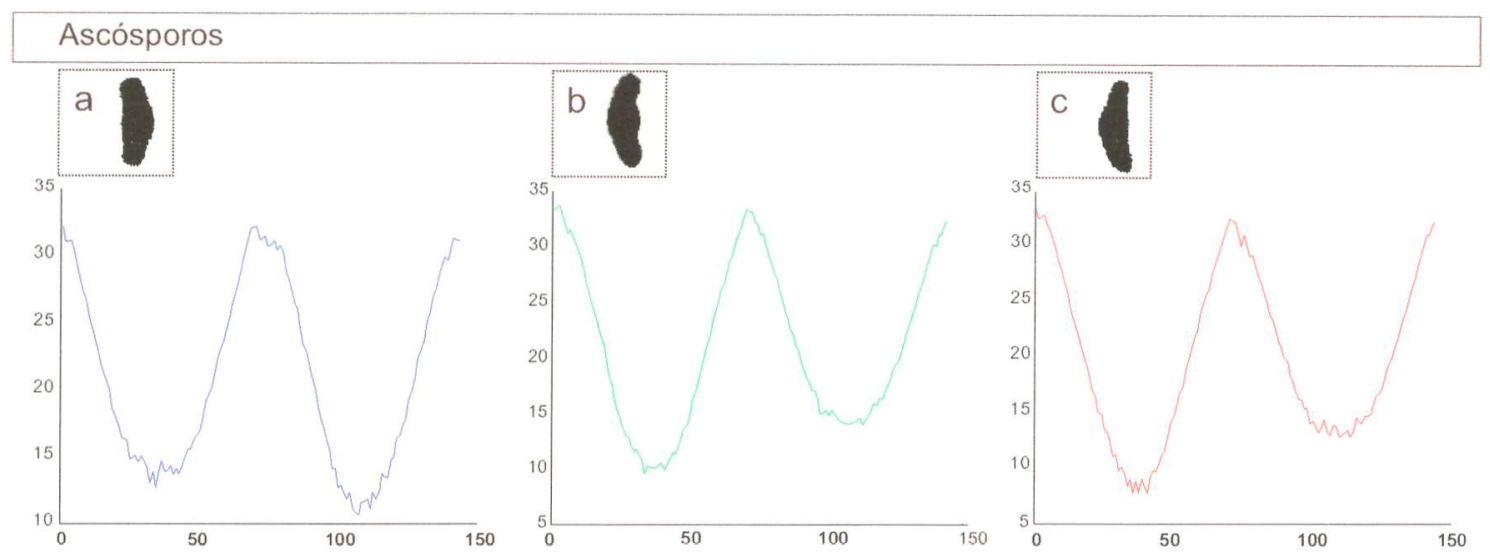

Figura 4.11: Assinaturas distância do centróide extraídas de amostras de ascósporos.
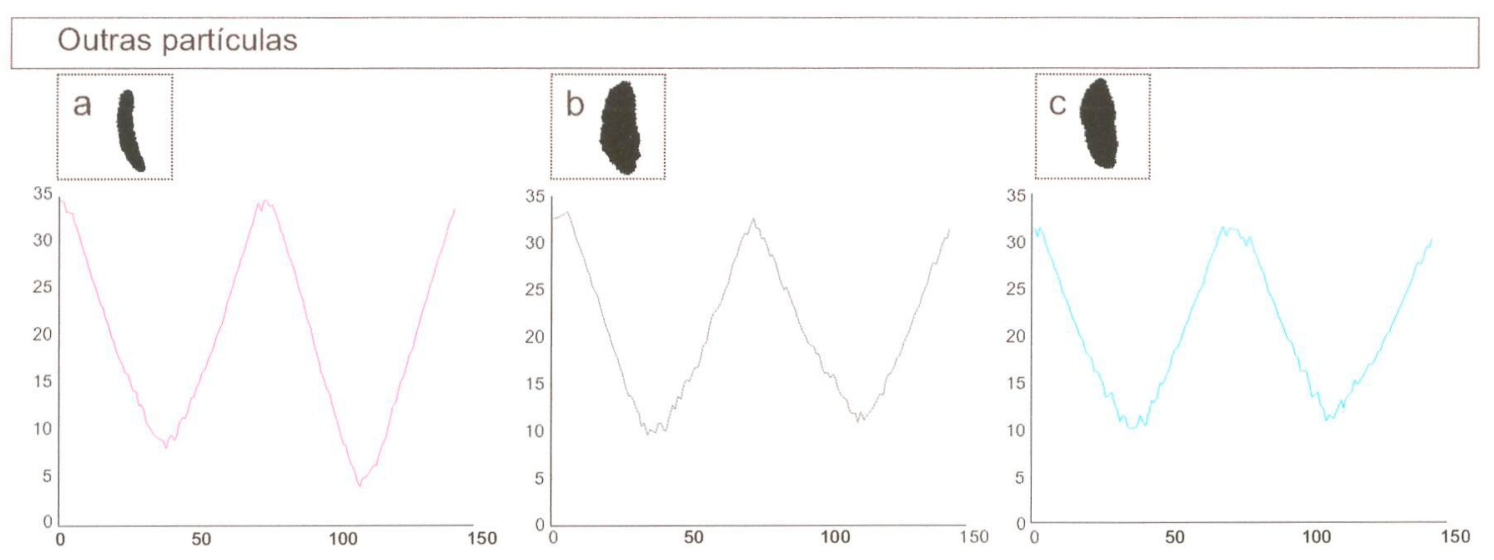

Figura 4.12: Assinaturas distância do centróide extraídas de amostras de outras partículas também encontradas nos discos de coletas.

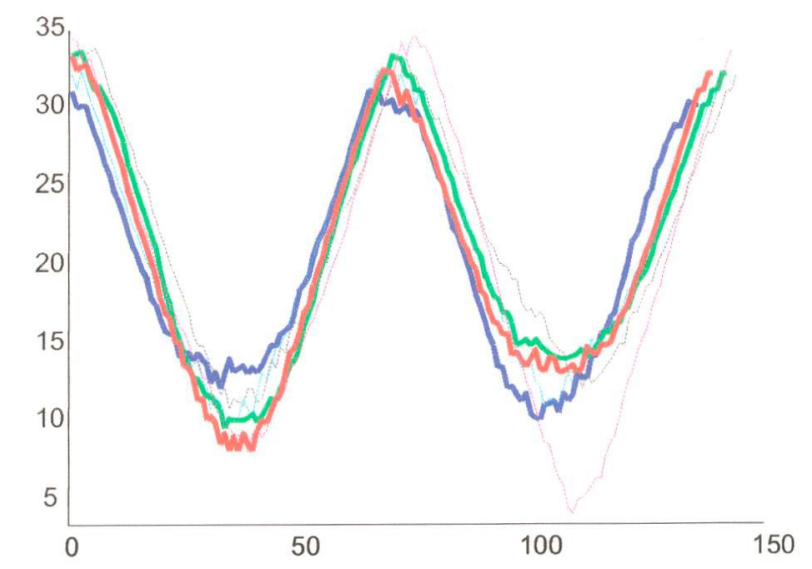

Figura 4.13: Comparação entre as assinaturas distância do centróide extraídas das amostras apresentadas nas Figuras 4.11 e 4.12. Em destaque as assinaturas referentes às amostras de ascósporos. 


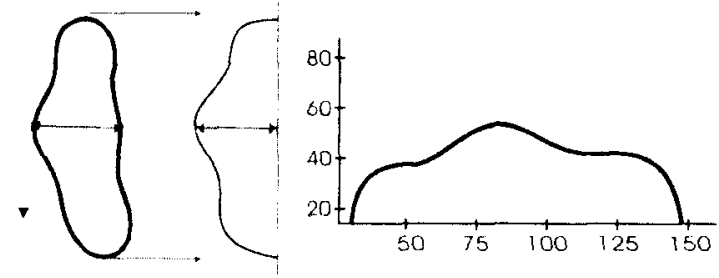

Figura 4.14: Projeção horizontal da forma de um ascósporo.

tras, como a vertical, mas nenhuma característica significante pôde ser observada

\subsubsection{Curvatura}

A curvatura das amostras é extraída com base na derivação dos sinais paramétricos do contorno. Há várias maneiras de se estimar a derivada dos sinais que compõem o contorno da forma: $x(n)$ e $y(n)$. Uma dessas maneiras é baseada na propriedade derivativa da Transformada de Fourier (Brigham, 1988), aplicada nesse experimento. A obtenção da curvatura é suscetível à influência de ruídos contidos no sinal original, os quais tendem a aumentar em razão do seu cálculo ser baseado na diferenciação numérica (Cesar e Costa, 1996a). Para contornar esse problema, um filtro Gaussiano é incorporado à curvatura, conforme mostrado na Equação 4.2 (Mokhtarian e Mackworth, 1992), sendo $K(f)$ e $G(f, \sigma)$ o sinal da curvatura e a Gaussiana no domínio da freqüência, respectivamente. O parâmetro $\sigma$ é responsável pelo desvio padrão do filtro Gaussiano aplicado para a suavização da curvatura. O sinal referente à curvatura de um ascósporo, considerando a extração do contorno no sentido anti-horário, é mostrado na Figura 4.18

$$
k(n, \sigma)=\Im^{-1}\{K(f) \cdot G(f, \sigma)\}
$$

Nas Figuras 4.19 e 4.20 são mostradas as curvaturas extraídas das amostras obtidas dos discos de coleta. Pode-se observar que há uma distinção clara entre as amostras de ascósporos das demais amostras. A curvatura referente às amostras de ascósporos apresentam uma importante característica: é possível notar no sinal a presença de dois picos maiores intercalados por dois picos menores. Os picos maiores representam as extremidades da forma do ascósporo. Já os picos menores representam a dilatação central, que é característico nos ascósporos. Embora em alguns casos essa dilatação se apresente de maneira sutil, a técnica baseada na curvatura da forma foi capaz de evidenciá-la na maioria das vezes. O parâmetro $\sigma$ foi definido empiricamente, com base nos testes realizados sobre o conjunto de amostras, sendo o valor escolhido de acordo com o seguinte critério: eliminar os ruídos do sinal (curvatura), preservando as características principais (no caso, os quatro picos). Com esse critério, o parâmetro selecionado foi $\sigma=0.22$, obtendo um resultado satisfatório quando aplicado ao conjunto de amostras.

Na Figura 4.21 é mostrada a comparação entre as curvaturas extraídas das diferentes amostras, com os sinais referentes às amostras de ascósporos destacados. É possível diferenciar visualmente os sinais referentes às amostras dos ascósporos, dada a característica principal 


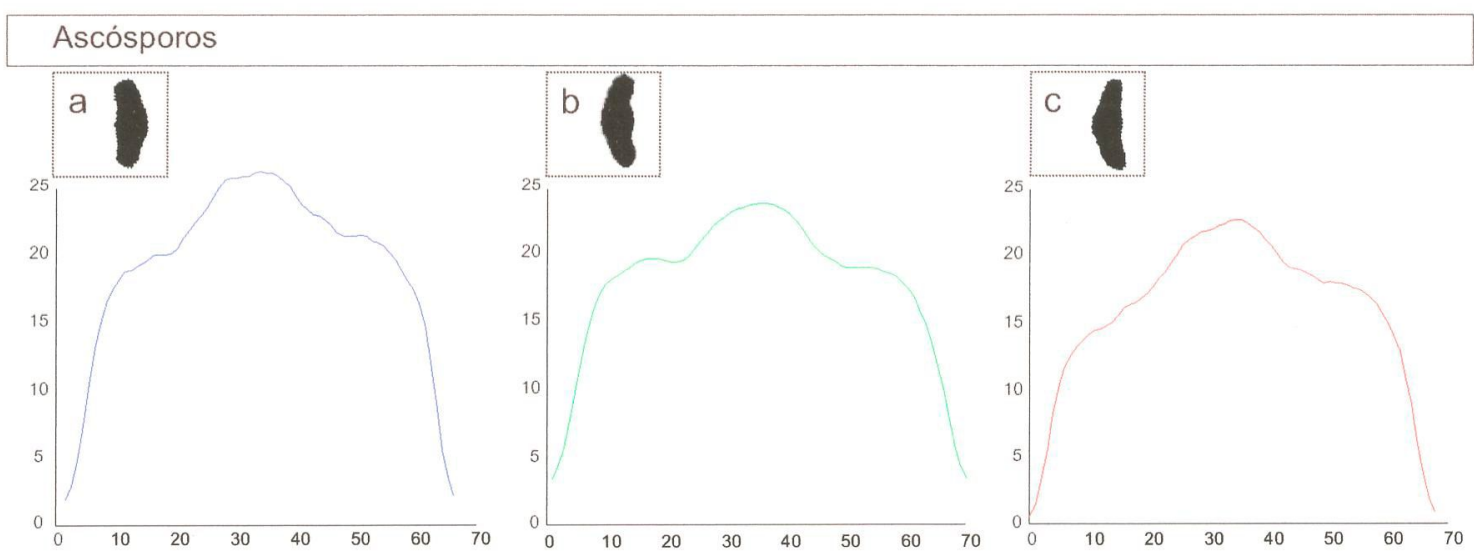

Figura 4.15: Projeções horizontais extraídas de amostras de ascósporos.

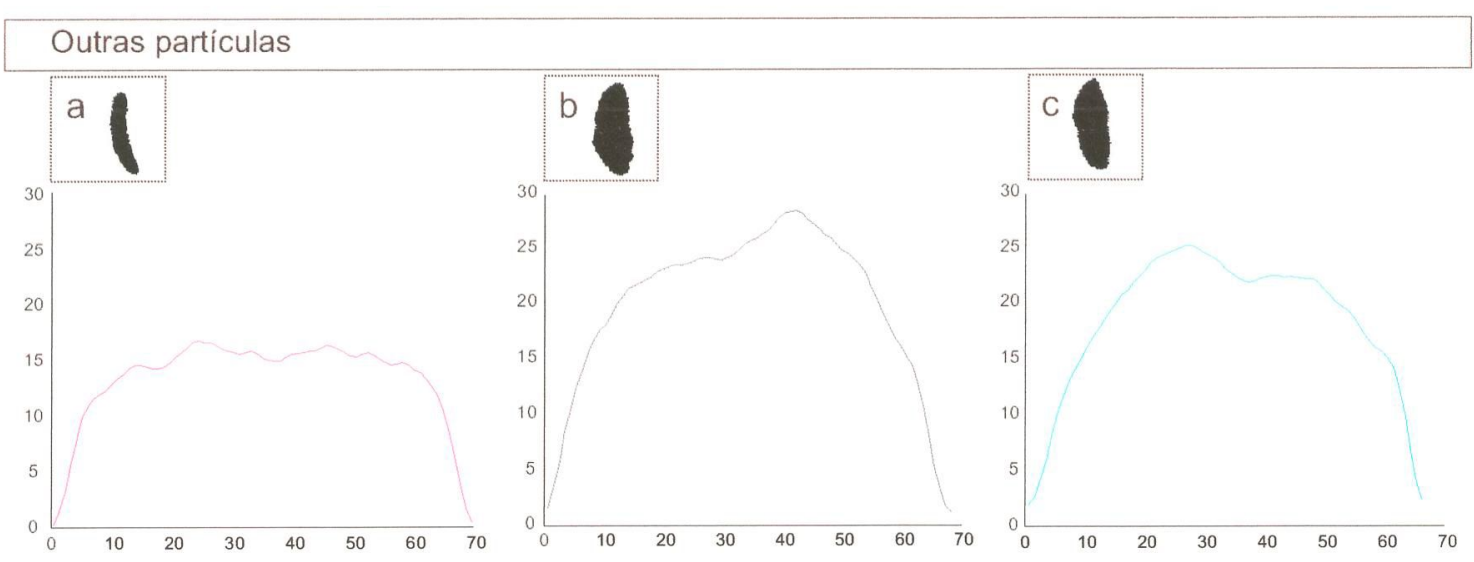

Figura 4.16: Projeções horizontais extraídas de amostras de outras partículas também encontradas nos discos de coletas.

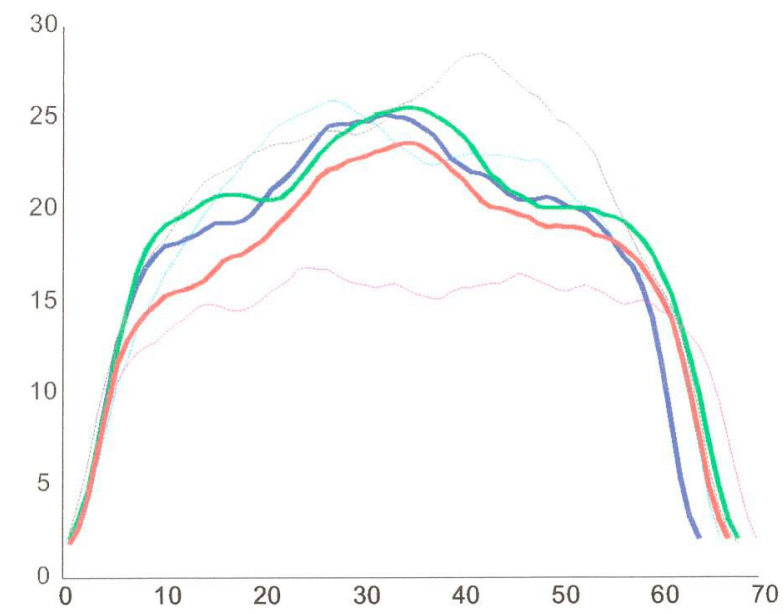

Figura 4.17: Comparação entre as projeções horizontais extraídas das amostras apresentadas nas Figuras 4.15 e 4.16. Em destaque os sinais referentes às amostras de ascósporos. 

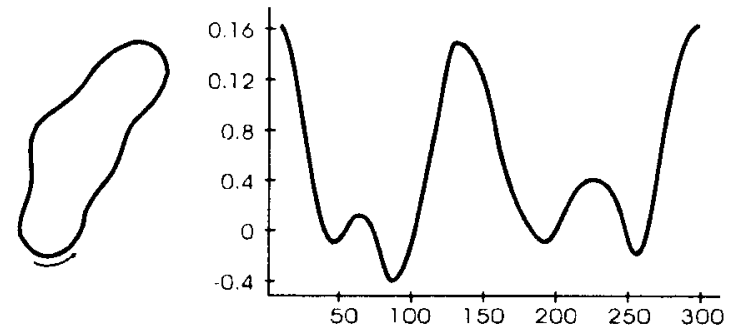

Figura 4.18: Curvatura da forma de um ascósporo.

apresentada pela curvatura: a quantidade e a disposição dos picos no sinal. O resultado obtido com a extração da curvatura do contorno da forma foi melhor em relação às outras assinaturas, pelo menos nessa etapa de comparação. Inicialmente, a informação extraída pela curvatura é mais discriminante do que as informações obtidas com as demais técnicas apresentadas.

\subsection{Momentos do Contorno}

Dentre as técnicas baseadas em momentos, foi escolhida a técnica proposta por Gupta e Srinath (1987), a qual se aplica sobre o contorno da forma. Para cada amostra é extraída a assinatura da forma, conforme a abordagem adotada pelos autores, e calcula-se os quatro momentos $F 1$, $F 2, F 3$ e $F 4$. Na Figura 4.22, em que são mostrados os descritores obtidos, é possível observar que há bastante similaridade entre os mesmos e, conseqüentemente, não é possível identificar as amostras de ascósporos. É importante ressaltar que, para as amostras encontradas nos discos, o sinal usado para o cálculo dos momentos é a assinatura da forma, calculada de acordo com a distância Euclidiana entre o centróide e os pontos do contorno, conforme apresentada anteriormente (Seção 4.3.2).

Para avaliar o resultado obtido com o uso dos momentos do contorno, foi realizada uma classificação baseada na distância mínima entre os vetores de características e o vetor médio referente à classe dos ascósporos. Cada um dos vetores é formado pelos quatro momentos do contorno. Foram usadas 60 amostras para esse teste, sendo 20 de ascósporos e 40 amostras de outras partículas também encontradas nos discos de coleta

No gráfico da Figura 4.23 é mostrado o resultado obtido, sendo possível observar que não houve uma distinção clara entre a classe de ascósporos em relação às demais amostras. Dessa maneira, foi definido um limiar $T$ para quantificar o resultado obtido. Foram considerados pertencentes à classe de ascósporos as amostras cuja distância fosse inferior ao limiar determinado. Considerando o limiar $T=0.2$, representado no gráfico pela linha pontilhada, um conjunto considerável de amostras foram identificadas incorretamente como ascósporos (17 falsos-positivos). Com esse mesmo limiar, também houve uma quantidade significativa de amostras de ascósporos que não foram identificadas ( 7 falsos-negativos), sendo um total de 24 erros em 60 amostras analisadas (aproximadamente 60\% de acerto), um resultado pouco satisfatório.

Por essa técnica usar como base um sinal unidimensional (assinatura da forma), e por observar que tal assinatura não possibilitou uma diferenciação satisfatória para o caso dos ascósporos, 


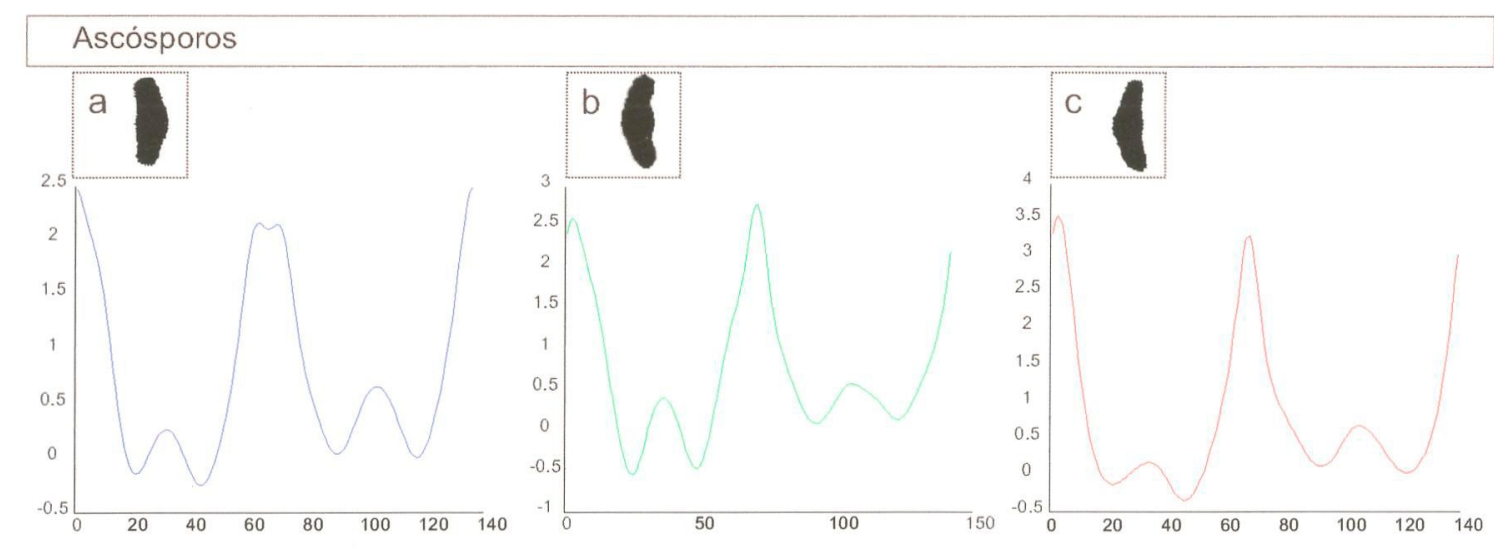

Figura 4.19: Curvaturas extraídas de amostras de ascósporos.

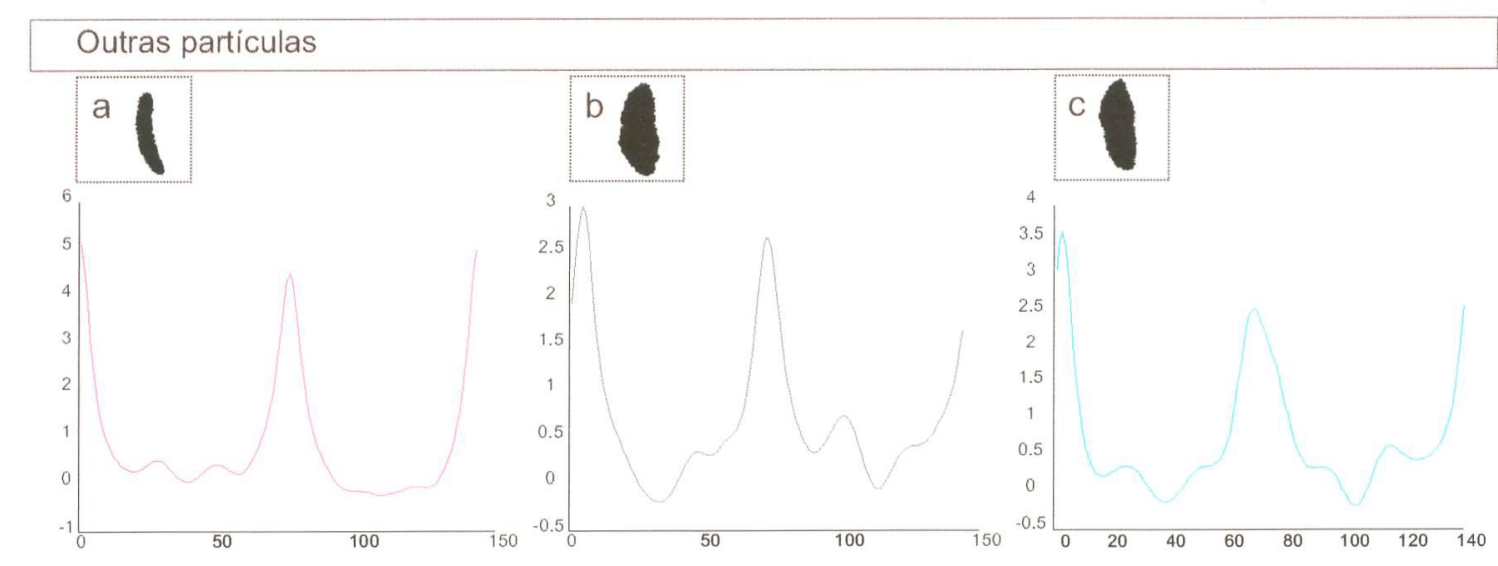

Figura 4.20: Curvaturas extraídas de amostras de outras partículas também encontradas nos discos de coletas.

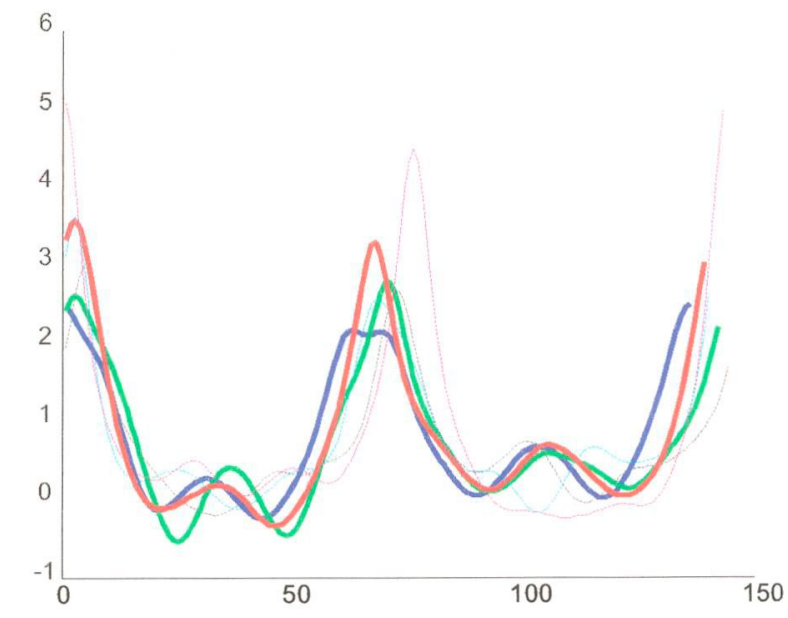

Figura 4.21: Comparação entre as curvaturas extraídas das amostras apresentadas nas Figuras 4.19 e 4.20. Em destaque os sinais referentes às amostras de ascósporos. 


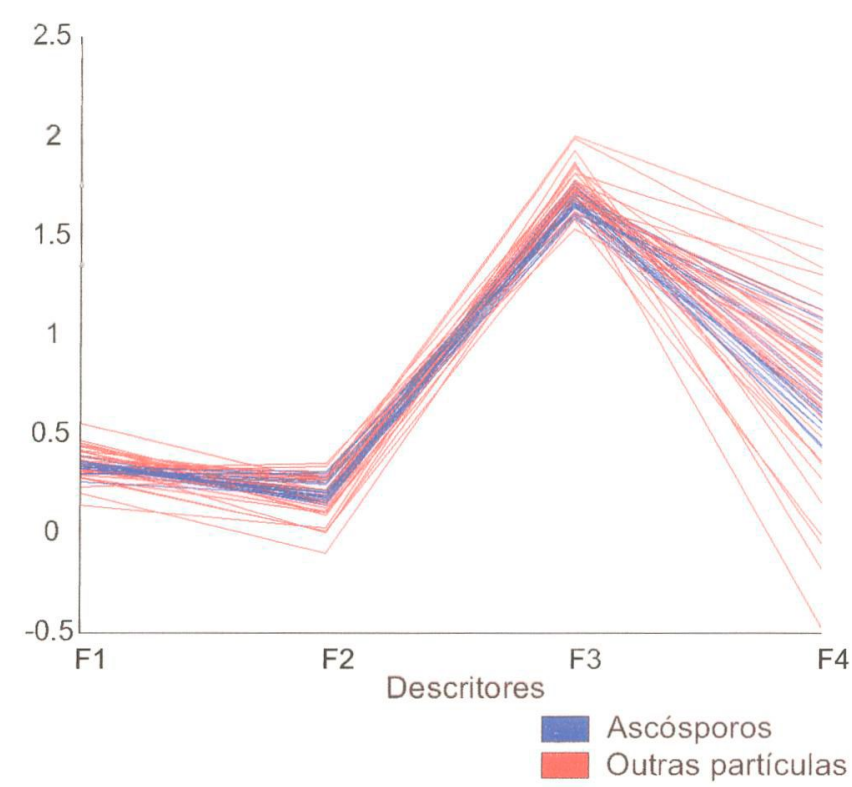

Figura 4.22: Descritores obtidos a partir dos momentos do contorno.
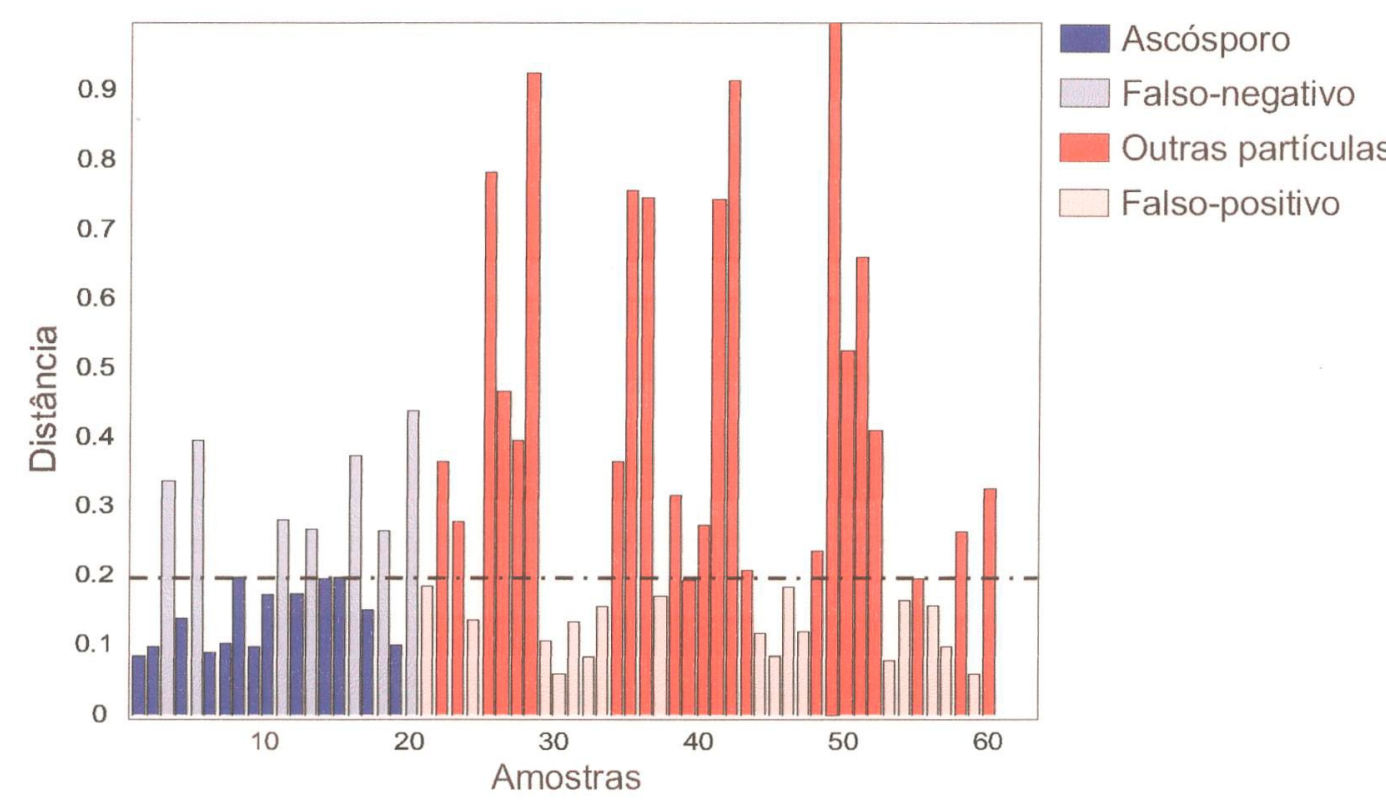

Figura 4.23: Distância calculada entre os vetores de características baseados nos momentos do contorno e o vetor médio referente à classe de ascósporos.

o experimento com momentos foi repetido usando, ao invés da assinatura, a curvatura da forma, uma vez que foi possível observar uma melhor caracterização das amostras por meio desse sinal (Seção 4.3). Entretanto, o resultado obtido com esse experimento não apresentou uma melhora significativa no resultado, como pode ser observado nos descritores apresentados no gráfico da Figura 4.24. Repetindo o processo de classificação baseada na distância mínima, efetuado anteriormente com base na distância Euclidiana entre os vetores de características, obtidos com o mesmo conjunto de amostras, e o vetor médio. Na Figura 4.25 é mostrado o gráfico contendo as distâncias calculadas para cada uma das amostras. Considerando o limiar $T=5$, a quantidade de amostras identificada incorretamente como ascósporos diminuiu em relação ao teste com momentos usando a assinatura ( 15 falsos-positivos). Além disso, a quantidade de amostras de 
ascósporos que não foi identificada também diminuiu (1 falso-negativo), um total de 16 erros em 60 amostras analisadas (aproximadamente $73 \%$ de acerto): resultado insuficiente, porém melhor do que o obtido aplicando momentos com base na assinatura da forma. Um grande problema encontrado nesse experimento foi definir um limiar que proporcionasse o melhor resultado. Para o teste com momentos, o limiar foi definido empiricamente, sendo escolhido o que permitisse uma melhor classificação das amostras (limiar ótimo). No entanto, não há como garantir que esse mesmo limiar sirva para um conjunto diferente de amostras e, tampouco, garantir a obtenção de um resultado melhor ou pior aplicando momentos em outros conjuntos de amostras.

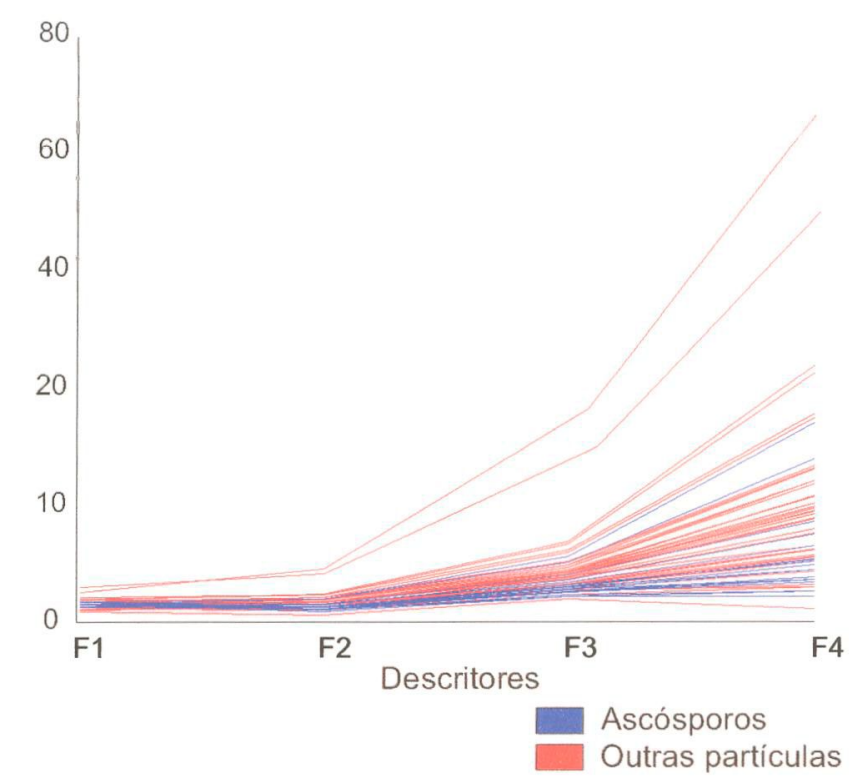

Figura 4.24: Descritores obtidos a partir dos momentos do contorno aplicado sobre a curvatura.

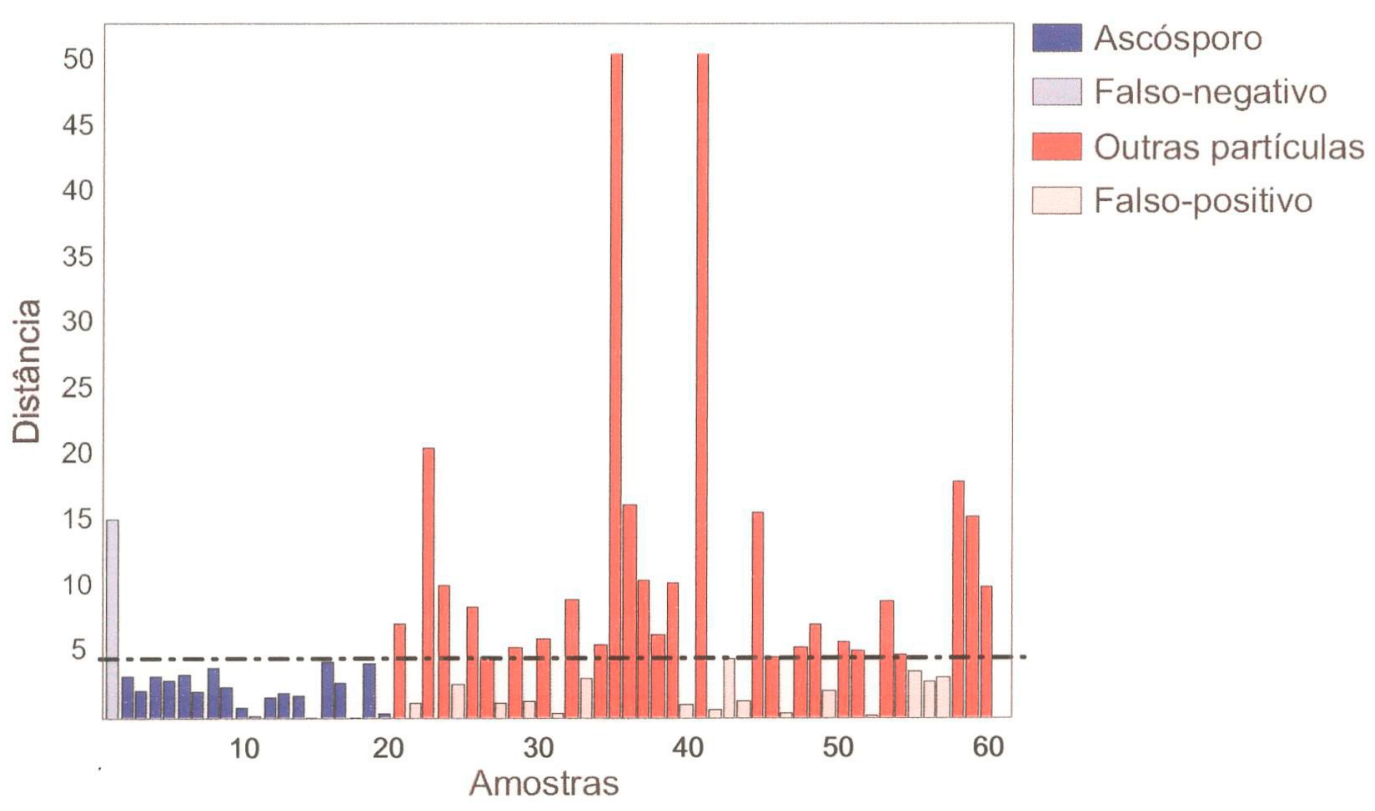

Figura 4.25: Distância calculada entre os vetores de características baseados nos momentos do contorno usando a curvatura e o vetor médio referente à classe de ascósporos. 
Também foram testados os momentos invariantes de $\mathrm{Hu}$ (1962), os quais não apresentaram resultados satisfatórios. As amostras para serem submetidas a essa técnica necessitam ser representadas por região, exigindo maior espaço para armazenamento e a normalização da região das amostras. Por essa razão, trabalhou-se apenas com o contorno da forma, que é mais fácil de manipular e armazenar.

\subsection{Análise do Espectro de Fourier}

A análise do espectro de Fourier é bastante explorada em problemas de visão computacional para a extração de características. Nesse sentido, os descritores de Fourier são um dos mais populares e consistem na seleção de coeficientes $U(f)$ obtidos com a Transformada de Fourier aplicada a um sinal unidimensional ou bidimensional. Para a definição dos descritores é considerada apenas a magnitude dos coeficientes, $\|U(f)\|$. Com isso, problemas quanto ao deslocamento do sinal no domínio do espaço são contornados, pois a fase do sinal é desconsiderada. Essa é uma importante vantagem explorada com o uso dos descritores. Também é usada como característica a densidade espectral, ou espectro da potência, pois ela permite evidenciar as diferenças existentes no espectro de Fourier, auxiliando na distinção entre os sinais. Além disso, esses descritores são considerados robustos à presença de ruídos e permitem representar uma determinada forma com um número reduzido de coeficientes.

Tais características são fundamentais na decisão quanto à aplicação dos descritores de Fourier, para se extrair, a partir do conjunto de assinaturas, os descritores que compõem os vetores de características que represente as amostras. A comparação direta entre as assinaturas seria inviável, pois os sinais apresentam ruídos, e mesmo com a normalização quanto à rotação, persistem problemas referentes ao deslocamento ou à inversão do sinal. Além disso, a maioria dos sinais obtidos por meio do contorno apresentam tamanhos diferentes, problemas esses que podem ser contornados com a aplicação dos descritores de Fourier. Para cada sinal, é preciso selecionar um conjunto com a mesma quantidade de descritores. Por exemplo, todos os sinais, mesmo com tamanhos diferentes, devem ser representados por meio de um vetor de características com aproximadamente 60 coeficientes, facilitando, dessa maneira, a comparação entre as assinaturas de diferentes amostras.

A seguir são apresentados os experimentos realizados e os resultados obtidos com o uso dos descritores de Fourier e da análise do espectro da potência, aplicados aos sinais unidimensionais extraídos com as técnicas apresentadas na Seção 4.3: sinais paramétricos de $x(n)$ e $y(n)$, assinatura com base na distância ao centróide, projeção horizontal e curvatura.

\subsubsection{Experimentos aplicando a Análise do Espectro da Potência}

Considerando os quatro tipos de sinais extraídos das amostras obtidas dos discos de coleta, experimentos foram realizados a fim de selecionar qual dentre os sinais apresenta maior potencial discriminante, permitindo, dessa maneira, a segregação das amostras. Foram consideradas 60 amostras dentre as quais 20 são de ascósporos e o restante de outras partículas, algumas semelhantes aos ascósporos, que também são encontradas nos discos de coleta. As amostras são representadas por vetores de características compostos por descritores de Fourier selecionados 
a partir da análise do espectro da potência. Os descritores são selecionados entre os coeficientes de baixa freqüência, considerando a densidade espectral desses coeficientes, ou seja, $\|U(f)\|^{2}$. Outro aspecto importante a ser considerado é que os descritores foram normalizados a fim de contornar alguns problemas resultantes da variância quanto à rotação, principalmente o deslocamento do sinal.

Para compor os vetores de características a serem usados em cada um dos experimentos foram selecionados 60 descritores. Essa quantidade de descritores foi definida com base na análise prévia das informações significantes contidas no espectro de Fourier. Dessa maneira, foram escolhidos os 30 primeiros e os 30 últimos coeficientes do espectro, pois os coeficientes de baixa freqüência ficam localizados na extremidade do espectro.

O processo de identificação dos ascósporos, aplicado nesses experimentos para análise da capacidade discriminate dos sinais empregados, consiste em um classificador estatístico baseado na distância mínima. Optou-se por essa abordagem por ela ser de fácil implementação. Nesse momento, não foi utilizada uma abordagem mais robusta, como por exemplo redes neurais artificiais, porque o objetivo principal dessa etapa foi selecionar a técnica que sinalizasse o melhor resultado na identificação das partículas. O aperfeiçoamento do processo de identificação, utilizando redes neurais artificiais, foi efetuado após a escolha da técnica para caracterização dos ascósporos.

Continuando a descrição dos experimentos com base na classificação pela distância mínima, definiu-se previamente, em cada um deles, um vetor médio $\mathbf{m}$ que representa a classe dos ascósporos. Para cada amostra submetida à análise é calculada a distância Euclidiana entre vetor de característica $x_{i}$, que representa a amostra, e o vetor médio $\mathbf{m}$, ou seja, $d\left(x_{i}\right)=\left|\mathbf{m}-x_{i}\right|$ sendo $|a|=\sqrt{a^{T} \cdot a}$.

A diversidade de partículas coletadas nos discos é grande, tornado inviável a definição de uma classe para cada tipo encontrado. Por essa razão, apenas duas classes foram definidas: Ascósporos e Outras particulas. O critério de decisão adotado para esses experimentos consiste na definição de uma distância mínima - um limiar $T$ - que determina se uma amostra pertence ou não a classe de ascósporos. Esse limiar foi definido empiricamente para cada um dos experimentos, com base no comportamento obtido durante a realização dos testes. Não foi definido um vetor médio para a classe Outras partículas, porque o resultado não condiz com a realidade, uma vez que a diferença entre os sinais obtidos das amostras dessa classe é muito grande, não havendo como explorar um fator de similaridade que permita o agrupamento das amostras com base na distância mínima entre os vetores. Dessa maneira, todas as amostras com $d\left(x_{i}\right)<T$ pertencem à classe Ascósporos, caso contrário, são consideradas amostras da classe Outras partículas. Os resultados obtidos com os experimentos realizados com cada uma das assinaturas são apresentados a seguir.

\subsubsection{Experimento I - Sinais Paramétricos de $x(n)$ e $y(n)$}

O contorno da forma é constituído pelos dois sinais $x(n)$ e $y(n)$. Para possibilitar a aplicação da Transformada de Fourier ao contorno da forma, o mesmo foi definido em um sinal complexo unidimensional $u(n)=x(n)+j \cdot y(n)$, sendo $j=\sqrt{-1}$. 
Para cada um dos contornos foram extraídos 60 descritores para a composição do vetor de características. Na Figura 4.26 é mostrado o gráfico contendo os descritores extraídos do contorno de 3 amostras de ascósporos comparado com os descritores de 3 amostras de outras partículas, amostras essas apresentadas à direita do gráfico. Observa-se que os descritores dessas amostras apresentam bastante similaridade, não sendo possível identificá-los visualmente. Analisando a forma de algumas dessas amostras é possível observar a proximidade entre elas, havendo alguns pequenos detalhes capazes de diferenciá-las, como a espessura.

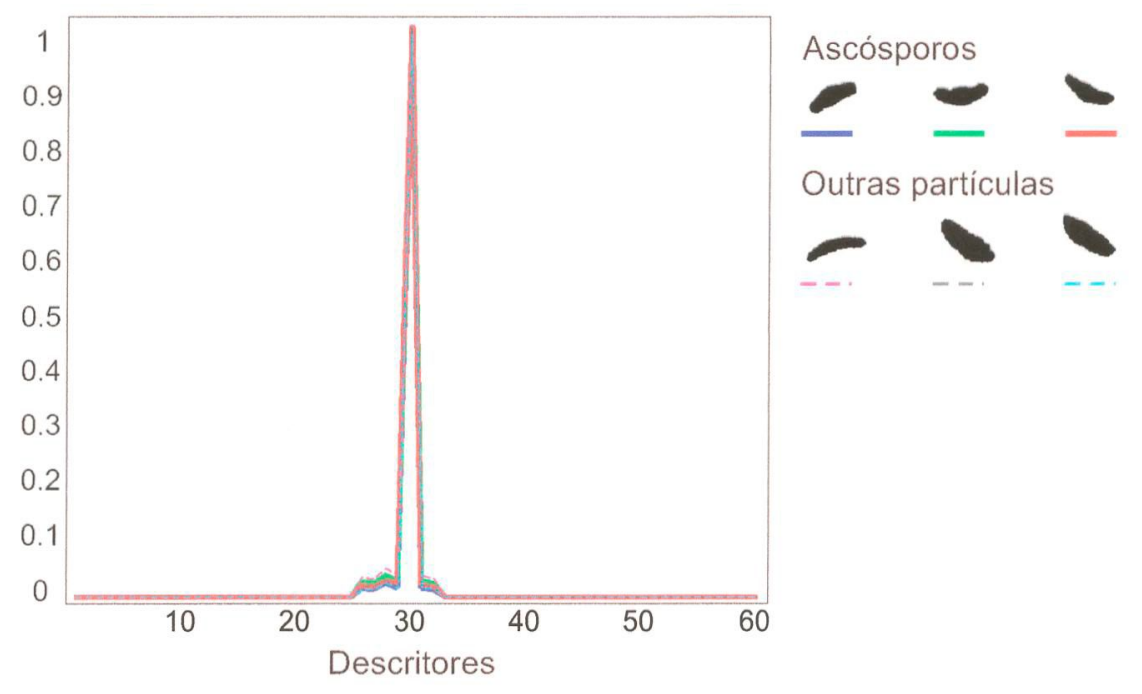

Figura 4.26: Descritores de Fourier obtidos a partir do contorno da forma das amostras apresentadas à direita.

Aplicando o processo de identificação com base no classificador por distância mínima, o resultado obtido, considerando o limiar $T=0.003$, foi de 3 falsos-positivos e de 11 falsos-negativos, completando um total de 14 erros em 60 amostras analisadas (aproximadamente $76 \%$ de acerto). As distâncias calculadas para cada uma das amostras em relação ao vetor médio $\mathbf{m}_{\text {contorno }}$ são mostradas no gráfico da Figura 4.27. Observa-se que não há um grupo definido de amostras que possam ser facilmente identificadas como ascósporos, sendo visível uma grande variação entre as distâncias, mesmo entre amostras de ascósporos. Conseqüentemente, não foi possível a obtenção de um resultado satisfatório, como já observado na comparação dos sinais paramétricos $x(n)$ e $y(n)$ mostrada na Seção 4.3.1.

\subsubsection{Experimento II - Assinatura baseada na distância do centróide}

A assinatura foi extraída considerando a distância entre o centróide da amostra e as coordenadas que compõem o contorno. O sinal extraído foi submetido à análise do espectro da potência para a obtenção dos descritores. Nesse experimento foi considerada a mesma quantidade de descritores na composição do vetor de característica para cada uma das amostras (60 descritores).

Na Figura 4.28 é mostrado o gráfico com os descritores obtidos a partir da assinatura da forma de 3 amostras de ascósporos e de 3 amostras de outras partículas, que são mostradas à direita do gráfico. Observa-se uma similaridade muito grande entre eles, não sendo possível distingui-los visualmente. Apesar da proximidade na forma das amostras, diferenças entre elas são percebidas, por exemplo, a presença ou não da dilatação central e a espessura. No entanto, 


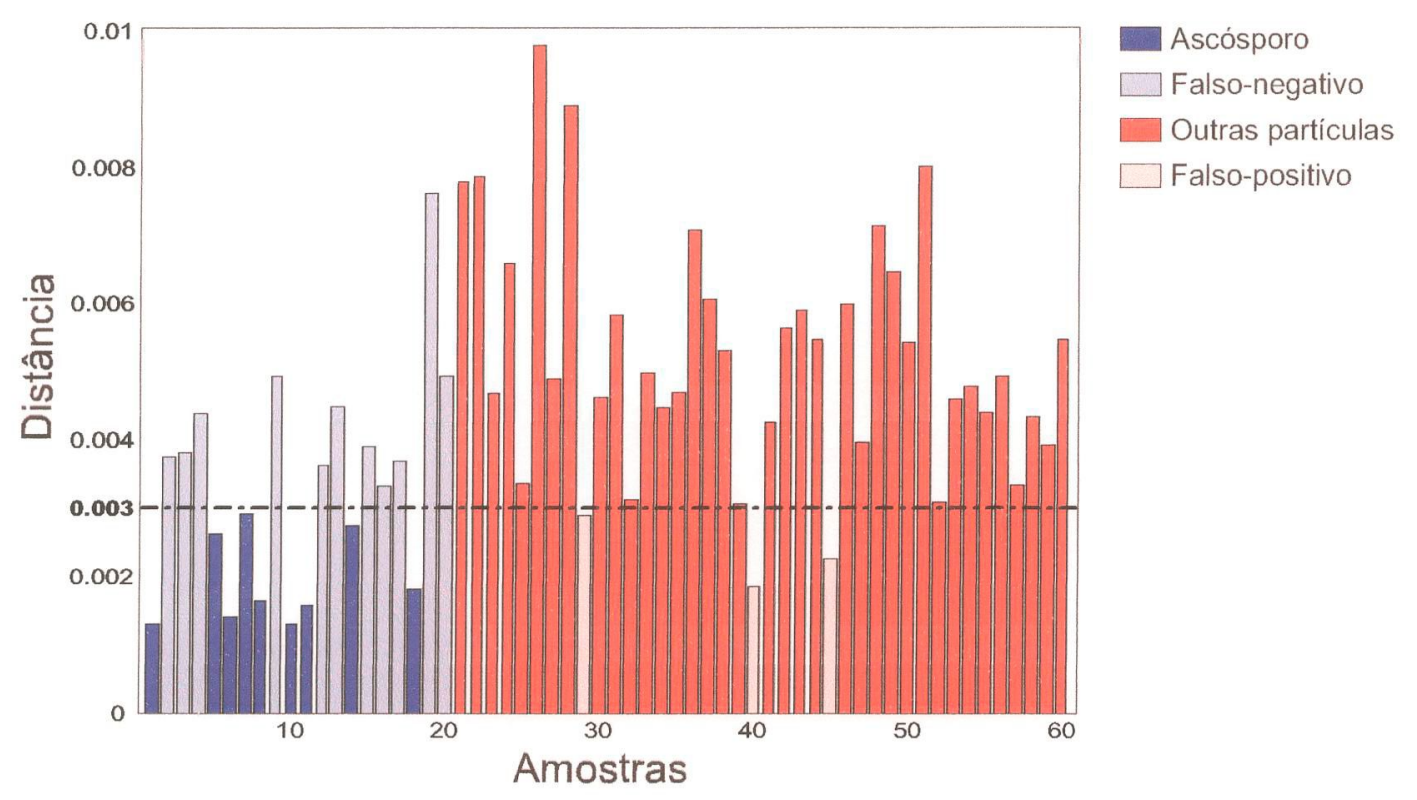

Figura 4.27: Distância calculada entre os vetores de características baseados no contorno da forma e o vetor médio referente à classe Ascósporos.

essas diferenças não foram evidenciadas pela assinatura da forma e, tampouco, pelos descritores obtidos com a análise do espectro da potência.

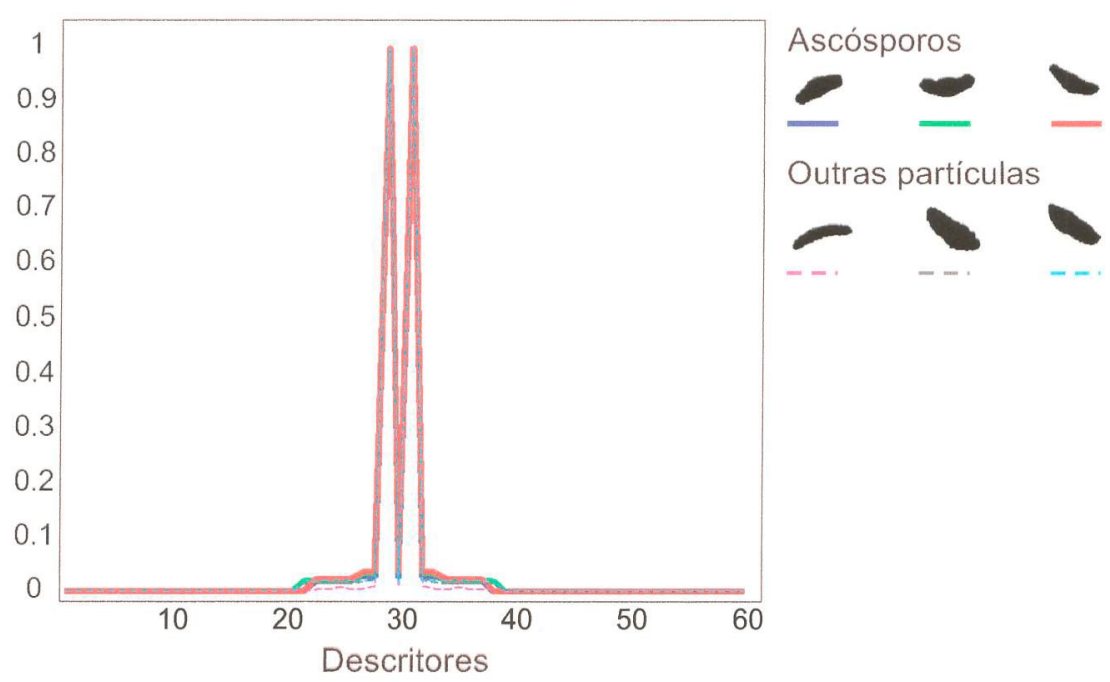

Figura 4.28: Descritores de Fourier obtidos a partir da assinatura distância do centróide de cada uma das amostras apresentadas à direita.

Aplicando o classificador por distância mínima sobre o conjunto de amostras, o resultado obtido, considerando-se o limiar $T=0.015$, foi de 9 falsos-positivos e de 7 falsos-negativos, completando um total de 16 erros em 60 amostras analisadas (aproximadamente $73 \%$ de acerto). As distâncias calculadas para cada uma das amostras em relação ao vetor médio $\mathbf{m}_{\text {assinatura }}$ são mostradas no gráfico da Figura 4.29. Semelhante ao experimento anterior (Experimento I), observa-se que houve ainda uma quantidade considerável de amostras classificadas erroneamente. A técnica baseada em assinatura não foi capaz de separar satisfatoriamente as amostras analisadas nesse experimento, especificamente, o que vem a confirmar o resultado durante a 
comparação entre as assinaturas realizada na Seção 4.3.2.

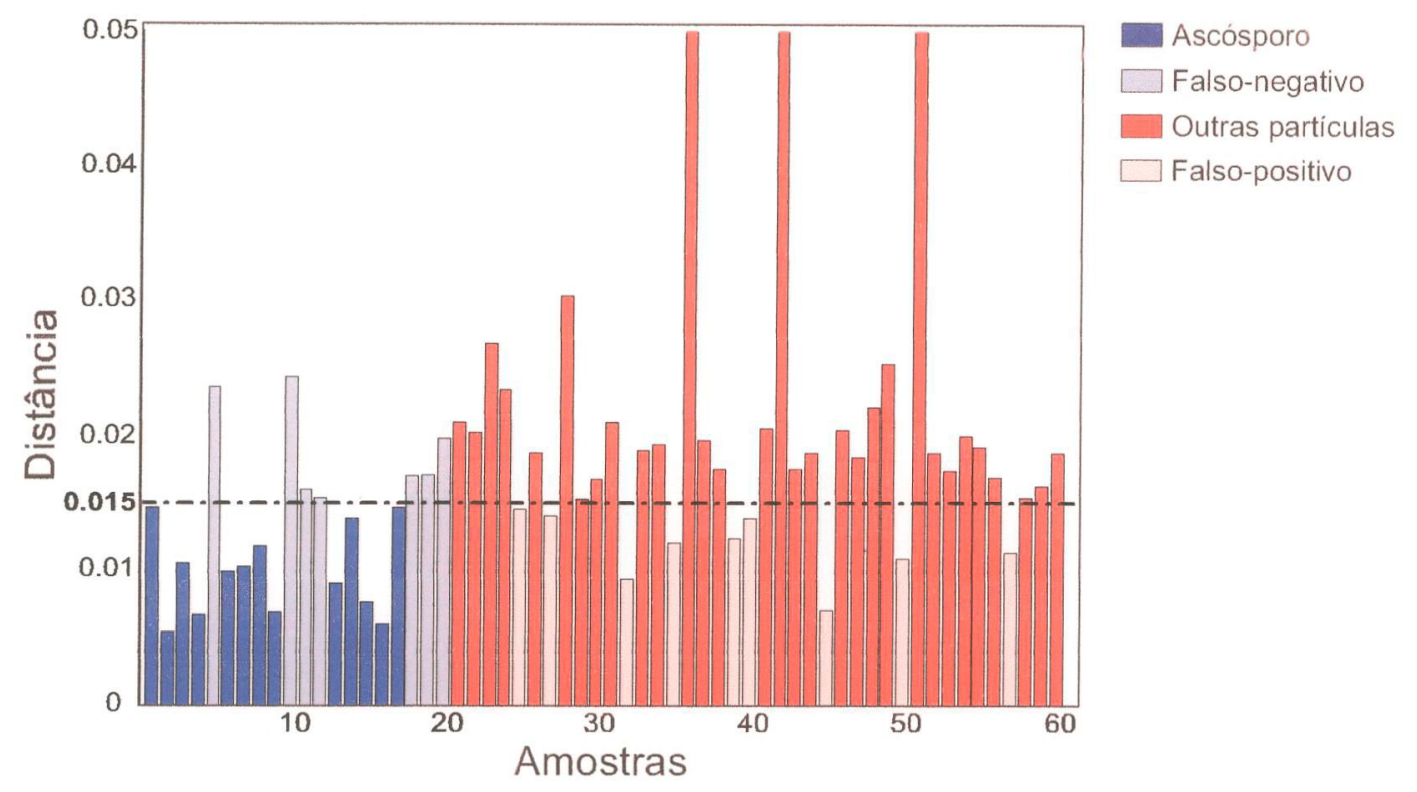

Figura 4.29: Distância calculada entre os vetores de características baseados na assinatura da forma e o vetor médio referente à classe Ascósporos.

\subsubsection{Experimento III - Projeção Horizontal}

O sinal usado nesse experimento foi obtido a partir da projeção horizontal da forma, sendo escolhidos 60 descritores com base na análise do espectro da potência, os compõem o vetor de características de cada uma das amostras.

Na Figura 4.30 é mostrado o gráfico com os descritores obtidos a partir da projeção horizontal de 3 amostras de ascósporos e de 3 amostras de outras partículas - amostras apresentadas à direita do gráfico. Analisando os descritores, observa-se que há uma diferença entre os sinais que, embora não seja grande, possibilita separar visualmente o grupo de amostras de ascósporos. Essa diferença ocorre em razão da dilatação central existente nos ascósporos, evidenciada na projeção horizontal. Observa-se também que essa técnica possibilitou uma melhor segregação dessas amostras, comparado aos descritores apresentados nos experimentos anteriores. No entanto, analisando nesse gráfico somente os descritores referentes às amostras de ascósporos, nota-se uma diferença no sinal representado em verde comparado aos demais sinais, que embora seja uma diferença pequena, pode afetar no processo de identificação.

Classificando o conjunto de amostras pela distância mínima, o resultado obtido, usando um limiar $T=0.1$, foi de 8 erros em 60 amostras analisadas (aproximadamente 87\% de acerto), sendo todos falsos-negativos. As distâncias calculadas para cada uma das amostras em relação ao vetor médio $\mathbf{m}_{\text {proj }}$ são mostradas no gráfico da Figura 4.31. Embora a quantidade de erros não seja grande e não exista nenhuma amostra identificada como falso-positivo, diversas amostras de ascósporos não foram identificadas. Analisando somente o resultado em relação ao conjunto de amostras de ascósporos, tem-se que 40\% das amostras de ascósporos analisadas não foram reconhecidas. Isso representa que o resultado obtido não é satisfatório, pois um percentual considerável de ascósporos deixou de ser identificado, podendo influen- 


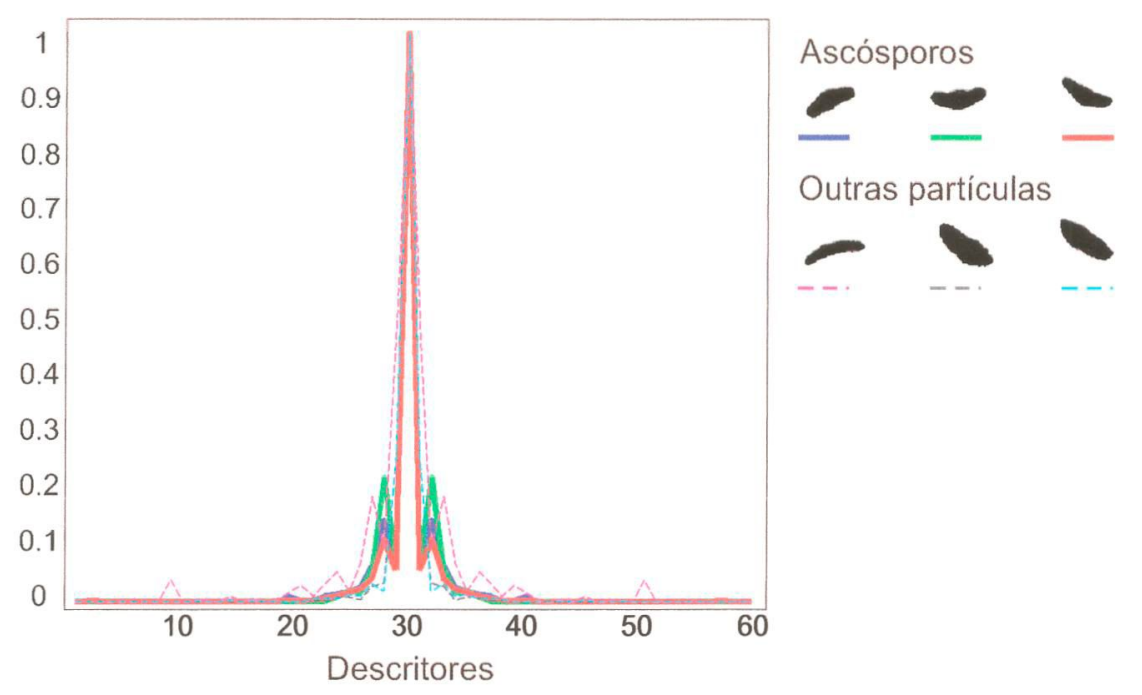

Figura 4.30: Descritores de Fourier obtidos a partir da projeção horizontal de cada uma das amostras apresentadas à direita.

ciar erroneamente na decisão do especialista. Ao alterar o limiar para diminuir o número de falsos-negativos, o percentual geral de acerto também diminuiu. Por exemplo, se for considerado um limiar $T=0.15$ para esse mesmo conjunto de amostras, o número de falsos-negativos é reduzido para 3 amostras, entretanto, 11 amostras são classificadas como ascósporos incorretamente (falsos-positivos), o que representa aproximadamente $76 \%$ de acerto, resultado próximo ao obtido com os experimentos anteriores.

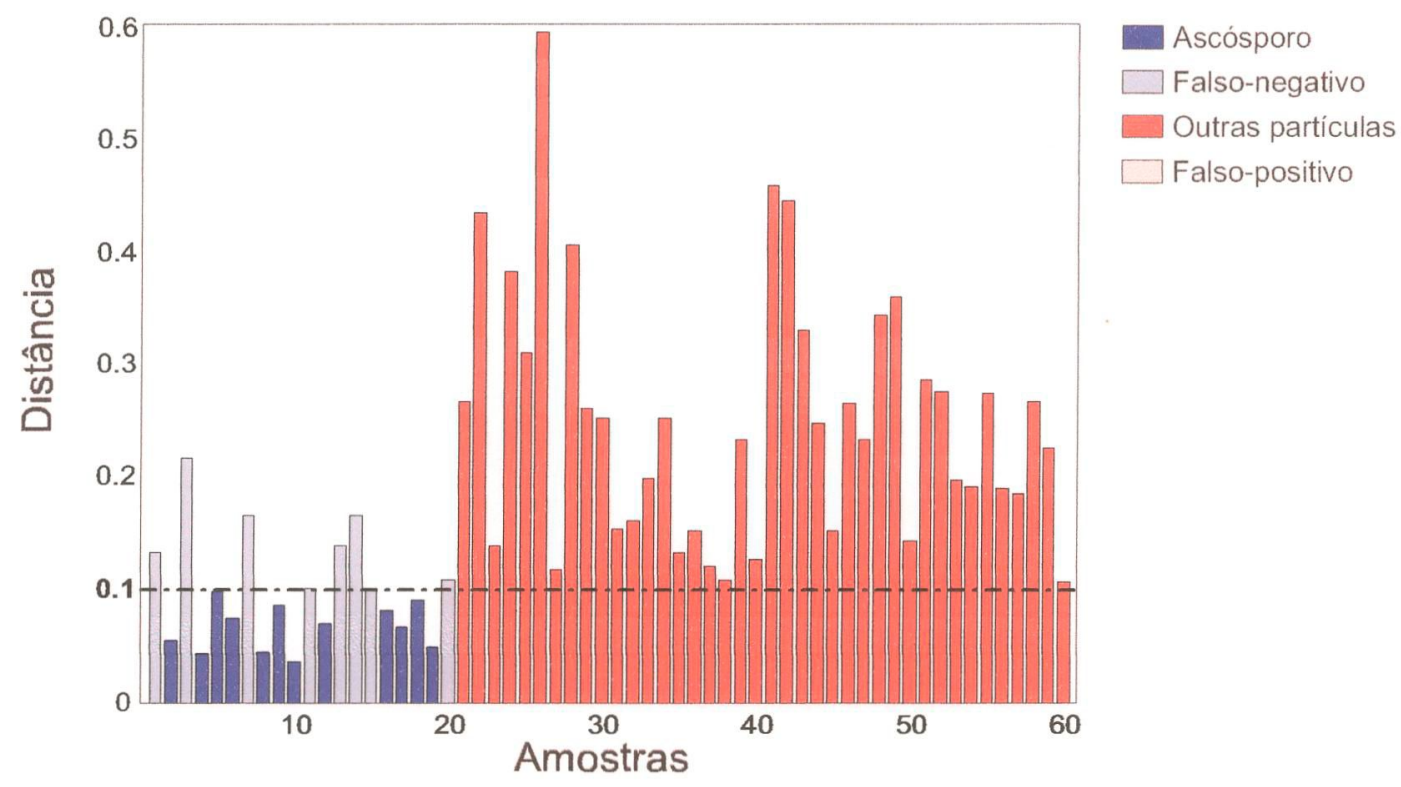

Figura 4.31: Distância calculada entre os vetores de características baseados na projeção horizontal da forma e o vetor médio referente à classe Ascósporos.

\subsubsection{Experimento IV - Curvatura}

A curvatura foi extraída a partir do contorno das amostras, sendo o sinal resultante submetido à análise do espectro da potência para a obtenção dos descritores. Ao todo foram selecionados 60 descritores para representar cada uma das amostras. 
Os descritores obtidos a partir da curvatura da forma de 3 amostras de ascósporos e de 3 amostras de outras partículas são mostrados na Figura 4.32. Analisando esses descritores, observa-se que há uma separação entre os descritores que representam as amostras de ascósporos e os que representam as demais partículas. Outro aspecto importante é a proximidade entre os sinais pertencentes à classe Ascósporos e, ao mesmo tempo, a diferença desses sinais em relação aos descritores das demais amostras (partículas pertencentes à classe Outras partículas), o que permite distinguir visualmente os sinais que pertencem à classe de ascósporos.

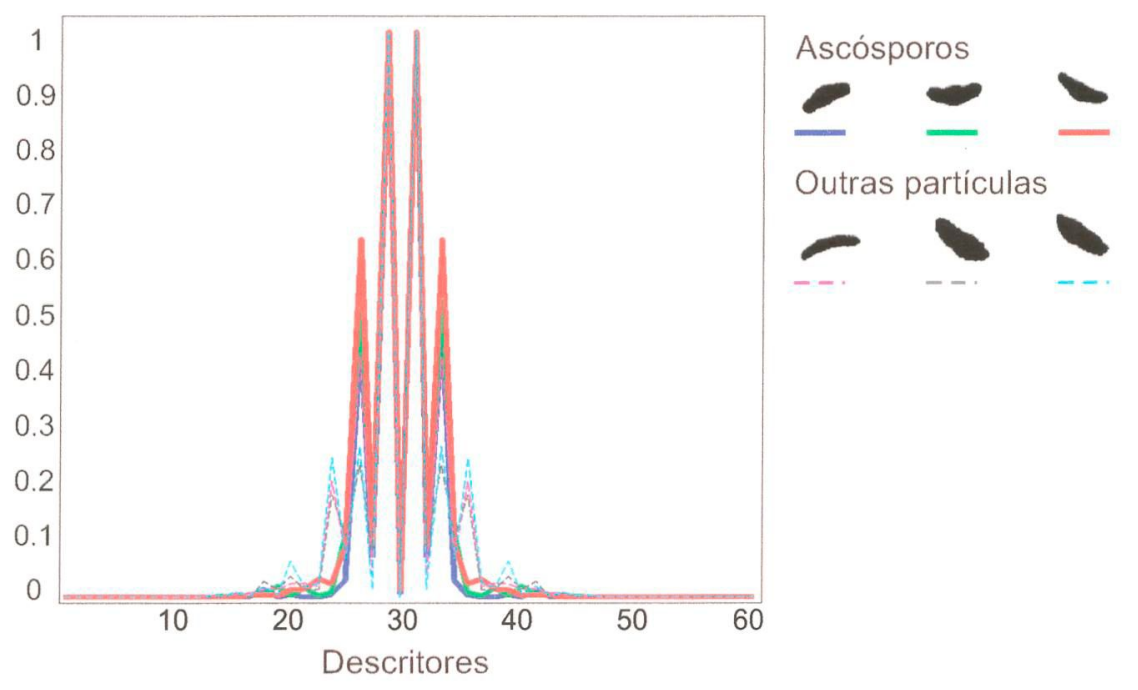

Figura 4.32: Descritores de Fourier obtidos a partir da curvatura extraída de cada uma das amostras apresentadas à direita.

Ao aplicar o classificador estatístico baseado na distância mínima sobre o conjunto de amostras, usando um limiar $T=0.3$, obteve-se como resultado 2 falsos-positivos e 3 falsos-negativos, num total de 5 erros em 60 amostras analisadas (aproximadamente $92 \%$ de acerto). As distâncias calculadas para cada uma das amostras em relação ao vetor médio $\mathbf{m}_{\text {curvatura }}$ são mostradas no gráfico da Figura 4.33. Esse resultado foi bastante satisfatório, considerando que o método de classificação baseado na definição de um limiar é relativamente simples. Além disso, o fato de apenas 5 amostras terem sido classificadas incorretamente sinaliza o potencial dessa técnica aplicada a este projeto, especificamente. Com relação aos três casos de falso-negativo, observou-se que as amostras apresentavam deformações as quais alteravam o sinal gerado pela curvatura, diferenciando-os das demais amostras de ascósporos. Nos outros dois casos de falsos-positivos, o erro ocorreu devido à semelhança das duas amostras analisadas com a forma de um ascósporo, gerando uma curvatura bastante semelhante e, conseqüentemente, um conjunto de descritores próximo ao vetor médio $\mathbf{m}_{\text {curvatura }}$.

\subsection{Descritores de Wavelets}

Os descritores de wavelets têm sido também aplicados em problemas de reconhecimento de padrões. Neste projeto, tais descritores foram aplicados para caracterizar o conjunto de amostras e analisar se eles permitem segregar corretamente as amostras de ascósporos das demais. A decomposição por wavelets foi aplicada sobre o sinal obtido com a curvatura, em razão do bom 


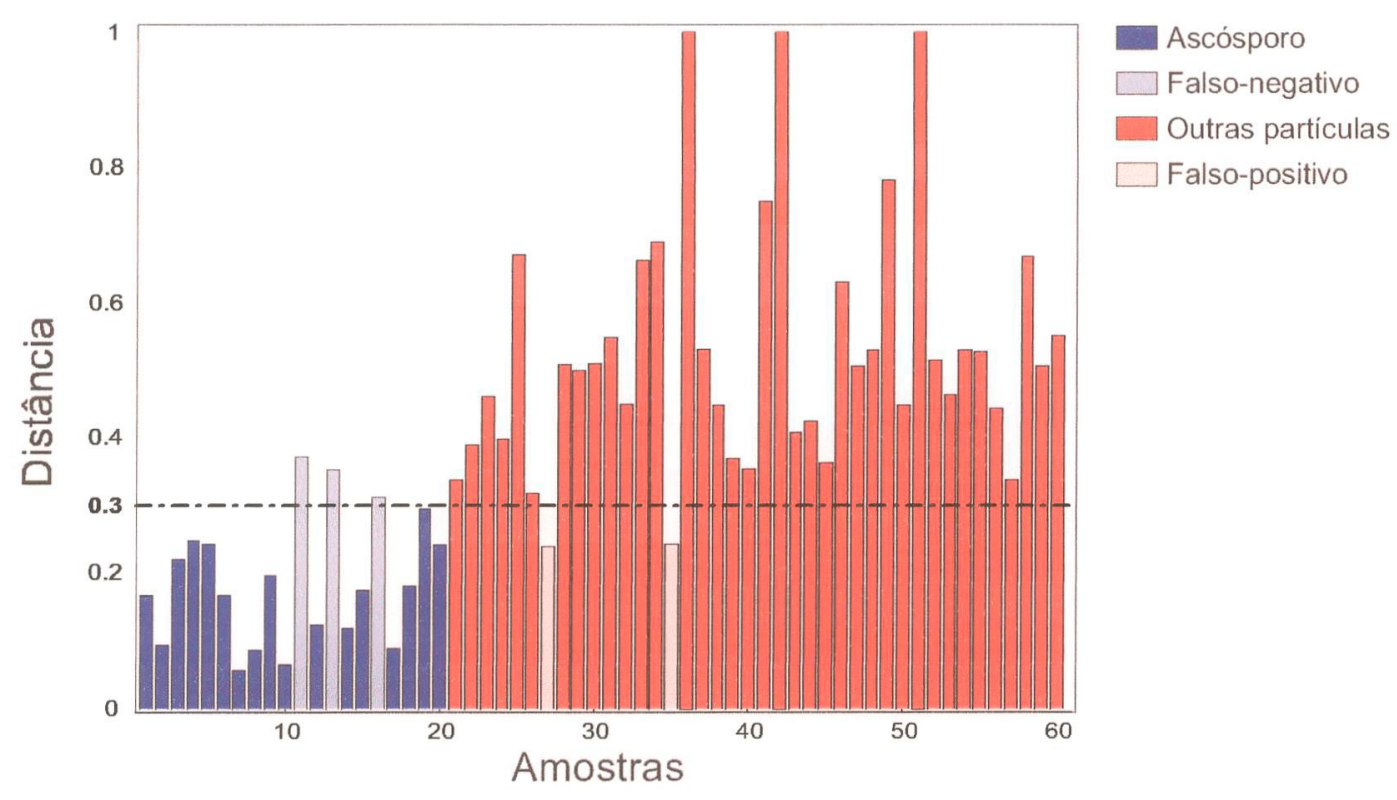

Figura 4.33: Distância calculada entre os vetores de características baseados na curvatura da forma e o vetor médio referente à classe Ascósporos.

resultado sinalizado pelos testes anteriores.

A família de wavelet considerada para esse teste foi a Daubechies. Essa família de wavelets tornou viável a análise discreta e, por isso, é bastante popular. Para efetuar a decomposição do sinal, aplicou-se a wavelet de ordem 4 (db4). As funções $\Phi$ (escala) e $\Psi$ (wavelet) da wavelet Daubechies db4, assim como os respectivos filtros de decomposição e reconstrução, são mostrados na Figura 4.34.
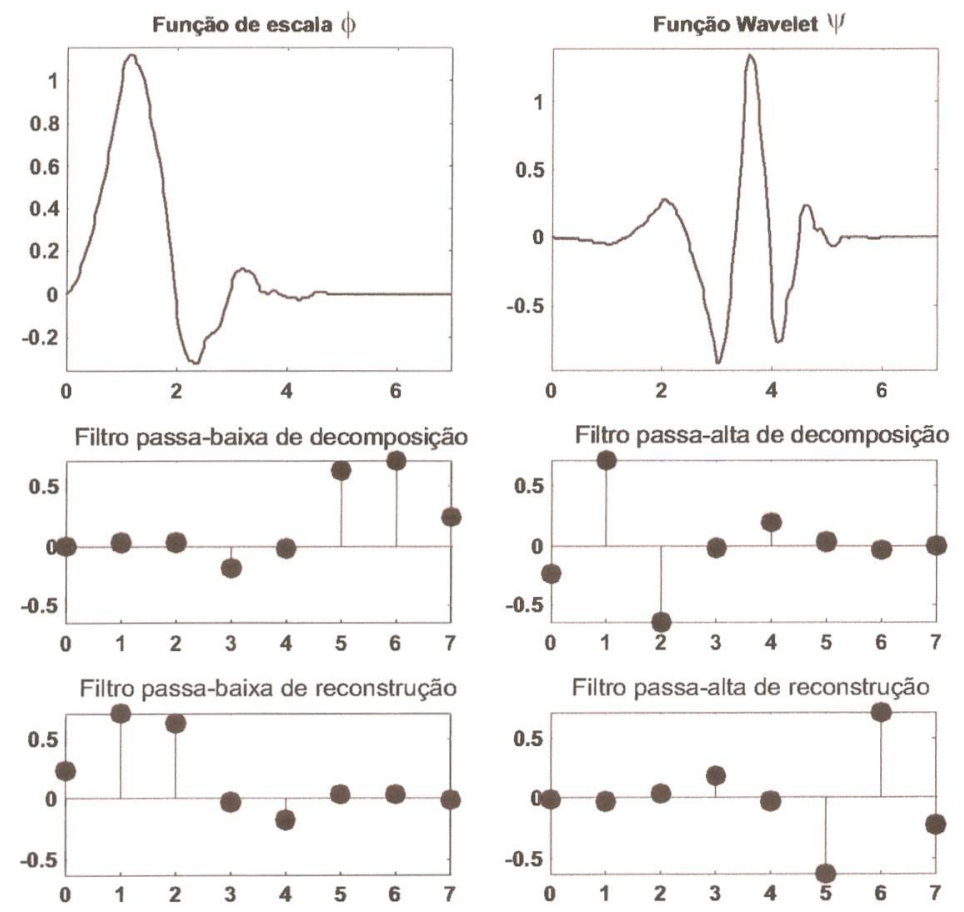

Figura 4.34: Funções da wavelet Daubechies db4.

Após a decomposição do sinal, o vetor de descritores é composto pela tendência do sinal e 
por uma parte do detalhe do sinal. Nesse caso, foram considerados os detalhes referentes aos níveis de decomposição 3, 4 e 5. Para ilustrar melhor o processo de decomposição, na Figura 4.35 é mostrada a árvore de decomposição referente à curvatura da amostra de um ascósporo. Foram realizados 5 níveis de decomposição, sendo $a_{n}$ e $d_{n}$, a tendência (aproximação) e o detalhe do sinal no nível de decomposição $n=[1 . .5]$, respectivamente. Na Figura 4.36 é mostrado o sinal resultante após o processo de decomposição. Nessa figura também são mostrados, separados por linhas pontilhadas, a tendência do último nível de decomposição e os detalhes extraídos em cada nível.

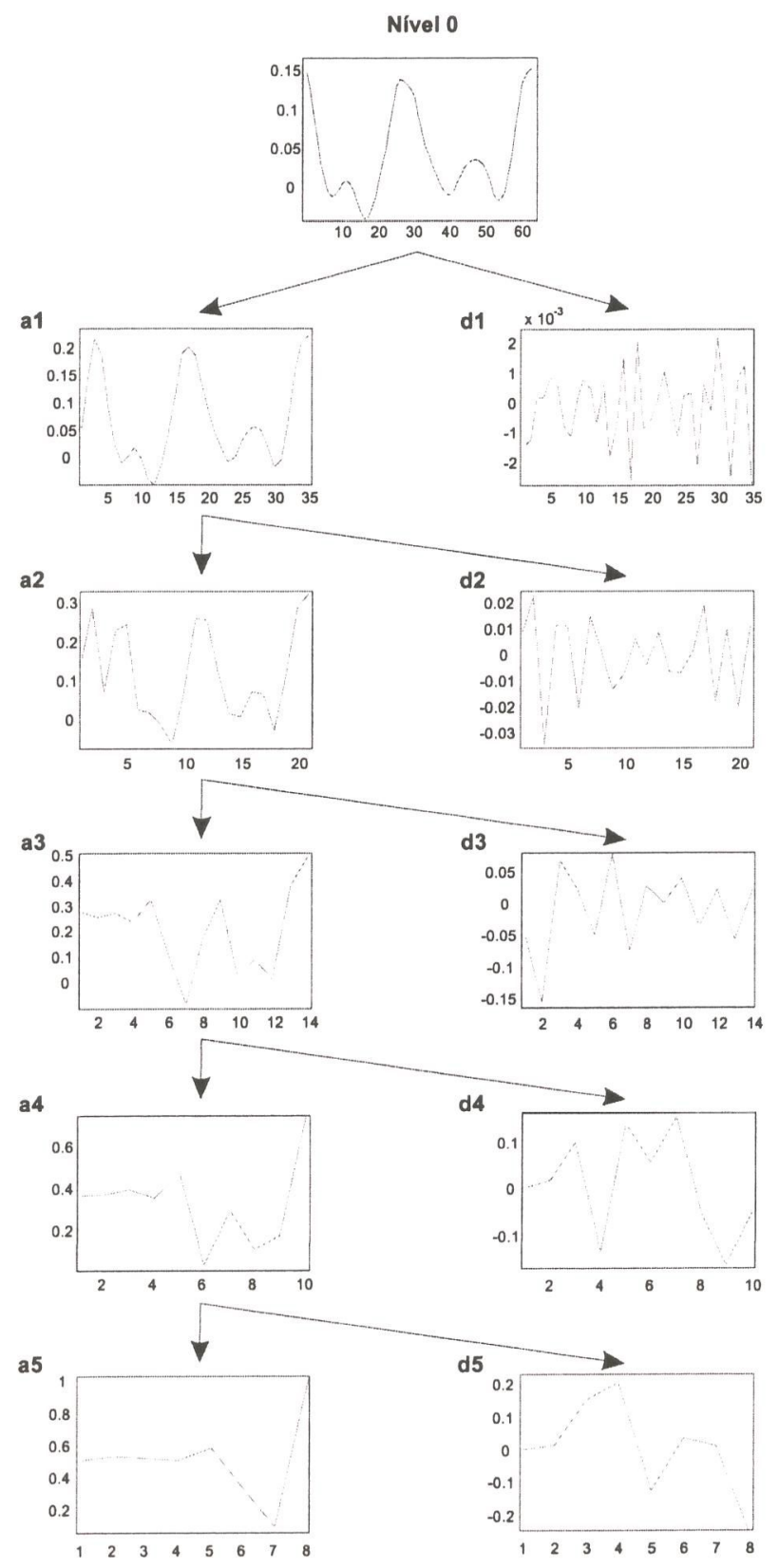

Figura 4.35: Árvore de decomposição aplicando a wavelet Daubechies db4 sobre a curvatura de um ascósporo - referente à decomposição mostrada na Figura 4.36. 


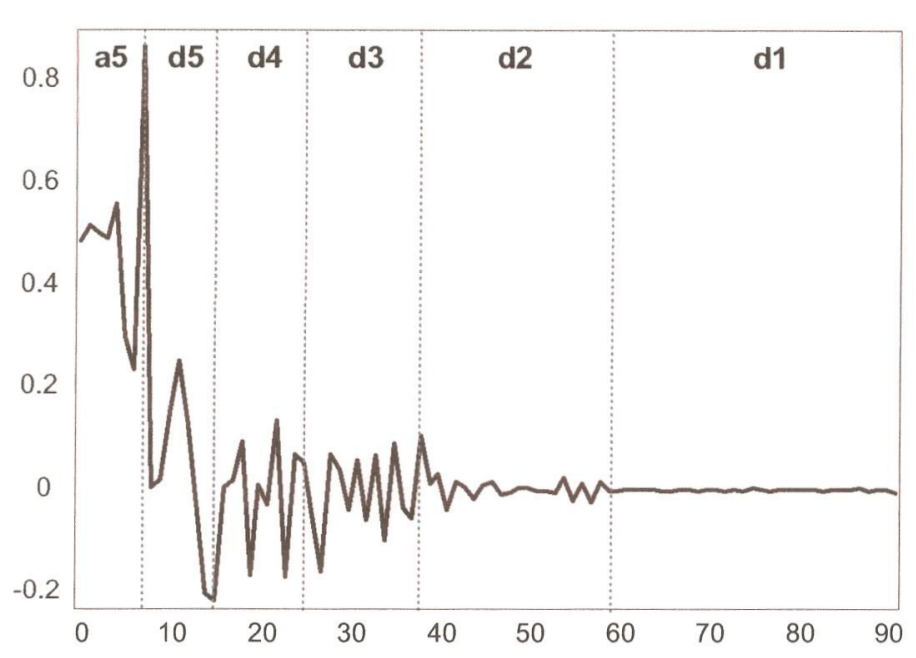

Figura 4.36: Sinal resultante da decomposição da curvatura de um ascósporo em 5 níveis.

Na Figura 4.37 são mostrados os descritores selecionados para cada uma das curvaturas referentes ao conjunto de amostras. Observa-se que, embora exista proximidade entre os sinais referentes às amostras de ascósporo, não há uma distinção clara em relação às demais amostras, o que não garante uma separação correta das partículas.

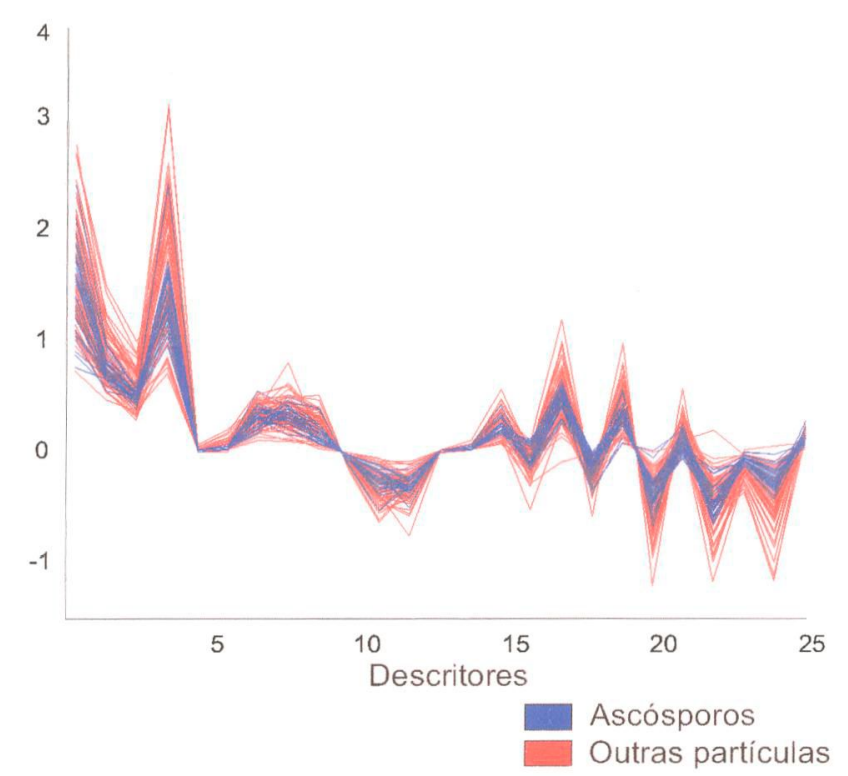

Figura 4.37: Descritores selecionados a partir da decomposição da curvatura das amostras por wavelets.

Baseado no mesmo processo de classificação aplicado nos experimentos com os descritores de Fourier (classificação por distância mínima) e sendo $\mathbf{m}_{\text {wavelets }} \mathbf{o}$ vetor médio referente à classe de ascósporos, calculou-se as distâncias entre os descritores e o vetor médio. O resultado obtido é mostrado na Figura 4.38. Considerando um limiar $T=0.6$, foram obtidos 11 falsos-positivos e 4 falsos-negativos, que representa um total de 15 erros em 60 amostras analisadas (aproximadamente $75 \%$ de acerto). O resultado obtido com os descritores de wavelets, considerando a abordagem adotada, compara-se ao resultado obtidos com os experimentos realizadas anteriormente com a assinatura baseada na distância ao centróide e com o contorno 
da forma. Por fim, uso dos descritores de wavelets não apresentou resultados melhores na identificação dos ascósporos, comparado aos obtidos com a curvatura e os descritores de Fourier. Outras famílias de wavelets, como a Coiflets, também foram testadas, mas os resultados foram semelhantes.

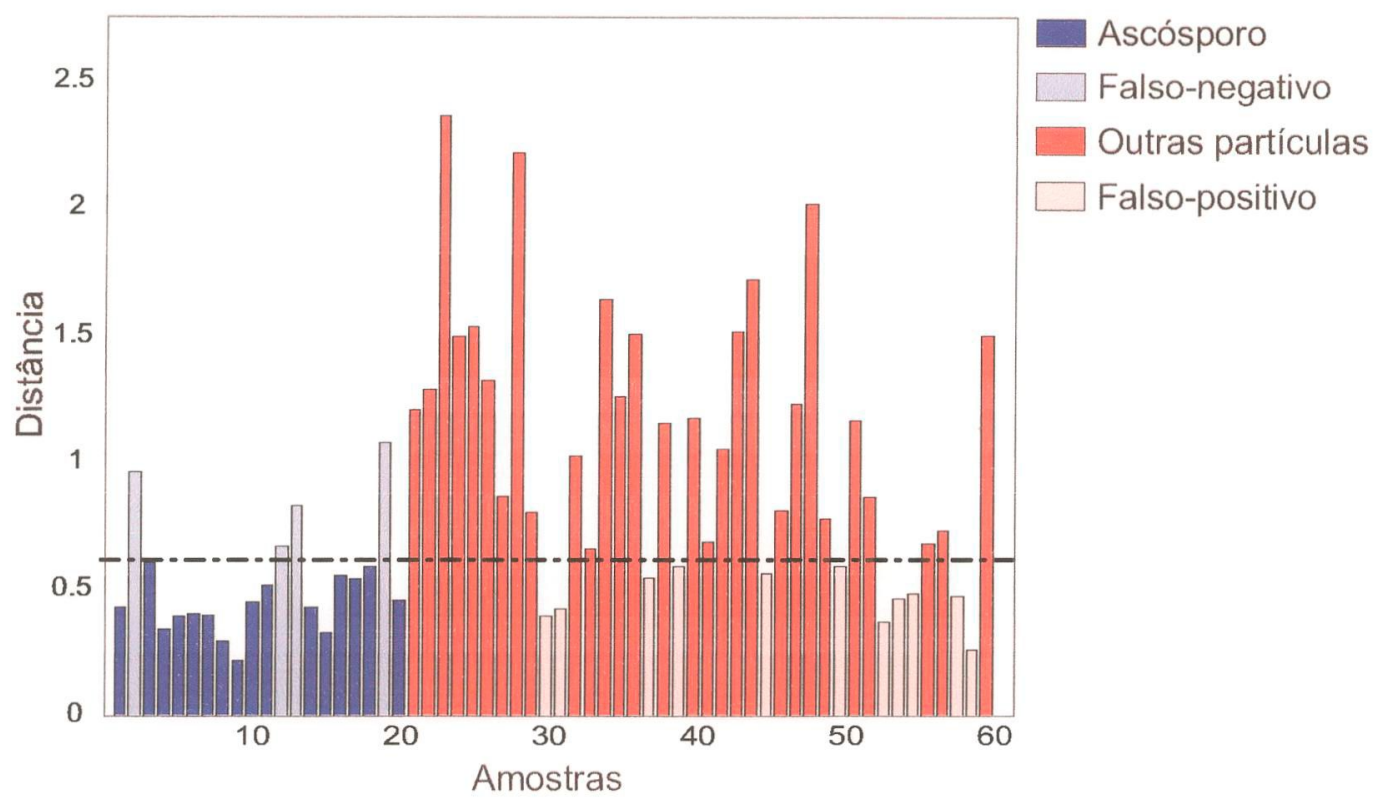

Figura 4.38: Distância calculada entre os vetores de características baseados nos descritores de wavelets e o vetor médio referente à classe dos ascósporos.

Em razão da transformada de wavelets ser variante quanto ao deslocamento do sinal, todas as amostras foram normalizadas antes do processo de decomposição. Há na literatura algumas técnicas que propõem alternativas para contornar esse problema, mas ao invés de aplicar tais técnicas, concentrou-se esforços, primeiramente, na análise dos sinais, a fim de se alcançar algum resultado significativo na identificação dos ascósporos. As abordagens para contornar o problema quanto à variância do sinal seriam tratadas posteriormente, caso um bom resultado tivesse sido alcançado.

\subsection{Considerações Finais}

Neste capítulo foram apresentados os resultados obtidos com cada uma das técnicas abordadas durante o levantamento bibliográfico. Em geral, as técnicas alcançaram no total percentuais de acerto acima de $60 \%$, o que não deixa de ser um resultado positivo. Na Tabela 4.1 um resumo dos resultados obtidos durante a comparação das técnicas é apresentado. Como pode ser observado, a abordagem baseada na curvatura da forma apresenta o melhor resultado (aproximadamente $92 \%$ de acerto). É importante ressaltar que esse resultado foi alcançado considerando apenas um tipo de característica - a curvatura - por meio dos descritores de Fourier.

Além da curvatura ter sinalizado um resultado satisfatório para a caracterização dos ascósporos, uma outra característica se demonstrou útil neste projeto: o perímetro. Tal característica permite que uma pré-seleção das amostras seja realizada. Com isso, parte das partículas de não ascósporos existentes na imagem são descartadas, reduzindo a quantidade de amostras a ser 
Tabela 4.1: Resumo dos resultados obtidos em cada um dos experimentos, aplicando-se as diferentes técnicas.

\begin{tabular}{l|c|c|c|c|c|c|c|c}
\cline { 2 - 9 } & \multicolumn{3}{|c|}{ Ascósporos } & \multicolumn{3}{c|}{ Outras Partículas } & \multicolumn{2}{c}{ Totais } \\
\hline Experimentos & Acertos & Erros & $\%$ Erro & Acertos & Erros & $\%$ Erro & Acertos & $\%$ Acertos \\
\hline \hline Momentos - Assinatura & 13 & 7 & $35 \%$ & 23 & 17 & $43 \%$ & 36 & $60 \%$ \\
\hline Momentos - Curvatura & 19 & 1 & $5 \%$ & 25 & 15 & $38 \%$ & 44 & $73 \%$ \\
\hline Fourier - Contorno & 9 & 11 & $55 \%$ & 37 & 3 & $8 \%$ & 46 & $76 \%$ \\
\hline Fourier - Assinatura & 13 & 7 & $35 \%$ & 31 & 9 & $23 \%$ & 44 & $73 \%$ \\
\hline Fourier - Projeção & 12 & 8 & $40 \%$ & 40 & 0 & $0 \%$ & 52 & $86 \%$ \\
\hline Fourier - Curvatura & 17 & 3 & $15 \%$ & 38 & 2 & $5 \%$ & 55 & $\mathbf{9 2 \%}$ \\
\hline Wavelets - Curvatura & 16 & 4 & $20 \%$ & 29 & 11 & $28 \%$ & 45 & $75 \%$ \\
\hline
\end{tabular}

submetida ao processo de extração de características e identificação.

É importante mencionar que os resultados apresentados e o estudo comparativo são específicos à identificação dos ascósporos da Guignardia citricarpa. 


\section{Sistema de Visão Computacional e Resultados Experimentais}

partir da seleção da abordagem a ser aplicada para a caracterização dos ascósporos do fungo Guignardia citricarpa - a curvatura, foram desenvolvidas as demais etapas necessárias a um sistema de visão computacional. Ao final desse processo, um protótipo do sistema foi implementado. A principal motivação para o desenvolvimento desse protótipo foi criar um ambiente que propiciasse a realização dos testes com as imagens dos discos de coleta, considerando a aplicação de todas as etapas desenvolvidas (segmentação, extração de características e identificação).

Neste capítulo são descritos as etapas envolvidas no desenvolvimento do sistema CITRUSVIS, assim como os métodos adotados em cada uma delas. Também são apresentados os resultados obtidos e o protótipo do sistema implementado.

\subsection{Sistema CitrusVIS}

O principal objetivo desse sistema é automatizar a identificação dos ascósporos existentes nas imagens adquiridas dos discos de coleta, aplicando-se técnicas de visão computacional e de reconhecimento de padrões. Um sistema típico de visão computacional envolve quatro etapas (Gonzalez e Woods, 2002): aquisição, segmentação, análise e extração de características e a classificação, conforme mostradas na Figura 5.1. Cada uma dessas etapas são detalhadas a seguir.

\subsubsection{Aquisição das Imagens}

As imagens utilizadas neste projeto são obtidas a partir dos discos de coletas, por meio de câmeras digitais acopladas a um microscópio convencional. Antes das imagens serem adquiridas, é aplicado sobre os discos um corante láctico azul, largamente utilizado em laboratórios de mi- 


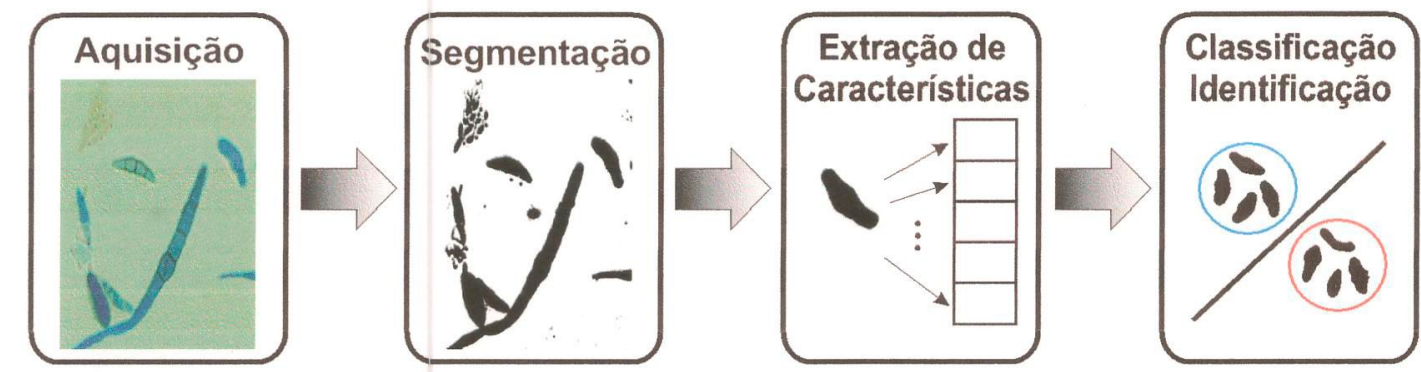

Figura 5.1: Etapas do Sistema de Visão Computacional CiTRUS Vis.

crobiologia. Esse corante é usado para tingir as estruturas hialinas ${ }^{1}$, indistintamente, permitindo que as mesmas possam ser vistas com o auxílio de um microscópio. São tingidos tanto os ascósporos da Guignardia citricarpa, quanto os demais esporos e hifas ${ }^{2}$ de outros fungos também capturados nos discos.

Na Figura 5.2 é mostrada uma das imagens obtidas dos discos de coletas. Nessa imagem podem ser observadas diferentes partículas que são coletadas nos pomares. Dentre essas partículas está destacado um ascósporo do fungo Guignardia citricarpa.

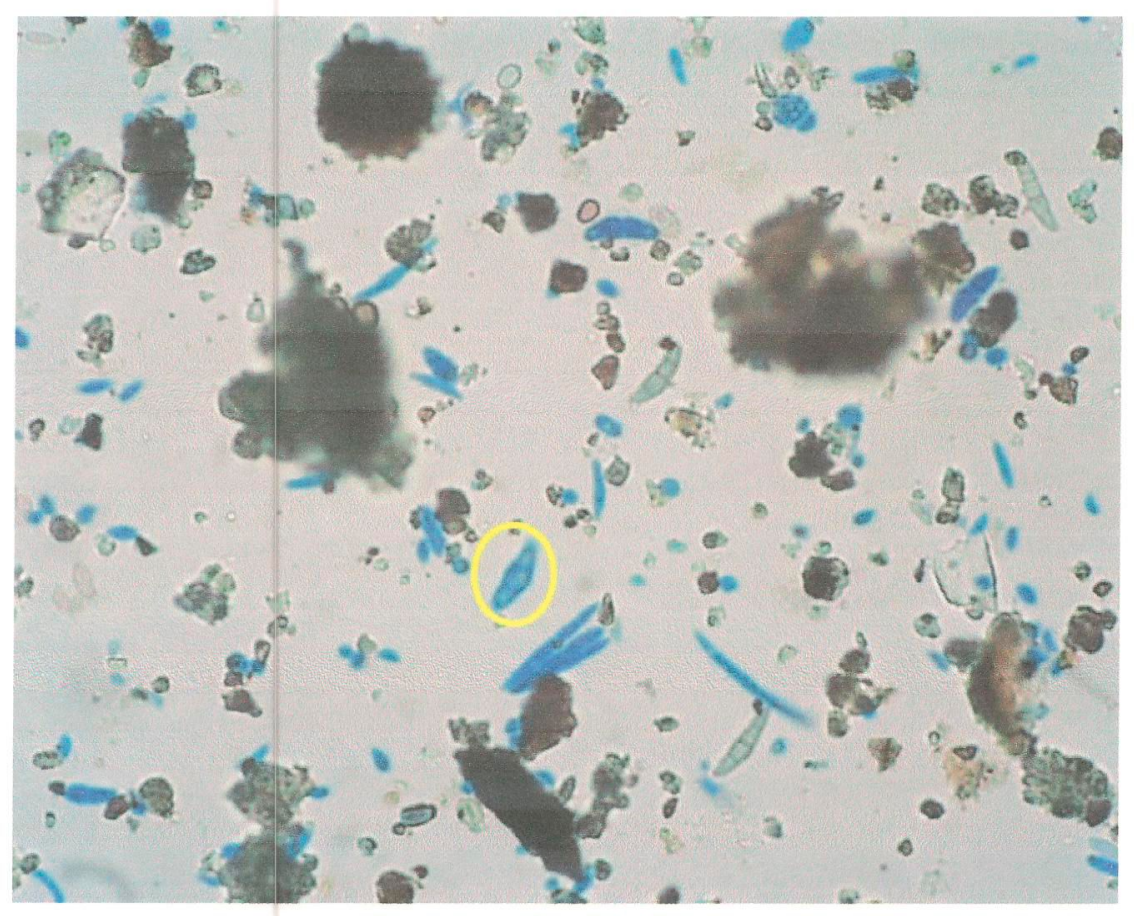

Figura 5.2: Imagem digital adquirida do disco de coleta ampliado por um microscópio. Em destaque, o ascósporo da Guignardia citricarpa.

A etapa de aquisição das imagens também foi realizada pela UNESP e pelo Fundecitrus, que disponibilizaram as imagens usadas durante o desenvolvimento deste trabalho. As imagens enviadas estão no formato $\mathrm{JPEG}^{3}$ e apresentam dimensões diferentes, sendo a maioria 640 × 512 pontos.

\footnotetext{
${ }^{1}$ Transparentes como o vidro

${ }^{2}$ Partes filamentosas dos fungos

${ }^{3}$ Padrão internacional proposto pelo comitê ISO Joint Photographers Expert Group
} 
Foram recebidas aproximadamente 70 imagens, dentre as quais foram detectados alguns problemas como: (i) diferentes colorações e tonalidades da imagem (fundo do disco) e das partículas, sendo algumas muito claras, dificultando a segmentação, (ii) borramentos em razão de mau ajuste do foco no microscópio, que, em alguns casos, acaba alterando a forma das partículas, sendo necessário um pré-processamento para aproveitamento da imagem e (iii) baixa qualidade em razão da compressão JPEG.

\subsubsection{Segmentação das Partículas}

A segmentação da imagem é uma das etapas mais importantes durante o desenvolvimento deste projeto, pois as etapas seguintes - análise e identificação - dependem de um bom resultado durante a segregação das partículas. Algumas alternativas foram aplicadas a fim de contornar alguns dos problemas apresentados pelas imagens (variação na intensidade, borramentos, etc.) e obter um resultado que seja satisfatório.

As técnicas utilizadas basearam-se na segmentação por limiarização. O resultado é uma imagem binarizada, com as partículas de interesse representadas por pontos em pretos. A seguir são apresentadas as alternativas empregadas para a segmentação das imagens dos discos de coleta e o resultado alcançado com sua aplicação.

\subsubsection{Segmentação usando o Modelo de Cor HSI}

Em um primeiro momento, a idéia foi aplicar uma segmentação que separasse as partículas com base na cor, em razão de algumas partículas existentes nos discos terem sido tingidas de azul, inclusive os ascósporos. As imagens foram convertidas de RGB para HSI (Rick, 2000) e somente o componente $H$, referente ao matiz, foi usado para se aplicar a limiarização. Os valores obtidos com a conversão estão normalizados entre 0 e 1 e considerando o intervalo referente à coloração azul, foram definidos dois limiares, $T_{i}=0.4 \mathrm{e} T_{f}=0.6$. Dessa maneira, apenas as partículas com coloração entre ciano e azul (devido às variações apresentadas na cor decorrentes do processo de tingimento) são segmentadas, descartando as demais partículas

Na Figura 5.3 são apresentadas as imagens obtidas durante o processo de conversão (Figura 5.3(b)) e de limiarização (Figura 5.3(c)). Como pode ser observado, o resultado obtido foi satisfatório. Alguns ruídos permanecem após o processo de limiarização, os quais podem ser removidos por meio de um filtro morfológico. Nesse teste, entretanto, foi usada uma imagem com alta resolução e sem perdas com compressão. Ao efetuar o mesmo teste usando o conjunto de imagens recebido, o resultado não foi o mesmo. Em razão das imagens terem sido compactadas no formato JPEG, boa parte da informação referente à cor foi descartada e, conseqüentemente, resultados ruins foram obtidos no processo de conversão de RGB para HSI, como mostrado na Figura 5.4(b). Dessa maneira, a segregação das partículas fica comprometida, com o surgimento de muitos ruídos e de deformações em algumas partículas, como pode ser observado na Figura 5.4(c).

Além disso, um outro problema observado, foi a coloração do fundo do disco apresentada por algumas imagens. Em alguns casos, não foi possível segmentar as partículas da imagem por limiarização, pois a coloração do fundo da imagem resultava em um matiz dentro do intervalo de 


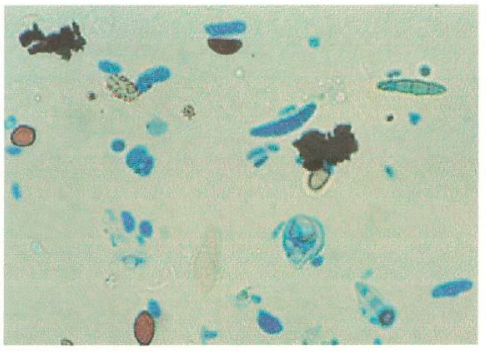

(a)

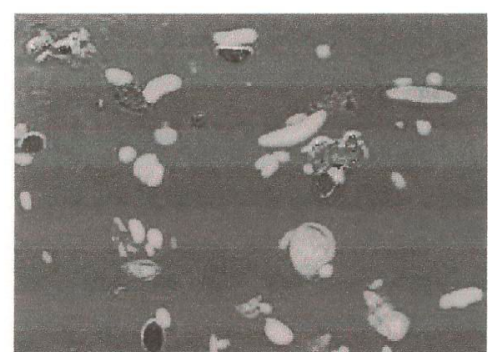

(b)

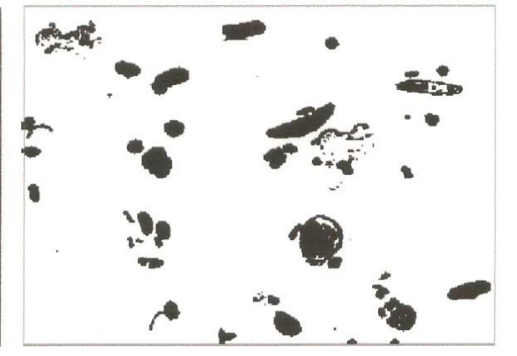

(c)

Figura 5.3: Limiarização por meio do matiz usando o modelo HSI: Imagem original (a), componente $\mathrm{H}$ após conversão de RGB para HSI (b) e resultado da limiarização considerando $T_{i}=0.4$ $\mathrm{e} T_{f}=0.6(\mathrm{c})$.

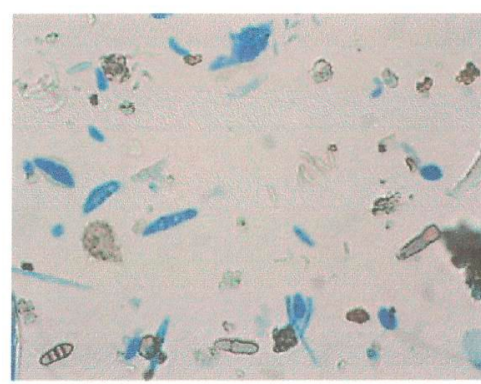

(a)

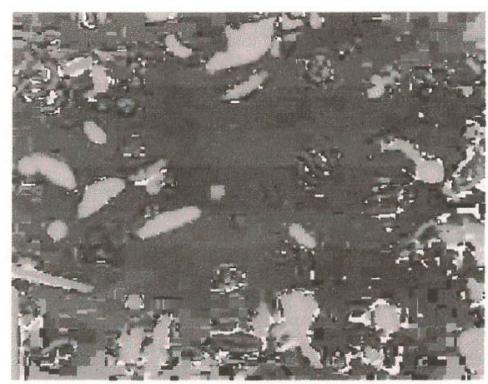

(b)

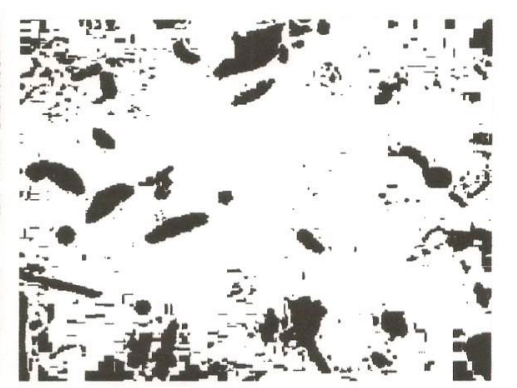

(c)

Figura 5.4: Problema encontrado com a limiarização por meio do matiz (modelo HSI), usando o conjunto de imagens recebido: Imagem original (a), componente $\mathrm{H}$ após conversão de RGB para HSI (b) e resultado da limiarização considerando $T_{i}=0.4 \mathrm{e} T_{f}=0.6$ (c)

cor definido. Em virtude da maioria das imagens terem apresentado alguns desses problemas, tal abordagem foi descartada, uma vez que não foi possível obter novas imagens, de melhor qualidade, a tempo de realizar outros experimentos.

\subsubsection{Segmentação usando um Filtro de Difusão Não-Linear}

Uma outra alternativa para a segmentação das partículas, foi a aplicação de um algoritmo de limiarização diretamente na imagem convertida para escala de cinza. Dentre os algoritmos de segmentação, optou-se por aplicar o de Otsu (1979), em razão do bom desempenho apresentado durante os testes realizados com esse algoritmo usando as imagens do disco de coleta. No entanto, ruídos ainda são gerados após o processo de limiarização, decorrentes da variação de níveis de cinza existentes nas imagens, o que não possibilitou uma boa segmentação.

Uma maneira de reduzir os ruídos presentes na imagem é a aplicação de filtros para a suavização da imagem, como o filtro Gaussiano (Gonzalez e Woods, 2002). Entretanto, esse filtro altera as regiões de fronteira, por causa do borramento que ele ocasiona nas bordas das partículas, alterando a forma de algumas delas após a limiarização, além de poder aumentar o número de partículas conexas.

Com isso, optou-se por aplicar o filtro de difusão não-linear proposto por Perona e Malik (1990), que realiza a suavização na imagem preservando as regiões de fronteira. Esse filtro reduz a variação dos níveis de cinza por região e, conseqüentemente, os ruídos após a limiarização 
(Weickert, 1997). A equação de difusão aplicada é definida por Perona e Malik (1990) como

$$
g(\|\nabla I\|)=\frac{1}{1+\left(\frac{\|\nabla I\|}{K}\right)^{2}}
$$

Para a aplicação desse filtro sobre a imagem $I$, foi considerado o parâmetro $K=4$ (limiar da fronteira). Esse parâmetro indica as regiões que são consideradas fronteiras, ou seja, para $\|\nabla I\|>K$. Nessas regiões, o processo de difusão tem menos efeito. Caso contrário, $\|\nabla I\|<$ $K$, o coeficiente de difusão é de alta amplitude e o efeito de suavização será mais forte (Morel e Solimini, 1995; Voci et. al., 2004). Além disso, o número de iterações considerado para a aplicação do filtro sobre as imagens dos discos foi $n=30$.

Na Figura 5.5 são mostrados os resultados obtidos com a aplicação dos filtros lineares e não-lineares sobre uma imagem obtida de um disco de coleta e as respectivas imagens após a limiarização. Nessa comparação pode ser observado que os dois filtros apresentam menos ruídos, comparado à limiarização quando aplicada diretamente à imagem original (Figura 5.5(b)). Entretanto, com o filtro de Perona-Malik (Figura 5.5(f)), é possível observar que a proximidade das formas obtidas, em relação às partículas originais, é maior do que as obtidas com filtro Gaussiano. Na imagem com o filtro Gaussiano (Figura 5.5(d)), pode-se observar que algumas partículas aparecem maiores do que realmente são, ou não aparecem inteiras. Nota-se também que a conexão entre as bordas de diferentes partículas aumenta.

Por fim, é importante ressaltar que, embora o filtro de Perona-Malik apresente um resultado melhor para esse caso de teste, o custo computacional com a aplicação dessa técnica é maior. Isso ocorre em razão do número de iterações necessárias para se obter um resultado satisfatório com o processo de difusão. Mesmo assim, essa foi a alternativa adotada para ser aplicada neste trabalho, principalmente por esse filtro manter a proximidade da forma obtida após a suavização com a forma original da partícula.

\subsubsection{Filtros Morfológicos}

Com a aplicação do filtro de Perona-Malik, os problemas quanto à ruídos e lacunas existente na forma das partículas são reduzidos, mas não eliminados. Além de alguns ruídos resultantes do processo de limiarização, partes de alguns filamentos e de outras partículas pequenas podem continuar aparecendo na imagem. Por esse motivo, um filtro morfológico é aplicado a fim eliminar os ruidos restantes.

Um outro aspecto positivo quanto à aplicação do filtro morfológico, está no fato dele suavizar as bordas das partículas, eliminando pequenos picos nas bordas e fechando pequenas lacunas. Para a aplicação do filtro foi considerado um elemento estruturante circular com dimensão $5 \times 5$. Na Figura 5.6 é mostrado o resultado obtido com a aplicação do filtro morfológico sobre a imagem limiarizada. 


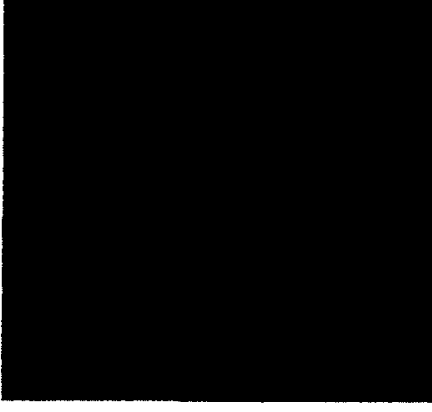

(a)

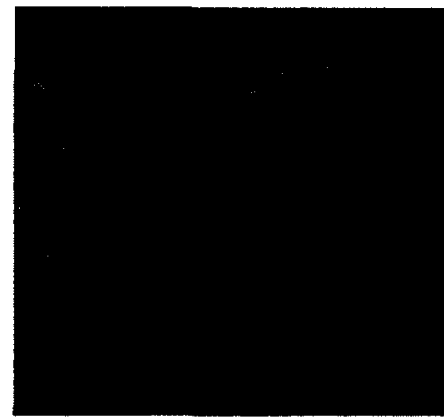

(c)

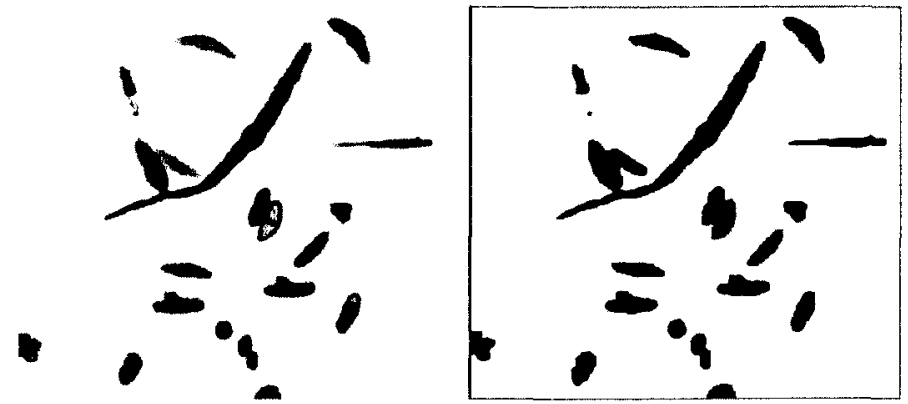

(e)

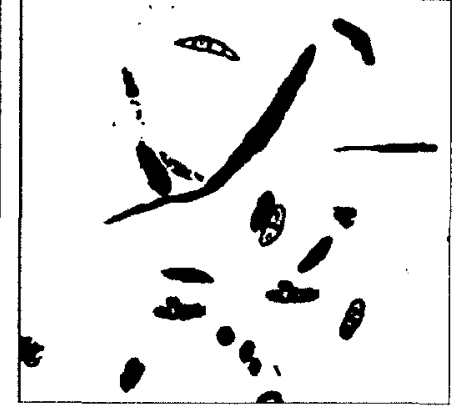

(b)

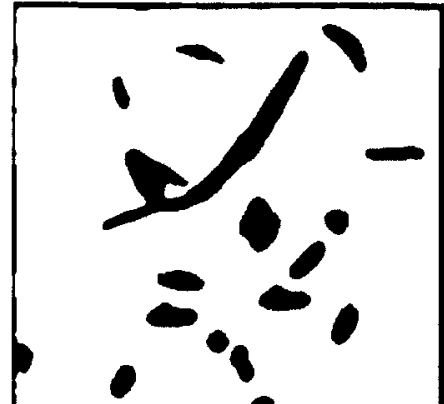

(d)

(f)

Figura 5.5: Comparação entre a aplicação dos filtros e o respectivo resultado após a limiarização da imagem: Imagem original em escala de cinza (a), limiarização da figura a (b), aplicação do filtro Gaussiano (5x5) (c), limiarização da figura c (d), aplicação do filtro de Perona-Malik (30 iterações e $K=4$ ) (e) e limiarização da figura e (f).

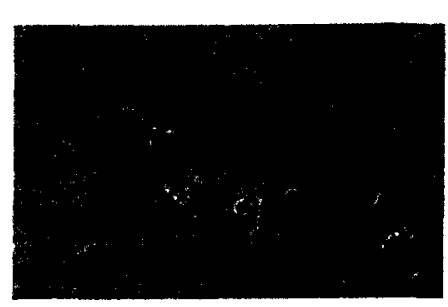

(a)

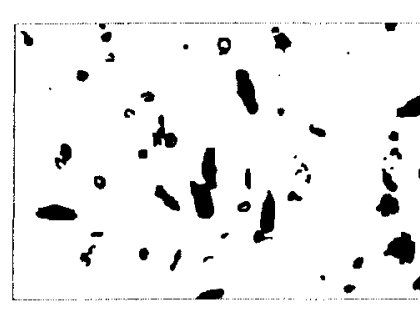

(b)

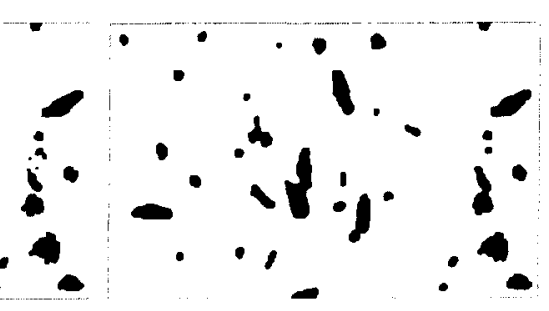

Figura 5.6: Aplicação do filtro morfológico para eliminação de ruídos, lacunas e pequenas partículas: Imagem original (a), imagem segmentada (b), resultado da aplicação do filtro morfológico (c) 


\subsubsection{Transformada Watershed}

Considerando que os objetos na imagem são analisados individualmente, uma das principais dificuldades encontradas nesse tipo de imagem refere-se à sobreposição ou à conexão entre as partículas. Essa classe de problemas é freqüentemente encontrada em imagens compostas por vários elementos, como é o caso das partículas coletadas nos discos. Para contornar esse problema, foi aplicada a técnica de morfologia matemática watershed Roerdink e Meijster (2000).

A abordagem adotada para a segregação dessas partículas consiste no algoritmo de imersão proposto por (Vincent e Soille, 1991). Para a aplicação desse algoritmo, faz-se necessário o uso da Transformada da Distância (Saito e Toriwaki, 1994) para a obtenção do mapa de distâncias, permitindo que a imagem binarizada possa ser interpretada como um relevo, necessário para a aplicação da transformada watershed. Com isso, todas as partículas passam a apresentar níveis de profundidade, a partir dos quais são definidos os mínimos locais para cada uma das regiões. Esses mínimos locais são usados como marcadores para as regiões, para que problemas, como o da supersegmentação da imagem, sejam evitados.

Nas Figuras 5.7(a) e (b), a imagem binarizada e o respectivo mapa de distâncias são mostrados. Na Figura 5.7(c) é mostrada a imagem com os marcadores (mínimos locais) definidos para cada região. O resultado final, obtido após a aplicação da transformada watershed, é mostrado na Figura 5.7(d).

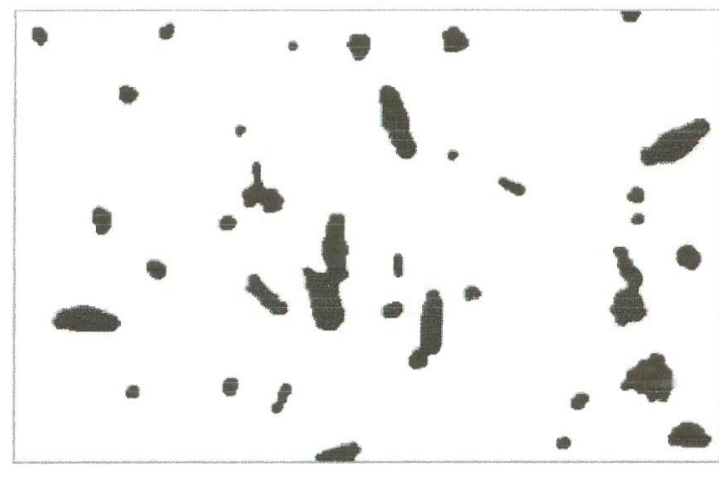

(a)

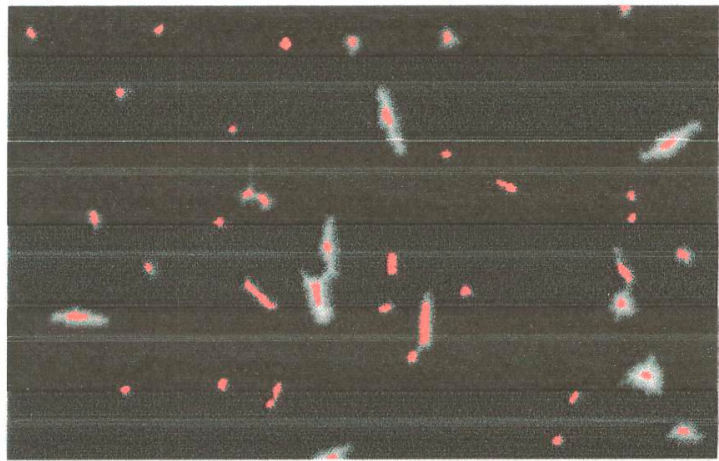

(c)

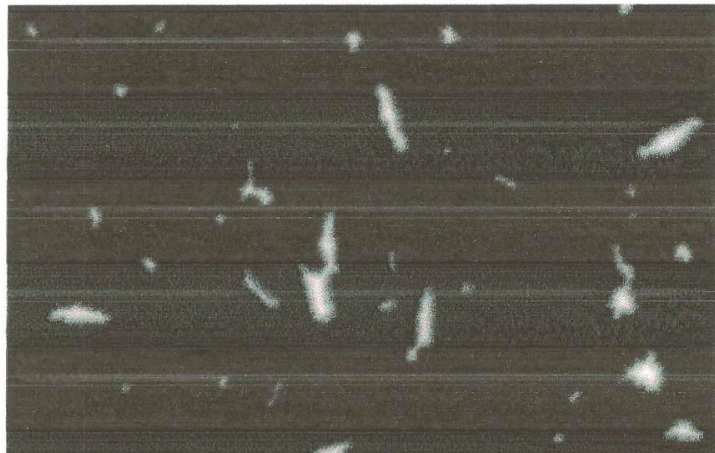

(b)

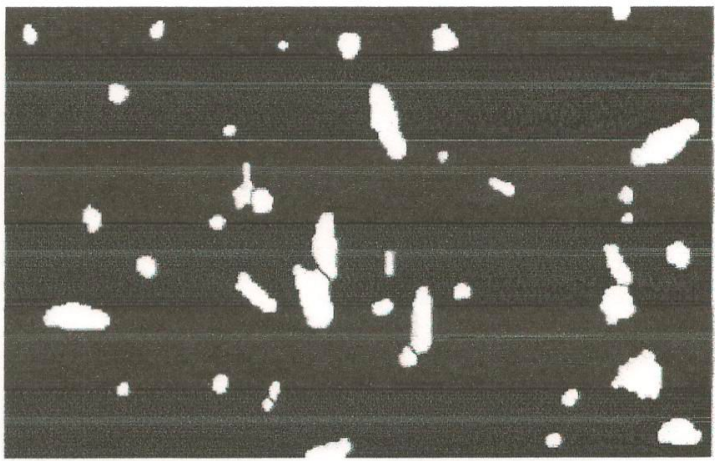

(d)

Figura 5.7: Aplicação da Transformada watershed para separação das partículas sobrepostas: Imagem binarizada (a), mapa de distância obtido após a aplicação da Transformada da Distância (b), marcadores selecionados a partir do mapa de distâncias (c) e o resultado obtido com a aplicação do algoritmo de imersão (d). 
Embora existam partículas sobrepostas nas imagens obtidas dos discos de coleta, algumas considerações devem ser feitas. Por se tratar de uma imagem binarizada, quando houver um grupo de partículas aglomeradas, a Transformada da Distância nem sempre possibilitará a definição correta dos marcadores das regiões, em relação à real disposição das partículas na imagem. Por exemplo, para o grupo de partículas mostrado na Figura 5.8, os marcadores não foram definidos corretamente por meio do mapa de distâncias e, conseqüentemente, o resultado obtido com a watershed não corresponde à separação real entre partículas. No entanto, segundo os especialistas na análise dos discos, são poucas as vezes que os ascósporos aparecem aglomeradas com outras partículas, o que também foi observado no conjunto de imagens usado neste projeto. Somente em algumas imagens foram encontrados casos de sobreposição, mas sempre entre poucas partículas. E quando conectadas por uma região pequena, essas partículas foram separadas por meio da watershed.

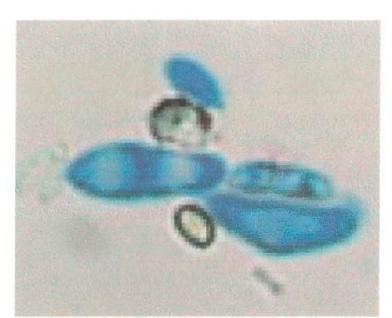

(a)

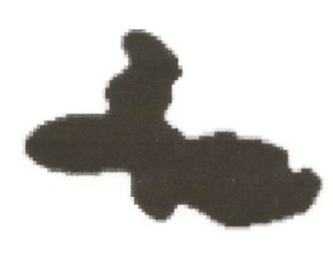

(b)

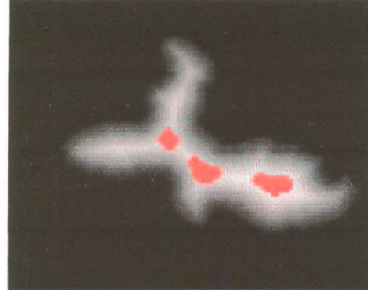

(c)

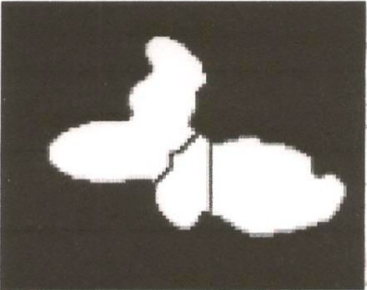

(d)

Figura 5.8: Problemas encontrados com a aplicação da Transformada watershed para separação de partículas aglomeradas: Imagem original (a), imagem binarizada (b), marcadores selecionados a partir do mapa de distâncias (c) e o resultado obtido com a aplicação do algoritmo de imersão (d).

\subsubsection{Análise e Extração de Características}

Após a etapa de segmentação, a análise é realizada em cada umas das partículas segmentadas para a extração dos respectivos vetores de características. Para a realização dessa etapa foi aplicada a abordagem baseada na curvatura da forma, que por sua vez é obtida por meio do contorno paramétrico. A seguir são apresentadas as etapas de extração do contorno e a obtenção dos descritores por meio da curvatura da forma.

\subsubsection{Extração do Contorno}

Para a extração do contorno das partículas foi aplicado o algoritmo seguidor do contorno (Costa e Cesar, 2000). No entanto, uma adaptação foi realizada para que em uma mesma imagem fossem extraídos os contornos de várias partículas, sendo cada um deles armazenados em uma lista encadeada. É importante ressaltar que as partículas conectadas à borda da imagem são descartadas, pois, em geral, essas partículas não estão completas, ou seja, parte da forma foi perdida durante a aquisição da imagem.

Durante a extração do contorno foi realizada a pré-seleção das amostras a partir do perímetro. Dessa maneira, somente as partículas com perímetro dentro do intervalo considerado - 120 a 220 pontos - são consideradas para a análise. Na Figura 5.9 é mostrada a imagem obtida do 
disco de coleta e os respectivos contornos extraídos de cada uma das amostras. Nessa figura é possível observar o resultado obtido com a pré-seleção por meio do perímetro, estando reduzido o número de partículas a serem submetidas ao processo de identificação.

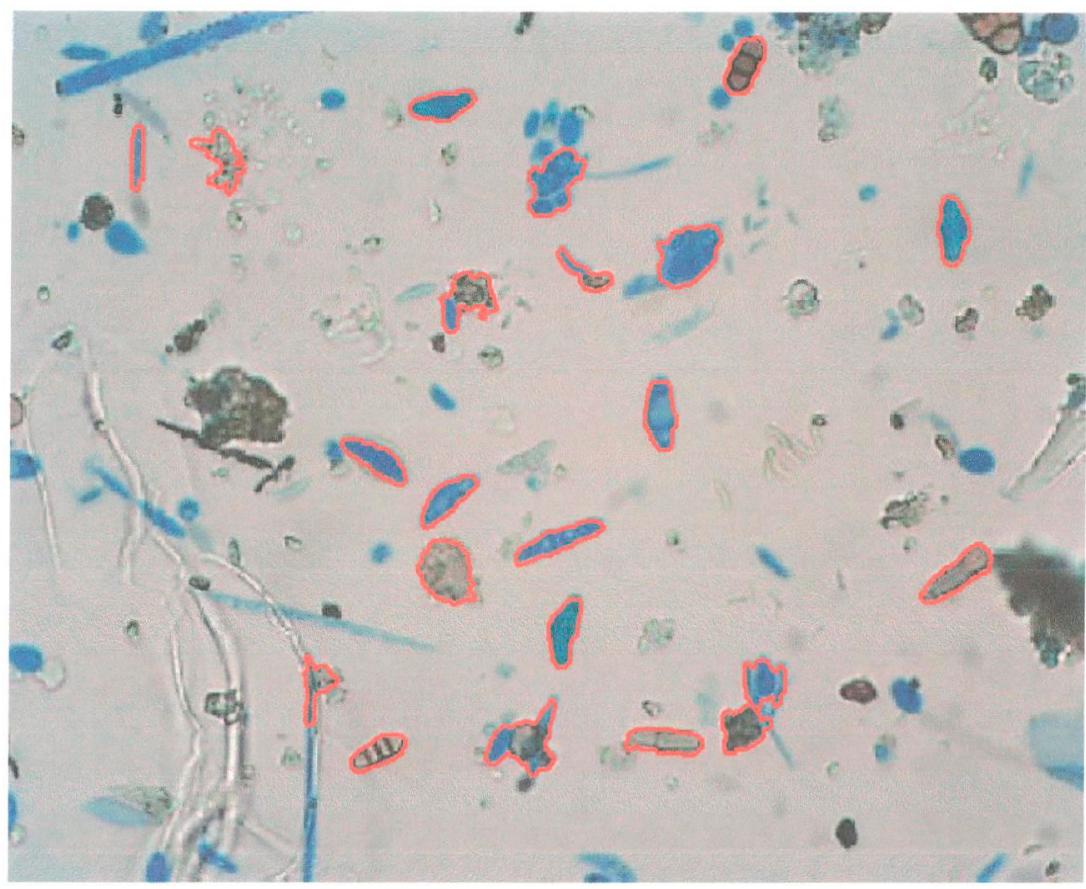

Figura 5.9: Contornos extraídos da imagem do disco de coleta obedecendo o critério de pré-seleção.

Por fim, um conjunto pré-selecionado de contornos é extraído de cada imagem para, em seguida, se efetuar a extração dos descritores.

\subsubsection{Extração dos Descritores}

Os descritores são extraídos a partir do conjunto de contornos obtido de cada uma das imagens submetidas à análise. Para cada um desses contornos calcula-se a curvatura, considerando $k(n, \sigma)=\Im^{-1}\{K(f) \cdot G(f, \sigma)\}$, sendo o desvio padrão do filtro Gaussiano $\sigma=0.22$.

Os descritores são obtidos com a aplicação da Transformada de Fourier sobre o sinal da curvatura, normalizando-se o espectro. Em seguida, considerando apenas a densidade espectral do sinal no domínio da freqüência (espectro da potência), são selecionados 60 descritores. Dessa maneira, cada uma das partículas obtidas da imagem passa a ser representada por um vetor de características e sobre os vetores são aplicados os métodos de reconhecimento de padrões.

\subsubsection{Identificação dos Ascósporos}

Nessa etapa, o objetivo foi aplicar técnicas de reconhecimento de padrões para validar a capacidade discriminate obtida com descrição das formas por meio da curvatura, neste trabalho, voltada à identificação dos ascósporos do fungo Guignardia citricarpa. Durante a comparação das técnicas, o bom resultado obtido com a classificação por meio da distância mínima fez com que a curvatura fosse a técnica selecionada para ser aplicada no na descrição das partículas. No entanto, em busca de melhorar o resultado já obtido com essa abordagem, optou-se por utilizar 
as Redes Neurais Artificiais.

Para a realização dos testes com rede neurais, foi utilizada a toolbox de Redes Neurais do MATLAB ${ }^{\circledR}$ (Demuth e Beale, 2003). Além dessa toolbox disponibilizar uma interface gráfica para a construção, o treinamento e a simulação da rede, ela também possibilita a integração da rede com as demais etapas envolvidas no sistema de visão, como a extração de características, o que facilitou o desenvolvimento de um protótipo para CITRUSVIS.

A rede selecionada foi uma feed-forward backpropagation com 60 entradas, duas camadas intermediárias, com 20 e 15 neurônios cada, e a camada de saída com 2 neurônios (Figura 5.10). Um dos neurônios da camada de saída representa a classe Ascósporos e o outro, a classe Outras particulas. O neurônio com o maior valor de saída indica a decisão da rede sobre a classe que padrão analisado pertence.

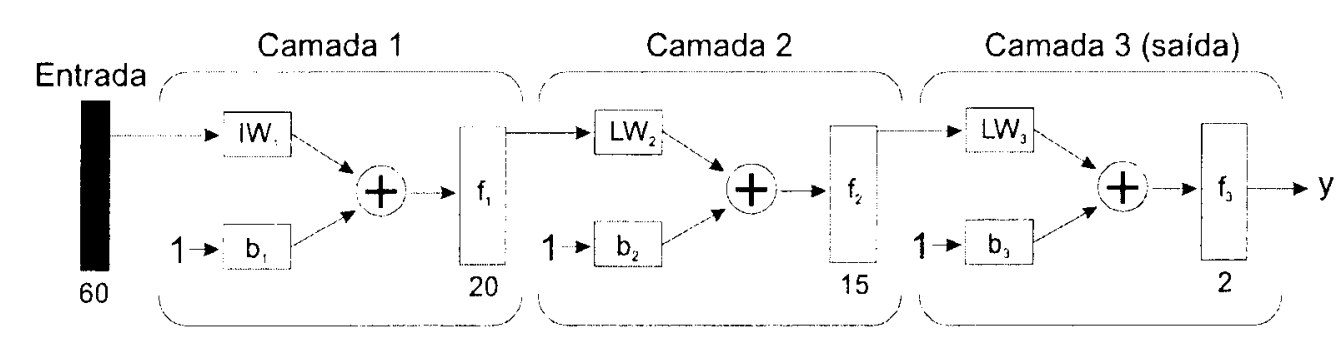

Figura 5.10: Topologia da rede utilizada no CITRUSVIS.

Para o treinamento da rede neural foi considerado um número maior de amostras, sendo essas amostras separadas em 3 conjuntos: treinamento, validação e teste. Foram utilizadas ao todo 300 amostras, com 60 descritores cada. As amostras foram divididas em 160 amostras para treinamento, 70 amostras para validação e 70 para teste. É importante ressaltar que não há repetições de amostras entre os conjuntos, ou seja, uma amostra que pertence ao conjunto de treinamento, não foi considerada nos demais conjuntos.

$\mathrm{O}$ algoritmo de treinamento usado foi o Levenberg-Marquardt backpropagation (trainlm) (Demuth e Beale, 2003; Hagan e Menhaj, 1994) e a função de ativação foi a função sigmoidal (logsig), cujo intervalo de saída está entre 0 e 1 . O desempenho obtido durante o treinamento, usando a topologia (20-15-2), foi de aproximadamente $6.9 e-8$, considerando como medida o erro quadrático médio (MSE). Outras topologias e outros algoritmos de treinamento, disponibilizados pela toolbox, foram testados, mas apresentaram desempenho inferior.

O resultado obtido com o uso da rede foi bastante satisfatório obtendo-se $98 \%$ de acerto, uma melhora considerável comparado ao resultado obtido com base na distância mínima entre os vetores de características (aproximadamente 92\% - ver Tabela 4.1). É importante ressaltar que esse resultado foi obtido com o conjunto de amostras pré-selecionados para o teste.

\subsection{Protótipo do Sistema de Visão Computacional - CitrusVis}

Um protótipo do sistema de visão para a identificação dos ascósporos do fungo Guignardia citricarpa foi desenvolvido a fim de propiciar um ambiente para a realização dos testes, usando 
as imagens obtidas dos discos de coleta. Além disso, esse ambiente facilita a visualização do resultado obtido, marcando na imagem do disco os ascósporos identificados.

Esse protótipo foi desenvolvido usando a interface gráfica do MATLAB ${ }^{\circledR}$. Optou-se por usar essa interface pela facilidade em integrar todas as etapas desenvolvidas (desde a segmentação da imagem até a identificação das partículas por meio das redes neurais), além do ambiente disponibilizar várias funcionalidades básicas. Na Figura 5.11 é mostrada a interface do protótipo desenvolvido.

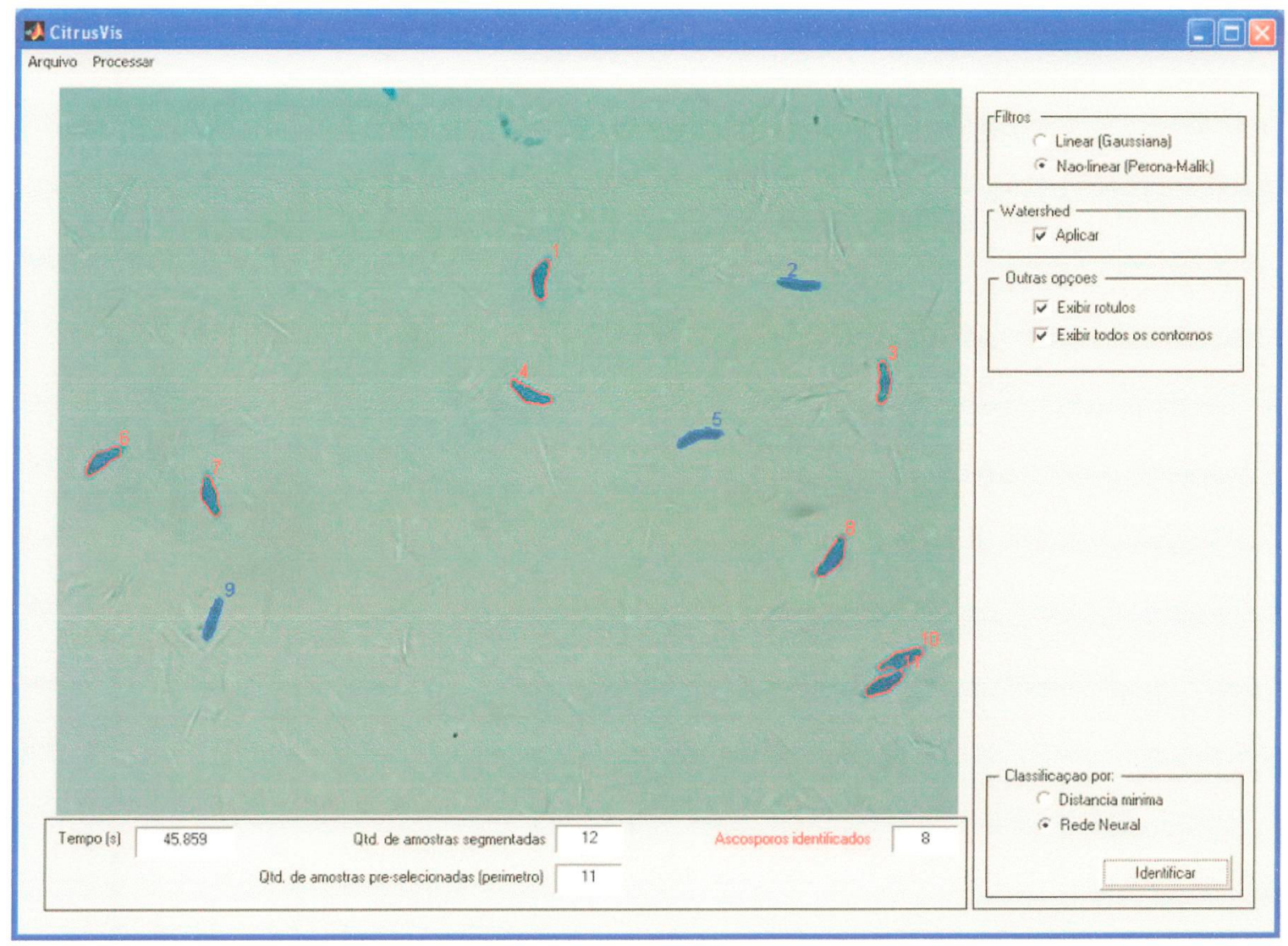

Figura 5.11: Interface do protótipo do CITRUSVIS.

Como a idéia principal desse protótipo foi a de construir um ambiente para testar e validar a abordagem adotada, algumas opções foram disponibilizadas a fim de permitir a seleção de algumas técnicas a serem aplicadas durante o processo de análise. Dessa maneira, possibilitando comparar melhor os resultados obtidos com a combinação de diferentes abordagens para a segmentação (filtros lineares ou não-lineares e a aplicação da watershed) e a identificação (baseada na distância mínima ou em redes neurais artificiais). Os resultados, além de exibidos em forma de texto (quantidade de amostras, quantidade de ascósporos e tempo), são mostrados sobre a própria imagem, sendo as partículas identificadas como ascósporos marcadas por um contorno em vermelho. Há também a opção para visualizar os demais contornos que foram pré-selecionados e também o rótulo das partículas (índice na lista de contornos), como mostrado na Figura 5.11. 


\subsection{Resultados Experimentais}

Para validar a solução adotada, foi realizada a análise com as imagens dos discos de coleta. Dessa maneira, todas as etapas desenvolvidas são aplicadas, desde a segmentação até a identificação das partículas existentes na imagem do disco. Para a realização desse experimento foram separados 3 conjuntos de imagens, chamados de Disco 1 (20 imagens), Disco 2 (15 imagens) e Disco 3 (20 imagens)

Foram realizados 3 experimentos, um para cada conjunto de imagens. Na avaliação dos resultados foram considerados os seguintes itens: tempo de processamento em segundos; quantidade de partículas segmentadas; quantidade de partículas pré-selecionadas pelo perímetro; número de erros ocorridos na pré-seleção (partículas de ascósporos que não foram pré-selecionadas); quantidade de ascósporos existentes na imagem (identificados manualmente); quantidade de ascósporos identificados corretamente pelo sistema; quantidade de falsos-positivos e falsos-negativos; e o erro total, que é a soma do número de erros ocorridos na pré-seleção e de erros da rede neural.

Os resultados obtidos com a análise de cada conjunto de imagens são apresentados nas Tabelas 5.1, 5.2 e 5.3. Nessas tabelas foram considerados dois tipos de erros: o erro referente à pré-seleção das partículas, que ocorre quando a partícula de um ascósporo não é pré-selecionada; e o erro referente à rede neural, que ocorre quando uma partícula pré-selecionada não é classificada corretamente pela rede. Neste último caso, ainda são separados os erros por falsos-positivos e por falsos-negativos, uma vez que nesse trabalho a ocorrência de falsos-negativos é mais preocupante do que a de falsos-positivos. Em cada uma dessas tabelas também é apresentado um resumo referente ao resultado geral obtido com o respectivo grupo de imagens.

Com base nos dados obtidos na análise dos 3 grupos de imagens, foi realizada uma avaliação geral dos experimentos, a qual é apresentada na Tabela 5.4.

O resultado geral obtido com esses experimentos foi de $96,6 \%$ de acerto na identificação das partículas existentes no disco, considerando apenas as partículas pré-selecionadas. Esse foi um resultado considerado mais que satisfatório, sinalizando o bom desempenho alcançado pela abordagem adotada para o CiTRUSVIs. Além disso, o tempo médio de processamento para cada imagem foi de um pouco mais de 1 minuto (66 segundos). Esse tempo foi considerado satisfatório, uma vez que o mesmo foi obtido por um protótipo do sistema e executado em um microcomputador Pentium $4^{\circledR}$ com 256 MB de memória RAM. Além disso, o protótipo é composto por scripts, os quais são interpretados.

Na Figura 5.12 são apresentadas 6 imagens com os ascósporos identificados por meio do protótipo desenvolvido. As marcações em vermelho indicam os ascósporos reconhecidos pela rede neural. Nessas imagens todas as partículas foram corretamente identificadas. Na Figura 5.13, entretanto, são apresentadas 6 imagens que apresentam erros na identificação (indicados pelas setas em amarelo). Dentre os exemplos mostrados, há erros tanto de falso-positivo quanto de falso-positivo. A ocorrência de falso-negativo, na maioria das vezes, foi por problemas na segmentação das partículas. Os casos de falso-positivo ocorreram em razão de partículas 
Tabela 5.1: Resultados obtidos com as imagens do Disco 1

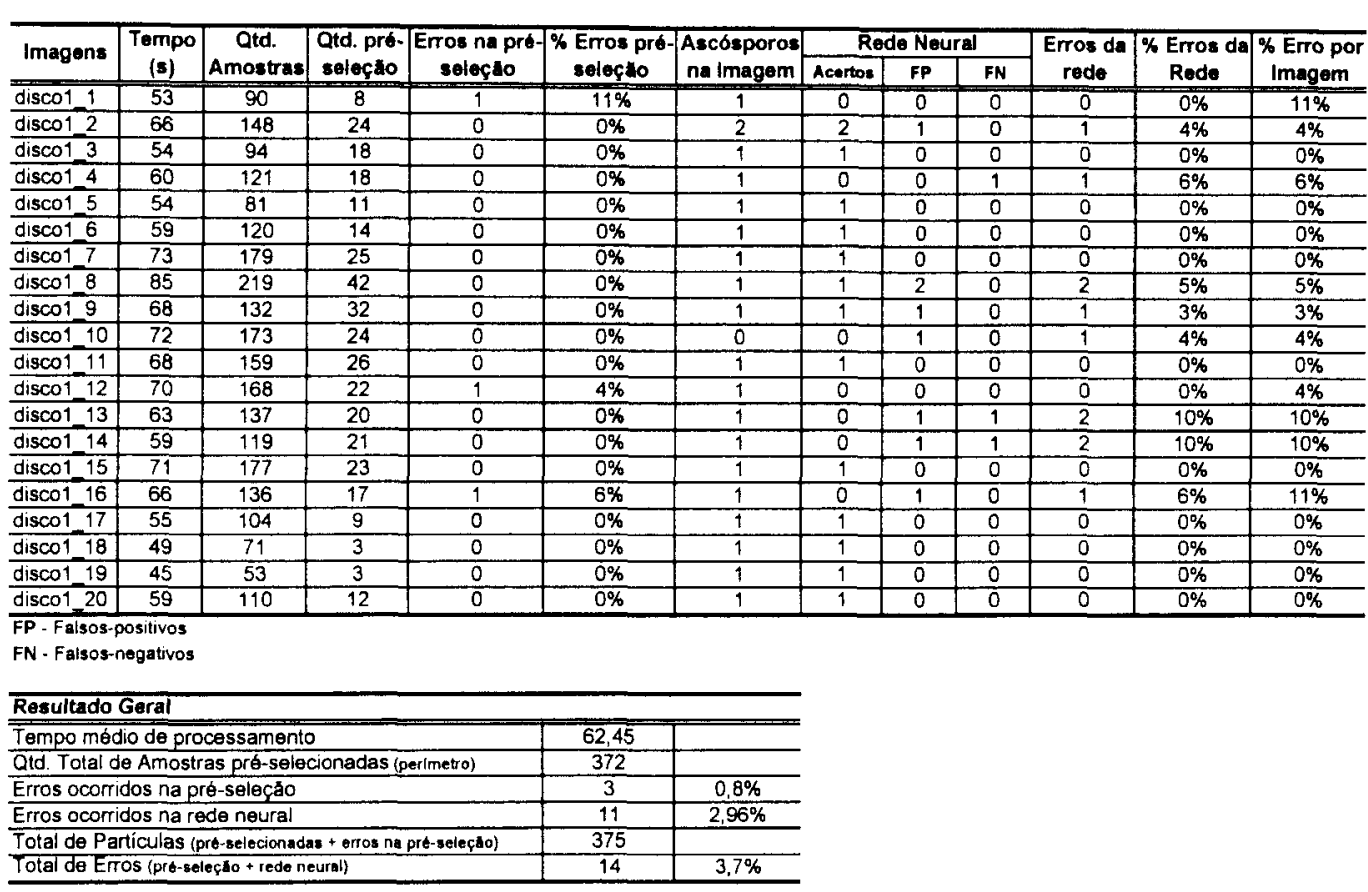

Tabela 5.2: Resultados obtidos com as imagens do Disco 2.

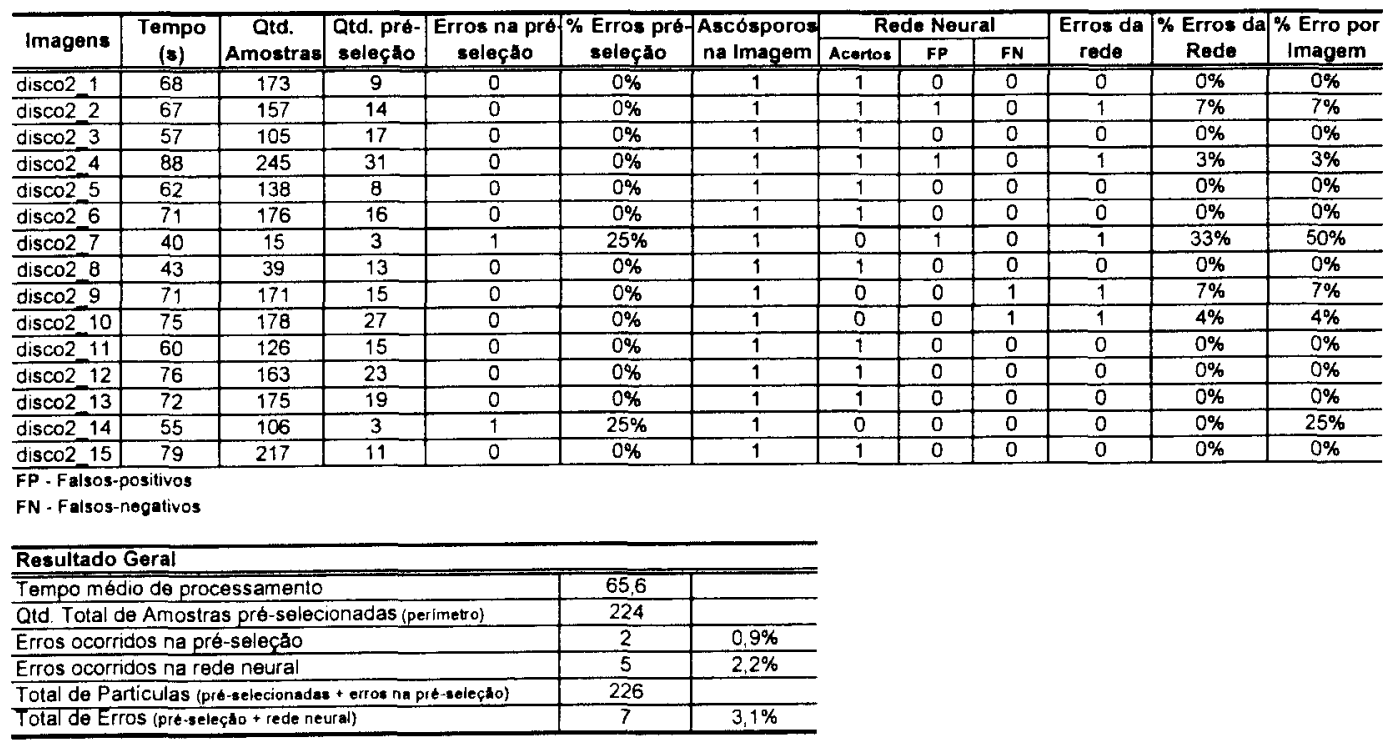

cuja forma é parecida com a de um ascósporo, ou que tenha o sinal da curvatura próximo à curvatura de um ascósporo. 
Tabela 5.3: Resultados obtidos com as imagens do Disco 3.

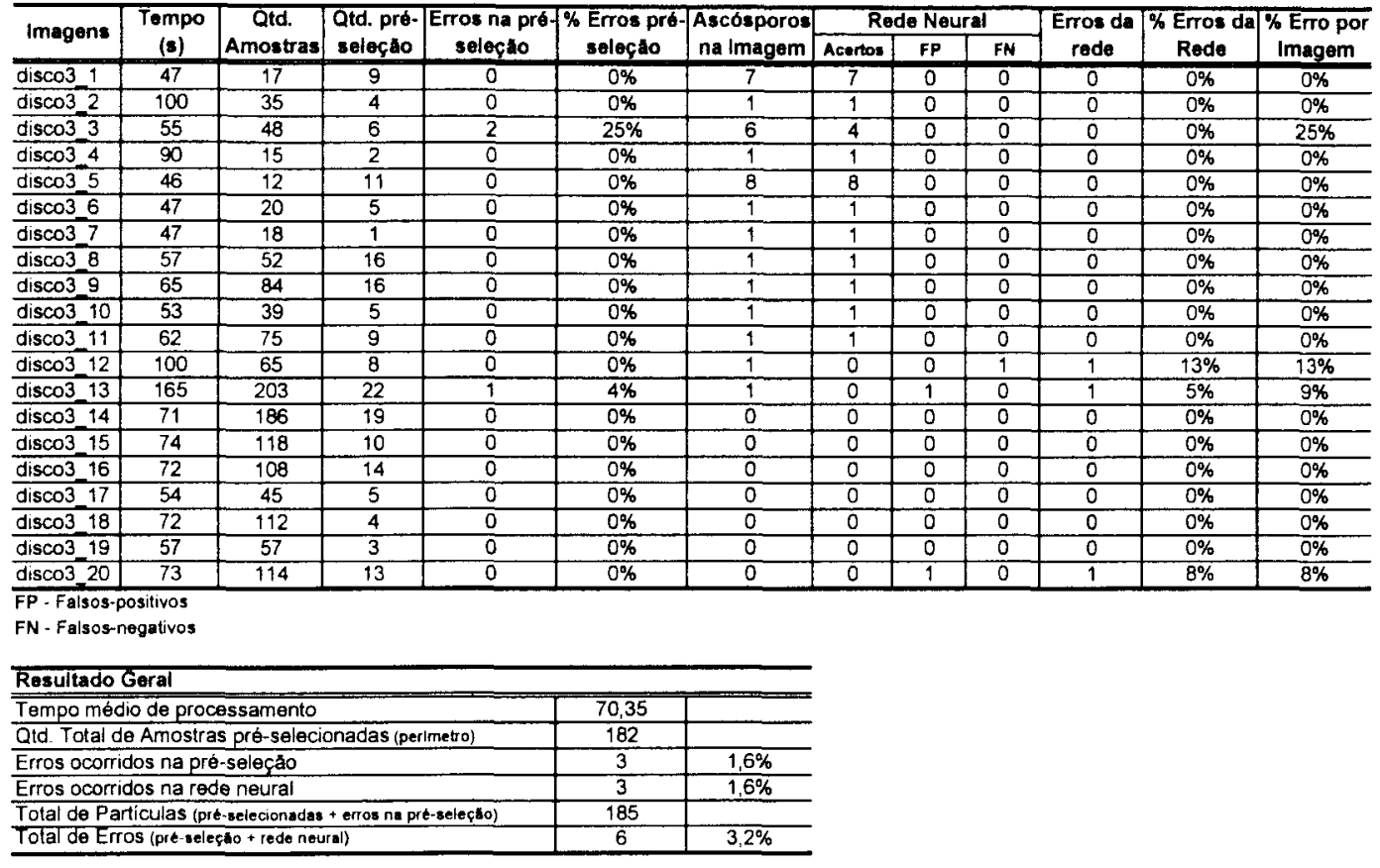

Tabela 5.4: Resultado Geral considerando todas as imagens (foram consideradas apenas as partículas pré-selecionadas a partir do perímetro)

\begin{tabular}{l|c|c}
\hline Resultado Geral (considerando as 55 imagens) \\
\hline \hline Tempo médio de processamento (s) & 66,13 & \\
\hline Qtd. Total de Amostras pré-selecionadas (perímetro) & 778 & \\
\hline Erros ocorridos na pré-seleção & 8 & $1,0 \%$ \\
\hline Erros ocorridos na rede neural & 19 & $2,4 \%$ \\
\hline Total de Partículas (pré-selecionadas + erros na pré-seleção) & 786 & \\
\hline Total de Erros (pré-seleção + rede neural) & 27 & $3,4 \%$ \\
\hline
\end{tabular}

\subsection{Considerações Finais}

Neste capítulo foram apresentadas as etapas desenvolvidas para o sistema de visão computacional CiTRUSVIS. O resultado obtido com a aplicação das técnicas selecionadas foi considerado bastante satisfatório. É importante ressaltar que grande parte desse resultado se deve à descrição das partículas por meio da curvatura da forma, a partir da qual foram extraídos os descritores de Fourier. Além disso, o desempenho obtido com a rede também atendeu as expectativas, dada a variedade das partículas submetidas à análise. A implementação do CiTRUSVIS, embora seja apenas um protótipo, foi bastante positiva, pois permitiu analisar o comportamento das técnicas em cada uma das etapas realizadas, bem como os resultados obtidos com cada uma delas. Também possibilitou observar a contribuição de cada técnica para o resultado final. Outro aspecto importante quanto ao protótipo foi a facilidade quanto à manipulação do conjunto de imagens e à obtenção dos resultados. O tempo de processamento para cada imagem foi satisfatório, considerando as técnicas que foram empregadas na análise. 


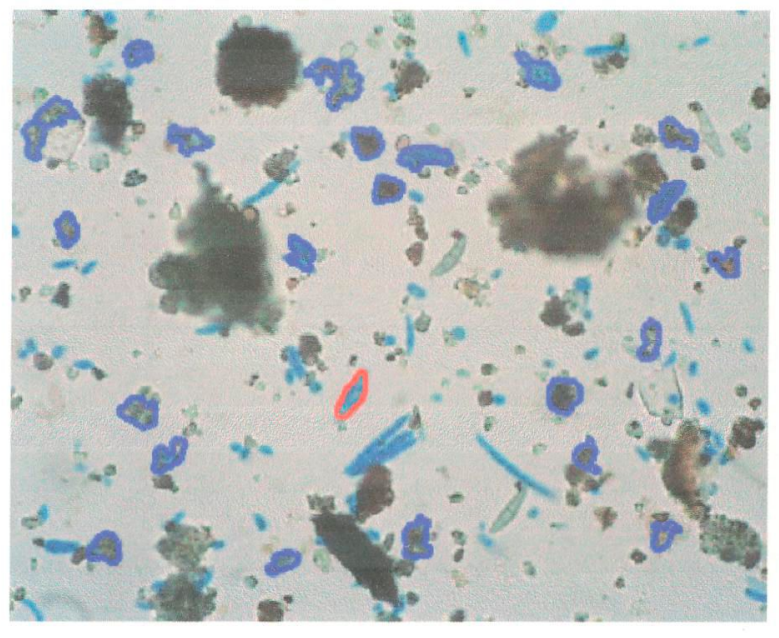

(a)

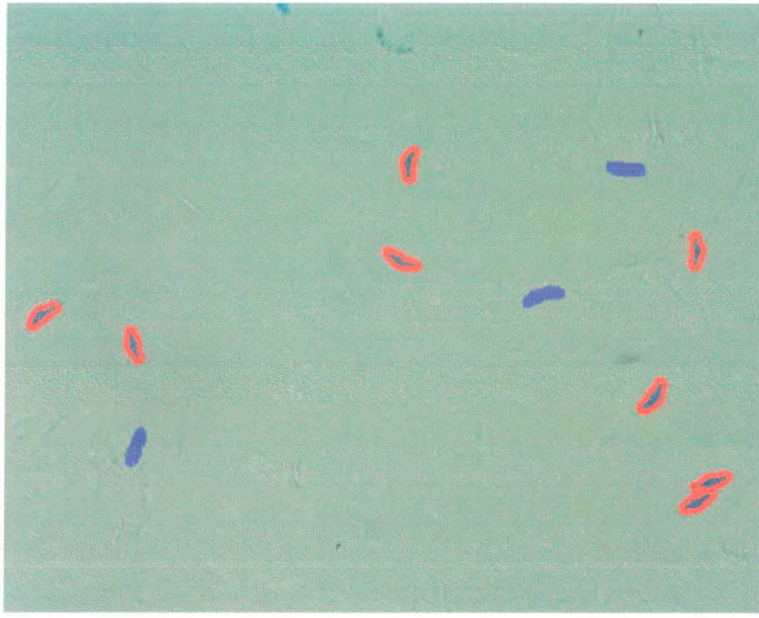

(c)

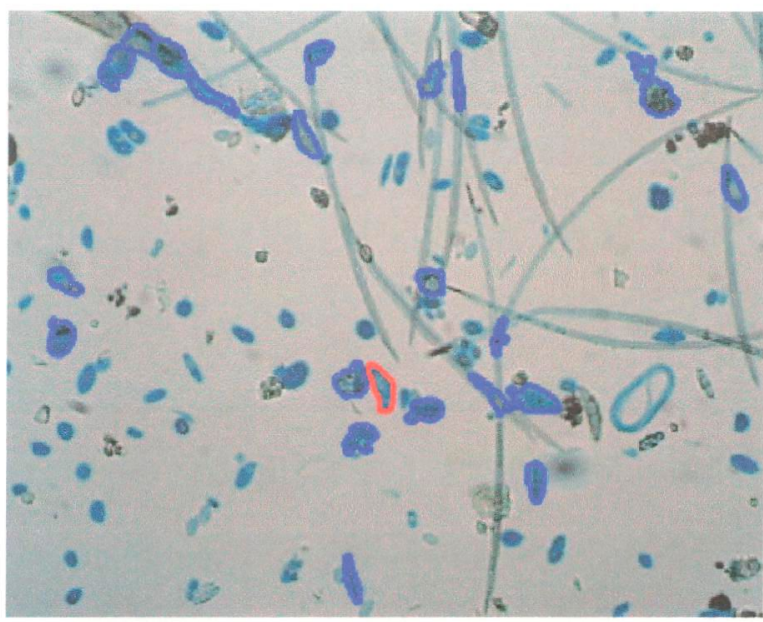

(e)

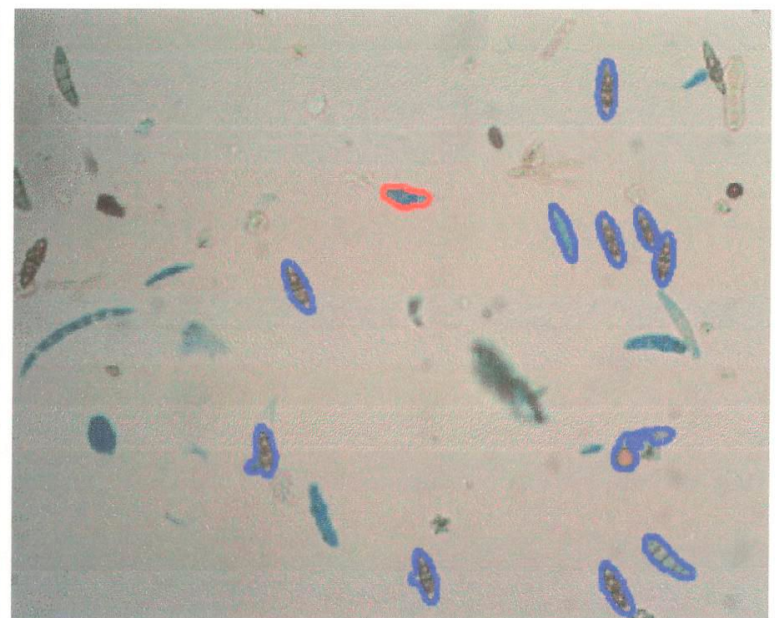

(b)

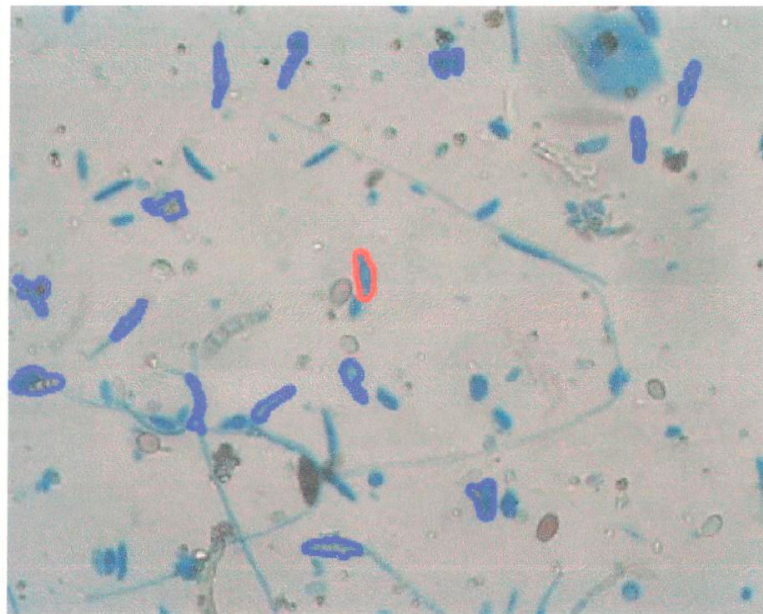

(d)

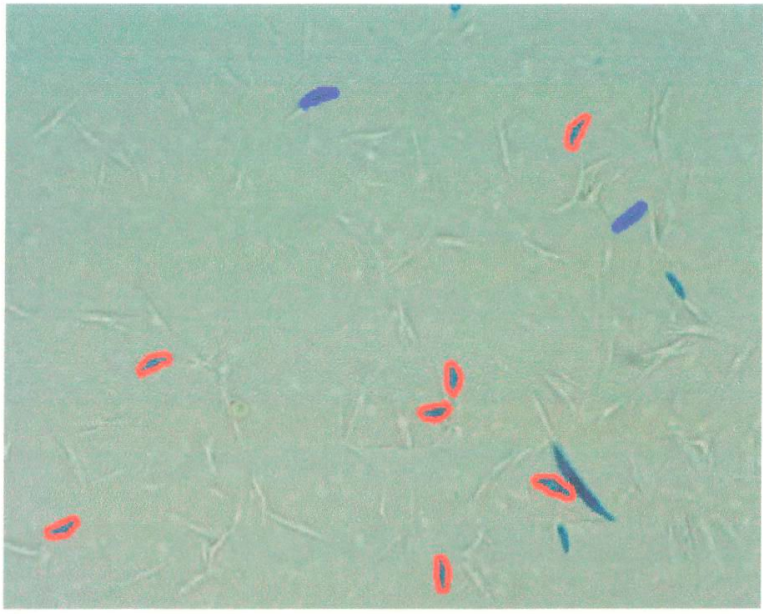

(f)

Figura 5.12: Imagens obtidas após o processo de análise. Em vermelho, são os ascósporos identificados corretamente, e em azul, as demais partículas. Esse resultado foi obtido com protótipo do CITRUSVIS.

Nos resultados apresentados anteriormente, foram consideradas apenas as partículas pré-selecionadas dentro do intervalo de perímetro definido. No entanto, a pré-seleção realizada ao se extrair o contorno das partículas, também é considerado um processo de classificação, no qual as 


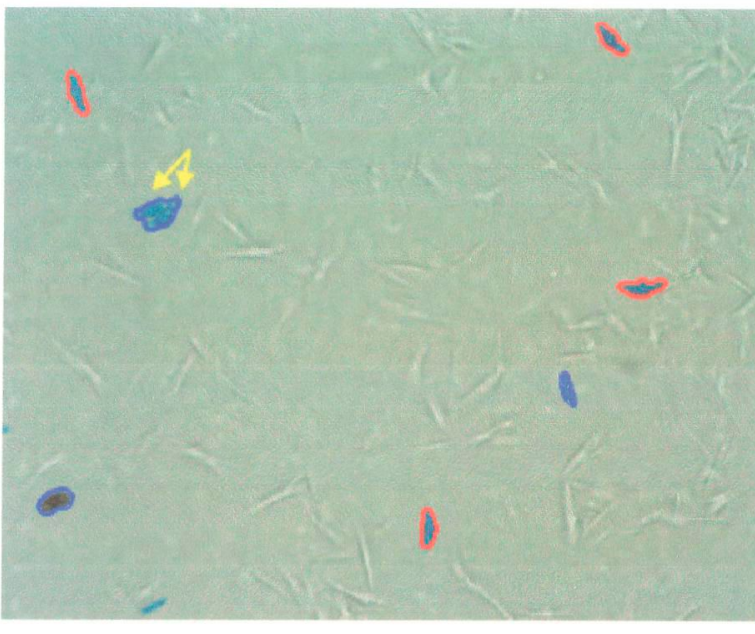

(a)

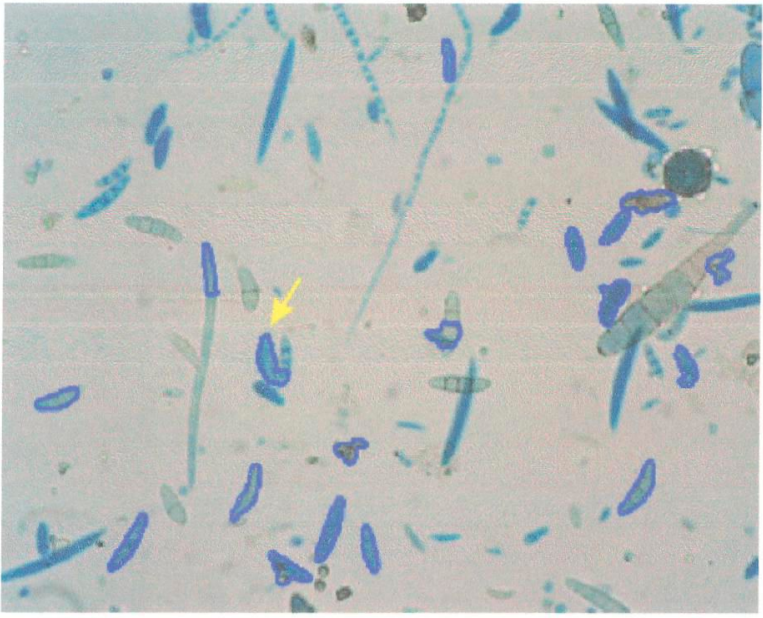

(c)

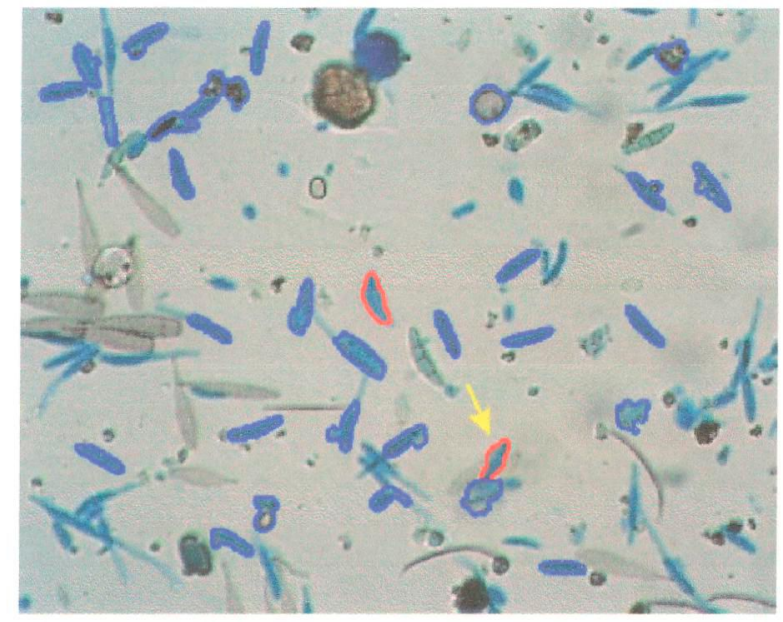

(e)

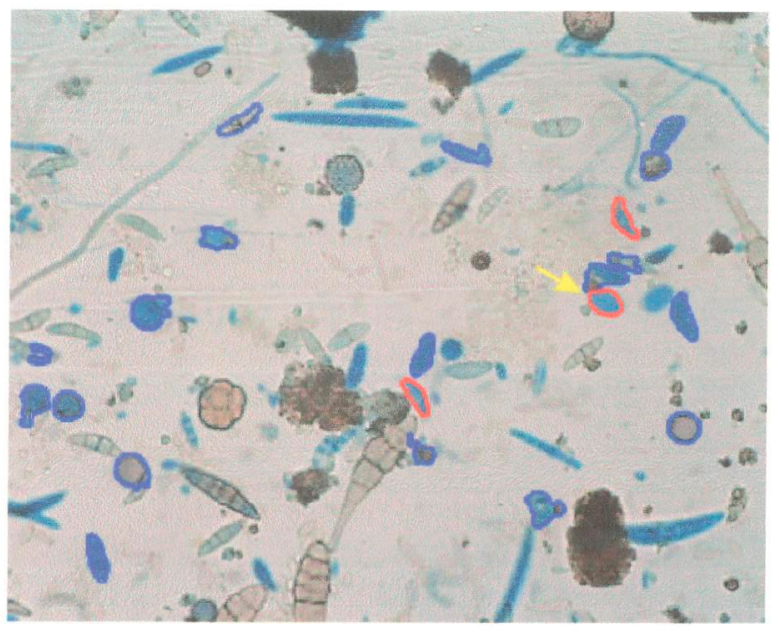

(b)

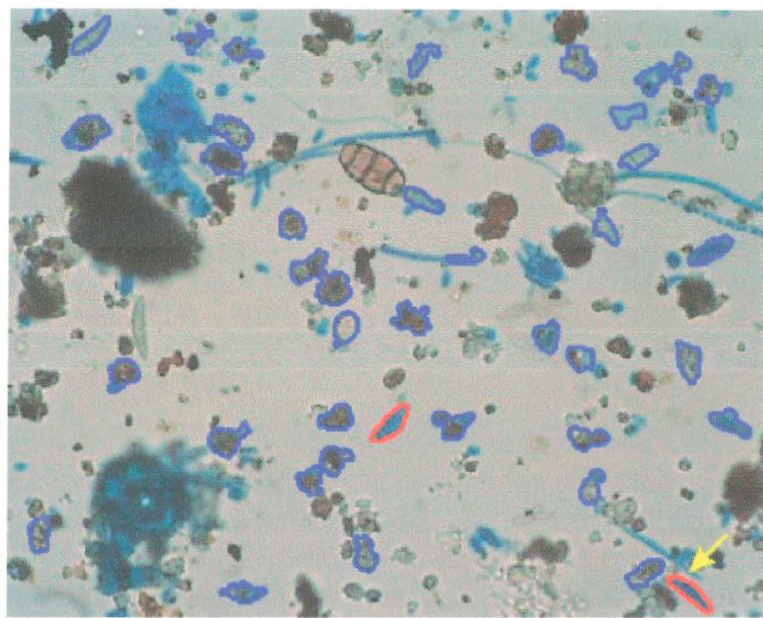

(d)

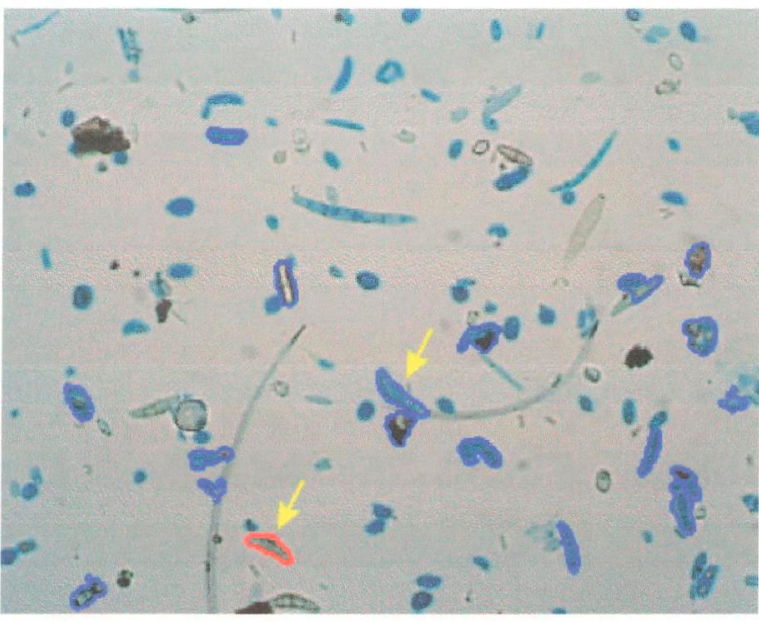

(f)

Figura 5.13: Imagens obtidas após o processo de análise que apresentaram erro na identificação. Em destaque (setas amarelas), são as partículas identificadas incorretamente.

partículas que não apresentavam perímetro dentro do intervalo considerado para os ascósporos, foram descartadas, ou seja, classificadas de imediato como não ascósporos. Dessa maneira, ao considerar todas as partículas segmentadas, indistintamente, o percentual de erro geral obtido foi de apenas $0,4 \%$, ou seja, $99,6 \%$ de acerto na classificação das partículas (Tabela 5.5). 
Tabela 5.5: Resultados obtido considerando todas as partículas segmentadas.

\begin{tabular}{c|c|c|c}
\hline Disco & Partículas segmentadas & Erros por disco & \% de Erro \\
\hline \hline $\mathbf{1}(20$ imagens $)$ & 2591 & 14 & $0,54 \%$ \\
\hline $\mathbf{2}(15$ imagens $)$ & 2184 & 7 & $0,32 \%$ \\
\hline $\mathbf{3}(20$ imagens $)$ & 1423 & 6 & $0,42 \%$ \\
\hline \hline Total & 6198 & 27 & $0,44 \%$ \\
\hline
\end{tabular}

Contudo, seria interessante a aplicação do experimento em um conjunto maior de imagens, a fim de realizar uma análise amostral de um número maior de discos, para comparar o resultado obtido pelo sistema ao resultado obtido com a análise manual. 


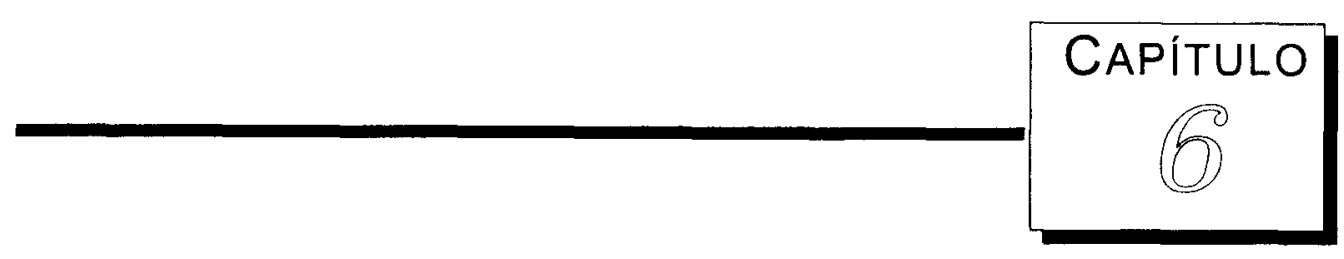

Conclusão

citricultura tem um importante papel na economia brasileira, pois o país é responsável por $80 \%$ da produção mundial de suco concentrado. No entanto, várias doenças e pragas, algumas delas ainda sem controle efetivo, preocupam produtores e empresas, apresentando-se como principal desafio para que a citricultura mantenha sua expressão no cenário mundial. Por esse motivo, a introdução de novas tecnologias integradas com recursos computacionais, visando à produtividade e à qualidade, passou a ser uma alternativa em busca de melhorias tanto na citricultura, quanto em outras produções.

Uma das principais doenças que ameaçam a produção de laranja é a mancha preta, que afeta principalmente a comercialização de frutas in natura. A identificação dos ascósporos do fungo Guignardia citricarpa, principais responsáveis pela introdução do patógeno no pomar, provê um importante mecanismo de auxílio no combate a essa doença. Diagnosticar a presença da doença no pomar antes que os sintomas comecem a aparecer é uma ação fundamental, pois os sintomas podem demorar até doze meses para surgirem. Considerando que os principais sintomas da doença são as lesões nos frutos, esperar pelo surgimento deles para que seja confirmada a presença da doença no pomar é inviável, pois, até que eles apareçam, todo o pomar pode ser infectado, sendo tarde para que um combate eficaz e de baixo custo possa ser efetuado. Uma estratégia é a identificação da doença por meio da infestação de ascósporos presentes no ar, que possibilita a identificação da doença antes do surgimento dos sintomas.

No entanto, para que esse diagnóstico seja obtido, faz-se necessária a coleta dos esporos em suspensão no pomar, que é efetuada por meio de um equipamento específico, e a análise dos discos de coleta por especialistas, que é realizada visualmente com o auxilio de um microscópio, para identificar e contar os ascósporos existentes. Essa tarefa é demorada e bastante desgastante para o ser humano, que com o cansaço pode cometer erros durante a análise. Além disso, dada a quantidade de discos a serem analisados por pomar, o número de pomares a serem monitorados e a necessidade de técnicos preparados para realizar a identificação, que, segundo os especialistas, não é uma tarefa trivial, logo inviável. Por esse motivo, foi proposto este traba- 
lho com o objetivo de desenvolver um sistema de visão computacional que auxilie o especialista no processo de identificação e contagem dos ascósporos do fungo, automatizando e, ao mesmo tempo, agilizando a etapa de análise dos discos.

Para o desenvolvimento desse sistema, foram envolvidas as áreas de visão computacional, morfologia matemática, processamento de imagens e de sinais, além de aspectos biológicos, sendo esta uma pesquisa multidisciplinar voltada para a área de agrotecnologia. A principal etapa desenvolvida neste trabalho, foi o estudo de técnicas para a caracterização dos ascósporos. Para a seleção dessas técnicas, um estudo comparativo foi realizado com base em um conjunto de amostras referente às formas encontradas nas imagens. Nesse estudo, a técnica selecionada foi a curvatura da forma associada aos descritores de Fourier, que apresentou o melhor resultado na caracterização e segregação do conjunto de amostras, comparada às demais técnicas abordadas.

Após a seleção das técnicas para a análise e extração de características, foi dada atenção às demais etapas necessárias a um sistema de visão computacional. Um resultado satisfatório foi alcançado com a combinação entre algumas delas, como a que ocorreu na fase de segmentação da imagem. Em razão das imagens conterem muitas partículas e não apresentarem uniformidade entre elas, a combinação de técnicas de limiarização com filtros não-lineares e a transformada watershed permitiu que grande parte das partículas fossem segmentadas corretamente. Na etapa de identificação das partículas, foram aplicadas duas técnicas: classificação por distância mínima e redes neurais artificiais. Dentre elas, foi selecionada a rede neural, por se ter obtido melhores resultados com ela. Ao fim desse estudo, um protótipo do sistema foi implementado em MATLAB ${ }^{\circledR}$ com o objetivo de testar e validar a funcionalidade das técnicas selecionadas. Com esse protótipo foi possível analisar cada uma das imagens, efetuando a contagem das partículas de ascósporos. Além disso, cada uma dessas partículas são marcadas na imagem para que o especialista possa verificar o resultado apresentado pelo protótipo.

É importante ressaltar que algumas imagens utilizadas para os testes apresentaram problemas que dificultaram a análise, como: a baixa qualidade e resolução das imagens, a falta de foco, que causou borramentos em algumas delas, a não padronização dos fatores de ampliação das imagens, entre outros. Mesmo com essas dificuldades, o resultado alcançado nos experimentos para a identificação dos ascósporos foi considerado bastante satisfatório $(96,6 \%$ de acerto), atendendo as expectativas. Acredita-se que esse resultado, no entanto, possa ser melhorado com o uso de imagens padronizadas e de melhor qualidade. Também deve ser considerado que esse resultado baseia-se apenas nas partículas que foram submetidas à identificação pela rede neural - as partículas pré-selecionadas em relação ao perímetro. Se for considerado o total de partículas segmentadas, o percentual de acerto é de $99,6 \%$, pois a pré-seleção a partir do perimetro elimina boa parte das partículas de não ascósporos. Além disso, essas imagens apresentaram uma variedade muito grande de partículas, inclusive partículas com formas bastante próximas à forma de um ascósporo. 


\subsection{Contribuições}

O presente trabalho teve como principais contribuições:

- a apresentação de uma solução para a detecção da doença da mancha preta (Guignardia citricarpa) aplicando-se técnicas de visão computacional;

- o desenvolvimento de um método para a identificação dos ascósporos do fungo Guignar dia citricarpa, que auxiliará no controle/combate da doença da mancha preta no pomares;

- a comparação entre diferentes técnicas de visão computacional para análise de formas, apresentando vantagens e desvantagens de cada uma delas, o que pode auxiliar ou oferecer alternativas a outras situações que apresentem problemas similares;

- o resultado satisfatório obtido com a combinação de diferentes técnicas para a melhoria do processo de segmentação, o qual foi baseado em limiarização com a aplicação de filtros não-lineares, neste caso o de Perona-Malik;

- o desenvolvimento do protótipo do CITRUSVIS com base nas técnicas estudadas, que possibilitou a realização dos experimentos envolvendo todas as etapas do sistema.

\subsection{Trabalhos Futuros}

Espera-se, com base no protótipo desenvolvido, a implementação do sistema completo (em linguagem compilada) que efetue a análise em lote dos discos pertencentes a um determinado pomar. Com isso, possibilitando uma análise estatística completa que forneça ao especialista um panorama da situação em que o pomar se encontra.

Outra possibilidade é adequar este trabalho na identificação de outras pragas e doenças, ou a problemas cuja aplicação seja similar. Também pode-se estudar a viabilidade de implementar um mecanismo que efetue a análise in loco (no pomar).

Um outro aspecto importante que pode contribuir na melhoria dos resultados é a adequação do processo de aquisição de imagens, procurando adquirir imagens com maior resolução, sem problemas de foco ou de variação de iluminação, se possível. Neste projeto, as etapas de coleta e aquisição de imagens foram realizadas por outras instituições, não tendo sido tomada nenhuma precaução quanto a esses fatores. Com a aquisição de imagens com boa qualidade e resolução, pode ser retomada a abordagem baseada na segmentação baseada no modelo de cor HSI. Dessa maneira, poderá ser testada a técnica com um conjunto melhor e maior de imagens.

Há também a possibilidade de se desenvolver um sistema baseado em conhecimento, que possa indicar a ação de combate à doença a ser realizada, com base na situação em que o pomar se apresenta. 


\section{Referências Bibliográficas}

Alvarez, L.; Lions, P. L.; MOREL, J. M. Image selective smoothing and edge detection by nonlinear diffusion, ii. SIAMJ. Numer. Anal., vol. 29, no. 3, pgs. 845-866, 1992.

Ankenbrandt, C. A.; Buckles, B. P.; Petry, F. E. Scene recognition using genetic algorithms with semantic nets. Pattern Recognition Letters, vol. 11, pgs. 285-293, 1990.

BAJlA, I.; HOLlÄNDER, I. Nonlinear filtering of magnetic resonance tomograms by geometry-driven diffusion. Mach. Vision Appl., vol. 10, no. 5-6, pgs. 243-255, 1998.

BALDASSARI, R. B. Influência de frutos sintomáticos na incidência em uma safra da Guignardia citricarpa na safra subseqüente e periodo de suscetibilidade de frutos de laranjeiras Natal e Valência. Dissertação de mestrado, Universidade Estadual Paulista, Jaboticabal, SP, 2001 .

Baldassari, R. B.; De Goes, A.; Santos, J. M.; Timossi, A. J. Microscopia eletrônica de varredura de isolados de Guignardia citricarpa obtidos de plantas cítricas. Summa Phytopathologica, vol. 27, no. 1, pgs. 88-92, 2001.

BARSHAN, B.; AYRULU, B. Fuzzy clustering and enumeration of target type based on sonar returns. Pattern Recognition, vol. 37, pgs. 189-199, 2004.

BERKHIN, P. Survey of clustering data mining techniques. Relatório técnico, Accrue Software, San Jose, CA, 2002.

BezdeK, J. C.; PAL, S. K. Fuzzy models for pattern recognition. Piscataway: IEEE Press, 1992.

Black, M.; SAPIRO, G.; MARIMONT, D.; HeEgER, D. Robust anisotropic diffusion. IEEE Transactions on Image Processing, vol. 7, no. 3, pgs. 421-432, 1998.

Braga, A. P.; Ludermir, T. B.; Carvalho, A. C. P. L. F. Redes neurais artificiais Teoria e aplicação. Rio de Janeiro: LTC, 262 pgs., 2000.

BRIghAM, E. O. The fast Fourier Transform and its application. Englewood Cliffs: Prentice Hall, 448 pgs, 1988. 
Castleman, K. R. Digital image processing. Englewood Cliffs, NJ: Prentice-Hall, 672 pgs., 1996.

CATté, F.; Lions, P.-L.; MORel, J.-M.; Coll, T. Image selective smoothing and edge detection by nonlinear diffusion. SIAM J. Numer. Anal., vol. 29, no. 1, pgs. 182-193, 1992.

CESAR, JR, R. M. Análise multi-escala de formas bidimensionais. Tese de doutorado, Universidade de São Paulo, São Carlos, SP, 1997.

CESAR, JR, R. M.; COSTA, L. D. F. Towards effective planar shape representation with multiscale digital curvature analysis based on signal processing techniques. Pattern Recognition, vol. 29 , no. 9 , pgs. 1559-1569, 1996a.

CESAR, JR, R. M.; COSTA, L. F. Shape caracterization in natural scales by using the multiscale bending energy. Em: ICPR 96, 1996b, pgs. 735-739.

Chong, C.-W.; Raveendran, P.; Mukundan, R. Translation and scale invariants of Legendre moments. Pattern Recognition, vol. 37, no. 1, pgs. 119-129, 2004.

de Defesa da Citricultura, F. F. Pinta preta, 2004.

Disponivel em http://www. fundecitrus.com.br/ppreta.htm I (Acessado em $01 / 2004)$

COSTA, L. F.; CESAR, JR, R. M. Shape analysis and classification: theory and practice. CRC Press, 659 pgs., 2000.

Demuth, H.; Beale, M. Neural network toolbox for use with Matlab. User's guide, The MathWorks, Inc., 2003.

DUdA, R. O.; HART, P. E.; STORK, D. G. Pattern classification. 2 ed.. Wiley Interscience, 680 pgs., 2001.

Dudani, S. A.; Breeding, K. J.; MCGhee, R. B. Aircraft identification by moment invariants. IEEE Trans. Computer, vol. 26, no. 1, pgs. 39-46, 1977.

Duncan, J. S.; Lee, F. A.; Smeulders, A. W. M.; Zaret, B. L. A bending energy model for measurement of cardiac shape deformity, IEEE Transactions on Medical Imaging, vol. 10 , no. 3, pgs. 307-320, 1991.

Duncan, J. S.; Smeulders, A.; LeE, F. A.; Zaret, B. L. Measurement of end diastolic shape deformity using bending energy. Em: Computers in Cardiology, 1988, pgs. 277-280.

DUNN, J. A fuzzy relative of the ISODATA process and its use in detecting compact well-separated clusters. Journal of Cybernetics, , no. 3, pgs. 32-57, 1974.

Egmont-PETERSEn, M.; Ridder, D.; Handels, H. Image processing with neural networks - a review. Pattern Recognition, vol. 35, pgs. 2279-2301, 2002. 
FABER, V. Clustering and the continuous k-means algorithm. Los Alamos Science Magazine, vol. 22, pgs. 138-144, 1994.

FLUSSER, J. On the independence of rotation moment invariants. Pattern Recognition, vol. 33, pgs. 1405-1410, 2000.

Flusser, J.; SUk, T. Pattern recognition by affine moment invariants. Pattern Recognition, vol. 26 , no. 1 , pgs. $167-174,1993$.

FLUSSER, J.; SUK, T. Affine moment invariants: a new tool for character recognition. Pattern Recognition Letters, vol. 15, pgs. 433-436, 1994.

FUKUNAGA, K. Introduction to statistical pattern recognition. Boston: Academic Press, 591 pgs., 1990.

Gonzalez, R. C.; Wintz, P. Digital image processing. Massachussetts: Addison-Wesley, 503 pgs., 1987.

GONZALEZ, R. C.; WoOdS, R. E. Digital image processing. Massachussetts: Addison-Wesley, 716 pgs., 1993.

Gonzalez, R. C.; Woods, R. E. Digital image processing. New Jersey: Prentice-Hall, 793 pgs., 2002.

Gonzalez-Rodriguez, M.; Benitez-Diaz, D.; Suarez-Araujo, C. P. Segmentation and recognition in visual chromatic spaces. CYBERNETICS SYSTEMS, vol. 21, pgs. $241-247,1990$.

GUPTA, L.; SRINATH, M. D. Contour sequence moments for the classification of closed planar shapes. Pattern Recognition, vol. 20, pgs. 267-272, 1987.

HaGAN, M. T.; MENHaJ, M. Training feedforward networks with the marquardt algorithm. IEEE Transactions on Neural Networks, vol. 5, no. 6, pgs. 989--993, 1994.

HeARn, D.; BAKer, M. P. Computer graphics. Prentice-Hall, 652 pgs., 1994.

HU, M. K. Visual pattern recognition by moment invariants. IEEE Transactions on Information Theory, vol. 8, no. 2, pgs. 179-187, 1962.

HUANG, Z. A fast clustering algorithm to cluster very large categorical data sets in data mining. Em: Research Issues on Data Mining and Knowledge Discovery, 1997.

HUANG, Z. Extensions to the k-means algorithm for clustering large data sets with categorical values. Data Mining and Knowledge Discovery, vol. 2, no. 3, pgs. 283-304, 1998.

JAIN, A. K. Fundamentals of digital image processing. Englewood Cliffs, NJ: Prentice-Hall, 569 pgs., 1989. 
JAIN, A. K.; DUIN, R. P. W.; MAO, J. Statistical pattern recognition: A review. IEEE Transactions on Pattern Analysis and Machine Intelligence, vol. 22, no. 1, pgs. 4-37, 2000.

JAIN, A. K.; MAO, J.; MOHIUdDin, K. M. Artificial neural networks: A tutorial. IEEE Computer, vol. 29 , no. 3 , pgs. $31-44,1996$.

Jain, A. K.; Murty, M. N.; FlynN, P. J. Data clustering: a review. ACM Computing Surveys, vol. 31, no. 3, pgs. 264-323, 1999.

Kauppinen, H.; Seppänen, T.; PietikäInen, M. An experimental comparison of autoregressive and fourier-based descriptors in $2 \mathrm{~d}$ shape classification. IEEE Trans. Pattern Anal. Mach. Intell., vol. 17, no. 2, pgs. 201-207, 1995.

LEVINE, M. D. Vision in man and machine. New York: McGraw-Hill, 574 pgs., 1985.

LIM, Y. W.; LEE, S. U. On the color image segmentation algorithm based on the thresholding and the fuzzy c-means techniques. PR, vol. 23, pgs. 935-952, 1990.

LONCARIC, S. A survey of shape analysis techniques. Pattern Recognition, vol. 31, no. 8, pgs. 983-1001, 1998 .

LOWE, D. G. Object recognition from local scale-invariant features. Em: Proc. of the International Conference on Computer Vision ICCV, Corfu, 1999, pgs. 1150-1157.

MA, E. W. M.; CHOW, T. W. S. A new shifting grid clustering algorithm. Pattern Recognition, vol. 37, pgs. 503-514, 2004.

MACQUEEN, J. Some methods for classifications and analysis of multivariate observations. Em: Fifth Berkeley Symposium on Mathematical statistics and probability, Berkeley: University of California Press, 1967, pgs. 281-297.

MALlAT, S. A wavelet tour of signal processing: Wavelet analysis and its applications). 2 ed.. San Diego: Academic Press, 637 pgs., 1999.

MARR, D. Vision. New York: W. H. Freeman and Company, 397 pgs., 1996.

MCCulloch, W. S.; PitTs, W. A logical calculus of ideas immanent in nervous activity. Bulletin of Mathematical Biophysics, vol. 5, pgs. 115-133, 1943.

Medioni, G. G.; Yasumoto, Y. Corner detection and curve representation using cubic B-splines. Computer Vision Graphics and Image Process, vol. 39, no. 3, pgs. 267-278, 1987.

Misiti, M.; Misiti, Y.; OppenheiM, G.; PogGi, J.-M. Wavelet toolbox for use with Matlab. User's guide, The MathWorks, Inc., 2004. 
MOKHTARIAN, F.; MACKWORTH, A. K. A theory of multi-scale, curvature-based shape representation for planar curves. IEEE Trans. Pattern Analysis and Machine Intelligence, vol. 14, no. 8, pgs. 789-805, 1992.

MOREL, J.-M.; SOlimini, S. Variational methods in image segmentation. Boston: Birkhäauser, 245 pgs., 1995

Neves, E. M.; Dayoub, M.; Dragone, D. S.; Neves, M. F. Citricultura brasileira: Efeitos econômico-financeiros, 1996 - 2000, 2004.

Disponível em http://www abecitrus . com. br/ (Acessado em 01/2004)

NEVES, M. F.; MARINO, M. K. Estudo da competitividade de cadeias integradas no Brasil: Impactos das zonas de livre comércio - cadeia: Citros, 2002.

Disponível em http://www abecitrus. com.br/(Acessado em 01/2004)

NORONHA, M. A. Escala diagramática para avaliação da mancha preta em folhas de citros e efeito de temperatura e da duração do molhamento na pré-penetração deconidios de Guig nardia citricarpa Kiely. Dissertação de mestrado, Universidade de São Paulo, Piracicaba, SP, 2002

OSOWSKI, S.; NGHIA, D. D. Fourier and wavelet descriptors for shape recognition using neural networks - a comparative study. Pattern Recognition, vol. 35, pgs. 1949-1957, 2002

OTSU, N. A threshold selection method from grey-level histograms. IEEE Trans. on Systems, Man, and Cybernetics, vol. 9, no. 1, pgs. 62-66, 1979

PARKER, J. R. Algorithms for image processing and computer vision. New York: Wiley Computer Publishing, 417 pgs., 1997.

PAVLIDIS, T. Algorithms for graphics and image processing. Computer Science Press, 416 pgs., 1982

PERONA, P.; MALIK, J. Scale-space and edge detection using anisotropic diffusion. IEEE Trans. Pattern Anal. Mach. Intell., vol. 12, no. 7, pgs. 629-639, 1990.

POLETTI, M. Varianilidade inter e intraespecifica na suscetibilidade de ácaros fitoseideos (acari phytoseiidae) a dicofol e deltametrina em citros. Dissertação de mestrado, Universidade de São Paulo, Piracicaba, SP, 2002.

RAUDYS, S. J.; JAIN, A. K. Small sample size effects in statistical pattern recognition: Recommendations for practitioners. IEEE Transactions on Pattern Analysis and Machine Intelligence, vol. 13, no. 3, pgs. 252-264, 1991

RICK, L. S. A real-time high performance universal colour transformation hardware system. Tese de doutorado, University of Kent at Canterbury, Canterbury - Kent, 2000. 
RoERdink, J. B.; MEIJster, A. The watershed transform: Definitions, algorithms and parallelization strategies. Fundamenta Informaticae, vol. 41, pgs. 187-228, 2000

Rosenfeld, A.; Johnston, E. Angle detection on digital curves. IEEE Trans. Computer, vol. 22 , pgs. $875-878,1973$.

Rumelhart, D. E.; MCClelland, J. L. Parallel distributed processing, vol. 1. The MIT Press, 576 pgs., 1986.

RUss, J. C. The image processing handbook. CRC Press, 732 pgs., 2002.

Sahoo, P. K.; Soltani, S.; WonG, A. K. C.; Chen, Y. C. A survey of thresholding techniques. Comput. Vision Graph. Image Process., vol. 41, no. 2, pgs. 233-260, 1988

SAITO, T.; TORIWAKI, J. I. New algorithms for euclidean distance transformation of an n-dimensional digitized picture with applications. Pattern Recognition, vol. 27, no. 11, pgs. $1551-1565,1994$

Salama, G. I.; Аввотt, A. L. Moment invariants and quantization effects. Em: CVPR 98, 1998, pgs. 157-163.

SECEX Ministério do Desenvolvimento, Indústria e Comércio - Secretaria do Comércio Exterior, 2003.

Disponivel em http://www. mdic.gov.br (Acessado em 10/2003)

SONKA, M.; HLAVAC, V.; BOYLE, R. Image processing, analysis, and machine vision. 2 ed.. Pacific Grove: Brooks Cole, 770 pgs., 1999.

SPósito, M. B. Dinâmica temporal e espacial da mancha preta (guignardia citricarpa) e quantificação dos danos causados à cultura dos citros. Tese de doutorado, Universidade de São Paulo, Piracicaba, SP, 2003.

Suri, J. S.; WU, D.; GaO, J.; SINGH, S.; LAXMinarayan, S. A comparison of state-of-the-art diffusion imaging techniques for smoothing medical/non-medical image data. Em: Proceedings of 16 th International Conference on Pattern Recognition, IEEE Computer Society, 2002, pgs. 508-511.

TAHRI, O,; CHAUMETTE, F. Applicattion of moment invariants to visual servoing. Em: IEEE International Conference on Robotics and Automation, Taipei, Taiwan, 2003, pgs. 14-19.

TAO, Y.; LAM, E. C. M.; TANG, Y. Y. Feature extraction using wavelet and fractal. Pattern Recognition Letters, vol. 22, no. 3-4, pgs. 271-287, 2001.

TOLEDO, L. R. O desafio dos pomos de ouro. Revista Globo Rural, , no. 232, pgs. 1-5, 2005.

Tou, J. T.; Gonzalez, R. C. Pattern recognition principles. Massachusetts: Addison-Wesley, 377 pgs., 1974. 
VINCENT, L.; SOILLE, P. Watersheds in digital spaces: an efficient algorithm based on immersion simulations. IEEE Transactions on Pattern Analysis and Machine Intelligence, vol. 13, no. 6 , pgs. 583-598, 1991.

Voci, F.; Eiho, S.; Sugimoto, N.; Sekiguchi, H. Estimating the gradient threshold in the perona-malik equation. IEEE Signal Processing Magazine, vol. 21, no. 3, pgs. 39-46, 2004 .

WEEKS, JR, A. R. Fundamentals of electronic image processing. SPIE/IEEE Press, 570 pgs., 1996

WEICKERT, J. A review of nonlinear diffusion filtering. Em: SCALE-SPACE '97: Proceedings of the First International Conference on Scale-Space Theory in Computer Vision, Springer-Verlag, 1997, pgs. 3-28.

ZHANG, D.; Chen, S. A comment on alternative c-means clustering algorithms. Pattern Recognition, vol. 37, pgs. 173-174, 2004. 